International

Journal of

Business and

Management

Vol. 4, No. 8

August 2009

CCSE

Canadian Center of Science and Education 


\section{Editorial Board}

Balakrishnan Parasuraman

Benjamin James. Inyang

Cyril Foropon

David H. Kent

Dennis Yao Dzansi Central University of Technology, South Africa

Donald Henry Ah Pak Xi' an Jiaotong-Liverpool University, China

Fulford Richard Edith Cowan University, Australia

Goi Chai Lee Curtin University of Technology, Malaysia

Hafizi Muhamad Ali Universiti Utara Malaysia, Malaysia

Kevin James Daly University of Western Sydney, Australia

K. G. Viswanadhan NSS College of Engineering, India

Lisa Wang Canadian Center of Science and Education, Canada

Mahdi Salehi Zanjan University, Iran

Matthew M.Chew Hong Kong Baptist University, Hong Kong

Muhammad Aslam Khan HITEC University Taxila, Pakistan

Muhammad Madi Bin Abdullah Universiti Teknologi Malaysia, Malaysia

Roberto Bergami Vitoria University, Australia

Sathya Swaroop Debasish Fakir Mohan University, India

Selcuk Burak Hasiloglu Pamukkale University, Turkey

Tobias Basse University of Applied Sciences, Germany 


\section{Contents}

Retailer-Supplier Relationship in Hong Kong: Asymmetry, Power Play, and Supply Chain Management

Matthew M. Chew \& Lai Ngun Veon L Sun

Competence Set Expansion Strategy and Application with General Connectivity Parameters

Jianxun Chen \& Junwen Feng

Review on Enterprise Growth Theories

Huiyuan Mao

Convergence on the Council Opinions of 2007 in Japan

Yanhong Pang \& Daojin Shi

The Reasons for Emergence of Born Global Firms----Taking China as an Example

Shuyi Zhang

Salesperson Professional Selling and the Effect on Buyer and Salesperson Relationship

Maznah Wan Omar, Kamaruzaman Jusoff \& Mohd Noor Mohd Ali

An Empirical Analysis on the Capital Structure of Chinese Listed IT Companies

Yuanxin Liu, Jing Ren \& Yan Zhuang

Disparity of Performance Indicators of Islamic Banks: Study on Bangladesh

Mamunur Rashid \& Ainun Nishat

The Impact of Spatial Externalities on the Economic Convergence in the Euro Mediterranean Countries

Amina NACEUR SBOUI \& Mohamed Amine HAMMAS

Study on the Disaster Harm and Pattern of Chinese Housing in Villages and Towns with Typical Building

Structures and the Countermeasures

Feng Han \& Yachen Liu

The Value and Effect of the Tourism Industry's Priority to Restoration and Rebuilding after Catastrophe

Hejiang Shen, Limei Yuan, Yana Liu, Zhang Ying \& Wei Fei

Evaluating Efficiency of Malaysian Banks Using Data Envelopment Analysis

Izah Mohd Tahir, Nor Mazlina Abu Bakar \& Sudin Haron

Cluster-mapping in China: the Empirical Evidence

Zhenming Sun

On the Market Risks Prevention of China's Commercial Banks' Financial Product under the Financial

Crisis

Mengchun Ding \& Hongxin $\mathrm{Li}$

HRM Practices and Organizational Performance: An Empirical Analysis

Kodjo Ezane Joseph \& Changjun Dai

Study on China's Sustainable Development of Rural Micro-credit

Lixin Tang

Awareness of Eco-label in Malaysia's Green Marketing Initiative

Nik Ramli Nik Abdul Rashid 


\section{Contents}

Study on Online Financing Based upon Internet and E-commerce

Chengfeng Long

Research on Homogeneous Structure of Manufacturing Industry from the Angle of the Division of Labor

Dongjun Mao

How Option Markets Affect Price Discovery on the Spot Markets: A Survey of the Empirical Literature and

Synthesis

Afef ANSI \& Olfa BEN OUDA

Research on Risks of Chinese Commercial Banks' Independent Innovation

Mingyou Wang, Jian Gui \& Jingting Ma

An Empirical Assessment of Hotel Departmental Managers Turnover Intentions: The Impact of

Organizational Justice

Salleh Mohd Radzi, Siti Zuraini Alan Ramley, Mohd Salehuddin, Zulhan Othman \& Mohd Hairi Jalis

The Construction of Human Resource Management System in Small and Medium-sized Private Enterprises

Jieyun Zhang \& Juhong Gong

Study on the Issue of Staff Training in Business Hotel

Qiumei Fan

A Preliminary Study of Strategic Competitiveness of MDF Industry in Peninsular Malaysia by Using SWOT

Analysis

Mohd Shahwahid Hj. Othman \& Abdul Rahim Abdul Samad

Investigation and Evaluation of Product-Supplier's Company

Huaping Chen 


\title{
Retailer-Supplier Relationship in Hong Kong: Asymmetry, Power Play, and Supply Chain Management
}

\author{
Matthew M. Chew \\ Department of Sociology, Hong Kong Baptist University \\ Kowloon Tong, Kowloon, Hong Kong SAR, China \\ Tel: 852-3411-7132 E-mail: mmtchew@hkbu.edu.hk \\ Lai Ngun Veon L Sun \\ Techne Research Limited, P.O.Box 97849 \\ Tsimshatsui Post Office, Kowloon, Hong Kong \\ E-mail: dr.sun@alumni.polyu.edu.hk
}

\begin{abstract}
This study investigates the characteristics of retailer-supplier relationship in Hong Kong, identify problems in it, and suggest ways to remedy them. We will demonstrate that Hong Kong's retail industry was and is dominated by small and medium sized retailers. However, small retailers in Hong Kong have not sufficiently adopted new retail technologies to manage their supply chains. This situation is undermining the efficiency of Hong Kong's retail industry. We recommend information systems providers, the management of small retailers, and suppliers to take steps to improve supply chain efficiency for small retailers. Information systems providers can help through designing affordable implementation and common modules. Suppliers in Hong Kong can actively build network, cultivate trust, and equip themselves with advanced information systems. Small and medium sized retailers in Hong Kong need to invest sufficient resources to implement retail information systems.
\end{abstract}

Keywords: Retailer-supplier relationship, Supply chain management, Retailing, SME, Hong Kong retailing, Retail information system

\section{Introduction}

The relationship between suppliers and retailers is an important topic because it greatly affects the retail industry and the distribution of goods to consumers. Supplier and retailer relationship is no longer based merely on terms of services and prices - the cost of merchandise is no longer the dominant competitive focus in the retail supply market. Suppliers are presently expected to assist retailers to sell faster, to reduce inventories on hand, and to serve their retail customer more adequately. Retailers and suppliers need to cooperate closely and obtain accurate business information in order to improve the profitability of retail operations.

What is the present state of supplier-retailer relationship in Hong Kong? Does it completely follow the general trends in developed Western economies? What kinds of locally specific problem it faces if it is different? Answers to these questions will be crucial for updating and further developing the retailing industry in Hong Kong. We will explore these questions in this paper. We will demonstrate that supplier-retailer relationship in Hong Kong is quite similar to that in Western contexts, but also display a major difference: the prevalence of small and medium-sized retail enterprises (SMEs) (Note 1). We investigate the extent to which small retailers dominate in Hong Kong through analyzing relevant statistical data. Because of this important difference, many of the recent technological advancements that would greatly facilitate the supplier-retailer chain functioning have been adopted exceedingly slowly in Hong Kong. We suggest some practical strategies that would let suppliers and small retailers to work together and benefit from retail technological advancements.

\section{Retailer-supplier relationship in Hong Kong}

\subsection{Supply chain management in Hong Kong: adoption of current global practices}

Inventory is a central problem for the retail management. Over-stocking could seriously undermine retailers' profit margin. Moreover, retailers have to deal with inventory at all times in order to deal with dynamic and changing 
consumer demands. Since the 1980s, retail inventory management entered a new era with the popularization of automation and computerization in business and the industries. Automation and computerization enable manufacturers and retailers to upgrade their scale of operations. Automation in the distribution channel and supply chain facilitates logistics between suppliers and retailers. Retailers are especially able to benefit from online information and computerized databases that let them efficiently keep track of consumer needs. A more efficient business operation allows retailers to internationalize and expand into overseas markets. One of the main advantages of internationalization is the retailer's ability to enjoy the economies of scale. Many international retailers have set up businesses in Hong Kong since the commencement of retail internationalization in the 1970s.

In the context of automation, computerization, and internationalization, how have Hong Kong retailers been dealing with the inventory management problem? The strategies that Hong Kong retailers adopt are in general not dissimilar to those adopted in the West, but they are not well implemented in Hong Kong because of the local particularities of Hong Kong's retailer-supplier relationship. We will briefly describe these strategies before we elaborate the local particularities and their consequences.

Current solutions to managing retail inventory can be largely categorized under the umbrella concept of supply chain management. Supply chain management is the integration of business process from suppliers that provides products, services, and information to retailers. The objectives are to reduce inventory stock in the chain, to facilitate customer services, and to build competitive advantages for the chain (Zuckerman, 2002). Retailers would hope to manage the supply and distribution of inventory, while suppliers would want to sell more by assisting retailers to manage inventory.

Central to supply chain management is retailers' emphasis on 'quick response' to consumer demands. Retailers would want to respond as quickly as possible to their customers' demands, gain speed in re-ordering their inventory, and accurately project future inventory needs. By having an adequate level of stock at the right time, retailers will have a smaller amount of excess stock. This shall in turn lower the need to mark down the sale price of merchandise in order to reduce inventory stock as well as to free up cash as buying funds. The result will be a higher profit margin. In order to achieve that, structural changes in the supply chain become necessary. For example, just-in-time delivery requires a close and lasting strategic alliance between retailers and suppliers that was unthinkable just a few decades ago. As we will see, large retailers in Hong Kong have successfully forged such cooperative relationship and close alliances with their suppliers.

Another major area of supply chain management is development and implementation of specialized computerized technologies. Electronic data interchange (EDI), for example, improves communication among different system platforms that may be used by different suppliers and retailers. It significantly shortens the lead time of delivery and facilitates alliances between retailers and suppliers (Cooper, Lambert, et al., 1997). Retail automation may be improved through technologies such as point-of-sale (POS) systems. Specialized computer hardware helps retailers to obtain updated information of their businesses so that retailers can promptly react to the market and to communicate with the most appropriate suppliers. The development of Universal Product Code (UPC) or bar coding helps to simplify coordination requirement among suppliers and retailers. Most recently, big retailers are taking further steps to utilize mobile technology - especially wireless technology such as Radio Frequency Identification (RFID) - to facilitate the informational processing. All of these technologies are being adopted in Hong Kong, although in an uneven way among firms in the industry.

\subsection{The power play between large retailers and suppliers}

Large retailers in the contemporary United States are becoming increasingly powerful as they gain influence in consumer markets. They also gain power over their suppliers because of their volume of purchasing (Wileman, 1997). Similarly, large retailers in Hong Kong purchase such huge quantities from their suppliers that they can overpower their suppliers. The suppliers to the large retailers are compelled to cooperate with these retailers and to develop long-term supplier-retailer relationships. A positive result is that the supply chains in these cases tend to be very well managed through cooperation between large retailers and their suppliers. Like large retailers elsewhere, those in Hong Kong are able to purchase the hardware and software technology needed for supply chain management. EDI, UPC and point-of-sale systems, for example, are commonly adopted by the large retailers in Hong Kong.

The overwhelming power of large retailers over their suppliers in Hong Kong is incurring some costs to the balance of the retailer-supplier relationship. Apart from compelling suppliers to maintain long-term and close alliances with large retailers, the power of large retailers forces suppliers to concede to very unfavorable business terms. For example, large supermarket chains in Hong Kong have been enjoying very favorable payment terms. They set up long payment periods of over 180 days of payments delay time. Large department stores in Hong Kong are also enjoying payment period of 90 days from suppliers. These large retailers obtain cash flow advantage from their retail customers, and do not need to pay their suppliers' invoice billing until a few months later. Another manifestation of large retailers' overwhelming power in the retailer-supplier relationship is that suppliers to large retailers have to pay additional listing fees to place their merchandise on shelves and additional promotional money in order to gain better visual display inside shops. 
Some suppliers are willing to pay the fees because they wish to display their merchandise in a better location inside shops to gain advantage over their competitors' products.

The extremely high rental rates of retail space in Hong Kong give another opportunity for large retailers to take advantage of their small suppliers. Large retailers presently carve up their floor space and rent it out as a 'shop in shop' atmosphere. Some department stores do not purchase merchandises and in its place make consignment arrangements with suppliers. They rent out their shop floor space to suppliers. In return retailers and suppliers split the sales revenue or retailers get commissions from sales. Under these arrangements, the retailers would not have their capital resources held up by merchandise, thereby avoiding problems of slow moving merchandise and aging stock. In other words, they are shifting the merchandising preparation role to their suppliers.

Whereas large retailers in Hong Kong unbalance the retailer-supplier relationship by overpowering their suppliers, small retailers in Hong Kong generally experience an unbalanced retailer-supplier relationship because of the limited size of their buying volume. Their position in the retailer-supplier relationship is unfavorable, especially compared against the backdrop of suppliers' treatment of large retailers. Small retailers in Hong Kong do not enjoy any of these benefits. For instance, they either pay on cash on delivery or pay on a very short lead-time of payment due day. Small retailers have to punctually pay their invoices to their suppliers in order to maintain workable supplier-retailer relationships. Moreover, many small and medium sized retailers do not invest in the updated retail technologies. Without the necessary hardware, software, expertise, and human capital, small retailers are not capable of managing the supply chain even if their suppliers are willing to cooperate with them in managing it.

\section{The important role of small retailers in Hong Kong's retail structure}

If Hong Kong's retail industry were primarily constituted by the powerful large operators described in the previous section, supply chain management would have been quite adequate even though asymmetric retailer-supplier relationships would still be an issue. But Hong Kong's retail industry remains to be dominated by small and medium sized operators. We will not be able to elaborate the complex historical and economic factors that brought about their dominance in this study, but we will illustrate how dominant small retailers are in Hong Kong's retail industry (Note 2).

We utilize data on the relative proportion of retail establishments of different sizes to illustrate how important small retailers are in Hong Kong (Note 3). Table 1 shows that small retailers account for over $99 \%$ of all retail establishments in Hong Kong since data was available (ie. from 1982 to 2006). The proportion is even larger if we add medium sized retailers to this count; they composed between $0.19 \%$ to $0.49 \%$ of total retail establishments between 1982 and 2006 . The number of small and medium sized retailers certainly tends to be large in comparison with that of large retailers simply because each individual small retailer is so small in size. The structure of Hong Kong's retail industry is not entirely reflected through data on the number of retail establishments. However, the extremely high ratio of small retailers compared to large ones is still noteworthy, especially when other indicators to be discussed below corroborates with the picture suggested by this ratio.

We have organized the data on the number of persons engaged in different sizes of retail establishments in Table 2 (Note 4). Between 1982 and 2006, the ratio of persons engaged by small retailers to the total number of persons engaged in the retail industry has been decreasing. But it still reached $54 \%$ in 2006 . These employment figures are another indication that small and medium sized retailers are rivaling large ones in the industry.

Not only do small and medium sized retailers hire more workers than large ones, they even buy more merchandise from suppliers in total. Merchandise purchase volume should be an accurate indicator of the relative importance of different retailers. We have organized the data on the purchase volume of retailers of different sizes in Table 3 . The interval data (data are not available in certain years) in Table 3 demonstrate that small retailers have collectively bought more from suppliers than large retailers between 1982 and 2006 (Note 5). Even though the percentages of purchase made by small retailers have been steadily decreasing since 1997, they still purchased $38 \%$ of the goods for sale in 2006 while large retailers only bought $34 \%$ of them.

Based on the above statistics, we conclude that small retailers play an important role in Hong Kong's retail industry, a role that is at least as important as large retailers. The statistics on merchandize purchase volume of small retailers especially suggest that SME retailers should not be relegated to a secondary role in their retailer-supplier relationship, though they are forced into an inferior bargaining position by their small sizes at present. The well-being of small retailers significantly affects the vitality of the retail industry in Hong Kong.

\section{How to improve retailer-supplier relationship and supply chain management for small Retailers}

Given the importance of small and medium sized retailers and the current weaknesses in their supply chain, we see an urgent need for formulating solutions to develop retailer-supplier relationship and improve supply chain management for small retailers in Hong Kong. Small retailers, suppliers, information systems providers, the government, and relevant non-profit organizations have different roles to play in providing solutions. 


\subsection{Information systems providers: catering to small retailers' demand for retail information systems}

Information is a strategic resource to retailers and command of updated retail information is a key to supply chain management. With updated information, retailers can make sound decisions in running their retail business and purchasing merchandise from suppliers to meet current demands of their customers. The maintenance of just-in-time delivery systems and effective inventory minimization also depend heavily on availability of updated open to buy information. The important benefits of retail information technology have been proven by the experience of large retailers in global retailing. Small retailers should also be able to benefit from the application of retail information system.

Retailers who wish to command updated retail operation information have to invest in communication systems and data management systems. The operation of these systems requires hardware, software, and expertise. In the current marketplace, retailers either develop information systems by themselves or purchase it in the form of a product from systems providers. Both alternatives require a significant amount of money and time.

The absolute majority of small retailers in Hong Kong have not invested the required time and resources on informational technologies. Catering to the informational needs of small retailers represents a good market opportunity for systems providers. We recommend systems providers to develop affordable implementations of retail information system. A possible direction to develop is the making use of affordable ways to transfer data between supplier and retailer via the internet. We also suggest systems providers to create common modules that cater to the common needs of small retailers in the Hong Kong marketplace. Common modules would drastically lower the overhead of small retailers on information systems. A senior person in the information system software provider industry concurs with our view of this business potential in provide for small retailers:

The adoption of retail information system and payment technology is important to facilitate the retail trade. [...] If we can provide a reliable, low cost retail information system solution to small medium sized retailers, it will not only enhance the retail practice in Hong Kong but also provide a business opportunity for systems providers.

\subsection{Small retailers: towards more adequate implementation and utilization of retail information systems}

The majority of retailers in Hong Kong are keen to enhance their electronic payment systems, such as the adoption of point-of-sale systems. But most small retailers are not enthusiastic about going beyond that and to actively implement and utilize contemporary retail technologies. For instance, whereas all large retailers in Hong Kong implement EDI and UPC, small retailers do not do so. Another example is point-of-sale registers and computerized scanning systems, which are already very common in global retailing and yet the majority of small retailers in Hong Kong still have not adopted them. Retail information is much more than what point-of-sale system alone can provide. And information system is more than a mere point-of-sale system at the shop front. Retail information system is an interacting organization of people, machines, and methods designed to produce a continuous flow of information for retailers' problem-solving and decision-making (Laudon and Laudon, 1997).

An information system is not one thing, but a group of things that work together. These things are called components of the systems, and they include equipment or hardware, software, data stored in the system, people to operate the system, and procedures for the people to follow (Nickerson, 1998).

SME retailers in Hong Kong need to conceptualize information flow in a more adequate way in order to build and manage them.

SME retailers should not stop even after they implement an adequate retail information system. Active and creative utilization of available retail operation data is needed for them to fully benefit from their information systems. For example, retailers have the option of developing customer relationship management and loyalty programs. These programs would result in loyal customers in the long run. Another possibility is to capture more data from front shop and back office operations in order to provide a better basis of decision-making.

\subsection{Suppliers: proactive adoption of retail technologies and networking with small retailers}

Given that a large share of the purchasing power lies in the sector of small retailers, suppliers should actively develop business networks with them. One of the components of developing business networks is the building of trust. Trust between retailers and suppliers are important because it facilitates sustained relationship and long term cooperation.

If retailers adopt new retail technologies to managing their business, suppliers also need to adopt the corresponding technologies to match with the retailers they service. Under such circumstances, suppliers who are willing to invest time and money into this kind of systematic cooperation will have competitive advantage over those that do not.

\subsection{The supportive role of the government and relevant non-profit organizations}

Given the importance the retailing industry to Hong Kong, the dominance of SMEs in the retailing industry, and current weaknesses of Hong Kong small retailers, the Hong Kong Special Administrative Region (HKSAR) government should 
devote more resources to help SMEs. Although the Hong Kong government refrains from direct intervention of the market, there are numerous indirect ways in which it can help.

While the government cannot directly sponsor any individual company, but it can do so indirectly through the funding projects of Hong Kong Productivity Council and other non-profit making associations. A number of useful projects have been funded and carried out. In recent years, the government has set up a 'Support and Consultation Center for SME' and funding schemes for SME such as 'SME loan guarantee scheme', 'SME export marketing fund', 'SME training fund', and 'SME development fund.' Other institutions such as GS1 Hong Kong is the organization in Hong Kong authorized to issue e-ID by a barcode format that facilitates efficient collaborative e-commerce and e-supply chain services. Its mission is to promote efficient trade practices through supporting global supply chain standards and technologies. Another non-profit making institution is the Hong Kong Retail Technology and Industry Association, which aim to facilitate better adoption of retail technology by Hong Kong retailers.

\section{Conclusion}

In examining the characteristics of retailer-supplier relationship in Hong Kong, we have found that large retailers in Hong Kong are already adopting globally recognized retail technologies to manage their supply chains and maintain stable retail-supplier relationships. However, we also find that Hong Kong's retail industry is dominated by small retailers, and that many small retailers have not embraced retail technologies to manage their supply chains. Information systems providers, the management of small retailers, and suppliers are encouraged to take steps to improve supply chain efficiency for small retailers. Information systems providers in Hong Kong can help through designing affordable implementation and common modules. Suppliers in Hong Kong can help by actively building networks and equipping themselves with useful information systems. Small and medium retailers in Hong Kong have to invest in the required resources to fully understand and implement retail information systems. The government in Hong Kong may contribute to playing a supportive role through non-profit organization and programs that target SMEs and retail technology. For future research on supply-retailer relationship in Hong Kong, an important topic would be how to make their supply chains more conducive to successful cross-border management. Many Hong Kong retailers including small and medium ones are setting up operations in mainland China and overseas, and they will face problems in addition to ones that we focused on in this study.

\section{References}

Census and Statistics Department. (1984-2008). Hong Kong Annual Digest of Statistics. Hong Kong: Government Printer.

Cooper, Martha C., Lambert, Douglas M., \& Pagh, Janus D. (1997). Supply chain management: more that a new name for logistics. The International Journal of Logistics Management, 8(1), 1-14.

The European Commission. (2009). 'SME Definition.' [Online] Available: http://ec.europa.eu/enterprise/enterprise_policy/sme_definition/index_en.htm (Retrieved from Mar 2 2009).

Laudon, Kenneth C., \& Laudon, Jane P. (1997). Essentials of Management Information Systems: Organization and Technology, $2^{\text {nd }}$ Edition. New Jersey: Prentice Hall.

Louis P. Bucklin. (1972). Competition and Evolution in the Distributive Trades. New Jersey: Prentice Hall.

Nickerson, Robert C. (2000). Business and Information Systems. New Jersey: Prentice Hall.

Wileman, Andrew. (1997). Retail Power Play. New York: New York University Press.

Zuckerman, Amy. (2002). Supply Chain Management. Oxford: Capstone Publishing.

\section{Notes}

Note 1. According to one of the European Commission's definitions, SMEs (small and medium-sized enterprises) are identified in the following way: "micro-enterprises are enterprises with less than 10 employees; small enterprises are those with less than 50 employees; and medium-sized enterprise are those with less than 250 employees" (The European Commission, 2009).

Note 2. The definition of SMEs in Hong Kong is made by the Trade and Industry Department, is that 'manufacturing enterprises with fewer than 100 employees and non-manufacturing enterprises with fewer than 50 employees are regarded as small enterprises and medium enterprises.' In contrast to the European Commission's definition, the maximum cut off point for medium-sized enterprises is not 250 employees but 100 . That is why in our tables on retail establishments in Hong Kong between 1982 and 2006, we categorize retail firms by four groups: 1-49 employees, $50-199,200-500$, and 500 and above. There is no grouping in the original government statistic with reference to the 250 employee cut off point.

Note 3. The definition of 'retail establishments' by the Census and Statistics Department in Hong Kong:

An establishment is defined as an economic unit, which engages under a single ownership or control, in one or predominantly one kind of economic activity, at a single physical location. Where separate figures relating to different 
activities or different locations under the same management are not available, a combined return is accepted for data collection purposes and in this case, the reporting unit is treated as an establishment" (Census and Statistics Department, 2002).

Note 4. Definition of number of persons engaged: the number of persons engaged = number of working proprietors, active partners, and unpaid family workers + number of employees (Census and Statistics Department, 2004).

Note 5. 'Purchases of goods for sale' refers to the total value of purchases of goods for sale in the retailing industry (Census and Statistics Department, 2004).

Table 1. Number of retail establishments by number of persons engaged in Hong Kong, 1982-2006

\begin{tabular}{|c|c|c|c|c|c|c|c|c|c|}
\hline \multirow{4}{*}{ Year } & \multicolumn{9}{|c|}{ Number of persons engaged } \\
\hline & \multicolumn{2}{|l|}{$1-49$} & \multicolumn{2}{|l|}{$50-199$} & \multicolumn{2}{|l|}{$200-499$} & \multicolumn{2}{|c|}{500 and over } & \multirow{3}{*}{ Total } \\
\hline & \multicolumn{8}{|c|}{ Number of Retail Establishments } & \\
\hline & $\begin{array}{l}\text { Number of } \\
\text { est. }\end{array}$ & $\begin{array}{l}\text { \%age of } \\
\text { total }\end{array}$ & $\begin{array}{l}\text { Number } \\
\text { of est. }\end{array}$ & $\begin{array}{l}\text { \%age of } \\
\text { total }\end{array}$ & $\begin{array}{l}\text { Number } \\
\text { of est. }\end{array}$ & $\begin{array}{l}\text { \%age of } \\
\text { total }\end{array}$ & $\begin{array}{l}\text { Number } \\
\text { of est. }\end{array}$ & $\begin{array}{l}\text { \%age } \\
\text { of total }\end{array}$ & \\
\hline 1982 & 43,113 & 99.65 & 109 & 0.25 & 34 & 0.08 & 9 & 0.02 & 43,265 \\
\hline 1983 & 45,520 & 99.63 & 123 & 0.27 & 34 & 0.07 & 10 & 0.02 & 45,687 \\
\hline 1984 & 49,330 & 99.64 & 135 & 0.27 & 30 & 0.06 & 13 & 0.03 & 49,508 \\
\hline 1985 & 47,483 & 99.71 & 90 & 0.19 & 34 & 0.07 & 13 & 0.03 & 47,620 \\
\hline 1986 & 51,171 & 99.61 & 155 & 0.30 & 30 & 0.06 & 13 & 0.03 & 51,369 \\
\hline 1987 & 50,749 & 99.62 & 140 & 0.27 & 37 & 0.07 & 17 & 0.03 & 50,943 \\
\hline 1988 & 51,010 & 99.57 & 158 & 0.31 & 46 & 0.09 & 18 & 0.04 & 51,232 \\
\hline 1989 & 50,881 & 99.56 & 149 & 0.29 & 54 & 0.11 & 20 & 0.04 & 51,104 \\
\hline 1990 & 53,626 & 99.59 & 143 & 0.27 & 51 & 0.09 & 25 & 0.05 & 53,845 \\
\hline 1991 & 55,295 & 99.59 & 157 & 0.28 & 44 & 0.08 & 29 & 0.05 & 55,525 \\
\hline 1992 & 60,418 & 99.53 & 202 & 0.33 & 57 & 0.09 & 28 & 0.05 & 60,705 \\
\hline 1993 & 57,232 & 99.50 & 215 & 0.37 & 47 & 0.08 & 27 & 0.05 & 57,521 \\
\hline 1994 & 58,118 & 99.58 & 171 & 0.29 & 41 & 0.07 & 33 & 0.06 & 58,363 \\
\hline 1995 & 55,627 & 99.52 & 189 & 0.34 & 50 & 0.09 & 28 & 0.05 & 55,894 \\
\hline 1996 & 56,175 & 99.43 & 242 & 0.43 & 48 & 0.08 & 34 & 0.06 & 56,499 \\
\hline 1997 & 53,212 & 99.46 & 203 & 0.38 & 54 & 0.10 & 34 & 0.06 & 53,503 \\
\hline 1998 & 48,997 & 99.42 & 216 & 0.44 & 43 & 0.09 & 25 & 0.05 & 49,281 \\
\hline 1999 & 47,617 & 99.53 & 154 & 0.32 & 41 & 0.09 & 28 & 0.06 & 47,840 \\
\hline 2000 & 48,923 & 99.49 & 177 & 0.36 & 44 & 0.09 & 29 & 0.06 & 49,173 \\
\hline 2001 & 49,427 & 99.49 & 180 & 0.36 & 45 & 0.09 & 27 & 0.05 & 49,679 \\
\hline 2002 & 48,809 & 99.50 & 168 & 0.34 & 49 & 0.10 & 28 & 0.06 & 49,054 \\
\hline 2003 & 47,127 & 99.50 & 164 & 0.35 & 46 & 0.10 & 27 & 0.06 & 47,364 \\
\hline 2004 & 46,048 & 99.43 & 179 & 0.39 & 50 & 0.11 & 32 & 0.07 & 46,310 \\
\hline 2005 & 46,415 & 99.33 & 230 & 0.49 & 49 & 0.10 & 35 & 0.07 & 46,729 \\
\hline 2006 & 46,916 & 99.34 & 213 & 0.45 & 62 & 0.13 & 36 & 0.08 & 47,228 \\
\hline
\end{tabular}

Source: Census and Statistics Department. (1984 to 2008). Hong Kong Annual Digest of Statistics. 
Table 2. Number of persons engaged in the retail industry by firm size in Hong Kong, 1982-2006

\begin{tabular}{|c|c|c|c|c|c|c|c|c|c|}
\hline \multirow{3}{*}{ Year } & \multicolumn{9}{|c|}{ Number of persons engaged } \\
\hline & \multicolumn{2}{|l|}{$1-49$} & \multicolumn{2}{|l|}{$50-199$} & \multicolumn{2}{|l|}{$200-499$} & \multicolumn{2}{|c|}{500 and over } & \multirow[b]{2}{*}{ Total } \\
\hline & Number & $\begin{array}{l}\text { \%age } \\
\text { of total }\end{array}$ & Number & $\begin{array}{l}\text { \%age } \\
\text { of } \\
\text { total }\end{array}$ & Number & $\begin{array}{l}\text { \%age } \\
\text { of } \\
\text { total }\end{array}$ & Number & $\begin{array}{l}\text { \%age } \\
\text { of } \\
\text { total }\end{array}$ & \\
\hline 1982 & 130,350 & 81.49 & 10,377 & 6.49 & 10,508 & 6.57 & 8,732 & 5.46 & 159,967 \\
\hline 1983 & 125,938 & 79.07 & 12,091 & 7.59 & 10,706 & 6.72 & 10,531 & 6.61 & 159,266 \\
\hline 1984 & 128,706 & 78.48 & 12,720 & 7.76 & 9,204 & 5.61 & 13,378 & 8.16 & 164,008 \\
\hline 1985 & 130,862 & 77.66 & 12,978 & 7.70 & 9,898 & 5.87 & 14,758 & 8.76 & 168,496 \\
\hline 1986 & 135,196 & 77.72 & 14,191 & 8.16 & 8,938 & 5.14 & 15,618 & 8.98 & 173,943 \\
\hline 1987 & 136,526 & 76.38 & 13,187 & 7.38 & 10,944 & 6.12 & 18,087 & 10.12 & 178,744 \\
\hline 1988 & 140,814 & 74.06 & 14,430 & 7.59 & 13,408 & 7.05 & 21,494 & 11.30 & 190,146 \\
\hline 1989 & 137,921 & 71.70 & 13,481 & 7.01 & 16,814 & 8.74 & 24,143 & 12.55 & 192,359 \\
\hline 1990 & 138,071 & 70.91 & 12,910 & 6.63 & 15,939 & 8.19 & 27,803 & 14.28 & 194,723 \\
\hline 1991 & 153,873 & 71.94 & 14,464 & 6.76 & 13,478 & 6.30 & 32,090 & 15.00 & 213,905 \\
\hline 1992 & 161,703 & 71.21 & 16,359 & 7.20 & 18,194 & 8.01 & 30,816 & 13.57 & 227,072 \\
\hline 1993 & 160,844 & 71.13 & 19,230 & 8.50 & 15,207 & 6.72 & 30,852 & 13.64 & 226,133 \\
\hline 1994 & 171,796 & 72.61 & 16,366 & 6.92 & 12,802 & 5.41 & 35,643 & 15.06 & 236,607 \\
\hline 1995 & 157,234 & 69.99 & 18,527 & 8.25 & 14,747 & 6.56 & 34,142 & 15.20 & 224,650 \\
\hline 1996 & 159,657 & 68.53 & 20,615 & 8.85 & 14,586 & 6.26 & 38,120 & 16.36 & 232,978 \\
\hline 1997 & 170,505 & 69.81 & 17,836 & 7.30 & 16,456 & 6.74 & 39,459 & 16.15 & 244,256 \\
\hline 1998 & 136,170 & 67.99 & 19,858 & 9.91 & 13,826 & 6.90 & 30,435 & 15.20 & 200,289 \\
\hline 1999 & 129,537 & 68.77 & 14,711 & 7.81 & 11,871 & 6.30 & 32,251 & 17.12 & 188,370 \\
\hline 2000 & 126,608 & 65.34 & 17,404 & 8.98 & 13,494 & 6.96 & 36,257 & 18.71 & 193,763 \\
\hline 2001 & 123,606 & 63.43 & 17,743 & 9.10 & 13,849 & 7.11 & 39,673 & 20.36 & 194,871 \\
\hline 2002 & 117,116 & 61.70 & 17,398 & 9.17 & 14,669 & 7.73 & 40,629 & 21.40 & 189,812 \\
\hline 2003 & 110,117 & 60.22 & 15,858 & 8.67 & 13,888 & 7.60 & 42,993 & 23.51 & 182,856 \\
\hline 2004 & 108,041 & 57.27 & 17,456 & 9.25 & 15,190 & 8.05 & 47,948 & 25.42 & 188,636 \\
\hline 2005 & 108,150 & 54.43 & 22,843 & 11.50 & 14,855 & 7.48 & 52,853 & 26.60 & 198,700 \\
\hline 2006 & 110,475 & 54.08 & 21,535 & 10.54 & 19,116 & 9.36 & 53,173 & 26.03 & 204,298 \\
\hline
\end{tabular}

Source: Census and Statistics Department. (1984-2008). Hong Kong Annual Digest of Statistics. 
Table 3. Purchases of goods for sale by different sizes of retail enterprises in Hong Kong, 1982-2006

\begin{tabular}{|c|c|c|c|c|c|c|c|c|c|}
\hline \multirow{4}{*}{ Year } & \multicolumn{7}{|c|}{ Number of people engaged } & \multirow[b]{2}{*}{$\%$} & \multirow{3}{*}{ Total } \\
\hline & $1-49$ & $\%$ & $50-199$ & $\%$ & $200-499$ & $\%$ & $500 \&$ over & & \\
\hline & \multicolumn{8}{|c|}{ Purchases of goods for sale } & \\
\hline & HK\$ million & & HK\$ million & & HK\$ million & & HK\$ million & & HK\$ million \\
\hline 1982 & 33,415 & 76 & 3,576 & 8 & 3,668 & 8 & 3,455 & 8 & 44,114 \\
\hline 1987 & 50,588 & 62 & 9,101 & 11 & 10,073 & 12 & 11,508 & 14 & 81,270 \\
\hline 1992 & 98,501 & 60 & 18,095 & 11 & 14,370 & 9 & 34,465 & 21 & 165,431 \\
\hline 1997 & 111,118 & 56 & 20,071 & 10 & 18,713 & 10 & 46,781 & 24 & 196,683 \\
\hline 1999 & 77,727 & 55 & 17,840 & 13 & 9,629 & 7 & 37,340 & 26 & 142,536 \\
\hline 2000 & 75,988 & 52 & 19,324 & 13 & NA & NA & NA & NA & 146,612 \\
\hline 2001 & 71,198 & 51 & NA & NA & 10,500 & 8 & NA & NA & 138,883 \\
\hline 2002 & 62,593 & 47 & 19,457 & 15 & 10,947 & 8 & 40,959 & 31 & 133,956 \\
\hline 2003 & 61,132 & 46 & 17,354 & 13 & NA & NA & NA & NA & 131,722 \\
\hline 2004 & 58,759 & 41 & 21,605 & 15 & 14,852 & 10 & 49,513 & 34 & 144,731 \\
\hline 2005 & 65,045 & 41 & 25,033 & 16 & 14,943 & 9 & 53,234 & 34 & 158,255 \\
\hline 2006 & 64,483 & 38 & 25,206 & 15 & 20,100 & 12 & 57,786 & 34 & 167,566 \\
\hline
\end{tabular}

Source: Census and Statistics Department. (1984-2008). Hong Kong Annual Digest of Statistics. 


\title{
Competence Set Expansion Strategy and Application with General Connectivity Parameters
}

\author{
Jianxun Chen \\ School of Economics and Management, Nanjing University of Science and Technology \\ Nanjing 210094, China \\ E-mail: cjianxun@mail.njust.edu.cn \\ Junwen Feng \\ School of Economics and Management, Nanjing University of Science and Technology \\ Nanjing 210094, China \\ E-mail: Fengjunwen8@hotmail.com
}

\begin{abstract}
Each decision making problem can be satisfactorily solved by using the expanding technologies of the Competence Set Analysis, where the competence set consists of the decision maker's ideas, knowledge, information, experience, skills and capacities, etc., directly or indirectly related to the decision making problem. This article proposes a heuristic method to find the optimal competence set expansion strategy with the connectivity parameters being general, that is, either symmetric or asymmetric. The optimality of the method is proven, and its applications in the personnel recruitment and training planning problems are discussed. Some conclusions and suggestions to be developed in a further work are included.
\end{abstract}

Keywords: Competence set expansion, Optimal strategy, Habitual domains

\section{Introduction}

Based on the decision maker's acquired competence set and the truly needed competence set to solve the decision making problems, the competence set expanding technology concentrates its study on the strategy of how and from where to start to expand the acquired competence set to the needed competence set to enable the decision maker or makers to confidently and successfully solve his, her or their decision making problems. Given the connectivity

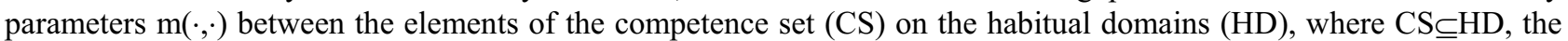
problem of how to expand from one CS to another CS is studied analytically and mathematically by Yu and Zhang (1990) when $\mathrm{m}(\cdot, \cdot)$ is symmetric, and Shi and $\mathrm{Yu}(1996)$ when $\mathrm{m}(\cdot, \cdot)$ is asymmetric. Li and $\mathrm{Yu}(1994)$ did some research work by means of deduction graphs without cycles when there are intermediate elements and multilevels. Under risky and uncertainty cases, Feng (2001) discussed the competence expansion problems and given several expansion strategies. Very Recently, Yu and Larbani (2009) discussed application of the competence set expansion in the game theory and several new ideas are put forwards. But they all studied using mathematical programming algorithms, especially, the integer programming algorithms, so even a simple problem often needed to be solved by using some software package. Furthermore, even though all these papers theoretically deal with the general cases, practically all can be only used to find the expanding process from a given skill, instead of a given set of skills.

In the article, as far as the general connectivity parameters $\mathrm{m}(\cdot, \cdot)$ ( maybe negative or positive) are concerned, based upon the digraphs, a heuristic method is given to find the optimal expansion strategy within a certain competence set or habitual domain. This heuristic method can also be used to optimally expand the acquired competence set to the needed competence set or habitual domain. The optimality and applications of the method are also discussed. This heuristic method differs from the methods developed in papers [1,2,3] in the following aspects: (1) It can deal with the case that there are cycles in the digraphs; (2) It can begin from any given acquired skills set; (3) It is a heuristic method rather than a analytical method; (4) The expansion process obtained may be not in the form of sequences which are the 
arrangements of the required skills; (5) It can handle the case that there are multivalues between the skills; (6) It is some kind of extension of the deduction graph method [3].

\section{The Heuristic Method Development for Expansion Strategy}

Suppose the discussed universal is some habitual domain HD which has a finite number ( say $\mathrm{n}$ ) of elements, that is, $\mathrm{HD}=\left\{\mathrm{x}_{1}, \mathrm{x}_{2}, \ldots, \mathrm{x}_{\mathrm{n}}\right\}$, then connectivity parameters $\mathrm{m}(\cdot, \cdot)$ between the elements in HD can be represented by an $\mathrm{n} \times \mathrm{n}$ matrix $\mathrm{M}=\left(\mathrm{m}_{\mathrm{ij}}\right)_{\mathrm{n} \times \mathrm{n}}$ where $\mathrm{m}_{\mathrm{ij}}=\mathrm{m}\left(\mathrm{x}_{\mathrm{i}}, \mathrm{x}_{\mathrm{j}}\right)$. Based upon the set HD and matrix $\mathrm{M}$, a digraph can be constructed with the vertices corresponding to elements $\mathrm{x}_{1}, \mathrm{x}_{2}, \ldots, \mathrm{x}_{\mathrm{n}}$, each arc representing the way a connectivity may be reached between any two elements in $\left\{\mathrm{x}_{1}, \mathrm{x}_{2}, \ldots, \mathrm{x}_{\mathrm{n}}\right\}$, and each arc weight being the corresponding connectivity parameter between the two elements. Let the deducted digraph from the HD and $\mathrm{M}$ be denoted by DG(HD, M).

Definition 1. An arborescence is defined as a directed tree (there is only one directed path between any pair of vertices or skills) in which no more than two arcs are directed into the same vertex. A branching is defined as a forest (a set of unconnected trees) in which each tree is an arborescence. A spanning arborescence of the digraph is an arborescence that is also a spanning tree. A spanning branching is any branching that includes every vertex in the digraph.

Definition 2. By an expansion strategy, we mean a spanning arborescence or spanning branching, that is, a directed spanning tree or a set of unconnected directed spanning trees in each of which no more than two arcs are directed into the same skill (vertex).

Definition 3. The connectivity of an arborescence (branching) is defined as the sum of the weights of the arcs in the corresponding arborescence (branching). A maximum arborescence (branching) of a digraph is any arborescences (branching) of the digraph with the largest possible weight sum.

Definition 4. An expansion strategy is optimal with respect to the sum operator among the connectivity parameters if it is a maximum spanning arborescence (if one exists).

Definition 5. An expansion strategy from a specified skill (vertex) is a strategy with the root being the vertex, and is optimal with respect to the sum operator if it is a maximum spanning arborescence rooted at the vertex.

Definition 6. An expansion strategy from a specified set of the skills (vertices) is a strategy with the root being within the set, and it is optimal with respect to the sum operator if it is a spanning arborescence rooted at some vertex in the set with the largest sum of the weights except the weights within the set.

From the above the definitions, we know that the concept of branching is more general than that of arborescences. Given the DG(HD,M), if we can find the maximum branching, then according to the following observations, we can easily find the maximum spanning arborescence ( optimal expansion strategy) by adding to each arc a large enough positive constant $\mathrm{N}$.

Firstly, a spanning branching is a spanning arborescence if and only if it has exactly one less arc than vertices. No branching has more arcs than this. Secondly, an optimum branching contains no arc with negative weight, and indeed may be empty if all connectivity parameters are not positive, that is, all $\mathrm{m}_{\mathrm{ij}} \leq 0$. And it is worth noting that even if all parameters are positive and the digraph contains a spanning arborescence, an optimum branching need not be an arborescence. Thirdly, a spanning arborescence which is optimum relative to weights $\mathrm{m}_{\mathrm{ij}}$ is also optimum relative to weights $\mathrm{m}_{\mathrm{ij}}+\mathrm{k}$ for any constant $\mathrm{k}$, and $\mathrm{m}_{\mathrm{ij}} \times \mathrm{k}$ for any positive constant $\mathrm{k}$ ( if all $\mathrm{m}_{\mathrm{ij}}$ 's are not negative, since every spanning arborescence has the same number of arcs. Fourthly, if there is a spanning arborescence in some digraph $\mathrm{DG}(\mathrm{HD}, \mathrm{M})$, then an optimum one, i.e., one which has a maximum total weight can be found as an optimum branching in the digraph $\mathrm{DG}(\mathrm{HD}, \mathrm{M}+\mathrm{h})$ where $\mathrm{M}+\mathrm{h}$ means the matrix $\left(\mathrm{m}_{\mathrm{ij}}+\mathrm{h}\right)$, and $\mathrm{h}>\sum\left|\mathrm{m}_{\mathrm{ij}}\right|$. This is because the constant $\mathrm{h}$ is larger than the difference in total weight (relative to weights $\mathrm{m}_{\mathrm{ij}}$ ) of any two branchings in the digraph, so an optimum branching in the digraph, relative to weights $\mathrm{m}_{\mathrm{ij}}{ }^{\prime}=\mathrm{m}_{\mathrm{ij}}+\mathrm{h}$ will be a branching with a maximum number of arcs, and in particular, it will be a spanning arborescence if and only if the digraph contains a spanning arborescence.

The optimal expansion strategy from the specified skill, say $\mathrm{x}_{0}$, can be obtained using the above method by adjoining a new arc carrying arbitrary weight which is directed toward $\mathrm{x}_{0}$ and from a new vertex having no other incident arcs, and letting the arcs directed toward $\mathrm{x}_{0}$ have zero weights.

The optimal expansion strategy from the specified skills set, say Sk, can be found using the above method by setting the weights with the heads in the set be zero and adjoining a new arc carrying an arbitrary weight which is directed toward some $\mathrm{x}_{0} \in \mathrm{Sk}$ and from a new vertex having no other incident arcs. The selection of $\mathrm{x}_{0} \in \mathrm{Sk}$ can be arbitrary. If the optimum exists, then there must exist some $\mathrm{x}_{0} \in$ Sk such that the corresponding spanning arborescence is rooted at the vertex $\mathrm{x}_{0}$.

There may be many optimal strategies.

We shall now proceed to describe the heuristic method to find the maximum branching. 
The maximum branching method uses two buckets, the vertex bucket and the arc bucket. The vertex bucket contains only vertices that have been examined; the arc bucket contains arcs tentatively selected for the maximum branching. The arcs in the arc bucket form a branching. Initially both buckets are empty.

The method successively examines the vertices in any arbitrary order. The examination of a vertex consists entirely of selecting the arc with the greatest positive weight that is directed into the vertex under examination (if any). If the addition of this arc to the arcs already selected for the arc bucket maintains a branching, then this arc is added to the arc bucket. Otherwise, this arc would form a cycle with some arcs already in the arc bucket. If this happens, then a new, smaller digraph is generated by "shrinking" the arcs and vertices in this cycle into a single vertex. Some of the arc costs are judiciously altered in the new, smaller digraph. The vertex and arc buckets are redefined for the new digraph as containing only their previous contents that appear in the new digraph. The examination of each vertex continues as before. The process stops when all vertices have been examined.

Upon termination, the arc bucket contains a branching for the final digraph. The final digraph is expanded back to its predecessor by expanding out its "artificial" vertex into a cycle. All but one of the arcs in this cycle is added to the arc bucket. The arc that is not added to the arc bucket is carefully selected so that the contents of the arc bucket retain a branching. This process is repeated until the original digraph is regenerated. The arcs in the arc bucket upon termination turn out to be a maximum branching.

Denote the original digraph for which the maximum branching is sought by $\mathrm{G}_{0}$, and denote each successive digraph generated from $\mathrm{G}_{0}$ by $\mathrm{G}_{1}, \mathrm{G}_{2}, \ldots$. The vertex and arc buckets used for these digraphs will be denoted by $\mathrm{V}_{0}, \mathrm{~V}_{1}, \ldots$ and $\mathrm{A}_{0}, \mathrm{~A}_{1}, \ldots$, respectively. We are now ready to state the method formally.

\section{Optimal (maximum) Expansion Strategy Method}

Initially, all buckets $\mathrm{V}_{0}, \mathrm{~V}_{1}, \ldots$ and $\mathrm{A}_{0}, \mathrm{~A}_{1}, \ldots$, are empty. Set $\mathrm{I}=0$.

Step 1. If all vertices of $G_{i}$ are in bucket $V_{i}$, go to step 3. Otherwise, select any vertex $v$ in $G_{i}$ that is not in bucket $V_{i}$. Place vertex $\mathrm{v}$ into bucket $\mathrm{V}_{\mathrm{i}}$. Select an $\operatorname{arc} \gamma$ with the greatest positive weight that is directed into $\mathrm{v}$. If no such arc exists, repeat step 1; otherwise, place arc $\gamma$ into bucket $A_{i}$. If the arcs in $A_{i}$ still form a branching repeat step 1; otherwise, go to step 2.

Step 2. Since the addition of arc $\gamma$ to $A_{i}$ no longer causes $A_{i}$ to form a branching, arc $\gamma$ forms a cycle with some of the $\operatorname{arcs}$ in $A_{i}$. Call this cycle $C_{i}$. Shrink all the arcs and vertices in $C_{i}$ into a single vertex called $v_{i}$. Call this new digraph $\mathrm{G}_{\mathrm{i}+1}$. Thus, any arc in $\mathrm{G}_{\mathrm{i}}$ that was incident to exactly one vertex in $\mathrm{C}_{\mathrm{i}}$ will be incident to vertex $v_{i}$ in digraph $\mathrm{G}_{\mathrm{i}+1}$. The vertices of $G_{i+1}$ are $v_{i}$ and all the vertices of $G_{i}$ not in $C_{i}$. Let the weight of each arc in $G_{i+1}$ be the same as its weight in $G_{i}$ except for the arcs in $G_{i+1}$ that are directed into $v_{i}$. For each arc $(x, y)$ in $G_{i}$ that transforms into an $\operatorname{arc}\left(x, v_{i}\right)$ in $G_{i+1}$, let

$$
\mathrm{m}\left(\mathrm{x}, \mathrm{v}_{\mathrm{i}}\right)=\mathrm{m}(\mathrm{x}, \mathrm{y})+\mathrm{m}(\mathrm{r}, \mathrm{s}) \text { - } \mathrm{m}(\mathrm{t}, \mathrm{y}) \text {--------------transformation equation }
$$

where $(r, s)$ is the minimum weight arc in cycle $C_{i}$, and where (t,y) is the unique arc in cycle $C_{i}$ whose head is vertex $y$. At this point, observe that $\mathrm{m}(\mathrm{r}, \mathrm{s}) \geq 0, \mathrm{~m}(\mathrm{t}, \mathrm{y}) \geq \mathrm{m}(\mathrm{r}, \mathrm{s})$ and $\mathrm{m}(\mathrm{t}, \mathrm{y}) \geq \mathrm{m}(\mathrm{x}, \mathrm{y})$ since arc $(\mathrm{t}, \mathrm{y})$ was selected as the arc directed into vertex $y$. Let $V_{i+1}$ contain all the vertices in $G_{i+1}$ that are in $V_{i}$, that is, $V_{i+1}=G_{i+1} \cap V_{i}$. Thus, $v_{i} \in V_{i+1}$. Let $A_{i+1}$ contain all the arcs in $G_{i+1}$ that are in $A_{i}$, i.e., $A_{i+1}=G_{i+1} \cap A_{i}$. Thus, $A_{i+1}$ contains the arcs in $A_{i}$ that are not in $C_{i}$.

Increase $\mathrm{i}$ by one, and return to step 1 .

Step 3. This step is reached only when all vertices of $G_{i}$ are in $V_{i}$ and the arcs in $A_{i}$ form a branching for $G_{i}$. If $i=0$, stop because the arcs in $A_{0}$ form a maximum branching for $G_{0}$. If $i \neq 0$, two cases are possible:

(a) Vertex $v_{i-1}$ is the root of some arborescence in branching $A_{i}$.

(b) Vertex $v_{i-1}$ is not the root of some arborescence in branching $A_{i}$.

If (a) occurs, then consider the arcs in $A_{i}$ together with the arcs in cycle $C_{i-1}$. These arcs contain exactly one cycle in digraph $\mathrm{G}_{\mathrm{i}-1}$, namely $\mathrm{C}_{\mathrm{i}-1}$. Delete from this set of arcs the arc in $\mathrm{C}_{\mathrm{i}-1}$ that has the smallest weight. The resulting set of arcs forms a branching for digraph $\mathrm{G}_{\mathrm{i}-1}$. Redefine $\mathrm{A}_{\mathrm{i}-1}$ to be this set of arcs.

If (b) occurs, then there is a unique $\operatorname{arc}\left(\mathrm{x}, \mathrm{v}_{\mathrm{i}-1}\right)$ in $\mathrm{A}_{\mathrm{i}}$ that is directed into vertex $\mathrm{v}_{\mathrm{i}-1}$. This $\operatorname{arc}\left(\mathrm{x}, \mathrm{v}_{\mathrm{i}-1}\right)$ corresponds in digraph $\mathrm{G}_{\mathrm{i}-1}$ to another arc, say arc $(\mathrm{x}, \mathrm{y})$, where vertex $\mathrm{y}$ is one of the vertices in cycle $\mathrm{C}_{\mathrm{i}-1}$ that was shrunk to form vertex $\mathrm{v}_{\mathrm{i}-1}$.

Consider the set of arcs in $A_{i}$ together with the arcs in cycle $C_{i-1}$. This set of arcs contains exactly one cycle in $\mathrm{G}_{\mathrm{i}-1}$, namely $\mathrm{C}_{\mathrm{i}-1}$, and exactly two arcs directed into vertex $\mathrm{y}$, namely arc (x,y) and an arc in cycle $\mathrm{C}_{\mathrm{i}-1}$. Delete the latter arc from this set of arcs. The remaining arcs in this set form a branching in digraph $\mathrm{G}_{\mathrm{i}-1}$. Redefine $\mathrm{A}_{\mathrm{i}-1}$ to be this set of arcs. Having redefined $\mathrm{A}_{\mathrm{i}-1}$, decrease $\mathrm{i}$ by one unit and repeat step 3 . 
The above maximum branching method can also be used to find (1) a minimum branching, (2) a maximum spanning arborescence (if one exists), (3) a minimum spanning arborescence (if one exists), (4) a maximum spanning arborescence rooted at a specified vertex (if one exists), and (5) a minimum spanning arborescence rooted at a specified vertex ( if one exists), (6) a maximum spanning arborescence rooted at a specified vertices set (if one exists), (7) a minimum spanning arborescence rooted at a specified vertices set (if one exists).

\section{Proof of the Optimality of the Method}

Consider any digraph $G_{t}$ produced by the method and consider the branching $A_{t}$ produced by step 3 for digraph $G_{t}$. First, it will be shown that if $A_{t}$ is a maximum branching for digraph $G_{t}$, then branching $A_{t-1}$ is a maximum branching for digraph $\mathrm{G}_{\mathrm{t}-1}$.

To prove this, some definitions are needed. Let $\mathrm{G}^{\prime}$ denote the subdigraph consisting of all arcs in $\mathrm{G}_{\mathrm{t}-1}$ not directed into a vertex in cycle $C_{t-1}$. Let $G^{\prime \prime}$ denote the subdigraph consisting of all the arcs in $G_{t-1}$ not in $G^{\prime}$. Thus, every arc of $G_{t-1}$ is present in exactly one of these subdigraphs $G^{\prime}$ and $G^{\prime \prime}$. Let $A_{t-1}^{\prime}$ denote the arcs in $A_{t-1}$ that are in $G^{\prime}$, and let $A_{t-1}^{\prime \prime}$ denote the arcs of $A_{t-1}$ that are in $G^{\prime \prime}$. Clearly, $A_{t-1}^{\prime}$ and $A_{t-1}^{\prime \prime}$ are branchings in $G^{\prime}$ and $G^{\prime \prime}$, respectively.

If branching $A_{t-1}$ is not a maximum branching for digraph $G_{t-1}$, then there exists some branching $B$ with greater total weight. Let $\mathrm{B}^{\prime}$ denote the arcs in $\mathrm{B}$ that are in $\mathrm{G}^{\prime}$, and let $\mathrm{B}^{\prime \prime}$ denote the arcs of $\mathrm{B}$ that are in $\mathrm{G}^{\prime \prime}$. Since $\mathrm{B}$ is a maximum branching, it follows that either $\mathrm{B}^{\prime}$ weighs more than $\mathrm{A}_{\mathrm{t}-1}^{\prime}$ or $\mathrm{B}^{\prime \prime}$ weighs more than $\mathrm{A}_{\mathrm{t}-1}^{\prime \prime}$.

Claim 1: $A_{t-1}^{\prime}$ is a maximum-weight branching for $\mathrm{G}^{\prime}$.

Claim 2: $\mathrm{A}_{\mathrm{t}-1}$ weighs as much as $\mathrm{B}^{\prime \prime}$.

If both claims 1 and 2 are true, it follows that $A_{t-1}$ must be a maximum branching for digraph $G_{t-1}$.

Note that the branching $A_{i}$ produced by the method for the terminal digraph $G_{i}$ is a maximum branching since it contains a maximum positively weighted arc directed into each vertex in $\mathrm{G}_{\mathrm{i}}$ if such an arc exists. Since the method produces a maximum branching for the terminal digraph $\mathrm{G}_{\mathrm{i}}$, then if both claims 1 and 2 are true, then the method must produce a maximum branching $A_{i-1}$ for $\mathrm{G}_{\mathrm{i}-1}$. By repeating this reasoning, we can conclude that if claims 1 and 2 are true, then the branching $A_{0}$ produced by the method is a maximum branching for the original digraph $\mathrm{G}_{0}$.

Hence, it remains only to show that claims 1 and 2 are valid.

Proof of claim 1. Suppose that cycle $\mathrm{C}_{\mathrm{t}-1}$ contains $\mathrm{n}$ vertices. There is one arc with positive weight directed into each of these $\mathrm{n}$ vertices in digraph $\mathrm{G}^{\prime}$ (otherwise, the method would not have formed cycle $\mathrm{C}_{\mathrm{t}-1}$ ). Since there are only $\mathrm{n}$ vertices in $\mathrm{G}^{\prime}$ that have arcs directed into themselves, a maximum branching for $\mathrm{G}^{\prime}$ cannot contain more than $\mathrm{n}$ arcs. Moreover, no branching in $\mathrm{G}^{\prime}$ can have weight exceeding the weight of cycle $\mathrm{C}_{\mathrm{t}-1}$, which consists of the maximum positive-weight arc directed into each of the $n$ vertices in cycle $C_{t-1}$. However, at least one of the arcs in $\mathrm{C}_{t-1}$ must be absent from any maximum branching for $\mathrm{G}^{\prime}$ since a branching cannot contain a cycle. Thus, at least one of these $\mathrm{n}$ vertices, say vertex $\mathrm{y} \in \mathrm{C}_{\mathrm{t}-1}$, must either have no branching arc directed into it or else have an arc $(\mathrm{x}, \mathrm{y}), \mathrm{x} \notin \mathrm{C}_{\mathrm{t}-1}$, directed into it.

For each vertex $z \in C_{t-1}$, construct a branching $B_{z}$ in $\mathrm{G}^{\prime}$ as follows:

(a) Include all arcs in cycle $\mathrm{C}_{\mathrm{t}-1}$ except the arc in cycle $\mathrm{C}_{\mathrm{t}-1}$ that is directed into vertex $\mathrm{z}$.

(b) Include any maximum positive-weight arc $(\mathrm{x}, \mathrm{z})$, where $\mathrm{x} \notin \mathrm{C}_{\mathrm{t}-1}$.

Select the branching $\mathrm{B}_{\mathrm{Z}}{ }^{*}$ with the greatest weight. From the transformation equation, branching $\mathrm{B}_{\mathrm{Z}}{ }^{*}$ is the branching $\mathrm{A}^{\prime \prime}{ }_{\mathrm{t}-1}$ generated by the method.

Consider any branching $B_{1}$ in $G^{\prime}$ that is not of the form $B_{z}$. If only one of the $\operatorname{arcs}$ of $C_{t-1}$ is not in $B_{1}$, it follows that $B_{1}$ cannot be a maximum branching for $\mathrm{G}^{\prime}$ since it is not of the form $\mathrm{B}_{\mathrm{z}}$. If two or more arcs of $\mathrm{C}_{\mathrm{t}-1}$ are not in $\mathrm{B}_{1}$, then either (1) each of these arcs is replaced by an arc of smaller weight directed into the same vertex or (2) no arc is directed into this vertex. In either case, this results in the decrease of the weight sum of arcs in the branching directed into the vertex. Hence, $B_{1}$ cannot be a maximum branching for $\mathrm{G}^{\prime}$. Thus, $\mathrm{A}_{\mathrm{t}-1}^{\prime}$ is a maximum branching for $\mathrm{G}^{\prime}$, and we can assume, without loss of generality, that $\mathrm{A}_{\mathrm{t}-1}^{\prime}$ is identical to $\mathrm{B}^{\prime}$. This concludes the proof of claim 1 .

Proof of Claim 2. Two cases are possible:

(a) Branching $A_{t}$ contains an arc $\left(x, v_{t-1}\right)$ directed into vertex $v_{t-1}$.

(b) Branching $A_{t}$ does not contain an arc directed into vertex $v_{t-1}$.

Case (a): By hypothesis, $\mathrm{A}_{\mathrm{t}}$ is a maximum branching for $\mathrm{G}_{\mathrm{t}}$ and contains an $\operatorname{arc}\left(\mathrm{x}, \mathrm{v}_{\mathrm{t}-1}\right)$ directed into $\mathrm{v}_{\mathrm{t}-1}$. From claim 1 , $\mathrm{B}^{\prime}$ is identical to $\mathrm{A}_{t-1}^{\prime}$ and hence $\mathrm{B}^{\prime}$ contains an arc $(\mathrm{x}, \mathrm{y})$, where $\mathrm{x} \in \mathrm{C}_{\mathrm{t}-1}$ and $\mathrm{y} \in \mathrm{C}_{\mathrm{t}-1}$. Since $\mathrm{B}$ is a branching in $\mathrm{G}_{\mathrm{t}-1}$, it follows that $\mathrm{B}^{\prime \prime}$ cannot contain a path of arcs from a vertex in $\mathrm{C}_{\mathrm{t}-1}$ to vertex $\mathrm{x}$. Thus, $\mathrm{B}^{\prime \prime}$ must be a maximum branching for $\mathrm{G}^{\prime \prime}$ that does not contain a path of arcs from a vertex in $\mathrm{C}_{\mathrm{t}-1}$ to vertex $\mathrm{x}$. 
Each arc in $G^{\prime \prime}$ corresponds to an arc with identical weight in $G_{t}$. Moreover, each branching in $G^{\prime \prime}$ corresponds to a branching in $G_{t}$ with identical weight. Consequently, if $A^{\prime \prime}-1$ is not a maximum branching in $G^{\prime \prime}$ that contains no path of arcs from a vertex in $C_{t-1}$ to a vertex $x$, then $A_{t}$ is not a maximum branching in $G_{t}$ that contains arc $\left(x, v_{t-1}\right)$, which is impossible. Hence, $\mathrm{A}_{\mathrm{t}-1}{ }_{1-1}$ has the same weight as $\mathrm{B}^{\prime \prime}$, which proves the claim for case (a).

Case (b): Each arc in $G^{\prime \prime}$ corresponds to an arc with identical weight in $G_{t}$. By hypothesis $A_{t}$ is a maximum branching for $G_{t}$. Since no arc in $A_{t}$ is directed into $v_{t-1}$, it follows that every arc in $A_{t}$ corresponds to an arc in $A_{t-1}^{\prime \prime}$. Moreover, any branching in $G^{\prime \prime}$ corresponds to a branching in $G_{t}$ with the same weight. Hence, if $A^{\prime \prime}{ }_{t-1}$ were not a maximum branching in $G^{\prime \prime}$, then $A_{t}$ would not be a maximum branching in $G_{t}$, which is a contradiction.

Thus, $\mathrm{A}^{\prime \prime}{ }_{\mathrm{t}-1}$ must be a maximum branching in $\mathrm{G}^{\prime \prime}$ and have the same weight as $\mathrm{B}^{\prime \prime}$, which completes the proof of claim 2. \#

\section{Applications in Personnel Recruiting and Training Program}

Consider an available position which needs several skills, say $4, \mathrm{x}_{1}, \mathrm{x}_{2}, \mathrm{x}_{3}, \mathrm{x}_{4}$, the connectivity parameters among the skills are represented by the following matrix:

Insert Table 1 here

The Research Committee's task is (1) if there is no candidate who has all of the four skills, how to select one of the candidates; (2) if each candidate only has one skill ( whether different or same) and the number of the candidates is equal to or greater than that of the needed skills, how to select; (3) if the Committee prefers some candidate, how to expand his or her acquired skills so that he or she can be qualified for the position.

Suppose the only criterion to be considered is the connectivity parameters among the skills. Problem (1) is a compound problem for problems (2) and (3), so the basic problems are (2) and (3). Furthermore, problem (2) is a problem to find the optimal expansion strategy, problem (3) is a problem to find the optimal expansion strategy from some specified skill or skills set.

$\sum\left|\mathrm{m}_{\mathrm{ij}}\right|=4.1$, so let $\mathrm{h}=5$, and $\mathrm{m}_{\mathrm{ij}}^{\prime}=\mathrm{m}_{\mathrm{ij}}+\mathrm{h}$. The adding results form the following matrix:

Insert Table 2 here

The process of finding the optimal expansion strategy is as follows.

The method will arbitrarily examine the skills or vertices in the subscript numerical order. The result of the examination of the first two skills is shown as follows:

Insert Table 3 here

After the skill $\mathrm{x}_{3}$ has been examined, the arcs in bucket $\mathrm{A}_{0}$ no longer form a branching since they contain a cycle ( $\left.\mathrm{x}_{2}, \mathrm{x}_{3}\right)$, $\left(\mathrm{x}_{3}, \mathrm{x}_{2}\right)$. At this point, the method shrinks this cycle into a vertex (or skill) $\mathrm{v}_{0}$. A new matrix or digraph resulting from this shrinking is following:

Insert Table 4 here

The result of the examination of the skills for the above matrix or digraph is following:

Insert Table 5 here

At this point, the method has generated a maximum branching for the above matrix consisting of $\operatorname{arcs}\left(\mathrm{x}_{4}, \mathrm{v}_{0}\right),\left(\mathrm{x}_{4}, \mathrm{x}_{1}\right)$. Using this branching, step 3 expands $\mathrm{v}_{0}$ back into its original cycle and adds $\operatorname{arcs}\left(\mathrm{x}_{3}, \mathrm{x}_{2}\right),\left(\mathrm{x}_{2}, \mathrm{x}_{3}\right)$ to the arcs $\left(\mathrm{x}_{4}, \mathrm{v}_{0}\right)$, $\left(\mathrm{x}_{4}, \mathrm{x}_{1}\right)$ already in the branching. Next, arc $\left(\mathrm{x}_{3}, \mathrm{x}_{2}\right)$ with the smaller weight is deleted from the branching so that only one branching arc, namely $\left(\mathrm{x}_{2}, \mathrm{x}_{3}\right)$ is directed into $\mathrm{x}_{3}$. The resulting branching consists of $\operatorname{arcs}\left(\mathrm{x}_{4}, \mathrm{x}_{2}\right),\left(\mathrm{x}_{2}, \mathrm{x}_{3}\right),\left(\mathrm{x}_{4}, \mathrm{x}_{1}\right)$. The total weight of this branching equals $5.5+5.4+5.6=16.5$, which is the maximum possible weight.

So, the committee should select the candidate who has the skill $\mathrm{x}_{4}$. If no candidate has the skill $\mathrm{x}_{4}$, the problem becomes problem (3).

Now suppose the committee prefers the candidate who only has the skill $\mathrm{x}_{2}$, then how does the committee expand his or her skills so as to fit the position?

By adding a "skill" $\mathrm{x}_{0}$, the following matrix is formed:

Insert Table 6 here

By adding the constant $\mathrm{h}=6$, the following matrix is formed:

Insert Table 7 here

The following result is reached:

Insert Table 8 here 
The shrinking process is performed because of the cycle $\left(\mathrm{x}_{4}, \mathrm{x}_{1}\right),\left(\mathrm{x}_{1}, \mathrm{x}_{4}\right)$, and the corresponding result is as follows:

Insert Table 9 here

The next examination result is as follows:

Insert Table 10 here

The maximum branching is obtained which consists of the $\operatorname{arcs}\left(\mathrm{x}_{2}, \mathrm{v}_{0}\right),\left(\mathrm{x}_{0}, \mathrm{x}_{2}\right),\left(\mathrm{x}_{2}, \mathrm{x}_{3}\right)$. Eliminating the $\left(\mathrm{x}_{1}, \mathrm{x}_{4}\right)$ from cycle $\left(\mathrm{x}_{1}, \mathrm{x}_{4}\right),\left(\mathrm{x}_{4}, \mathrm{x}_{1}\right)$, finally, we get the optimal expansion strategy: $\left(\mathrm{x}_{0}, \mathrm{x}_{2}\right),\left(\mathrm{x}_{2}, \mathrm{x}_{3}\right),\left(\mathrm{x}_{2}, \mathrm{x}_{4}\right),\left(\mathrm{x}_{4}, \mathrm{x}_{1}\right)$ with a maximum weight 7.0+6.4+6.4+6.6=26.4. So the optimal expansion strategy is $x_{2} \rightarrow x_{3}, x_{2} \rightarrow x_{4}, x_{4} \rightarrow x_{1}$.

Furthermore, suppose the candidate the committee preferred has the skills $\mathrm{x}_{1}$ and $\mathrm{x}_{2}$, then how could the candidate expand his or her skills so as to fit the position?

Add a new vertex $\mathrm{x}_{0}$ and $\operatorname{arc}\left(\mathrm{x}_{0}, \mathrm{x}_{1}\right)$ to the original digraph, and form a new matrix as follows:

Insert Table 11 here

The examination result is as follows:

Insert Table 12 here

The optimal expansion strategy has been obtained: $\mathrm{x}_{0} \rightarrow \mathrm{x}_{1}, \mathrm{x}_{2} \rightarrow \mathrm{x}_{3}, \mathrm{x}_{1} \rightarrow \mathrm{x}_{4}$, i.e., $\mathrm{x}_{2} \rightarrow \mathrm{x}_{3}, \mathrm{x}_{1} \rightarrow \mathrm{x}_{4}$ with the total weight $6.4+6.5=12.9$.

\section{Conclusions}

A heuristic method to find the optimal expansion strategy has been provided based on the digraphic concept with the expansion parameters being general (symmetric or asymmetric, having cycles or no cycles). The optimality of the method has been proven, and its applications in the personnel recruiting and training program is demonstrated step by step. Some research problems are still open. For example, if the parameters are multidimensional or fuzzy, how can we construct the corresponding method? And if the parameters are not additive, how can we define and design the expansion strategy? Especially, if the information between the skills is provided in the form of the activation propensity function, what do we do? Furthermore, if the skills are fuzzy, possibilistic or probabilistic, what do we do?

\section{References}

Feng J.W. (2001). Competence Set Expansion under Risk and Uncertainty. Journal of Systems Engineering and Electronics, Vol.11, No.2, 655-679.

Larbani M. and Yu P.L. (2009). Two-Person Second-Order Games, Part2: Restructuring Operations to Reach a Win-Win Profile. Journal of Optimization Theory and Application, January, 2009 online.

Li, H.L., and Yu, P.L. (1994). Optimal Competence Set Expansion Using Deduction Graphs. Journal of Optimization Theory and Applications, Vol. 80, No.1, 75-91.

Shi, D.S. and Yu, P.L. (1996). Optimal Expansion and Design of Competence Set with Asymmetric Acquiring Costs. Journal of Optimization Theory and Applications, Vol.88, No. 3, 643-658.

Yu P.L. and Larbani M. (2009). Two-Person Second-Order Games, Part1: Formulation and Transition Anatomy. Journal of Optimization Theory and Application, January, 2009 online.

Yu, P.L., and Zhang, D. (1990). A Foundation for Competence Set Analysis. Mathematical Social Sciences, Vol.20, 251-299. 
Table 1. The skill matrix

\begin{tabular}{c|cccc}
\hline $\mathrm{m}\left(\mathrm{x}_{\mathrm{i}}, \mathrm{x}_{\mathrm{j}}\right)$ & $\mathrm{x}_{1}$ & $\mathrm{x}_{2}$ & $\mathrm{x}_{3}$ & $\mathrm{x}_{4}$ \\
\hline $\mathrm{x}_{1}$ & $/$ & 0.1 & 0.2 & 0.5 \\
$\mathrm{x}_{2}$ & 0.2 & $/$ & 0.4 & 0.4 \\
$\mathrm{x}_{3}$ & 0.3 & 0.5 & $/$ & 0.2 \\
$\mathrm{x}_{4}$ & 0.6 & 0.5 & 0.3 & $/$ \\
\hline
\end{tabular}

Table 2. The adjusted skill matrix

\begin{tabular}{c|cccc}
\hline $\mathrm{m}^{\prime}\left(\mathrm{x}_{\mathrm{i}}, \mathrm{x}_{\mathrm{j}}\right)$ & $\mathrm{x}_{1}$ & $\mathrm{x}_{2}$ & $\mathrm{x}_{3}$ & $\mathrm{x}_{4}$ \\
\hline $\mathrm{x}_{1}$ & $/$ & 5.1 & 5.2 & 5.5 \\
$\mathrm{x}_{2}$ & 5.2 & $/$ & 5.4 & 5.4 \\
$\mathrm{x}_{3}$ & 5.3 & 5.5 & $/$ & 5.2 \\
$\mathrm{x}_{4}$ & 5.6 & 5.5 & 5.3 & $/$ \\
\hline
\end{tabular}

Table 3. The first two skills examination result

\begin{tabular}{llll}
\hline vertex examined & \multicolumn{1}{c}{$\mathrm{V}_{0}$} & \multicolumn{1}{c}{$\mathrm{A}_{0}$} \\
\hline & $\mathrm{x}_{1}$ & $\mathrm{x}_{1}$ & $\left(\mathrm{x}_{4}, \mathrm{x}_{1}\right)$ \\
& $\mathrm{x}_{2}$ & $\mathrm{x}_{1}, \mathrm{x}_{2}$ & $\left(\mathrm{x}_{4}, \mathrm{x}_{1}\right),\left(\mathrm{x}_{3}, \mathrm{x}_{2}\right)$ \\
& $\mathrm{x}_{3}$ & $\mathrm{x}_{1}, \mathrm{x}_{2}, \mathrm{x}_{3}$ & $\left(\mathrm{x}_{4}, \mathrm{x}_{1}\right),\left(\mathrm{x}_{3}, \mathrm{x}_{2}\right),\left(\mathrm{x}_{2}, \mathrm{x}_{3}\right)$ \\
\hline
\end{tabular}

Table 4. The new skill matrix after first shrinking process

\begin{tabular}{r|cccc}
\hline & & $\mathrm{v}_{0}$ & $\mathrm{x}_{1}$ & $\mathrm{x}_{4}$ \\
\hline $\mathrm{v}_{0}$ & $/$ & $/$ & $/$ \\
$\mathrm{x}_{1}$ & $0.0)$ & $(5.2$, & $/$ & 5.5 \\
$\mathrm{x}_{4}$ & $5.3)$ & $(5.4$, & 5.6 & $/$ \\
\hline
\end{tabular}

Table 5. The examination for the new skill matrix

\begin{tabular}{ccc}
\hline vertex examined & $\mathrm{V}_{0}$ & $\mathrm{~A}_{0}$ \\
\hline $\mathrm{v}_{0}$ & $\mathrm{v}_{0}$ & $\left(\mathrm{x}_{4}, \mathrm{v}_{0}\right)$ \\
$\mathrm{x}_{1}$ & $\mathrm{v}_{0}, \mathrm{x}_{1}$ & $\left(\mathrm{x}_{4}, \mathrm{v}_{0}\right),\left(\mathrm{x}_{4}, \mathrm{x}_{1}\right)$ \\
$\mathrm{x}_{4}$ & $\mathrm{v}_{0}, \mathrm{x}_{1}, \mathrm{x}_{4}$ & $\left(\mathrm{x}_{4}, \mathrm{v}_{0}\right),\left(\mathrm{x}_{4}, \mathrm{x}_{1}\right)$ \\
\hline
\end{tabular}


Table 6. The skill matrix for new problem

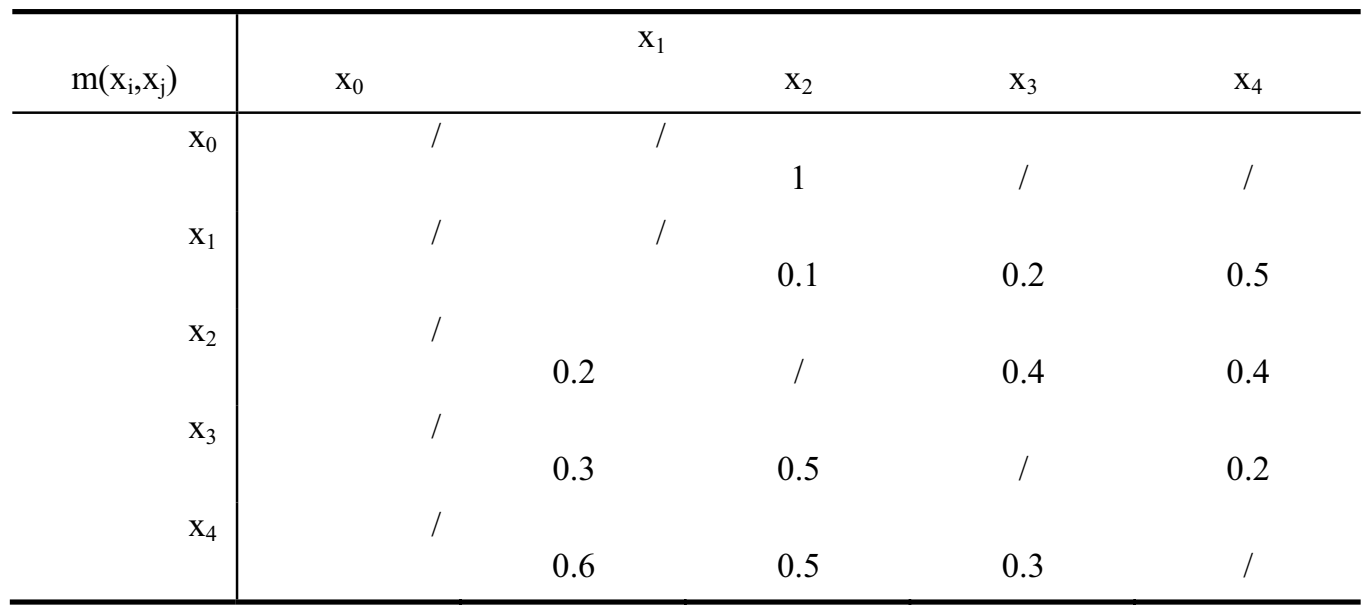

Table 7. The skill matrix after adding

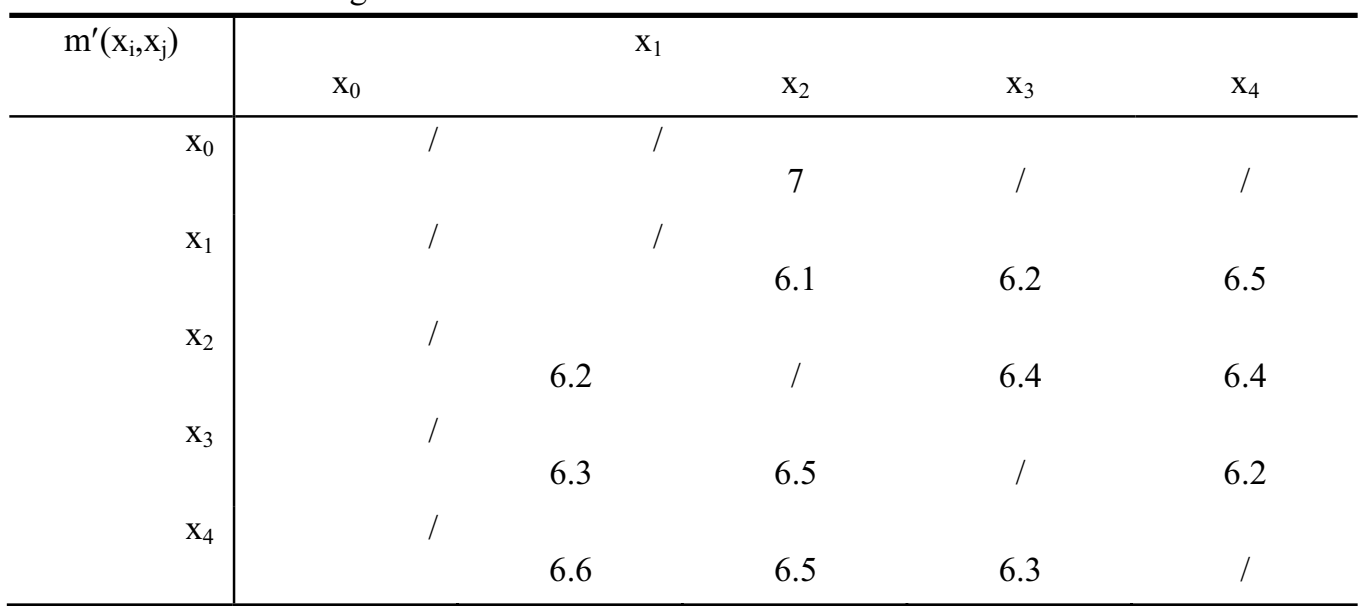

Table 8 . The vertex examination

\begin{tabular}{ccc}
\hline vertex examined & \multicolumn{1}{c}{$\mathrm{V}_{0}$} & $\mathrm{~A}_{0}$ \\
\hline $\mathrm{x}_{0}$ & $\mathrm{x}_{0}$ & $\left(\mathrm{x}_{4}, \mathrm{x}_{1}\right)$ \\
$\mathrm{x}_{1}$ & $\mathrm{x}_{0}, \mathrm{x}_{1}$ & $\left(\mathrm{x}_{4}, \mathrm{x}_{1}\right),\left(\mathrm{x}_{0}, \mathrm{x}_{2}\right)$ \\
$\mathrm{x}_{2}$ & $\mathrm{x}_{0}, \mathrm{x}_{1}, \mathrm{x}_{2}$ & $\left(\mathrm{x}_{4}, \mathrm{x}_{1}\right),\left(\mathrm{x}_{0}, \mathrm{x}_{2}\right),\left(\mathrm{x}_{2}, \mathrm{x}_{3}\right)$ \\
$\mathrm{x}_{3}$ & $\mathrm{x}_{0}, \mathrm{x}_{1}, \mathrm{x}_{2}, \mathrm{x}_{3}$ & $\left(\mathrm{x}_{4}, \mathrm{x}_{1}\right),\left(\mathrm{x}_{0}, \mathrm{x}_{2}\right),\left(\mathrm{x}_{2}, \mathrm{x}_{3}\right),\left(\mathrm{x}_{1}, \mathrm{x}_{4}\right)$
\end{tabular}

Table 9. The vertex shrinking

\begin{tabular}{c|rccc}
\hline & $\mathrm{v}_{0}$ & $\mathrm{x}_{0}$ & $\mathrm{x}_{2}$ & $\mathrm{x}_{3}$ \\
\hline $\mathrm{v}_{0}$ & $/$ & $/$ & $/$ & $/$ \\
& & & & \\
$\mathrm{x}_{0}$ & 0 & $/$ & 7 & 6.4 \\
$\mathrm{x}_{1}$ & $(6.1,6.4)$ & $/$ & $/$ & $/$ \\
$\mathrm{x}_{4}$ & $(6.2,6.2)$ & $/$ & 6.5 & \\
\hline
\end{tabular}


Table 10. The 2nd vertex examination

\begin{tabular}{ccc}
\hline vertex examined & $\mathrm{V}_{0}$ & $\mathrm{~A}_{0}$ \\
\hline $\mathrm{v}_{0}$ & $\mathrm{v}_{0}$ & $\left(\mathrm{x}_{2}, \mathrm{v}_{0}\right)$ \\
$\mathrm{x}_{0}$ & $\mathrm{v}_{0}, \mathrm{x}_{0}$ & $\left(\mathrm{x}_{2}, \mathrm{v}_{0}\right)$ \\
$\mathrm{x}_{2}$ & $\mathrm{v}_{0}, \mathrm{x}_{0}, \mathrm{x}_{2}$ & $\left(\mathrm{x}_{2}, \mathrm{v}_{0}\right),\left(\mathrm{x}_{0}, \mathrm{x}_{2}\right)$ \\
$\mathrm{x}_{3}$ & $\mathrm{v}_{0}, \mathrm{x}_{0}, \mathrm{x}_{2}, \mathrm{x}_{3}$ & $\left(\mathrm{x}_{2}, \mathrm{v}_{0}\right),\left(\mathrm{x}_{0}, \mathrm{x}_{2}\right),\left(\mathrm{x}_{2}, \mathrm{x}_{3}\right)$ \\
\hline
\end{tabular}

Table 11. The 2 nd vertex adding

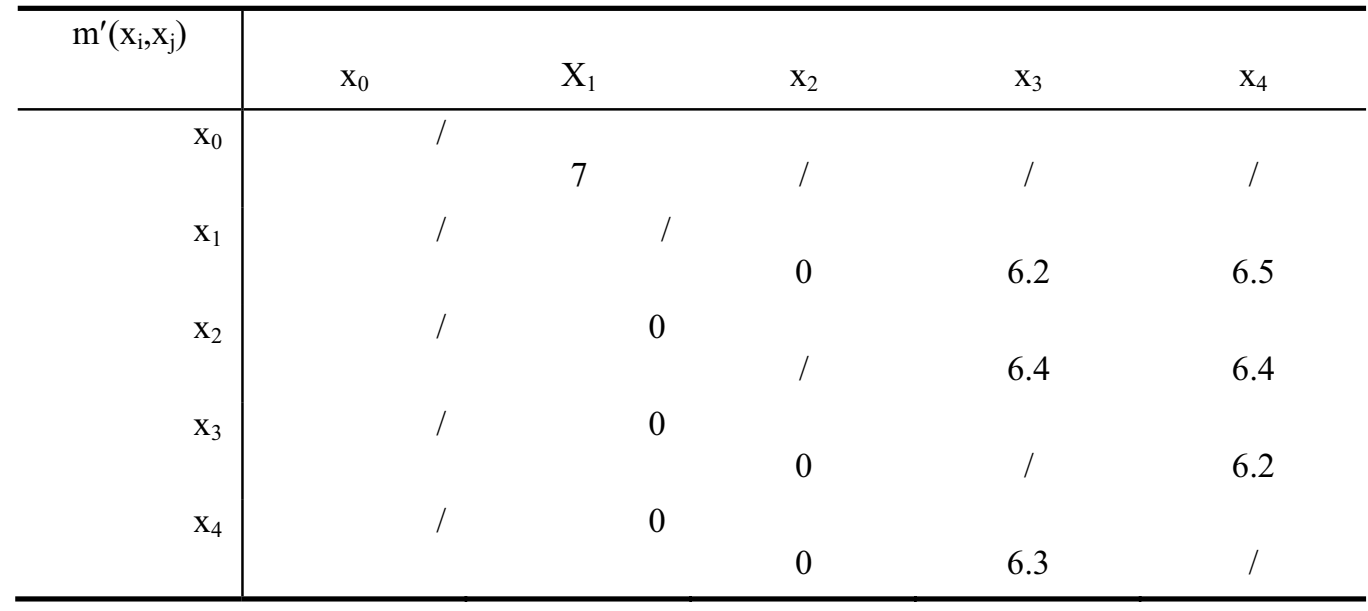

Table 12. The 3rd vertex examination

\begin{tabular}{ccc}
\hline vertex examined & $\mathrm{V}_{0}$ & $\mathrm{~A}_{0}$ \\
\hline $\mathrm{x}_{0}$ & $\mathrm{x}_{0}$ & \\
$\mathrm{x}_{1}$ & $\mathrm{x}_{0}, \mathrm{x}_{1}$ & $\left(\mathrm{x}_{0}, \mathrm{x}_{1}\right)$ \\
$\mathrm{x}_{2}$ & $\mathrm{x}_{0}, \mathrm{x}_{1}, \mathrm{x}_{2}$ & $\left(\mathrm{x}_{0}, \mathrm{x}_{1}\right)$ \\
$\mathrm{x}_{3}$ & $\mathrm{x}_{0}, \mathrm{x}_{1}, \mathrm{x}_{2}, \mathrm{x}_{3}$ & $\left(\mathrm{x}_{0}, \mathrm{x}_{1}\right),\left(\mathrm{x}_{2}, \mathrm{x}_{3}\right)$ \\
$\mathrm{x}_{4}$ & $\mathrm{x}_{0}, \mathrm{x}_{1}, \mathrm{x}_{2}, \mathrm{x}_{3}, \mathrm{x}_{4}$ & $\left(\mathrm{x}_{0}, \mathrm{x}_{1}\right),\left(\mathrm{x}_{2}, \mathrm{x}_{3}\right),\left(\mathrm{x}_{1}, \mathrm{x}_{4}\right)$ \\
\hline
\end{tabular}




\title{
Review on Enterprise Growth Theories
}

\author{
Huiyuan Mao \\ Tourism and Geography Science College, Shenyang University \\ Shenyang 110044, China \\ Tel: 86-24-2389-4862Ｅ-mail: maohuiyuan2004@126.com
}

\begin{abstract}
The research is financed by the Liaoning Provincial Society and Science Fund (No. 2008LSLKTGLX-92). (Sponsoring information)
\end{abstract}

\begin{abstract}
Through defining and analyzing the meanings of enterprise growth and enterprise growthiness, the existing theoretical results about the enterprise growth were expounded, abstracted and evaluated from different views, which is expected to further provide theoretical references and supports to study the problem of enterprise growth.
\end{abstract}

Keywords: Enterprise, Growthiness, Growth theory

As the economic globalization and the process of system marketization go on, the competition in the global market becomes increasingly intense. Taking US with strong enterprise energy and competitive force as the example, in 100 strongest enterprises listed in Forbes in 1978, there were three of them to be bankrupted, and 35 of them to be purchased, and 30 of them which could not enter into the 100 strongest enterprises list of Forbes in 2006, and only 32 of them to be still on the list. In this period, $68 \%$ of past winners were eliminated from the list. It is obvious that the intense market competition and the survival press were so strong.

This kind of structure change of the international environment has largely changed the survival and growth environment of enterprises in the various regions all over the world, which promotes them more quickly to seek new growth and transformation way, so the new tendency of world enterprise growth and transformation has been formed. The theoretical researches are the base of practical researches, so to better accomplish the researches about the enterprise growth, the systematic analysis and induction of existing foreign and domestic enterprise growth theories are made in the article.

\section{Enterprise growth and enterprise growthiness}

\subsection{Meanings of enterprise growth}

The enterprise growth is used to describe a development process of enterprise from small to big and from weak to strong. The meanings of development exceeds the meanings of growth, and it includes not only the growth process of things, but the generation stage growing out of noting before growth and the periodic process of the stage, i.e. the cycle process going round and round. However, the enterprise growth is a complex adjustment process which is different to the simple scale extension. It takes the balance adjustments of various relations in the interior and the exterior of the enterprise as the essential character, and it is the process of balanced development from unbalance to balance, and from lower balance to higher balance. Therefore, the meanings of enterprise growth is the development process that enterprise keeps the tendencies of balanced and stable growth of total performance level (including output, sales volume, profit and asset gross) or keeps realizing the large enhancement of total performance and the stage spanning of development quality and level (Sun, 2004, P.66-69). In the meanings of enterprise growth, following three connotations are contained.

(1) The time property of enterprise growth. The premise to analyze the growth of enterprise is long period in which the long-term development tendency and process of enterprise are observed, and it is not the status of enterprise in certain time point.

(2) The dynamic property of enterprise growth. The growth of enterprise is not a stable process without troubles. In the growth process, enterprise always transits from balance to unbalance, and the result is to transit from unbalance to balance and from lower balance to higher balancer through unbalance. 
(3) The enterprise growth is the unification of quantity and quality. The increase of quantity is embodied in the extension of enterprise scale such as the increases of sales volume, market share, production value, profit and employee. And the growth of quality is embodied in the enhancement of enterprise quality, which includes the technological innovation ability from immature to mature production technology, the optimal efficiency of investment and output, the organizational innovation and reform.

\subsection{Enterprise growthiness}

The growthiness of enterprise means the ability of enterprise to grow continually, quickly and healthily. Concretely speaking, the enterprise growthiness is the value-added ability obtained by the enterprise through the optimization of the change speed between production factor and production result in the development process, which is represented by that the enterprise and the relative industry have the development property, the product foreground is wide, the enterprise scale is extending year by year, and the management benefit increases continually. The research of enterprise growthiness should centralize in the growth ability of enterprise, and this ability should include practical development ability and growth potential. High growth rate is only the exterior representation of the enterprise with high growth character, and the enterprise with high growth rate in some aspects uncertainly has high growthiness. Furthermore, the growth speed is only one aspect to measure the enterprise growthiness, and the enterprise growthiness should also be analyzed completely, systematically and comprehensively from others angles such as efficiency and competition advantage.

The enterprise growthiness includes two aspects at least. The first one is the survival ability of enterprise. In the intensive market competition, the base of sustainable growth for enterprise is the survival ability of enterprise, and the generation of survival ability depends on the new technology, new product and new originality possessed by the enterprise when it is founded, which can make the enterprise to possess future wider space the competition advantage. The second one is the sustainable development ability of enterprise. After the generation period, the enterprise survives in the market in virtue of its special survival ability, and whether the enterprise faces favorable circumstance or adversity, it can possess the sustainable development ability to exceed itself and keep developing. Therefore, the enterprise growthiness should be considered from multiple angles and layers, and it can not be simply concluded as the character in certain one aspect in the development process of enterprise.

\section{Foreign relative theory researches about enterprise growth}

British management professor, Penrose's Enterprises Growth Theories published in 1959 established the base of the enterprise growth theory. Thereafter, the enterprise growth theory has been concerned by the economics academe and the management theory academe. Up to now, three theoretical opinions have been formed in foreign researchers about the enterprise growth theory, i.e. the growth theory based on the scale boundary theory, the growth theory based on the lifecycle, and the growth theory based on gene combination.

\subsection{The enterprise growth theory based on the scale boundary theory}

In these researches about the enterprise growth theory, the scale boundary theory is very important. The enterprise growth theory includes multiple analysis angels and concept systems. First, various researches hold different concepts of growth, so the diversification of analyzing growth status scale is generated. Second, there are many opinions to describe the curve and growth rate of the growth status. Third, the opinions about the growth mechanism including the growth drive and reason of enterprise are also different. In addition, most above growth theories review the enterprise growth from the economic view. The enterprise growth theory based on the scale boundary is based on Coase's (1937) transaction cost theory. Coase thought that the marketable character of enterprise is the substitute of the price mechanism. Coase utilized the concept of transaction cost to explain the reason of enterprise generation and define the scale. His opinion when discussing the enterprise scale was that when the added transaction was organized by the enterprise, the scale of the enterprise would be extended, and it was organized by another enterprise or the market, the scale of the enterprise didn't be changed, and when the scale of the enterprise is extended, the added transaction cost in the enterprise equaled the cost to accomplish this transaction in the market or the cost of the added transaction organized by another enterprise.

\subsection{The enterprise growth theory based on the lifecycle theory}

In the late of 1980 s, some foreign monographs begun to review the enterprise growth from the survival and development view of the living enterprise, which regarded the enterprise as a life body to dynamically evaluate the characters and countermeasures in various stages of enterprise growth. The representative books included Ichak Adizes's "Enterprise Life Cycle (1988)"and Arie de Gues' "The Living Company (1996)". In the "Enterprise Life Cycle", the enterprise was assimilated to the life body, and the life cycle theory thought that as the life body would go through the life course from born, growth to death, the enterprise would also experience the process from generation, growth, aging and death. As the flexibility of enterprise gradually decreases and the controllability of enterprise gradually increases and decreases, the enterprise growth can be divided into the growth stage, the regeneration and 
mature stage, and the aging stage. The growth stage includes gestation stage, infant stage and step-learning stage. The regeneration and mature stage includes youth stage and prime stage. The aging and death stage includes stabilization stage, noble stage, early bureaucracy stage, bureaucracy stage and death. The character changes of various stages in the lifecycle of enterprise essentially reflect the change of enterprise culture, and to keep lively enterprise culture and flexible organization structure is very important in this theory. The book of "The Living Company" put forward to distinguish the "life company" which was managed for the survival and the "economic company" which was managed for the profit.

\subsection{The enterprise growth theory based on the gene combination theory}

For this theory, the most representative book is Francsi J Gouillart and James N Kelly's "Business Transformation (1988)". In this book, the enterprise was regarded as the organism, and various influencing factors on the enterprise were looked upon genes and chromosomes, which presented a special view. The concept of "Biological Corporation" was proposed in the book, and the eternal life of the life body, "Biological Corporation", rested with that whether it had the ability to drive all systems to transform synchronously, and describe these systems, i.e. "twelve biological corporation systems". The business transformation theory thought that the role of the leader was the gene engineer of "Biological Corporation". Just like the organism, because of the tiny mistake of DNA reproduction, certain gene will mutate, and the result of this mutation may be good or bad, and maybe this mutation just limits the theoretical base shape which induces last bad private enterprise growth and makes the individual develop to good direction. Therefore, the environment change doesn't means good or bad, and the key problem is that the change means opportunity or threat for the "Biological Corporation", i.e. the enterprise. So the transformation of "Biological Corporation" should be the transformation of various systems together.

\section{Chinese relative theory researches about enterprise growth}

In the book of "Enterprise Growth Theory", Yang Du (1996) developed Penrose's enterprise growth theory, started from the concept of management resource, and induced "the general rule of the enterprise growth irrelative with nationality" through analyzing the quantity, extension, structure and dominant subject of the management resource (Yang, 1996).

Based on Yang Du's 2D enterprise growth mode theoretical model, Zhang Lin'ge (1998) absorbed the research results of modern competitive theory, and established the 3D enterprise growth theoretical model (Zhang, 1998, P.45-49), i.e. Yang Du's 2D enterprise growth mode theoretical model was extended from 2D to 3D, and the enterprise growth was analyzed from three angles including scale, diversification and competitive force.

Li Zhicheng and Diao Zhaofeng (2003) put forward the concept of "enterprise growth force" (Li, 2003, P.86-89). They thought that the enterprise growth force means the enterprise's ability and potential to realize the extension of "quantity" and enhance the "quality" in future period, and it decided the probability and development degree of enterprise development.

$\mathrm{Xu}$ Xiaoming and $\mathrm{Xu}$ Zhen (2005) analyzed several kinds of foreign and domestic enterprise growth theory research results based on the view of resource base, discussed five important parts including heterogenic hypothesis, comprehensive knowledge accumulation growth, dynamic competitive advantage of resource, industrial analysis route, and behavior and learning of the modern enterprise growth theory, and analyzed the practical meanings of the theory (Xu, 2005, P.92-99).

Tang Wenxian and Li Panfeng (2005) analyzed the development course of relative enterprise growth theories from three aspects including scale, knowledge and system, and effectively classified the relative enterprise growth theory (Tang, 2005, P.17-21). They pointed out that the enterprise growth was an interactive process with scale extension, knowledge accumulation and system construction.

Starting from the enterprise growth system theory, Wu Aiqi and Jia Shenghua (2007) pointed out three enterprise growth mechanisms existed in the practice, i.e. the interior growth mechanism, the merger growth mechanism and the network growth mechanism, and analyzed the strategic ideas of three growth mechanisms.

In various western theories and opinions about the enterprise growth theory, to analyze the enterprise growth from the scale boundary angle takes Coase's mutual substitution theory of enterprise and market as the start, and the focus is to review the exterior boundary of the enterprise, and to analyze the enterprise growth from the life cycle angle takes the disharmony of the organizational scale extension and the enterprise culture as the start, and the focus is to review the dynamic growth view of the enterprise, and to analyze the enterprise growth from the gene combination angle takes the mutual relation theory of the interior management process and management function as the start, and the focus is to review the interior micro operation mechanism of the enterprise. The domestic researches of the enterprise growth theory experienced initially learning, understanding and present enriching and developing, and one of most prominent characters is that the researchers always use western enterprise growth theories for references and consciously persist in the combination of theoretical research and Chinese practice, so the research direction is more and more clear and the research idea is wider and wider. Based on the enterprise growth theory, it should discuss the enterprise growthiness 
from multiple aspects and angles, which can comprehensively evaluate the growthiness of the growth-type enterprise.

\section{References}

Li, Zhicheng \& Diao, Zhaofeng. (2003). On Business Growth Force and Its Generating Mechanism. Journal of Wuhan University of Technology (Information \& Management Engineering). No.25(5), P. 86-89.

Sun, Xuemin. (2004). The Growth Essence and Ways of the Middle and Small Enterprises. Journal of Zhengzhou University (Philosophy and Social Science Edition), No. 34(4), P. 66-69.

Tang, Wenxian \& Li, Panfeng. (2005). Theory of Firm Growth Based on Three Dimensions. Soft Science, No.19(1), P.17-21.

$\mathrm{Xu}$, Xiaoming \& Xu, Zhen. (2005). Probing into Firm's Growth Theory Based on Resources View. R\&D Management, No. 17(2), P. 92-99.

Yang, Du. (1996). Enterprise Growth Theory. Beijing: China Renmin University Press.

Zhang, Lin'ge. (1998). Theoretical Model of 3D Enterprise Growth Mode. Nankai Economic Studies, No. 5, P.45-49. 


\title{
Convergence on the Council Opinions of 2007 in Japan
}

\author{
Yanhong Pang \& Daojin Shi \\ School of Economics and Management, Zhejiang Forestry University \\ Lin'an 311300, China \\ E-mail: pyh166@126.com
}

This research paper was Supported by Startup Foundation for Introducing Talents of Zhejiang Forestry University and Institute of Accounting of Zhejiang Forestry University.

\begin{abstract}
In order to improve the effectiveness of internal control, the Business Accounting Council (BAC) established the Subcommittee which held 16 special meetings to discuss and develop a set of standards of internal control for Japan from February 2005 to January 2007. The BAC did not finalize the Council Opinions of 2007 until February 15, 2007. Based on the minutes of the Subcommittee meetings, this paper mainly traces the process of establishing the standards and practice standards for management assessment and audit concerning internal control over financial reporting, focusing on the changes of standards in the setting process. The history of internal control is also briefly reviewed in this paper.
\end{abstract}

Keywords: Internal control over financial reporting, Management assessment and audit concerning, Council opinions

\section{Simple Review of Internal Control in Japan}

\subsection{Research on Internal Control over Financial Reporting}

Based on the postwar securities democratization, the newly formed Japanese accounting profession was very weak on the research of auditing on the side of Certified Public Accountants (CPAs). It did not clarify what internal control was from researcher's standpoint until 1970, the Special Committee of Japanese Accounting Association (Special Committee) issued the report titled "Research on Internal Control over Financial Reporting". In this report, internal control was defined as a generic term of system, organization, method and procedure which was set by the management in order to safeguard assets, assure the accuracy and reliability of the accounting record, and to generally plan, adjust and evaluate the management activities. This definition shows that the objectives of internal control were (1) to safeguard assets which belongs to asset management, (2) to assure the accuracy and reliability of the accounting record which refers to accounting management, (3) to make the management activities effective and efficient which relates to process management. Thus the internal control that should be evaluated by the auditor of financial statements audit was divided into asset management and accounting management. This classification was consistent with that of AICPA at that time. However, the Special Committee could not distinct control from management since it used "management" but not "control" in this definition.

\subsection{Auditing Standards related to Internal Control}

In response to the dramatically changing of auditing environment, in December, 1991, the revised Auditing Standards, Working Rules of Audit Procedures of Field Work and Working Rules of Audit Procedures in Reporting (ASh3) were issued. It was for the first time that Japanese auditing standard-setting body, the Business Accounting Council (BAC) of the Ministry of Finance (MOF), introduced a new concept of internal control and the risk approach. As a standard of field work [Section 3], ASh3 stipulated that when planning the audit and determining the audit procedure, timing, and the extent of tests to be performed, the auditor should obtain a sufficient understanding of internal control, and fully consider the materiality of audit object, audit risk and other factors. ASh3 also addressed the working rules of audit procedure of field work [Section 5] when the auditor made an audit planning and evaluated the effectiveness of internal control and the audit risk. The risk approach was reconfirmed by the revised auditing standards in 2002 (ASh14) and developed in the revised auditing standards in 2005 (ASh17). ASh14 explicitly prescribed three components (inherent 
risk, control risk and detection risk) of audit risk and their relationship. ASh17 combined inherent risk and control risk into material misstatement risk.

\subsection{Necessity for Improvement of Internal Control}

In the United States, the importance of companies' internal controls has been widely recognized since a series of misconducts occurred in the United States such as the Enron case. To enhance the effectiveness of the internal control, Public Company Accounting Reform and Investor Protection Act of 2002 (Sarbanes-Oxley Act of 2002) was issued and the management of the Securities and Exchange Commission (SEC) registrant were required to prepare the internal control report, in which an assessment of the effectiveness of the internal control over financial reporting became an important part. Moreover, each registrant was subject to an audit by certified public accountants.

In Japan, improper practices (e.g., the representative suit against Kobe Steel in 2002 and the Kanebo accounting fraud of 2004) have also been observed recently concerning corporate information disclosure under the Securities and Exchange Law, especially in the annual report. These may indicate that the function of internal control to ensure the reliability of corporate disclosure worked ineffectively. As is well known, the securities market cannot fulfill its function perfectly unless corporate information is fairly disclosed to the investors. Thus, it is necessary to enhance the effectiveness of internal control.

\section{Toward Exposure Draft of Standards for Management Assessment and Audit concerning Internal Control over Financial Reporting}

\subsection{Process of Exposure Draft of Standards}

The development of the standard of the assessment by management and audit by the auditor on the effectiveness of internal control over financial reporting came to the agenda of a general meeting of the BAC in January 2005. One of the most important contents of the general meeting was to discuss the effectiveness of internal control and establish the Internal Control Subcommittee (Subcommittee) (Note 1). Discussions started from February 2005 in the first meeting of the Subcommittee. Based on the second and third Subcommittee meetings' reviewing the existing internal control standards of other countries, the Subcommittee put forward the key points of setting assessment and auditing standards of internal control over financial reporting in the $4^{\text {th }}$ meeting and formed the "Preliminary Draft: Standards of for Management Assessment and Audit concerning Internal Control Over Financial Reporting" (Preliminary Draft) in following four Subcommittee meetings. After considering the statement of witness's opinions (the $9^{\text {th }}$ meeting) and the discussions in the Subcommittee meetings, the Subcommittee revised the Preliminary Draft of Standards (the $10^{\text {th }}$ meeting) and formed Exposure Draft of Standards (the $11^{\text {th }}$ meeting). The proceeding toward Exposure Draft Standards can be seen in table 1 .

\subsection{Key Points of Setting Assessment and Audit Standards of Internal Control over Financial Reporting}

In the $4^{\text {th }}$ Subcommittee meeting, Tagaya [2005], the director for financial accounting, introduced the key points of setting assessment and audit standards of internal control over financial reporting which are summarized in table 2. 17 key points covering framework of internal control, assessment and audit of internal control and report of assessment and audit were discussed in the meeting.

Insert Table 1 here

\subsection{Preliminary Draft of Standards of Internal Control over Financial Reporting}

Based on the framework of COSO report, discussions and opinions of the Subcommittee meetings, three parts of Preliminary Draft of Standards were formed and discussed in the $5^{\text {th }}, 6^{\text {th }}$ and $7^{\text {th }}$ Subcommittee meeting respectively. The summary of the three parts revised according to the opinion formed in the meeting composed of the whole Preliminary Draft of Standards in the $8^{\text {th }}$ meeting. The following issues were main focuses in the discussion.

\section{Basic Framework of Internal Control}

In the $5^{\text {th }}$ meeting, internal control was defined as a process and system set and operated by board of directors, management and others in the organization and incorporated in its operating activities in order to provide reasonable assurance of achieving four objectives: effectiveness and efficiency of business operations, reliability of financial reporting, compliance with applicable laws and regulations relevant to business activities, and safeguarding of assets. Internal control consisted of six basic components: control environment, risk assessment and response, control activities, information and communication, monitoring, and control using information technology (IT control).

It pointed out that internal control was a process and a system within the organization which was similar to the definition in the COSO report. It also extended the COSO report in the objectives and components. Based on the Japan's condition, it added safeguarding of assets and control using information technology (IT control) as the appropriate objective and component for Japan. Safeguarding of assets was first described to prevent or detect the illegal acquisition, use, and the disposal of the property. IT control was divided into company-level control and 
process-level control. However, the components were not included in the definition of internal control in the $5^{\text {th }}$ meeting.

Insert Table 2 here

According to the opinion that received from the Subcommittee meetings, the Revised Preliminary Draft of Standards which was discussed in the $8^{\text {th }}$ meeting changed in the following aspects. In consideration of the description that "illegal acquisition..." in the safeguarding of assets might result in misunderstanding, the Revised Preliminary Draft of Standards revised "illegal" into "unauthorized". To enhance the understanding of reliability of financial reporting, the scope was expanded to ensure the reliability of financial statements and the information that could have a material effect on financial statements. It added a new section titled "Positioning of the Framework" which included the sections of the relationship between objectives and components of internal control and the limitations of internal control that were addressed in the $5^{\text {th }}$ meeting, and added the section of "Roles and Responsibilities of Relevant Persons", such as management, board of directors, and the like. The section of "Internal Control Documentation" and the section of "Internal Control over Financial Reporting and Its Effectiveness" were deleted.

\section{Assessment and Report on Internal Control over Financial Reporting}

The sixth meeting introduced and discussed assessment and report on internal control over financial reporting, including relevant definitions, scope and method of assessment, and management's report on internal control over financial reporting. It clarified that management had the role and responsibility to design and operate internal control as well as assess the effectiveness of internal control over financial report on the consolidated bases and report its conclusion externally in order to ensure the reliability of financial reporting. In the reasonable scope, management should first assess the company-level control and, based on the result, assess process-level control.

No significant changes were found in the Revised Preliminary Draft of Standards. Aiming at the censure that it was difficult to understand the effectiveness of internal control, the Revised Preliminary Draft of Standards explained that the effectiveness of internal control over financial reporting signified an internal control that was designed and operated in accordance with an appropriate internal control framework and was free of material weakness. The material weakness was a deficiency that had a reasonable possibility of material effect on financial reporting. In short, it was clarified that the effectiveness of internal control was free of material weakness. To define the effectiveness of internal control and the material weakness respectively was conducive to removing the misunderstanding of the deficiency of internal control and material weakness (Note 2). On the supplementary information of the management's report, instead of the description of "subsequent events" in the sixth meeting, the Preliminary Draft of Standards addressed that (1) subsequent events that would have a material impact on assessments of the effectiveness of internal control over financial reporting and (2) remediation and other matters pertaining to material weakness implemented after the end of the fiscal year. It specified the items of supplementary information and was consistent with statement of the remediation of material weakness in internal control in method of assessing internal control over financial reporting.

\section{Audit of Internal Control over Financial Reporting}

The audit on internal control over financial reporting was discussed in the $7^{\text {th }}$ Subcommittee meeting in the following aspects: (1) objective of the internal control audit by financial statement auditors, (2) relationship between the internal control audit and the financial statement audit, (3) performance of the internal control audit, and (4) auditor's report. It required that the external auditors of financial statements should audit internal control report by management and express their opinions in the auditor's report on whether the management's internal control report fairly stated the result of the assessment.

The contents discussed in the $8^{\text {th }}$ meeting varied as follows. On the objective of the internal control audit by financial statement auditors, the Revised Preliminary Draft of Standards emphasized that it must be mindful of not burdening excessively when the auditor thought about a specific procedure. The Revised Preliminary Draft of Standards mentioned that the internal control audit and financial statement audit, taken as a whole, should be performed by the same external auditor. Further, the same external auditor was clarified in the note that it meant not only the same audit firm but also the same engagement partner that conducted the audit. The modification of the auditor's report was mainly presented in the description of auditor's opinion. The Revised Preliminary Draft of Standards added the treatment under the condition that the internal control report by management included a material weakness in internal control over financial reporting and reasons why they had not been remedied. On such cases, when the auditor concluded these statements were fairly stated and therefore expressed an unqualified opinion, the external auditor must include the information in the internal control audit report on the material weakness and the reason why it has not been remedied. On the contrary, when the auditor concluded that they were not fairly stated, the auditor should express adverse opinion. The inappropriateness and the reasons should be included in the internal control audit report. The section of "Disclaimer Opinion" was deleted. In accordance with assessment and report on internal control over financial reporting, the contents of additional information were revised to (1) subsequent events that would have a material impact on 
assessments of the effectiveness of internal control over financial reporting and (2) remediation and other matters pertaining to material weakness implemented after the end of the fiscal year.

\subsection{Exposure Draft of Standards}

Considering statement of witness's opinion(Note 3), the Revised Preliminary Draft of Standards was revised in the tenth and eleventh Subcommittee meetings. On July 13, 2005, the FSA issued "Exposure Draft of Standards for Management Assessment and Audit concerning Internal Control over Financial Reporting" to request public comment, which composed of the Revised Preliminary Draft and a preface. The preface described the general background of discussions, structure and contents of the standards, etc. The Exposure Draft of Standards established the basic structure of the standard of internal control over financial reporting and laid a good foundation for the formal standards.

Table 3 shows the outline of the Exposure Draft of Standards. Compared to the Revised Preliminary Draft of Standards which was discussed in the 8th Subcommittee meeting, the Exposure Draft of Standards mainly varied in the following aspects.

Changes of "I Basic Framework of Internal Control". On the objective of internal control, based on the opinion of Member Yagi and Task Force Member Suzuki, safeguarding of assets was revised to ensure that assets were acquired, used and disposed of in accordance with proper procedure and approvals. Thus, it can prevent the acquirement, use and disposal of assets from improper procedure and disapprovals. In order to clarify the abstract theory, the Exposure Draft of Standards gave some illustrations for every component of internal control in the note. The section of "Positioning of the Framework in the Preliminary Draft of Standards" was reorganized as three sections. The relationship between objective and basic components and a new part were recognized as section of "I 3 Design and Operation of Internal Control". The new part mainly addressed that in order to achieve the objective of internal control, management should manage to design and operate internal control system in terms of their environment that surrounded the company. The limitation of internal control and roles and responsibilities of relevant persons were listed as section "I 4" and "I 5"respectively. In I 5, the Exposure Draft of Standards clearly defined that management should be representatives of the enforcement organization, such as representative directors, chief executive officers, and so on.

Insert Table 3 here

\section{Changes of "II Assessment and Report on Internal Control over Financial Reporting"}

The definition of internal control over financial reporting was changed. In the Revised Preliminary Draft of Standards, internal control over financial reporting was defined as an internal control that was related to the reliability of financial reporting. The Exposure Draft of Standards changed "related to" to "necessary to ensure" which toned up the objective of internal control and management assessment of internal control (i.e., ensuring the reliability of financial reporting). The Exposure Draft of Standards divided II 2 into two subsections: (1) assessment of the effectiveness of internal control over financial reporting, and (2) determination of the scope of assessment in which it emphasized that management should determine the scope of assessment in the order of matters listed and explained the "presentation and disclosure of financial statements" with examples on how to determine the scope from the perspective of degree of quantitative and qualitative impact on financial statements. Risk factor was attached weight to the assessment of company-level control of II 3 (2) in which it addressed that management should sufficiently assess risks occurring inside/outside the organization and fully consider all matters that could have significant impact on overall financial reporting. The Exposure Draft of Standards added a new section of "Limitation of the Scope of Assessment" as II 3 (6), which stated the treatment when sufficient assessment procedures for a certain part of the internal control could not be performed due to unavoidable circumstances. In such cases, based on fully comprehending the impact on the financial reporting, management may exclude such procedures and assess the effectiveness of internal control over financial reporting. The methods for presenting the results of assessments on internal control were listed in II 4 (5) of the Exposure Draft of Standards, which included the statements that were effective, effective but excluding unperformed procedures due to unavoidable circumstances, and not effective and disclaimer of opinion.

\section{Changes of "III Audit on Internal Control over Financial Reporting"}

First, the statement of objective of internal control audit by financial statement auditors (III 1) was changed a lot. The Exposure Draft of Standards noted that the objective of internal control audit was to have external auditors express opinion on whether the management's internal control report fairly stated the results of the assessment in accordance with generally accepted assessment standards for internal control in all material respects. A new term of "internal control audit report" appeared to express the auditor's opinion. The criterion of issuance of unqualified opinion was that the auditor had obtained reasonable assurance that the internal control report by management did not include any material misstatements. On the relationship of the internal control audit and the financial statement audit, the Exposure Draft of Standards pointed out that the audit evidence obtained in the process of the internal control audit might be used as audit evidence for financial statement audit, and vice versa. As the supplement of report and remediation of material weakness in internal control of III 3 (5), the Exposure Draft of Standards requested that the external auditor should 
report the results of the internal control audit to the management, board of directors, corporate auditors or audit committee. When identifying deficiencies in the internal control, the external auditors must report to them by the final date of the Company Law Audit. On the auditor's report of III 4, the subsection of "disclaimer of opinions" was replaced by "exceptions to opinions". Compared to the Revised Preliminary Draft of Standards, the Exposure Draft of Standards fully considered the condition when external auditors identified inappropriate parts in the internal control report regarding the scope, procedures and results of the assessment determined by the management, they should express a qualified opinion with exceptive items unless they could conclude that the internal control report was significantly misstated. In such cases, they should express the opinion that the internal control report was not fairly stated.

\section{Toward Standards for Management Assessment and Audit concerning Internal Control over Financial Reporting}

\subsection{Summary of Comments on and Responses to Exposure Draft of Standards}

After the issuance of the Exposure Draft of Standards, about 40 comments from Japanese Institute of Certified Public Accountants (JICPA), various business groups, auditing firms, companies, and individuals had been received till August 31,2005 . The contents of comments and relevant responses were summarized and discussed in the $12^{\text {th }}$ Subcommittee meeting. Based on the materials distributed in the meeting, this study quantified the comments and responses to the Exposure Draft of Standards. The comment was summarized in terms of each item of the Exposure Draft of Standards and similar opinion was gathered. Table 4 shows the result of the quantification. Among the total item of 486, the statistical amount of comments represented the first is the comments on framework of internal control [I]. The comments on II and III rank the second and the third respectively. The comments on the preface stand the last. Responses to the comment are divided into four categories: comments that will be or have been treated with in the preface, comments that will be or have been handled in the Standards, comments that will be discussed in the Practice Standards and comments that have been discussed but are considered not necessary to response to. The result shows that $41.80 \%$ of the comments will be discussed in the Practice Standards. This indicates that the public has the strong will to need the practice standards and that the Subcommittee will meet the requirement.

\subsection{Difference between Standards and Exposure Draft of Standards}

After considering the public comments, the Exposure Draft was revised again and was finally issued as "Standards for Management Assessment and Audit concerning Internal Control over Financial Reporting" on December 8, 2005. The Standards varied the Exposure Draft of Standards from the following respects.

\section{Insert Table 4 here}

The significant changes of the framework of internal control lay in the definition of internal control and the description of IT component. Based on the comment of lacking description of relationship among four objectives in the definition and of the overlap of the basic components of internal control in I 1 (2) and I 2, the Standards described that the four objectives were distinct but overlapped each other, deleted I 1 (2) and clarified that internal control composed of four specific objectives and six specific basic components in the internal control definition. Thus, the statement of internal control definition became more complete and more appropriate for Japanese situation. The Standards deleted the section of I 3 and incorporated its contents which included the relationship between objectives and basic components and design and operation of internal control to the section of definition of internal control. One of the significant changes in basic components of internal control was the description on IT [I 2 (6)]. Based on the comment that it was difficult to understand the "use of IT", the Standards changed it into "response to IT" which was defined to establish appropriate policies and procedures in advance in order to achieve organizational objectives and respond appropriately to IT inside/outside the organization when performing business activities based on the policies and procedures. It also pointed out that response to IT was not always independent from other components of internal control. Of the contents of response to IT, the subsection of "response to IT environment" was newly added. It firstly defined the IT environment as the internal/external use of IT that was needed for the organization's activities, the level of IT penetration into the society and market, the use of IT for the company's transactions, and a series of information systems on which the organization selectively relied and others. It also pointed out that in order to achieve the objectives of internal control the organization should respond appropriately to IT environment based on the policies and procedures that were established in advance. The subsection of "use of IT" in the Exposure Draft of Standards was replaced by "use of IT and IT controls" which referred to the integral parts of other components of internal control and was assessed as a whole.

Assessment and report on internal control over financial reporting varied from the Exposure Draft of Standards as follows: (1) It added "in accordance with generally accepted assessment standards for internal control" when management assessed the internal control over financial reporting. The Exposure Draft of Standards defined material weakness as "a deficiency that has a reasonable possibility of having effect on financial reporting" while the Standards 
changed it into "...having a material effect...". Therefore, the statements were more accurate and scrupulous. (2) When addressing assessment of the effectiveness of internal control over financial reporting, the Standards added that the internal control over outsourced processes should be in the scope for the assessment. In order not to cause any misunderstanding, the term of "financial statement" and "report" were changed into "financial reporting" and "internal control report" in II 3 (4) and II 4 (2) respectively. In the supplementary information, a modifier of "pertaining to material weakness" was added after "remediation and other matters" which was implemented after the end of the fiscal year.

Little was modified on audit on internal control over financial reporting. In relation to objective of the internal control audit by financial statement auditors, based on the comment that the words of "internal control audit report" might give an impression as if the auditor would assess the effectiveness of internal control directly, the Standards explained that "such (auditor's) opinions on the internal control report are expressed in the audit report on internal control assessment ('internal control audit report' hereafter)" [III 1]. According to the comment, the Standards also defined the reasonable assurance as external auditors had obtained sufficient competent evidence to express such opinions.

\section{Toward Exposure Draft of Practice Standards for Management Assessment and Audit concerning Internal Control over Financial Reporting}

\subsection{Establishment of Working Group of Subcommittee}

During the course of publishing the Exposure Draft of Standards of July, 2005, many comments were received of which over 40 percent required to develop a set of practical guidance in order to implement the Standard (see table 4). Based on the comment, the Subcommittee decided to further insight into the practice standards for supporting the Standards in the $12^{\text {th }}$ Subcommittee meeting and established a special Working Group under the Subcommittee in the $13^{\text {th }}$ Subcommittee meeting. The Working Group would prepare the preliminary draft of the practice standards under the directions of the Subcommittee. Main considerations concerning the practice standards which came from the opinions received from the Exposure Draft of Standards and the make-up of the Working Group were discussed in the $13^{\text {th }}$ Subcommittee meeting. In order to establish a series of high quality guidelines for the practice, all 22 Working Group members were practitioners from different areas such as auditing, business, etc. so that they could represent interests of different groups. Mr. Takashi Hashimoto was appointed the chairman. As well as in the Standards, three parts were expected in the Practice Standards. The first was considerations on the basic framework of internal control. Based on the Japanese current condition, besides explaining each of the four objectives and six basic components, the Working Group planned to focus on and give a more detailed explanation on the safeguarding of the assets and response to IT which were added to COSO framework. Considerations on assessment and report on internal control over financial reporting ranked the second. According to the discussion of the Subcommittee meeting, the guideline for material weakness, determination of the scope of assessment, and so on would be considered sufficiently. The last considerations were audit on internal control over financial reporting. Main issues concerning the procedures on evaluation of the assessment of company-level controls and process-level controls, reporting and remediation of material weakness in internal controls, and etc. would be explained substantially.

\subsection{Exposure Draft of Practice Standards}

After establishment, the Working Group of the Subcommittee was actively engaged in preparing the practice standards. While fully reviewing existing internal control standards abroad and giving enough attention to the possible considerations in Japan, the Working Group established the practice standards which included three parts and discussed the contents in the $14^{\text {th }}$ and $15^{\text {th }}$ Subcommittee meetings respectively. On November 21, 2006, the FSA released the Exposure Draft titled the "Practice Standards for Management Assessment and Audit of Internal Control over Financial Reporting" (Exposure Draft of Practice Standards). The document was intended to supplement the "Standards for Management Assessment and Audit of Internal Control over Financial Reporting" (Standards), which was issued in December 8, 2005.

Consistent with the Standards, three parts were included in the Exposure Draft of Practice Standards. In the part of "I Basic Framework of Internal Control", except for four parts in the Standard of 2005, a new section titled "Establishment of Internal Control over Financial Reporting" was added in the Exposure Draft of Practice Standards of 2006. It described the key considerations and process of establishing internal control over financial reporting. The section of key considerations listed key points to consider when establishing internal control over financial reporting according to the internal control basic framework. The process section illustrated the general steps to prepare for an assessment of internal control and to report the result of the assessment: (1) determination of basic plan and policy, (2) understanding of state of internal control design, and (3) a response to and remediation of identified deficiencies. The supplement of this part provided concrete guideline for management establishing, assessment and report internal control over financial reporting. Response to IT, as the sixth component of internal control, was an important part in the Exposure Draft of Practice Standards as well as in the Standards. The "Response to IT" component included that: (1) "response to IT environment" described the requirement to understand and response to the IT environment surrounding the organization. 
Factors surrounding the IT environments that were common to many organizations were listed as examples, such as IT pervasiveness into society and markets, stability of IT-based information system, and the like; (2) "use of IT and IT controls" included two subsections of "use of IT" and "IT controls". The former explained how organizations could use IT to enhance the effectiveness and efficiency of other components of internal control and provided special examples to support it. The latter listed examples of IT control objectives for achieving the organizational objectives. To achieve IT control objectives IT general controls and IT application control were required.

On the part of "II Assessment and Report on Internal Control over Financial Reporting", the Standards included a section of "4 Management's Report on Internal Control over Financial Reporting" while the Exposure Draft of Practice Standards did not included such a section. Therefore, there were three sections in this part. First, the Exposure Draft of Practice Standards defined and clarified the scope of financial reporting and provided the concrete guidelines for determining material weakness. The Standards defined the financial reporting as "external reporting that both relate to financial statements and disclosure information and others that could have a material effect on the reliability of financial statements" [II 1 (1)]. The Exposure Draft of Practice Standards further explained that financial statements were the consolidated financial statements while "disclosure information and others that could have a material effect on the reliability of financial statements" was defined as disclosure information and others (except financial statements) included in the annual report and examples were also listed to identify such information [II 1 [1]]. Consequently, the disclosure information and consolidated financial statements compose the financial reporting. When determining whether a control deficiency is a material weakness, both quantitative and qualitative facts must be considered. The Exposure Draft of Practice Standards stated the concrete index (a percentage of consolidated total assets, consolidated sales, consolidated income before income taxes and minority interests) and the acceptable threshold $5 \%$. This will be conductive to the performance of the Standards. Second, the Exposure Draft of Practice Standards explained management assessment of internal control over financial reporting, and scope of assessment. On the assessment of the company-level controls, aiming at the regulation that "the assessment of internal control over financial reporting effectiveness should be, in principle, performed on a consolidated basis" in the Standards [II 2 (1)], the Exposure Draft of Practice Standards stated when determining the scope of assessment, the consolidated subsidiaries (including partnership), equity method affiliated companies and foreign subsidiaries would be subject to the process. It specially stipulated the assessment of outsourced process, including scope of assessment of outsourced processes and assessment of internal controls over outsourced processes such as validation via sampling, use of service organization assessment results, etc. Based on the assessment of company-level controls, the Exposure Draft of Practice Standards provided for the procedures for determining the scope of assessment of business processes: selecting significant locations or business units, identifying business processes to be assessed, and communication with external auditor(s). Third, the Exposure Draft of Practice Standards stipulated concrete method of assessing internal control over financial reporting. It explained the use of top-down approach in detail under which management should first assess internal controls that had a material impact on overall consolidated financial reporting (i.e., company-level controls) and, based on the results, assess the internal control incorporated into business processes (i.e., process-level controls). On the assessment of company-level controls, the Exposure Draft of Practice Standards provided 42 assessment items [Exhibit 1], most of which are similar to the items listed in the "Principles Evaluation Matrix" of COSO's Internal Control over Financial Reporting - Guidance for Smaller Public Companies issued in July 2006. Four steps were provided to assess the process-level controls based on the result of assessment of company-level controls. The Exposure Draft of Practice Standards also provided guidance on determining the effectiveness of internal control over financial reporting.

The part of "III Audit on Internal Control over Financial Reporting" included five sections. Section "III 1 Objective of Internal Control Audit" emphasized that external auditors should express their opinions on the management's assertions that were the assessment results of internal control effectiveness but not directly evaluate the design and operating effectiveness of internal controls. External auditors' simultaneous provision of internal control audit service and non-audit certification services was restricted in section "III 2 Relationship between the Internal Control Audit and the Financial Statement Audit". The section of "Performance of the Internal Control Audit" in the Standards was divided into two sections in the Exposure Draft of Practice Standards. One was "III 3 Audit Planning and the Scope of Assessment" and the other was "III 4 Performance of the Internal Control Audit". The matters to be considered for audit planning for internal control audit and for assessing the appropriateness of scope of assessment were listed in the former while the concrete evaluation of assessment of company-level controls and process-level controls were explained in the latter. The last section was "III 5 Auditor's Report", which described the expression of an opinion including exceptions to opinions.

\section{Toward Council Opinions of 2007}

After the Exposure Draft of Practice Standards was published in November 21, 2006, the FAS requested comments from the public until December 20, 2006. During this period 190 comment letters were received, which consisted of 59 from corporations (including various groups) and 131 from individuals (including CPA, lawyer and others). In the $16^{\text {th }}$ Subcommittee meeting, based on the comments, BAC revised the Exposure Draft of Practice Standards and put it 
together with the Standards issued in December 8, 2005. Thus "On the Setting of the Standards and Practice Standards for Management Assessment and Audit concerning Internal Control over Financial Reporting (Council Opinions)" (Council Opinions of 2007) ${ }^{[9]}$ came into being.

\subsection{Summary of Comment Letters}

According to minutes of $16^{\text {th }}$ Subcommittee meeting, the comments were divided into overall comments and comments for the individual items [see table 5]. There were four categories in the comments for the individual items: (1) necessary responses in the Practice Standards, (2) things that should be discussed in government ordinances, Cabinet Office regulations, and etc., (3) things difficult to respond or not necessary to respond, and (4) other comments. The specific comments of (3) were not listed in the table since the Subcommittee thought that it was difficult or not necessary to respond to. For example, the comment pointed out that in the II 1 [2] A "a. determining quantitative materiality", numerical criterion of consolidated income before income taxes had been set. Therefore, consolidated sales and other related part of materiality in the Practice Standards should also be set. However, the Subcommittee argued that the guideline for determining material weakness could not be presented uniformly because it varied based on the environment or business nature of the companies. In the Practice Standards, considering the convenience of the practice and possibility of generalization to some degree on consolidated income before income taxes, approximate $5 \%$ was set. Referring to this about 5\% criterion, other items should be judged individually in terms of impact on reliability of financial reporting. On the comments of (4), the Subcommittee explained its way of thinking by a table in the meeting.

\subsection{Revised Exposure Draft of Standards and Council Opinions of 2007}

Based on the comments, BAC revised the Exposure Draft of Practice Standards and put it together with the Standards issued in December 8, 2005 to form the Council Opinions of 2007. The contents of the Council Opinions of 2007 included three parts: the introduction, the Standards, and Practice Standards for Management Assessment and Audit concerning Internal Control over Financial Reporting (the Practice Standards).

\subsubsection{Introduction of the Council Opinions of 2007}

This was the explanation part of the Council Opinions of 2007. General background of discussions and structure and contents of the Standards and the Practice Standards were stated. The contents of the Standards basically followed those of the Standards of December 8, 2005 and some amendment was made according to the progress afterwards. The contents of the Practice Standard were a new section in this part, including basic framework of internal control, assessment and report on internal control over financial reporting, and audit on internal control over financial reporting. The effective date was also added in this part.

Insert Table 5 here

\subsubsection{Main Changes in the Standards}

Compared to the Standards of December 8, 2005, there is no substantial modification in the Standards part except some small changes. For example, in the paragraph 2 of II 2 (2), "management should, first based on the determination of significant locations or business units, examine the scope of assessment ...", "first" was deleted. In the paragraph 2 of III 3 (4), “... external auditors must obtain audit evidence for key audit objectives, such as existence or occurrence, completeness, rights and obligations, valuation, allocation, presentation and disclosure, authority and responsibility, and record", "authority and responsibility, and record" were deleted. In the III 4 (6), a new additional information was added which was "[4] The scope for which sufficient assessment procedures could not be performed and relevant reasons, when external auditors judge that the management could not perform a certain part of the assessment procedures due to unavoidable circumstances and therefore express an unqualified opinion".

\subsubsection{Main Changes in the Practice Standards}

Based on the necessary responses in the Practice Standards of comments for the individual item which were discussed in the $16^{\text {th }}$ Subcommittee meeting, the Practice Standards were revised as follows.

Guidelines for Determining Material Weakness. In "II 1 [2] Guidelines for Determining Material Weakness", two paragraphs were added to address that the guideline for determining material weakness could not be presented uniformly since it varied according to the environment or business nature of the companies. Simultaneously, it emphasized that the material weakness, basically, should be judged in terms of impact on the likelihood and impact of misstatements related to financial reporting.

Determining the Scope of Assessment of Business Processes. On the method for determining business process scope, aiming at the comment of lacking consistency between "based on significant locations or business unit" in the Exposure Draft of Practice Standards [II 2 (2)] and "based on important accounts" in the Standards(Note 4), the BAC deleted "first" and added "based on the determination of significant locations or business units". Thus, the Practice Standards clarified the beginning from the selection of an important business unit base when determining business process scope. Based on the comment that the scope of assessment of period-end financial reporting should be clarified from a 
company-wide perspective, the repeated words such as "in the business processes" and "all the business units" were deleted in "II 2 (2) Determination of the Scope of Assessment". It added "... to be assessed from the company-wide perspective" to the note when giving example tasks of period-end financial reporting reprocess. Therefore, it was clear that the difference of this illustration from others was to assess the period-end financial reporting reprocess (primarily performed by accounting department) from the company-wide perspective. On selecting significant locations or business units, in accordance with the comment that it did not specified whether "a certain ratio of consolidated sales" was the sales after elimination of inter-company transaction or that of before elimination of inter-company, in Note 2 of II 2 (2)[1], "certain ratio may be, for example, two-thirds of total sales on a consolidated basis and others" was specified. It also added "instead of two-thirds of total sales on a consolidation basis, a certain ratio may be applied to sales before elimination of inter-company transactions" to the end of the note. In identifying business processes to be assessed, in terms of the comment whether the cost accounting process should be included in the business process to the inventory, a paragraph was newly added to the II 2 (2) [2], which noted that management was not generally required to assess the entire costing process but enough of the process for the end-of-period inventory valuation within the costing process.

Company-level Controls and Process-level Controls. According to the comment that the difference between "particularly effective" and "effective" should be clarified when simple assessment procedure was taken in consideration to judge the "particularly effective" of company-level control, in II 3 (2) [3] "... if the company-level controls 'can be judged as particularly effective', the assessment of process-level controls may be simplified...", "can be judged as particularly effective" was revised to "are assessed as operating effectively". Therefore, the problem of difference or inconsistency between the two words was resolved. The example that "deficiencies existing in internal controls over IT relating to its assessing limitation were left unimproved" was pointed out to be improper as an example of company-level control deficiency. Based on that comment, the BAC revised it into "deficiencies existing in internal controls over IT relating to financial reporting are left unimproved". In the Exhibit 3 Risk Control Matrix (Example), in response to the comment whether it was an appropriate example since "shipping of different goods or amount from the shipment request" in the "controls" of "shipping" might not necessarily lead to the misstatement, "shipping of different goods or amount from the shipment request" was revised to "shipping of a smaller number of goods than requested". According to the comment of clarifying the external auditor's treatment when sufficient assessment procedures could not be performed for a certain part, BAC explained it in detail in III 5 (2). External auditors should issue an unqualified opinion in the internal control audit report if they could conclude management's assessment of internal control over financial reporting was fairly stated in all material respects in conformity with generally accepted assessment standards for internal control, except that sufficient assessment procedures could not be performed due to unavoidable circumstances. In such cases, the scope that the management excluded from the assessment due to unavoidable circumstances and relevant reasons must be added to the internal control audit report. As additional information, it was also added to III 5 (3).

\section{Summary}

Along with the heightening of improper practices in recent years, the BAC realized the importance of enhancing internal control and established the Subcommittee and its Working Group to develop internal control standards. Based on fully understanding the existing internal control standards, especially the standards in the United States, and sufficiently considering Japan's concrete condition, the Subcommittee held 16 special meetings in which the representatives both in theory and in practice had heated discussions and amended the drafts with careful considerations again and again. As a result, after over two years of effort, on February 15, 2007 the BAC released the standards and the practice standards for management assessment and audit concerning over financial reporting that would conform to the situation in Japan. It is expected that the management risk and audit risk can be further reduced by enhancing the effectiveness of internal control over financial reporting after the Council Opinions of 2007 become effective.

\section{References}

Business Accounting Council of the Financial Services Agency. (2002). Auditing Standard, Business Accounting Council of the Financial Services Agency. [Online]A vailable: http://web.kyoto-inet.or.jp/people/fujino/auditst.doc, March 15, 2006. (Japanese)

Business Accounting Council of the Financial Services Agency. (2005). Auditing Standard, Business Accounting Council of the Financial Services Agency. [Online] Available: http://www.k3.dion.ne.jp/ afujico/kaikei/kansa/kijyunh171028.htm, July 9, 2007. (Japanese)

Business Accounting Council of the Financial Services Agency. (2005). Exposure Draft of Standards for Management Assessment and Audit concerning Internal Control over Financial Reporting. (Japanese)

Business Accounting Council of the Financial Services Agency. (2005). Standards for Management Assessment and Audit concerning Internal Control over Financial Reporting. (Japanese)

Business Accounting Council of the Financial Services Agency. (2006). Exposure Draft of Practice Standards for 
Management Assessment and Audit concerning Internal Control over Financial Reporting. (Japanese)

Business Accounting Council of the Financial Services Agency. (2007). On the Setting of the Standards and Practice Standards for Management Assessment and Audit concerning Internal Control over Financial Reporting (Council Opinions). (Japanese)

Business Accounting Council of the Ministry of Finance. (1991). Auditing Standard, Working Rules of Audit Procedures of Field Work and Working Rules of Audit Procedures in Reporting, Business Accounting Council of the Ministry of Finance. (Japanese)

Internal Control Subcommittee of Business Accounting Council of the Financial Services Agency 2005-2007, 1st-16th Meetings of Internal Control Subcommittee. [Online] Available: http://www.fsa.go.jp/singi/singi_kigyou/top_gijiroku.html\#naibu. May 6, 2007. (Japanese)

Special Committee of Japanese Accounting Association. (1970). Research on Internal Control over Financial Reporting. (Japanese)

\section{Notes}

Note 1. The Subcommittee was established by the BAC and was responsible for establishing standards of internal control.

Note 2. In the 6th Subcommittee meeting, the effectiveness of internal control over financial reporting referred to the condition that no deficiency that had a reasonable possibility of material effect on financial reporting (i.e., material weakness) existed in the internal control.

Note 3. In the 9th Subcommittee meeting, practitioner representatives in different areas as witnesses stated their opinions on the assessment and audit standards of internal control over financial reporting. They were Norio Hagiwara (Representative Director of the Mamezou Corporation), Hiroshi Mikitani (President and Representative Director of the Rakutenn Corporation), Tetsuo Mazuda (Vice President of Japan Federation of Bar Association), Kazuo Tezsuka (Lawyer), Hiromichi Oogawa (Standing Director of Japan Corporate Auditors Association), and Yukihisa Kannda (Managing Director of the Institute of Internal Auditors-Japan).

Note 4. The Standards II 2 (2) addressed "Management should first examine the scope of assessment for these items from the perspective of their degree of quantitative and qualitative impact on the presentation and disclosure of financial statements." At the same time, with regard to "presentation and disclosure of financial statements", it took the determination of important account as example in the note. 
Table 1. Proceedings toward Exposure Draft of Standards

\begin{tabular}{cl}
\hline $\begin{array}{c}\text { Subcommittee } \\
\text { meetings }\end{array}$ & \multicolumn{1}{c}{ Main contents } \\
\hline $1^{\text {st }}$ & Necessity of setting standards of internal control \\
$2^{\text {nd }}$ and $3^{\text {rd }}$ & Existing internal control standards and Japanese practice of internal control \\
$4^{\text {th }}$ & Key points of setting standards of internal control \\
$5-8^{\text {th }}$ & Preliminary Draft of Standards \\
$9^{\text {th }}$ & Statement of witness's opinions \\
$10-11^{\text {th }}$ & Revised Preliminary Draft of Standards and Exposure Draft of Standards
\end{tabular}

Source: Minutes of $1^{\text {st }}-11^{\text {th }}$ Internal Control Subcommittee Meetings

Table 2. Key Points of Setting Assessment and Audit Standards

\begin{tabular}{|c|c|}
\hline Code & Key Points \\
\hline I & Framework of internal control \\
\hline A & Necessity of international explanation besides Japanese actual condition \\
\hline B & Development of objective and components based on COSO Report \\
\hline $\mathrm{C}$ & Besides external report, internal report is also required (e.g., UK and Canada) \\
\hline $\mathrm{D}$ & Appropriate form of framework (U.S. COSO or UK Framework) \\
\hline $\mathrm{E}$ & Business scale \\
\hline II & Assessment and audit of internal control \\
\hline A & Objective of assessment and audit \\
\hline $\mathrm{a}$ & Understanding of company-level control \\
\hline $\mathrm{b}$ & Deterrent of management fraud \\
\hline c & Management confirmation was limited to reliability of financial reporting (COSO) \\
\hline d & Expansion of assessment scope from financial reporting to annual report \\
\hline $\mathrm{B}$ & Method of assessment and audit \\
\hline $\mathrm{a}$ & Audit (the U.S.) or review (UK and France) \\
\hline $\mathrm{b}$ & Benefit and cost of process assessment and audit \\
\hline $\mathrm{c}$ & Consolidated base or separate base \\
\hline d & Corporate auditors or audit committee and external auditors \\
\hline e & Position of audit report of corporate auditors in Securities and Exchange Law \\
\hline f & IT control \\
\hline III & Report of assessment and audit \\
\hline A & Direct reporting or indirect reporting \\
\hline B & External auditor and management on setting internal control \\
\hline
\end{tabular}

Source: Minutes of $4^{\text {th }}$ Internal Control Subcommittee Meeting ${ }^{[5]}$ 
Table 3. Outline of Exposure Draft of Standards

\section{Basic Framework of Internal Control}

A Definition of Internal Control

B Basic Components of Internal Control

C Design and Operation of Internal Control*

D Limitations of Internal Control

E Roles and Responsibilities of Personnel Who Perform Internal Control

\section{Assessment and Report on Internal Control over Financial Reporting}

A Definitions Related to the Assessment of Internal Control over Financial Reporting

B Assessment of Internal Control over Financial Reporting, and Scope of Assessment

C Method of Assessing Internal Control over Financial Reporting

D Management's Report on Internal Control over Financial Reporting

\section{Audit on Internal Control over Financial Reporting}

A Objective of the Internal Control Audit by Financial Statement Auditor

B Relationship between the Internal Control Audit and the Financial Statement Audit

C Performance of the Internal Control Audit

D Auditor's Report

* This section was deleted in the Standards issued in the December 8, 2005.

Source: Exposure Draft of Standards for Management Assessment and Audit concerning Internal Control over Financial Reporting

Table 4. Summary of Comments on and Responses to Exposure Draft of Standards

\begin{tabular}{l|l|l|l|l|l|l|l|l|l}
\hline \multirow{2}{*}{ Section } & \multirow{2}{*}{ Item } & \multicolumn{2}{l}{ Responses to comments } \\
\cline { 3 - 10 } & & \multicolumn{2}{l|}{ Preface } & \multicolumn{2}{l|}{ Standards } & \multicolumn{2}{l}{ Practice Standards } & \multicolumn{2}{l}{ No response } \\
\cline { 3 - 10 } & & Number & $\%$ & Number & $\%$ & Number & $\%$ & Number & $\%$ \\
\hline Preface & 98 & 32 & 32.65 & 2 & 2.04 & 31 & 31.63 & 33 & 33.68 \\
I & 142 & 18.16 & 12.79 & 36 & 25.35 & 25.34 & 17.85 & 62.5 & 44.01 \\
II & 130 & - & - & 11.33 & 8.72 & 86.83 & 66.79 & 31.84 & 24.49 \\
III & 116 & - & - & 3 & 2.59 & 60 & 51.72 & 53 & 45.69 \\
Total & 486 & 50.16 & 10.32 & 52.33 & 10.77 & 203.17 & 41.80 & 180.34 & 37.11 \\
\hline
\end{tabular}

Source: Minutes of $12^{\text {th }}$ Internal Control Subcommittee Meeting

Note:

Preface: based on the comment, responses will be or has been done in the Preface.

Standards: based on the comment, responses will be or has been done in the Standards.

Practice Standards: the contents that should be regulated in the Practice Standards.

No response: the comment that has been discussed but no response will be or has been done and the reasons why.

Source: Minutes of $16^{\text {th }}$ Internal Control Subcommittee. 
Table 5. Summary of Comments on Exposure Draft of Practice Standards

\section{Overall Comments}

1. It is expected to clear away swallowing US-SOX on trust and to particularly evaluate the points which have presented in courteous draft based on the characteristics of Japan.

2. It is welcome for the manager to present the concrete samples or numeric examples of the pending problems when narrowing the scope.

3. Is it cruel to deal the small and medium-sized companies with the same standards?

4. The auditor should be requested not to become conservative.

5. It should be a strict standard as a whole.

\section{Comments for the Individual Items}

\section{Necessary responses in Practice Standards}

a. Which is better for a certain ratio of consolidated sales, the sales before offsetting or after offsetting?

b. On the method for determining business process scope, it lacks of consistency between the Standards and Practice Standards.

c. The scope of assessment of period-end financial reporting should be clarified from a company-wide perspective.

d. Is the cost accounting process included in the inventory business process?

e. The example that rises as company-level internal control was improper in "There is deficiency in IT-based internal control due to its assessing limitation and it has been left without being improved" (II 3 (4) [1] C d).

f. Is it an appropriate example that in the "Risk Control Matrix (Example)", "shipping of different goods or amount from the shipment request" in the "controls" of "shipping" might not necessarily lead to the misstatement?

g. The treatment in the audit should be clarified when the scope of the assessment is restricted by unavoidable circumstances.

h. The difference between "particularly effective" and "effective" should be clarified when simple assessment procedure was taken in to judge "particularly effective" of company-level control.

2. Things that should be discussed in government ordinances, Cabinet Office regulations, and etc.

a. Items and forms of internal control report and internal control audit report should be described clearly.

b. The treatment of the registrants of the U.S. SEC which should follow Section 404 of SOX should be clearly addressed.

c. How to deal with subsidiaries of overseas?

d. The treatment of the subsidiary should be specified when the accounting period was different.

\section{Things difficult to respond or not necessary to respond.}

\section{Other comments}




\title{
The Reasons for Emergence of Born Global Firms ----Taking China as an Example
}

\author{
Shuyi Zhang \\ Economic \& Management College, Zhejiang Sci \& Tech University \\ School of Business Administration, Shanghai Finance University \\ 995 Shang chuan Road, Pudong \\ Shanghai 201209, China
}

Tel: 86-21-5021-8899Ｅ-mail: shyzhangvt@gmail.com

\begin{abstract}
With economic globalization and marketing integration, the born global firms, emerging as a new kind of enterprise, have arouses a wide rage of academic interest recently. Based on the previous research, this paper, taking the example of Zhejiang province, China, probes firstly into the main forming reasons of the born global including entrepreneurship, niche market, international management experience, and network, then points out the current problems of lacking innovative entrepreneurship, shorting of manager, Unreasonable industry structure, and finally, the paper puts forward some countermeasures from theoretical and practical approach for the Zhejiang born global firms.
\end{abstract}

Keywords: Born global, International management, Entrepreneur

\section{Background of research and literature review}

The roll of small and medium firms within the emerging market economy is well documented. We could find the increasingly active small firms in international market with estimates around 30 percent contribution to total Asia-Pacific Economic Cooperation. However, we could find that plenty of small businesses fail at their infancy or within a few years of inception. Some scholars attributed this to "resource poverty", lacking of financial capital or management skills. Within the past decades, a special kind of small firms, named as born global firms, has drawn academic attention. They entered the international market, sometimes bypassing to domestic market rapidly, overcoming partially the difficulty related resource and products. Born global firms are small ones that challenge the conventional theories of incremental or gradual internationalization because of the constraint of the "resource poverty" which limit the strategic option. A recent review of a decade of internationalization (Rialp-Criado, Rialp-Criado, Knight, 2002) concludes that the literature remains fragmented with a comprehensive explanation and casual model of phenomenon still lacking (Knight et al. 1996; Oviatt \& McDougall, 1997; Servais \& Rasmussen, 2000). In particular, little is known about the born global market strategies and process for understanding global market needs and developing new products.

Of course, constructing a unified theory goes beyond the limits of this study. Here we focus on the main factors in the rapid internationalization market performance of born global firms of Zhejiang province, China. How Zhejiang born global firms overcome their resource poverty has important implications not only for broadening the international business, but for developing theories of internationalization and international market performance also, and this is also the focus of this research.

Therefore, the research problem guiding this study is: what is the main factor about the internationalization processes of Zhejiang born global firms? And what are the existing issues about the Zhejiang born global firms and its countermeasures afterwards?

\section{The emergence of the Zhejiang born global firms}

The traditional international model U (Johanson and Vahlne, 1977, 1990) and model I (Bilkey and Tesar, 1977; Cavusgil, 1980; Reid, 1981) thought that the internationalization of the enterprise is usually a continuous process of evolution initiates from the domestic market into the international market along the path of geographical rotation and operating 
procedure. The essence of the model is the scale economy and similar demand preference, the former emphases the effect of the scale economy, while the latter thinks that the company should cumulate the experience and efficiency before exporting the products to the similar country, and stepping into the international trade. The above theory is the research finding of the giant company and its effect has been identified again and again by the development of the multinational company. But it is always the doubt whether it can be applied to the small and medium company. The international practice at home and abroad challenges the traditional cognition.

The challenge came firstly from European multinational company of science and technology. A report about 328 export oriented enterprises, which consists of the Sweden, Norway, Finland and Denmark, showed that most export enterprises began their international business right after their establishment, the offshore business is about 20 percent within one year, and could reach more than 50 percent after two years (Medson and Servais, 1997). They are organization of using the resources of many countries at the very beginning and sell the products in many countries to attain the competitive advantage. The responsiveness and the capability are the main factors of consideration (Oviatt and McDougall, 1994). Medson and Servais (1997) describe them as taking the international or global step after their initiation. Knight and Cavusgil (1996) further considered that the born global enterprises are those small tech-oriented companies with the employee less than 500, operating in the global market in the initial stage, using the cutting edge technology, meeting the demands of niche market with its high-tech products, the annual amount of sales less than $\$ 100$ millions, and the offshore business reach a quarter of the total sales within three years. Albeit most literature shows that the phenomenon of born global firms present to the emerging industries or high-tech sectors, and research demonstrated afterwards that born global firms can be find in so-called old and mature industry such as arts and crafts, and traditional industry in China (Yang, 2007).

A McKinsey report indicates that, compared with the traditional firms, the born global firms have the following characteristics: it views the world as the whole market not just the simple extension at the very beginning; its export more than one product within two years of establishment, and the export amount surpass the 25 percent of total sales; be established by the active entrepreneur, and has breaking process or technology; could develop a unique product originality, or new style of business; more value added in the product, usually in industrial products.

The private economy of Zhejiang province, China, focuses on the traditional industry of textile, leather, hardware, and is booming with the characteristics of cluster intergrowth. Relied on the unique entrepreneurship, Zhejiang private economy marches into the international market after the development of domestic market, now we could find Zhejiang entrepreneurs everywhere in European, America and other countries or regions. Although most company's globalization move along the path of domestic market first, international market second, some pioneer traditional companies who located in Wenzhou, Taizhou, Hangzhou, Ninbo, etc, go along the different direction, say, they pay the same attention to the domestic and international market, sometimes emphasis more on the international market, and finally bring out a new model of born global firms which is different with the European and American. Even though some Chinese scholars have been studying such an intriguing problem (Zhao, 2004; Yang, 2007), limited by the initial establish stage of export-oriented firms, the previous researches are in the beginning stage overall. That is why we interested in such a challenge topics.

\section{The motives of Zhejiang born global firms}

Since the born global having draw attention of academic community, the endeavor to explain such a phenomenon have never ceased. McDougall et al (1994) pointed out that traditional monopolistic advantage theory, product life cycle theory, internationalization stage theory and internalization theory, couldn't give born global firms a reasonable explanation. Basically, the explanation splits into two parts, one falls into the macro-aspect which attributes the born global firms to the change of the macro-environment, the other falls into micro-aspect which ascribes to the certain factors that relate to individual firms. For example, Medson and Servais (1997) attributed it to three aspects, such as the demand of the emerging market, the technology about the produce, transportation and communication, and more professional talent. Saarenketo (2002) proposed eight assumptions and attempted to verify the relationship between the market response and market concentration during their internationalization. Rialp-Criao, Rialp-Criao and Knight (2002) studied and reviewed the most representative 27 academic papers covering 15 kinds of journals, and came to the conclusion that the emerging market, technology development, global network and alliance, are key factors related with born global firms.

Mcdougall, Shane and Oviatt (1994) hoped to answer the formation of born global firms from three aspects. The first is about the subject of the internationalization, in their opinion, most of them are entrepreneurs who keep an ear to the ground of the outside information, they are either immigrant or have individual relationship with the overseas, or have experiences of internationalization; the second is the reason of born global, based on resource point of view, they explained why the born global happened in the inception of entrepreneur by overcoming the inherent inertia of refusing the change in the process of internationalization, and those born global entrepreneurs who circumventing the existing independent path at the very beginning, and are apt to get the resource globally; and the third is the type of business, 
born global firms control many important asset not by over investment but by multi-structure in the attainable scope of management.

As for the Zhejiang born global firms, Yang (2007) thought that the entrepreneurship, organizational learning and the enterprises network are the primary causes. Chen (2008) conducted an empirical study about the relationship between the entrepreneurship of the team and the company performance. Some researchers explored the impact on the internationalization performance of entrepreneurship and experience of born global firms with the case of Shenzhen, China. By studying the born global firms of the Yangze River Delta, Zhao (2004) demonstrated the importance of the global economy, niche market, technology improvement, and the implicit sensitivity.

Comparing with the foreign born global firms oriented high technology, most Zhejiang born global firms focus on the traditional industry because of their traditional inheritance. Generally speaking, the impetus of Zhejiang born global firms is attributed to the unique entrepreneurship, the network of businessman globally, the precise niche market, and technological development.

\subsection{The unique Zhejiang entrepreneurship}

Zhejiang is always in short of resource. There is a saying that the Zhejiang province is consists of 70 percent of mountain, 20 percent of land and 10 percent of water. With the economic reform and open-up, Zhejiang is famous for its private economy, no matter in it's inception and booming stage, we could find the unique entrepreneurship among Zhejiang born global firms, which is summarized as hardworking, pioneering innovation, the keen-to-change, the commitment to keep-faith, and the self-correcting inclusiveness. The innovation is the undercurrent keynote of the Zhejiang entrepreneurship. In fact, it is the innovation inheriting form old generation that turns the Zhejiang from resource of scarcity to richness, and become the pillar of Chinese national economy. Being good at catching market opportunity and starving for change, the asset of Zhejiang human resource, is the core competency of Zhejiang. As a matter of fact, you could find Zhejiang businessman anywhere no matter where you are going to. Made in Zhejiang, once the name of counterfeiting or inferior quality products, now turn out to be the name of competitive and high quality products.

It is the entrepreneur who is the carrier of the entrepreneurship. Zhejiang entrepreneurs are not only the businessman who allocates the resource, but also the important valuable asset themselves. They are tireless, aggressive, no taking things as they have, and not losing themselves for the achievements they have got (Luo, 2000). The large qualities of entrepreneurs who scattered in government administrative departments, state or private owned firms, are the talents for Zhejiang economic development. It is predisposition of entrepreneur that makes them not satisfying the status quo and advancing the organizational innovation so as to lead the small and medium born global firms.

Proposition 1: The innovation is the main factor of Zhejiang born global firms, the more innovative, the more inclined to born global firms.

\subsection{Accurate niche market}

Limited to the natural resource and size, most Zhejiang small and medium enterprises are difficult to compete with the large scale rivals, they usually choose the neglected market which is frail and potential as their target. For example, many enterprisers initiated their business from tiny-earning and become the profitable ones by means of accumulation such as "the king of button", "the king of stocking" which have a big market share afterwards.

The cluster economy and specialized zone, which derived from the niche market, are the prominent characteristics of Zhejiang economy. Because of the small size, the single enterprise is difficult to get cutting edge technology, high productive capacity. On the one hand, they usually unite to face the challenge by strategic alliance; on the other hand, they coordinate to form the specialized industrial zone by supply-demand chain, or the value chain so as to make more money for the customer as well as the company themselves.

In the strategy process of the born global firms, Zhejiang enterprises usually choose niche market at their infancy, and concentrate the natural and human resource on international market by the support of powerful cluster and specialization, and become the number one firstly, and then extend their market frontier, build the competitive barrier afterwards, and finally, obtain and strengthen the leadership in global market by stages. Usually, Zhejiang born global firms seldom go out beyond their control. Focusing on the specific industry, they persist in not stepping into unfamiliar industry, and not do what they have no assurance. Relying on the persistence and marching in niche market slowly and surely, they have obtained the profitable market gradually.

Proposition 2: The niche market is crucial for the Zhejiang born global firms. The more accurate market they focus on, the more market share and more leading position they will get.

\subsection{The international management background}

While competing with the rivals directly or indirectly, Zhejiang enterprises know well the international convention gradually, it benefits the global firms much, especially for those founders had working experience abroad or with 
international background. Feiyue Group, located in Taizhou, once a home shoe repairing factory, now turn out to be the large scale shoe maker who has more than 300 kinds of sewing products. At the very beginning, Feiyue sold its products in Latin America, Africa and many Asian countries and regions, and got much of the international experiences gradually, the company employed top foreign talents to conduct research and development, which help them to extend the global market within 20 years.

There are two basic models of Zhejiang born global firms, one is the split model, by which the global firm was derived from the parent company; and the other is established model which was founded by those who have been the top management team members and familiar with the international market very well. At the same time, the born global firms have obtained a plenty of managerial experiences in the process of international cooperation and competition. During the last decades, Zhejiang provincial government have done much either in introducing foreign talented person, or providing favorable policy to attract overseas to start their business in Zhejiang, and all these ensure the global firms booming in the international market now.

Proposition 3: The previous international background is very helpful for the born global firms, the more overseas experience the founder has, the more market share the firm extend in the future.

\subsection{The extensive enterprise network}

One of the most outstanding features of Zhejiang born global firms is the enterprise network based on interpersonal relationship by means of consanguinity, affinity, which was maintained and enforced by the inter-firm communication. This kind of interpersonal relationship network was established and demonstrated by cluster production and specialization. With more and more Zhejiang overseas' participation, the "Zhejiang village" or "Wenzhou village" could be seen around the world. And the relationship network in turn promotes their business. For example, after contacting with Wenzhou businessman who settled down in Hong Kong, Wenzhou lighter soon marched into the international market and got the most shares in light industry afterwards. Such an example could been found very often in such a industries, such as costume, shoes and hats, toys and other notions, in which the company has comparative advantages over the rivals.

In order to avoid the marketing risk, Zhejiang born global firms usually set up overseas industries zone led by one or more powerful firms, with the development of the zone, it attracts the other enterprises to settle down. The Yuemei Group, once set up a textile zone in Nigeria, and attracted other firms in upstream or downstream supply chain, and finally formed an industry chain from spinning, weaving, embroidering, knitting, to a complete set of costume. At present, Zhejiang has four state level overseas export-oriented economic and trade cooperation zones.

As for the network forming, the Zhejiang born global firms not only make use of existing network, but also develop new network so as to perfect the global network. For example, the Younger Group, a leading company focused on clothing, obtained 14 production bases located in the Sri Lanka, Philippine by merges and acquisitions, at the same time, it obtained more than 20 well-know brands, the top management team that has experience to supervise and design international brand.

To date, the investment model of Zhejiang born global firms have transformed from setting up offshore trading department to establishing overseas manufacturing factory, research and development center, and the establishment of offshore process is the new trend of foreign trade. So we have the following proposition.

Proposition 4: The Zhejiang born global firms is famous for its worldwide network. The more extensive network they have, the more resources they share.

\section{The problems and countermeasures for Zhejiang born global firms}

Zhejiang has something in common with the former Japan. As we all know, the Japan industry model has three features: to pursue the perfection at all costs, to improve and produce the innovation invented by other nations extensively, and to form the compact team. This model, emphasizing on the introversion without paying attention to the extraversion, focuses on the stable and gradual innovation of the manufacturing process instead of product breakthrough on the one hand; and also made it run into the tragedy of foam economy on the other hand. Generally speaking, Zhejiang born global firms are now short of the managerial innovation, extensive international market, and competitive strategic strategy fro some enterprises. Looking back the development of Zhejiang born global firms, we could find existing and potential problems as follow.

\subsection{Lacking plenty of innovative entrepreneurship}

The entrepreneurship is vital to the existence and development of born global firms. The personal endowment, say, risk preference, pioneering innovation, has a great influence on them. With the acceleration of global economy and integration of the international market, more and more global economic connection could be seen. Irrational factors don't work to allocate the resources inside or outside the enterprise, and hinder the growth of born global firms afterwards. Under such a circumstance, the Zhejiang entrepreneurship should go forward and fulfill the transition from 
the irrationality to rationality that needs more pioneer and innovative entrepreneurs. Therefore, the new generation should inherit their parents' entrepreneurship, comply with the main trends of global economy, and carry out three crucial transformations according to the market change, that is to say, to turn from the domestic market to international market, from developing countries to developed countries, and from the middle parts of manufacturing to the both ends of design and market in the value chain.

\subsection{Be in short of capable manager}

Born global firms need lots of higher qualified talent who not only familiar with the international convention, but have potential managerial capability also. Usually, one could find the family background in Zhejiang born global firms; even those with trillions of dollars of market share are still governed by the family member or their relatives. Because of their small size and insufficient international background at the very beginning, most Chinese traditional management characterized as man-ruled usually works. With the extensive management concerning about the strategic management and complex decision-making, more professionals are needed for international business. Thus the born global firms should employ more international managerial talents, and empower the executives to compete and cooperate in the global market.

\subsection{Unreasonable industry structure}

Most European born global firms focus on high-tech industry, such as information technology, telecommunication, electronics, and so on, while most Zhejiang born global firms derive from traditional labor-intensive industry. From viewpoint of international trend, high-tech industry, especially those integrating the modern telecommunication, information technology, have high value added and boom fast in the near future. Therefore, Zhejiang born global firms had better transform from traditional industry to modern technology, say, to transform from the traditional labor-intensive industry to the high-tech oriented industry.

One of the most likely ways to access to advanced technology is to invest the prosperous technology industry in developed countries, then to transmit and to spread to domestic enterprise so as to bring the "spillover effect" or "demonstration effect" into play. Usually, the technology attained by investment is comparatively more reliable than transforming or importing. According to the international convention, Zhejiang born global firms had better make good use of the international market, to build the overseas technology center with the reference of leading talents.

\section{The direction of further research}

As a new phenomenon, more and more born global firms have been found in Zhejiang, and other regions in China, and many other countries and regions. It's of theoretical and practical significance to study the academic frontier and promote the practice for small and medium enterprises. Based on the literature review, this paper probes into the impetus, the existing and potential problems of Zhejiang born global firms, and puts forth some suggestions. The future research could be done along the following two directions. The first is qualitative study of analyzing the pattern and its characteristics by the depth interview and questionnaire; and the other is qualitative analysis to study the internal relationship between the characteristic variables and performance of born global firms based on the cross-section or longitude data so as to advance the academic research.

\section{Acknowledgements}

I wish to thank Richard E. Wokutch, Pamplin Professor in the Department of Management at Virginia Tech, for inviting me to conduct a short time research as a visiting scholar in 2008. I am grateful for valuable suggestions from my colleagues of Zhejiang Sci \& Tech University and Shanghai Finance University as well as my graduate students.

\section{References}

Bell, J., McNaughton, R. \& Young, S. (2001). Born-again Global Firms: An Extension of the Born Global Phenomenon. Journal of International Management, 7: 173-189.

Bilkey, W. J. \& Tesar, G.. (1977). The Export Behaviour of Smaller-sized Wisconsin Manufacturing Firms. Journal of International Business Studies, 8 (1): 93-98.

Cavusgil, S.T. (1980). On the internationalization process of firms, European Research, 8(6): 273-281.

Chen, Zhongwei, \& Hao, Jailing. (2008). Empirical study on the relation between the entrepreneurship of team and performance of firms (in Chinese). Management Science, 21(1): 9-48.

Johanson, J. \& Vahlne, J.-E. (1977). The Internationalisation Process of the Firm: A Model of Knowledge Development and Increasing Foreign Markets Commitment. Journal of International Business Studies, 8 (1): 23-32.

Johanson, J. \& Vahlne, J.-E. (1990). The Mechanism of Internationalisatio. International Marketing Review, 7 (4): 11-24.

Knight, G. A., \& Cavusgil S. T. (1996). The born global firm: a challenge to traditional internationalization theory, In S. 
T., Cavusgil \& T. K. Madsen (eds.), Export internationalizing research - enrichment and challenges: 11-26, NY: JAI Press Inc.

Luo, Weidong. (2000). The entrepreneurship and the development of Zhejiang economy (in Chinese). Zhejiang Social Science, (2):13 15.

Madsen, T.K. \& Servais, P. (1997). The internationalization of born globals: an evolutionary process? International Business Review, 6(6): 561-583.

McDougall, P.P., Shane, S. \& Oviatt, B.M. (1994). Explaining the Formation of International New Ventures. Journal of Business Venturing, 9 (6): 469-487.

Oviatt, B. M. \& McDougall, P.P. (1994). Toward a Theory of International New Ventures. Journal of International Business Studies, 25 (1): 45-64.

Oviatt, B.M. \& McDougall, P.P. (1995). Global Start-ups: Entrepreneurs on a Worldwide Stage. Academy of Management Executive, 9 (2): 30-43.

Oviatt, B.M. \& McDougall, P.P. (1997). Challenges for Internationalisation Process Theory: The Case of International New Ventures. Management International Review, 37 Special Issue 1997/2: 85-99.

Reid, S.D. (1981). The Decision-maker and Export Entry and Expansion. Journal of International Business Studies, 12 (2): 101-112.

Rialp, A., Rialp, J., \& Knight, G.A. (2002). The Phenomenon of International New Ventures, Global Start-ups, and Born-Globals: What Do We Know After a Decade (1993-2002) of Exhaustive Scientific Inquiry?. Working paper, No. 2002/11.

Saarenketo, S. (2002). Born globals - Internationalization of small and medium-sized knowledge-intensive firms. Lappeenranta: Lappeenranta University of Technology.

Servais, P. \& Rasmussen, E.S. (2000). Different types of international new ventures, paper presented at the annual meeting of academy of international business (November), Phoenix, AZ., USA: 1-27.

Yang Zhong, Zhang Xia, Chen Yang and Liao Wenyan. (2007). Study on the sustainable driving force, the case study of the stage difference of cycle of born global firms (in Chinese). Management World, (6):122 136.

Yin, R. (1989). Case Study Research, Design and Methods. Beverly Hills, CA: Sage.

Zhao youzhen. (2004). The born global firm, concept, phenomenon, cause and enlightenments (in Chinese). International Business Study, (3): 65-69. 


\title{
Salesperson Professional Selling and the Effect
}

\section{on Buyer and Salesperson Relationship}

\author{
Maznah Wan Omar \\ Faculty of Business Management, Universiti Teknologi MARA \\ Kedah, Malaysia \\ Tel: 60-4-4562-550 E-mail: maznah199@kedah.uitm.edu.my \\ Kamaruzaman Jusoff (Corresponding author) \\ Department of Forest Production, Faculty of Forestry, Universiti Putra Malaysia \\ 43400 UPM Serdang, Selangor, Malaysia \\ Tel: 60-3-8946-7176 E-mail: kjusoff@yahoo.com \\ Mohd Noor Mohd Ali \\ Department of Physics, Universiti Teknologi MARA \\ Pulau Pinang, Malaysia \\ Tel: 60-4-4243-069 E-mail: mohdnoorma@ppinang.uitm.edu.my
}

\begin{abstract}
Regardless of the growing importance and emphasis on relationship marketing, a complete operation of this concept is still unclear. There is a lack of studies that explore the impact of factors such as salesperson professional selling on customer loyalty. This study seeks to verify the relationship between salesperson knowledge and adaptive selling. Computer retail customers with different cultural backgrounds were used as respondents in this study. Respondents were asked to rate their evaluations of customer loyalty towards the salesperson knowledge and adaptive selling skills through a self-administered questionnaires which were written in English language and Bahasa Malaysia. Correlation analyses with Pearson's $r$ coefficient were performed to identify the degree of one variable's position that occupies the same relative position on another variable. In addition, preliminary analyses were carried out to ensure no violation of the assumptions for linearity, normality, and homoscedasticity. No violations of the assumptions were found. The results of inter-correlation variables of the study indicate that the salesperson professional selling abilities which comprise of salesperson knowledge and adaptive selling managed to show a strong relationship with customer loyalty.
\end{abstract}

Keywords: Salesperson knowledge, Adaptive selling, Customer loyalty

\section{Introduction}

In recent years, a number of authors have addressed this issue of the changing role of the sales force. Cravens (1995) listed a number of critical agenda items for reinventing the sales organization. Among those are (1) building long-term relationships with customers, including assessing customer value and setting priorities; (2) creating sales organizational forms that are more nimble and adaptable to the needs of direct customer groups; (3) gaining greater job ownership and commitment from salespeople by removing functional barriers within the organization and leveraging the team experience; (4) shifting sales management style from commanding to coaching; (5) leveraging available technology for sales success; and (6) better-integrating salesperson performance evaluation to incorporate the full range of activities and outcomes relevant within sales jobs today.

As competition deepens, products and services become more indistinguishable, and markets become established, it is becoming increasingly tougher for companies in retailing industries to distinguish themselves from other stores. Simply offering customers with technical solutions to problems does not be sufficient anymore to be competitive and obtain and retain market share. Various value-added services, which commence before the actual operation begins, had gone far beyond it, so as to stay competitive and develop customer loyalty. Research and business customs have shown that 
upholding customers through value-added services costs less than obtaining new ones (Anderson et al., 1994; Reichheld, 1993; Wetzels et al., 1998). A prevailing belief holds that an essential key to performance rests with the ability to sustain customer relationships (Anderson et al., 1994; Ganesan, 1994).

Up-and-coming trends of the extent and scope recorded above require a re-evaluation of the activities that salespeople must execute in order to successfully build and manage customer loyalty. Marshall et al., (1999), interviewed a diversity of professional salespeople to give evidence for 49 new sales activities that were not pointed out in Moncrief's (1986) original list. These latest activities fall into the following main categories: communication technology, selling technology, activities related to adaptive and consultative selling, and team-oriented activities. Many of the specific activities within these categories involve skills and content knowledge dissimilar from those traditionally observed in the past as key salesperson success factors.

This study therefore investigates the salesperson professional selling (salesperson knowledge and adaptive selling) and the effect on buyer and salesperson relationship through customer loyalty, in the Malaysian retail sector. Oliver's (1997) model which follows the cognition-affect-conation pattern is use in the development of this study.

\section{Methods}

\subsection{Sampling design}

To have a representative finding, the sampling technique used must be objective. This is an important effort adopted by most researchers in order to furnish a finding pertinent to the general. To choose the sample for this study, probability random sampling was used. A probability sample is necessary if the sample is to be representative of the population (Reeves, 1992). Therefore, a two-stage systematic sampling technique is employed in this study.

\subsection{Population and sample size}

The unit of analysis for this study is individual customers who patronize the electrical appliance store. Studying primary consumer groups permits a more valid and reliable clarification to the model research in this study. A total number of 500 samples will be collected from 5 different locations in the states of Penang, Kedah, and Perlis. In determining the sample size for this study, sample size selected were based on the criteria set according to Roscoe's rule of thumb (cited in Sekaran, 2003) i.e. a sample that is larger than 30 and less than 500 are appropriate for most research, and the size must be several times larger (10 times or more) for multiple regression analysis to be conducted.

Electrical appliance store will be used in this study to permeate good interactions between salesperson and customers as selling electrical product involve a non-routine kind of buying behavior. Obviously, electrical products are mostly classified as specialty goods. Thus consumers will try to gain as much information about the product, either from the salesperson itself or from other sources, before they make the final purchase decision.

Subsequently, small distributors are chosen for this study as they don't provide facilities such as easy payments, membership card, Plus One loyalty programmed, extended warranty on goods purchased. Such facilities mentioned, can influence why customers visit the same store again in the future. Thus, a true loyalty will not be portrayed in such conditions.

\subsection{Data analysis}

To test the research hypotheses, the Pearson's product moment correlation coefficient $(r)$ were computed as a measure of correlations to examine the patterns and directions that exist in the association between the variables. In addition, this analysis was carried out to determine the interdependency of the study variables.

\section{Results and Discussion}

\subsection{Demographic data}

Results from the analysis of the demographic profile of respondents indicate that there is a greater representation of customers in Kedah (41.4\%), Penang (34.4\%) and in Perlis (24.4\%) respectively. This is viewed as being reflective of the accessibility to respondents.

Majority of the sample are male (65\%) as compared to female (35\%). Respondents spanned the range of age categories from 15 to 64 years of age, with the majority $(43.3 \%)$ of the respondents included in the survey sample being between the ages of $15-25$ years, followed by the $26-35$ age groups at $30.4 \%$. The next largest age group was the $36-45$ years at $18.2 \%$.

\subsection{Correlation between salesperson professional selling (salesperson knowledge, adaptive selling) and customer loyalty}

All the components of salesperson professional selling dimensions were statistically significant, ranging from $r=.57(\mathrm{p}$ $<.01)$ to $r=.58(\mathrm{p}<.01)$. The dimensions of salesperson professional selling managed to show strong relationships with customer loyalty. For example, there is a strong positive correlation between repurchase intention and salesperson 
knowledge $(r=.57, \mathrm{p}<.01)$, adaptive selling $(r=.58, \mathrm{p}<.01)$. The second dimension of customer loyalty which is intention to positive word-of-mouth, when correlate with salesperson knowledge and adaptive selling also shows a strong relationships, ranging from $r=.47(\mathrm{p}=<.01)$ to $r=.51(\mathrm{p}<.01)$. As a whole, the pattern of the correlation table displayed that both dimension of customer loyalty is positively and significantly correlated with all the salesperson professional selling dimensions.

Although correlations among all variables were significant and positively correlated, the strength of the correlations was well below .90. Results from this study indicate that there was no serious multi-collinearity problem for all variables in this study. Results on the correlation analyses on the study variables suggested that if the salesperson has high salesperson knowledge and adaptive selling skill, customers tend to experience greater affective commitment towards the salesperson. High affective commitment will then generate greater satisfaction. Subsequently, leads to customer loyalty.

\section{Conclusion}

It can be concluded that this study are significant to marketers on an applied level, whereby the results provide information to retailers to help them to be more effective in providing appropriate customer service levels in the area of salesperson professional selling. The nature of the product used in this research may help to explain the reported importance of the sales presentation knowledge and adaptive selling skills delivered to customers. Electrical goods are often complex or technical, have numerous features, and change frequently due to the inclusion of new features or combinations of features. For their part, customers shopping for electrical products may find it easy to be overwhelmed with numerous details and become confused. They may well be seeking a straightforward presentation of only that information that will help them make a choice. Salespeople in this product category are typically much more knowledgeable than the customer, and may be eager to explain technical features of the product. Thus signify the importance of a function of a salesperson in ensuring that customers will be satisfied and are willing to return to the store again in the future.

\section{References}

Anderson, E. W., Fornell, C., \& Lehmann, D.R. (1994). Customer satisfaction, market share, and profitability: findings from Sweden. Journal of Marketing, 58 (July), 53-66.

Cravens, D.W. (1995). The changing role of the sales force. Marketing Management, 4 (Fall), 48-57.

Ganesan, S. (1994). Determinants of long-term orientation in buyer-seller relationships. Journal of Marketing, 58(April), 1-19.

Marshall, G.W., Moncrief, W.C., \& Lassk, F.J. (1999). The current state of sales forces activities. Industrial Marketing Management, 28 (January), 87-98.

Moncrief, W.C. (1986). Selling activity and sales position taxonomies for industrial sales forces. Journal of Oliver, R.L. (1997). Satisfaction: A Behavioral Perspective on the Consumer. New York: The McGraw-Hill Companies, Inc.

Reeves, C. C. (1992). Quantitative research for the behavior sciences. New York, NY: John Wiley \& Sons, Inc.

Reichheld, F. (1993). Loyalty based management. Harvard Business Review, 71 (March-April), 64-73.

Sekaran, U. (2003). Research Methods for Business: A Skill Building Approach. $4^{\text {th }}$ ed., John Wiley \& Sons, Inc., 292-295.

Wetzels, M., Ruyter, K. d., \& Birgelen, M.V. (1998). Marketing service relationships: the role of commitment. Journal of Business \& Industrial Marketing, 13(4/5), 406-423.

Wood, M.F. (1995). Get more for your product or service: develop value added buyers. American Salesman, 40(April), 3-7. 


\title{
An Empirical Analysis on the Capital Structure of Chinese
}

\section{Listed IT Companies}

\author{
Yuanxin Liu \& Jing Ren \\ School of Business Administration, North China Electric Power University \\ Beijing 102206, China \\ E-mail: yuanxin09@126.com \\ Yan Zhuang \\ Shenyang Institute of Aeronautical and Engineering \\ Shenyang 110034, China
}

\begin{abstract}
The idea of this study is to identify the determinants of corporate financial structure for the IT industry in China which is a promising service industry but is facing challenges and risk in the Global financial turmoil. In this paper, we analyze the determinants of the capital structure for a panel of 92 IT companies listed in the China stock exchange. Six traditional explanatory variables are adopted in the study, including size, profitability, tangibility, liquidity, profit growth rate and growth opportunity. Linear regressions are used to study the effects of the factors. It is found that the size of companies are positively related to leverage, while growth and profitability, liquidity, profit growth rate and growth opportunity are negatively associated with leverage. The sign of these relations suggest that both the pecking order theory and trade off hypothesis are at work in explaining the capital structure of IT companies.
\end{abstract}

Keywords: Capital Structure, IT company, China capital market

\section{Introduction}

The empirical literature suggests a number of factors that may influence the financial structure of a company. As argued by Timan and Wessels(1988)and Harris and Reviv(1991), the choice of explanatory variables in the analysis of crosssectional variation in capital structure is fraught with difficulty. Rajan and Zingales (1995) in their study of capital structure in the G-7 economies find gearing in the UK to be positively related to tangibility (the proportion of fixed to total assets) and the size of the company, but negatively related to the level of profitability and the market-to-book ratio. The results of Rajan and Zingales (1995) are highly dependent upon the precise definition of gearing being examined.

Most of the empirical evidence on capital structure comes from studies of the determinants of corporate debt ratios e.g.Tima and Wessels(1988), Rajanand Zingales (1995), Graham(1996)and studies of issuing firms' debt vs. equity financing choice Marsh(1982),Jallilv and and Harris(1984). Horakimian et al.(2003)have successfully identified firm characteristics such as size, R\&D intensity, market-to-book ratio of assets, stock returns, asset tangibility, profitability and the marginal tax rate as important determinants of corporate financing choices. Baner(2004)examined the capital structure of listed companies in Visegrad countries(Czech Republic, Hungary, Poland and Slovak Republic).In his study, six potential determinants of capital structure are analyzed: size, profitability, tangibility, growth opportunities, non-debt tax shields and volatility.

Much of the empirical research on the determinants has been directed largely towards companies in developed countries. However, there has been relatively little research done to this date on companies listed in countries experiencing transition from a planned to market economic system like China. Chen (2004)is the first to study determinants of firm-level capital structure in China using a balanced panel of 77 listed companies. Huang and Song (2006)use a data set, which contains the market and accounting data, from more than 1000 Chinese listed companies from 1994 to 2000 ,to document the characteristics of these firms in terms of capital structure. They reported that the leverage in Chinese firms increases with firm size, non-debt tax shields and fixed assets, and decreases with profitability and correlates with industries. LinPing et al.(2005)also conducted an investigation and show that the capital structures differ according to size.

As an important impetus for economic growth in modern times, the IT industry has greatly promoted sustainable 
development in China. As the business environment, the requirement of management is substantial different with other traditional industries, the capital structure of IT companies has its specific characteristics. It is imperative for IT companies to be able to finance their activities and grow over time if they are ever to play an increasing and predominant role in creating value, providing employment as well as income in terms of profits, dividends and wages to households, and expanding the size of the directly productive sector in the Dynamic economy. It is important in this regard to understand how IT companies in China to finance their operations by examining their capital structure determinants. This article will identify the determinants and their power over the enterprise values which in turn help IT companies to programmatically build up a healthy and fruitful capital structure and maintain a stable prosperity and growth.

\section{Research methodology}

\subsection{Sample set}

This paper uses market and accounting data of more than 90 Chinese listed IT companies from the China Stock Market in the period between 2004 to 2007.To ensure the accuracy and subjectiveness, the industry classification of those companies are all aligned with the industry classification published by the China Securities Regulatory Commission(CSRC)in 2001. Meanwhile, the selection of the companies follow the below rules :1.In order to reduce the distraction of the data from new IPO companies, only companies listed before Dec 31th,2003 are enrolled into the study.(2).All the companies that been marked as 'ST' during the period are removed from the sample to avoid confusion. As a result, the final sample set consists of a balanced panel of 92 firms. And the 92 companies left includes 17 from Shenzhen A share,50 from Shanghai A shares, 18 from SMB shares ,5 from the Third shares, one from Shenzhen B shares and one from Shanghai B share. The 92 companies cover the four major sub-industries of IT industry which are Telecommunication and Equipment manufacturer; Computer and related manufacturer; Telecommunication service industry including telecommunication service and other communication service ;Computer based Application service.

\subsection{Sample characteristics}

\subsubsection{Overall features of the descriptive statistics over the samples.}

Insert Table 1 here

As we can see from the table 1, the debt ratio of the 92 corporations in the four years' period are $43.5287 \%(2004)$, $44.3584 \%(2005), 45.7696 \%(2006)$ and $43.9847 \%$ (2007) with the average at $44.4104 \%$ which is lower than the average of all the listed companies in Chinese Security Market. We can also know that the ratio maintain a medium level variation during the 4 years' period.

\subsubsection{The stability of the overall features in the listed companies.}

To have a better understanding of the stability of debt ratio of the sample during the four years of the IT industry as a whole and the four sub-industries, a illustration are drawn as below.

\section{Insert Figure 1 here}

As we can see from this figure, the IT industry as a whole has remained relatively stable and all the sub-industries also keep a similar stability with the maximum deviation less than 5 percent. Among the four sub-industries, the most stable one is the telecommunication \& equipment manufacturer and Computer and related manufacturer.

\subsection{Regression models and variables}

Since the sample contains data across firms and over time, the panel data method is employed. This thesis adopts a method with one-time access and multiple analysis. We will wipe off some variable according to the result and economic meaning until the model can be checked out from perspective of statistics and economics. The model is as follow:

$$
Y=C+a X_{1}+b X_{2}+c X_{3}+d X_{4}+e X_{5}+f X_{6}
$$

$\mathrm{C}$ is a constant, $a, b, c, d, e_{\text {and }} f$ are separately the coefficient of $X_{1}, X_{2}, X_{3}, X_{4}, X_{5}$ and $X_{6}$

Y: capital structure with debt ratio as the index

$\mathrm{X} 1$ : corporation size with the logarithm of asset as the index. Companies with larger size tend to be more diversified and hence their cash flow are less volatile. Size may then be inversely related to the probability of bankruptcy (Titman and Wessels, 1988; Rajan and Zingales, 1995). Ferri and Jones (1979) suggest that large firms have easier access to the markets and can borrow at better conditions. Overall, larger firms with less asymmetric information problems should tend to have more equity than debt and thus have lower leverage. 
X2: Profitability with earnings before interest and tax(EBIT)scaled by total assets as the index. In contrast to theoretical studies, most empirical studies show that leverage is negatively related to profitability. Friend and Lang (1988),and Titman and Wessels(1988)obtain such findings from US firms. Kester (1986) finds that leverage is negatively related to profitability in both the US and Japan. More recent studies using international data also confirm this finding (Rajan and Zingales(1995),and Wald(1999)for developed countries).Long and Maltiz (1985)find leverage to be positively related to profitability,but the relationship is not statistically significant. Wald (1999)even claims that "profitability has the largest single effect on debt/asset ratios."

X3: Tangibility with capital asset and stocks ratio as the index. Tangible assets are likely to have an impact on the borrowing decisions of a firm because they are less subject to informational asymmetries and usually they have a greater value than intangible assets in case of bankruptcy. Additionally, the moral hazard risks are reduced when the firm offers tangible assets as collateral, because this constitutes a positive signal to the creditors who can request the selling of these assets in the case of default. As such, tangible assets constitute a good collateral for loans.

X4: Liquidity using the Liquidity ratio as the index. Using liquidity ratio as an indicator, Wang Juan and Fenglin Yang (2002) confirmed a trade-off relationship between the collateral value of assets and debt ratio.Their finding is almost contrary to the pecking order pattern of financing. They argued that even if listed firms in China are capable of repaying their debts, they would still prefer to employ equity finance.

X5: Growth potential with the profit growth rate after tax as the index. The agency theory states that the growth potential is negatively correlated with debt asset ratio. This theory assumes that firms with a high growth potential are more flexible with regard to their options for future investment projects. In the case of a large number of debt obligations, these firms may have to relinquish potentially beneficial projects that in turn may lead to insufficient investments.

X6: Growth opportunity with the rate of main operation growth as the index. For companies with growth opportunities, the use of debt is limited as in the case of bankruptcy, the value of growth opportunities will be close to zero. Jung et al.(1996)show that firms should use equity to finance their growth because such financing reduces agency costs between shareholders and managers, whereas firms with less growth prospects should use debt because it has a disciplinary role(Jensen,1986; Stulz,1990).

\section{Regression results}

Table 2 report the sample correlation coefficients between all the variable and capital structure. Table 3 report the sample correlation coefficients between all the variable and capital structure after wiping off the constant. Table 4 represent the result that wiped off the net assets and the main operation growth rate.

From the model, we can see that the coefficient of determination is 0.923 and it shows that the model can ideally fit the sample data. With $\mathrm{F}$ equal to 263.512 , it means that all the independent variables and the dependent variable have a significant linear correlation. With $\mathrm{D}-\mathrm{W}$ equal to 2.182 and $\mathrm{dL}=1.59, \mathrm{dU}=1.73$ when $\mathrm{N}=92$ and $\mathrm{K}=4$ (the number of variables),we can see no self-correlation. Meanwhile, as all VIF is less than 10,we see no multiple collinear. Residuals Distribution show no heteroscedasticity.

Hence, we are confident that the equation is as follow:

$$
Y=3.85 X_{1}+40.09 X_{3}-1.85 X_{4}-0.005 X_{5}
$$

\section{Conclusion}

Through the empirical study of the 92 IT corporations, we find the result as follow:

The corporation size and capital structure have positive correlation but this kind of correlation is not significant. The positive impact of size on leverage is consistent with the results of many empirical studies(Rajan and Zingales, 1995; Booth et al.2001; Frank and Goyal,2002).The larger a company's scale is, the more stable its profitability will be as the larger company has lower risk of bankrupt and it has a higher debted capability. Also large companies have easier access to the bond markets. Although this kind of correlation is not significant and its effect on capital structure is as distinct as those IT companies in developed countries, we can expect the correlation between scale and capital structure will become more and more significant within Chinese IT corporations as the globalization are affecting Chinese economics more deeply and more companies are participating in the international competitions.

The profitability and capital structure has negative correlation. Retained profit is the quickest and easiest source of finance for most companies compared with new equity issuance due to the transaction costs associated with share issuance and the restrictions on firms' operating performance for applying for new equity issuance. Furthermore, since the majority of new equity is issued through share allotments, new issues usually lead to a decline in the firm's stock price. Therefore retained profit is the preferred primary method of raising additional capital. Meanwhile, most of the management of the Chinese listed companies prefers equity financing rather than debt financing because the former is not binding as a company with higher profit are easily to obtain equity financing than those elsewise. 
However, the relationship is not significant. The main reason is that Chinese companies pay more attentions to how to get fund rather than which way is the most efficient way to obtain the funding. So we can easily understand when these companies have the characteristics as follow:

--The indebted financing is high while equity capital is low.

--External financing is high while internal fund is low.

--Indirect fund is high while direct fund is low.

Asset value and capital structure has distinct positive correlation, it can be interpreted by the theory of agency costs, bankruptcy theory and pecking order theory. And we can also get the same conclusion from the characters of capital structure in IT corporations.

Liquidity and capital structure has negative correlation: if a company has more current assets, the fund can be used to invest instead of external short-term indebted fund. And we see that this assumption is validated by the empirical study.

Development potential (measured by Profit growth rate)has negative correlation with capital structure, but it is not significant. Development potential is the accumulation capability. Though the trade-off theory and pecking order theory disagree on this point, both of them can explain the situation with IT corporations while the pecking order theory is more suitable.

Growing opportunities and capital structure has negative correlation, but it is not significant.

According to the trade-off theory, firms holding future growth opportunities tend to borrow less than firms holding more tangible assets because growth opportunities cannot be collateralised. Further, agency theory argues that firms have a tendency to expropriate wealth from debt holders (Myers,1977; Jensen,1986). The high market capitalizations in China may also indicate that the growth opportunities associated with listed firms have been recognized by the capital market; therefore, banks are willing to assign higher valuations to highly levered firms and issue more long-term debt to finance the firms' growth opportunities.

From the result of the regression, we can see that the coefficient are big except the growth rate which mean that those factor has significant affect over the capital structure. That imply that certain firm-specific factors that affect firms' leverage in the Western countries also affect Chinese companies' leverage. This has shown that Chinese-listed firms have followed the basic rules of a market economy despite the state controlling ownership.

\section{Acknowledgment}

This research is supported by National Natural Science Foundation of China №70501010; by the Natural Science Foundation of Beijing city under Grant №9072009 ;by the elitist plan of Beijing under Grant №20071D1600900432.

\section{References}

Belsley, D.A., Kuh, E., and Welsch, R.E. (1980). Regression Diagnostics, John Wiley \& Sons,Inc., New York, NY.

Booth, I., V. Aivazian, A. (2001). Demirguc-Kunt and V. Maksimovic, Capital Structure in Developing Countries. Journal of Finance, 56, pp. 87-130.

Brealy, R. A. and S. C. Myers. (2003). Principles of Corporate Finance, 7th ed. McGraw-Hill.

Chen, J. (2004). Determinants of capital structure of Chinese-listed companies. Journal of Business Research, Vol. 57, pp.1341-51.

Chen, J. J. (2003). Determinants of Capital Structure of Chine-listed Companies. Journal of Business Research, 57,pp. 1341-1351.

Fama, E. F. and K. R. French. (2002). Testing Trade-Off and Pecking Order Predictions, about Dividends and Debt. The Review of Financial Studies, 15, pp. 1-33.

G. O. Young. (1964). Synthetic structure of industrial plastics(Book style with paper title and editor), in Plastics, 2nd ed. Vol. 3, J. Peters, Ed. New York: McGraw-Hill, pp. 15-64.

Harris, M. and A. Raviv. (1991). The Theory of Capital Structure. Journal of Finance, 46, pp. 297-355.

Harris, M.and Raviv. (1991). The theory of capital structure. Journal of Finance, 46, pp.334.

He, Qing. (2007). Corporation Financing policy and system study of capital structure, Economy science press.

Huang, R. and J. Ritter. (2005). Test the Market Timing Theory of Capital Structure, Working Paper, University of Florida.

Huang, Samuel G.H., and Frank M. Song. (2006). The Determinants of Capital Structure: Evidence from China. China Economic Review, 17, 14-35. 
Kong, Xiaowen. (2005). Choice of China corporation's capital structure- theory and emprical analysis [Phd thesis]. Guangdong Jinan University.

Li, Guozhong. (2007). Capital structure determination Multilayer dynamic study. Beijing: CPU press, $167-207$.

Li, Zhiqiang \& Dong, Yanan. (2003). Study of IT corporation's affection factors on capital structure. Transaction of Neimengguo financing and economy institute, (2).

Miller, Merton H. (1977). Debt and Taxes. Journal of Finance, 2, No.2, pp.261-275.

Modigliani Franco and Miller, Merton H. (1967). Some Estimates of the Cost of Capital to the Eletalric Utility Industry, 1954-1957. American Economic Review, 57, pp.1288-1300.

Titman and Wessels. (1998). The determinants of capital structure choice. Journal of Finance, 43, pp.17.

Wang, Huacheng. (2006). Financing management study. Beijing, China Finance Press.

Yan, Haojun. (2006). China corporation's capital structure study based on dynamic adjust model[Phd thesis].Shanghai: Institute of economy and management in TongJi University.

Zhang, Xiyu. (2003). IT corporation' capital structure affection factors. Statistics and decision making, 7.

Table 1. Overall features of the Descriptive statistics(Unit: \%)

\begin{tabular}{c|c|c|c|c|c}
\hline & Sample Size & Min & Max & Mean & Standard dev. \\
\hline 2004 & 92 & 2.72 & 84.08 & 43.52 & 17.951 \\
\hline 2005 & 92 & 0.35 & 86.87 & 44.35 & 17.394 \\
\hline 2006 & 92 & 6.25 & 76.32 & 45.76 & 16.409 \\
\hline 2007 & 92 & 7.04 & 72.01 & 43.98 & 15.052 \\
\hline Avg. & 92 & & 44.41 & \\
\hline
\end{tabular}

Table 2. First regression Coefficients(a)

\begin{tabular}{|c|c|c|c|c|c|c|c|}
\hline \multirow[b]{2}{*}{ Model } & \multicolumn{2}{|c|}{$\begin{array}{l}\text { Unstandardized } \\
\text { Coefficients }\end{array}$} & \multirow{2}{*}{\begin{tabular}{|l} 
Std. Co. \\
Beta
\end{tabular}} & \multirow[b]{2}{*}{$t$} & \multirow[b]{2}{*}{ Sig. } & \multicolumn{2}{|c|}{ Collinearity Statistics } \\
\hline & $\mathrm{B}$ & Std.Error & & & & & \\
\hline (Constant) & 11.793 & 33.579 & & 0.351 & 0.726 & & \\
\hline Logarithm of total asset & 2.646 & 3.64 & 0.065 & 0.727 & 0.469 & 0.783 & 1.278 \\
\hline Profit rate of net assets & -0.073 & 0.123 & -0.072 & -0.596 & 0.553 & 0.427 & 2.342 \\
\hline capital asset and stocks ratio & 39.98 & 10.184 & 0.333 & 3.926 & 0 & 0.872 & 1.147 \\
\hline Liquidity & -1.896 & 0.411 & -0.415 & -4.616 & 0 & 0.773 & 1.293 \\
\hline Profit growth rate after tax & -0.004 & 0.002 & -0.182 & -1.521 & 0.132 & 0.439 & 2.278 \\
\hline Main operation growth rate & -0.003 & 0.021 & -0.012 & -0.14 & 0.889 & 0.885 & 1.131 \\
\hline
\end{tabular}

Table 3. Second regression Coefficients(a,b)

\begin{tabular}{|c|c|c|c|c|c|c|c|}
\hline \multirow[b]{2}{*}{ Model } & \multicolumn{2}{|c|}{$\begin{array}{l}\text { Unstandardized } \\
\text { Coefficients }\end{array}$} & \multirow{2}{*}{\begin{tabular}{|c|}
$\begin{array}{c}\text { Standardized } \\
\text { Coefficients }\end{array}$ \\
Beta
\end{tabular}} & \multirow[b]{2}{*}{$\mathrm{t}$} & \multirow[b]{2}{*}{ Sig. } & \multicolumn{2}{|c|}{ Collinearity Statistics } \\
\hline & B & Std.Error & & & & & \\
\hline Logarithm of total asset & 3.915 & 0.446 & 0.759 & 8.782 & 0 & 0.12 & 8.364 \\
\hline Profit rate of net assets & -0.067 & 0.121 & -0.027 & -0.553 & 0.581 & 0.379 & 2.642 \\
\hline Capital assets \& stocks ratio & 39.942 & 10.131 & 0.303 & 3.942 & 0 & 0.151 & 6.64 \\
\hline Liquidity & -1.839 & 0.375 & -0.184 & -4.905 & 0 & 0.632 & 1.583 \\
\hline Profit growth rate after tax & -0.004 & 0.002 & -0.072 & -1.634 & 0.106 & 0.456 & 2.194 \\
\hline Main operation growth rate & -0.002 & 0.02 & -0.003 & -0.09 & 0.928 & 0.809 & 1.237 \\
\hline
\end{tabular}


Table 4. Third regression Coefficients $(\mathrm{a}, \mathrm{b})$

\begin{tabular}{|c|c|c|c|c|c|c|c|}
\hline \multirow[b]{2}{*}{ Model } & \multicolumn{2}{|c|}{$\begin{array}{l}\text { Unstandardized } \\
\text { Coefficients }\end{array}$} & \multirow{2}{*}{$\begin{array}{c}\text { Standardized } \\
\text { Coefficients }\end{array}$} & \multirow[b]{2}{*}{$\mathrm{t}$} & \multirow[b]{2}{*}{ Sig. } & \multicolumn{2}{|c|}{$\begin{array}{l}\text { Collinearity } \\
\text { Statistics }\end{array}$} \\
\hline & B & Std.Error & & & & & \\
\hline Logarithm of total asset & 3.854 & 0.429 & 0.747 & 8.978 & 0 & 0.127 & 7.901 \\
\hline Profit growing rate after tax & -0.005 & 0.002 & -0.091 & -3.039 & 0.003 & 0.976 & 1.025 \\
\hline Liquidity & -1.857 & 0.367 & -0.186 & -5.057 & 0 & 0.646 & 1.548 \\
\hline Capital assets \& stocks rate & 40.094 & 10.007 & 0.305 & 4.007 & 0 & 0.152 & 6.6 \\
\hline
\end{tabular}

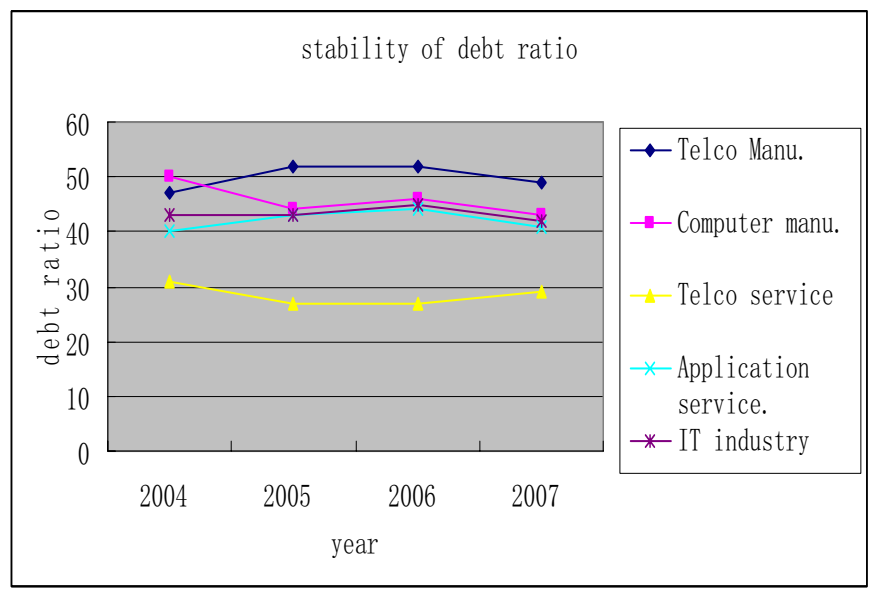

Figure 1. Stability of the Overall features in IT industry 


\title{
Disparity of Performance Indicators of Islamic Banks:
}

\section{Study on Bangladesh}

\author{
Mamunur Rashid \\ Ph.D. Student, Graduate School of Business, National University of Malaysia (UKM) \\ UKM Bangi, Selangor, Malaysia 43650 \\ Hand Phone: 60166377245 E-mail: mamun.finance@gmail.com
}

Ainun Nishat

Department of Business Administration, East West University

43 Mohakhali C/A, Dhaka 1212, Bangladesh

Tel: 88-02-9339-863Ｅ-mail: anishat@gmail.com

\begin{abstract}
Islamic banking is still in emergent stage. However, according to Islamic Financial Services Board (IFSB), the industry is growing at the rate of $15 \%$ every year. As it is operating under a distinct system of banking, Islamic Shariah, Islamic banks have been facing immense competition from other Islamic banks and conventional banks of domestic and multination origin. Moreover, banking is an important industry, which is responsible for the development of the global economic condition. Hence, analysis of performance and identification of the problems, at a continuous basis, are basic necessities for Islamic banks. This study considers 12 important financial ratios and common size income statement and balance sheet information of Islamic banks for 2001 to 2006. The ratios were compared with simple industry average and other banks after distributing these into three generations, namely; generation one, two and three. Results showed poor performance of Islamic banking sector in almost every aspect, especially in the areas of profit maximization, investor management and operating inefficiency. The report identified unique banking system, lack of efficient human resources, lack of marketing and awareness creating activities, absence of Islamic capital and inter-bank markets and lack of direct government control as precedent problems. The study reported to bring about immediate change in HR management and policy, changes in operating policy, increase in marketing and awareness creating activity, guidelines and supervision of the government through direct Islamic Banking Law.
\end{abstract}

Keywords: Islamic banking, Performance analysis, Common size statements

\section{Introduction}

Banking is a crucial global financial service industry. The fundamental functions enclosed by a bank comprise mobilizing deposit and deploying that in credits of divergent categories in contour with the requirement of various customers. The interest of the extensive variety of people is strongly related to banks' operation and performance. For the sake of investors' safety, regulators are also engrossed in monitoring performance of banks all over. More than $90 \%$ of financial assets of Bangladesh are owned by different category of bank, which is also largely contributing to the growth in the county's GDP and employment (Ali and Howlader, 2005). Since, banking activity affects the overall economic performance; incessant measurement of performance of these financial institutions has been indispensable.

The deteriorating health of the banking industry and surge for bank failures globally entitle for renewed interest in bank performance analysis (Mansur et al, 1993). Evaluating banking industry performance has been difficult, since the industry has close affiliation with various economic units. Not only the complex economic affiliation, banks are engaged with social welfare of diverse motives. Moreover, this activity has been even skinned as the banks have started to establish them as global, universal, technologically sophisticated, therefore highly regulated and customer driven financial institutions.

Islamic banks have enhanced a new dimension in banking initiated on religious standard. The industry is growing at an astounding rate over the last four decades Global Islamic financial services industry grew at a rate of $10-15 \%$ during 
1995 to 2005. By the end of 2005, total asset value stood at US\$700 Billion and at an annual growth of $15 \%$ until 2010, the industry could growth to US\$1.4 Trillion and to US\$2.8 Trillion by 2015 (IFSB Website, 2008). With the increasing demand and competition against conventional financial institutions, it is indispensable to contrast performance of Islamic banks with other competitors.

This study contrasts financial performance and its deviations among different conventional and Islamic banks in Bangladesh with the following specific objectives:

1. Comparative profitability status of Islamic and other banks

2. Comparative riskiness of Islamic and other banks

3. Comparison of performance of Islamic Banks with the industry average and different generations of banks

4. Identifying points-of-riskiness for Islamic Banking Sector and recommendation on possible turning points

\section{Bank Performance Analysis: Literature Review}

Banking sector is the key to economic growth in Bangladesh. It has significant contribution in country's GDP growth and in other economic developments. To develop a stagnant, war affected economy; the initial policy taken by Government of Bangladesh was to nationalize the banking sector. Ali and Howlader (2005) stated that one of the central causes of nationalization was to exaggerate control over the banking sector, which might result in regimented economical prosperity. As the market has been expanding with multi-level development activities, demand for more customer pleasant banking sector has started to emerge. Denationalization procedure started in 1982 and banking industry has started breathing again (Ali and Howlader, 2005). At present banking sector stands at over 6\% growth in its contribution in GDP (Bangladesh Bank Annual Report, 2005).

What induce bank performance? Numerous studies have been conducted on bank sector performance analysis, impact of performance issues on economic growth, riskiness of banks, service development of banks, and financial behavior of banks. Other efforts can also be remembered that signified to establish an employable index of performance that can be evaluated time to time for inferring conclusion on the status of financial performance of the banks of different countries. Bangladesh Bank has been following the CAMEL rating to rank the banks based on their financial performance. Under this rating, significant issues like capital adequacy, asset management, managerial efficiency, earnings quality and liquidity are employed. However, no specific index has been identified to contrast the Islamic bank sector performance with that of the conventional bank sector performance. Moreover, according to our acquaintance, none of such studies conducted in Bangladesh could reach beyond to compare between Islamic and Conventional banking sector performance.

Bank performance analysis might hold various motives such as Shu (2002) conducted studies in Hong Kong to see affiliation between macroeconomic condition and average asset quality of banks. Gerlach and Peng (2003) study concentrated on lending opportunities, economic performance and regulatory measures in their bank sector performance analysis. Other studies examined competition and its impact on profit margins (Johnston and Buttle, 2001), the growth of non-interest income (Mansur et al, 1993), capital management (Mansur et al, 1993), cost efficiency (Kwan, 2002; Jiang et al, 2003; Bonin and Leven, 1996, Gunay, 2004), industry consolidation (Jackson, 1975), banking regulation (Kumbhakar and Sarkar, 2003).

Government regulation exerted approximately as an intermediate against profitability and productivity of banking sector in numerous countries. Many of the developed economies undertook massive deregulation effort to liberalize the banking sector since 1980s' (Kumbhakar and Sarkar, 2003). The relaxation of stringent regulation thereafter began to contribute in overall economic development, productivity, employment generation. In recent years, specific performance related issues such as profitability has been widely covered in numerous studies. Among others, the Return on Asset, Return on Equity, Interest Margin and Net Profit Margin were considered in analyzing the cause-and-effect of banks' success (Seiford and Zhu, 1999; Tatje and Lovell, 1999; Soteriou and Zenios, 1999).

Various other sets of performance analysis highlighted the successful structural or allocational presence of banks in specific territory. Number of employees, branch coverage, population coverage of branch and ATM network, per employee expense, credit and deposit ratio, number of deposit and credit accounts have been the focal point of study (Athanassopoulos, 1998; Harker and Zenios, 1999; Berger and Humphrey, 1997; Seiford and Zhu, 1999, Huda et al, 2007). Studies went beyond operational and allocative performance. Seiford and Zhu (1999), Gunay (2004), Johnston and Buttle (2001) studied the impact of bank's financial ratios on its stock market performance.

Among several studies conducted on banking sector of Bangladesh, Siddique and Islam (2001) identified some extensive features which affect the profitability of the banking sectors. They have drawn a regression analysis and found the result significant by taking profitability as the dependent variable and factors like number of employees, number of branches, amount of investment, amount of asset, amount of time deposit and number of advance account as independent variables. 
Financial intermediation in Islamic framework is based on profit-loss sharing principles (Chapra, 1985) unlike on debtor-creditor relationship (Hassan \& Tariq, 1992), where a conventional principle of prefixing profit has been replaced with a variable rate of return based on real economic performance (Mangla \& Uppal, 1990). In acquaintance of the differences between conventional and Islamic financial banks, some frequent arguments have to be identified to analyze and differentiate operational and financial performance.

Ahmad and Hassan (2007) analyzed the asset quality, capital ratios, operational ratios such as net profit margin, net interest income, income to asset ratio, non-interest income to asset ratio and liquidity ratios for seven years from 1994 to 2001. Islamic banks on an average were the preeminent performer in terms of lowest non-performing to gross loan ratio, capital funds to total asset ratio, capital funds to net loans ratio, capital funds to short-term loan ratio, capital funds to liabilities ratio, non-interest expense to average asset ratio and most of the liquidity ratios. Therefore, it can be concluded that Islamic banks are outperforming others in capital adequacy and adequate liquidity. Except Return on Equity Ratio, Islamic Banks were at par with the industry in all other cases.

Sarker (1999) analyzed the productive efficiency, operational efficiency, allocative efficiency, distributive efficiency and the stabilization efficiency of Islamic banks in Bangladesh. However, the study did not illustrate any industry average of the ratios that could be used further to compare performance of Islamic banks with other competitors considering similar platform. Therefore, generalization of the result was not feasible. Nonetheless, the study found Islami Bank Bangladesh Limited as the leader in the market in profit maximization ratios, loan recovery ratios, and branch and employee coverage during the year 1998 to 2004.

The central bank of Bangladesh has recently established the strategy for merger of banks and also has increased the capital requirement of chartering a new bank to 400 Crore Taka. (Bangladesh Bank Press Relies, 2007). To meet the challenge of Basel II, which might increase the capital reserve of banks, banks will approach to capital market with new IPOs' or they will seek for possible mergers with other successful and largely capitalized banks. This might create strong pressure on the capital market as well. Moreover, restructuring of large NCBs' is in progress and government of Bangladesh is sincerely thinking to initiate a separate law on Islamic Insurance. So, a vital alteration possibly will transpire in near future in banking sector, which would entail examining the stability and strength of the sector.

\section{Banking Sector Performance in Bangladesh: Current Status}

Banking sector in Bangladesh comprises of Nationalized Commercial Banks (NCBs'), Development Financial Institutions (DFIs'), Private Commercial Banks (PCBs') and Foreign Commercial Banks (FCBs'). Majority of the banks are privately owned and are from second generation (See Annexure). Total number of banks became 49 in 2004 from 50 of 1998 due to merger of a FCB. Banks were historically concentrating mostly on the rural areas, since the basic objective was rural socio-economical development (Uddin et al, 1985; Ali and Howlader, 2005, p. 65).

\section{Insert Table 1 Here}

Networking of branches in the urban areas in 2004 has increased noticeably (Table 1). Only the DFIs' have the majority of the branch concentrated in the rural areas as because their core objective is to develop rural agriculture, small industries and community based infrastructural development. PCBs' have average $72 \%$ of their branches in the urban areas mostly in Dhaka, Chittagong and Sylhet divisions (Schedule Bank Statistics, 2004). All of the FCB's branches are located in the urban areas since their concentration is high-income group. Significant shifting occurs in deposit mobilization between 1998 and 2004 among different types of banks. Table 01 show that bankers are mostly collecting urban deposits. This was ensued because of low-income generation in the rural areas, higher migration of the rural people to the urban areas and higher cost-benefit ratio for the bank operation in the rural areas (Huda et al, 2007). Though NCBs' have been pioneering the deposit collection from the public and private deposits; PCBs' are rapidly expanding market with creative service offering. Huda et al (2007) study found out that the PCBs' and the FCBs' are more focused in target market selection and service offerings. However, fast disbursement of retail loans without verifying the customer carefully has made few private banks very risky compared to others.

Credit deployment has significantly amplified among the competing groups. Following the urban credit, credit disbursement in the rural areas has improved. Some of the private banks are lately opening branches in semi-urban and rural areas. But still the proportion of credit deployment has been noteworthy in the urban areas and this trend is being sizable to the PCBs' (Schedule Bank Statistics, 2004). FCBs' have been very much keen to monitor the credits and their ratio of NPL to total loans is $-1.4 \%$ in 2004. As table 1 show that PCBs' have been very efficacious in controlling the bad loans since the ratio is $4.6 \%$ in 2004 compared to a very high ratio of $26.3 \%$ in 1998 . Most of the banks have access liquidity accept DFIs'. Liquid Reserve Ratio is the highest for the FCB's. LRR for FCBs' is 39.8\% in 1998 and $37.8 \%$ in 2004. Due to undecorated lending risk management, the required capital becomes higher for DFIs' and NCBs', since they could not able to meet the CRR requirement successfully. Out of many, depraved political administration and lack of customer management were largely responsible for this (Rashid and Huda, 2007).

\section{Insert Table 2 here}


Islamic banking in Bangladesh started its journey in 1983 with the inauguration of Islami Bank Bangladesh Limited. The number of banks offering only Islamic banking appeared to be 6 at the end of June 2007 (Table 02). 10 conventional banks are offering Islamic banking services through separate branches. Number of branches in June 2007 of Islamic banks has increased by 12 from June 2006. Approximately 28\% employees of the total Private Sector banks are from Islamic Banks. By the end of June 2007, 14.3\% of the total bank sector deposit was collected by Islamic banks, which was $9.67 \%$ at the end of June 2006. Islamic banks' credit with respect to total industry credit grew up to $17.2 \%$ at the end of June 2007, which was approximately 3\% higher than that of June 2006. Following this higher acceptance, one entirely conventional bank, EXIM Bank, was been transformed to Islamic Bank from 2003. Few others are in the process of such conversion. Competition has developed severely among pure Islamic, conventional Islamic windows, multinational conventional and Islamic ventures in Bangladesh, which has constructed the cornerstone of appropriate performance intervention for the Islamic Banking industry.

\section{Methodology}

This study goes beyond what Ahmad and Hassan (2007) and Sarker (1999) did. In their studies, they have simply identified some ratios to present the then status of Islamic banks. We have collected annual reports of commercial banks those are listed with Dhaka Stock Exchange for 2001 to 2006. Banks were then categorized based on generations; the first generations (banks inaugurated in the 80s'), second generations (banks started in during 90s') and the third generations (banks launched after 90s'); and also based on whether they are operating on Islamic or conventional principles. A list of these banks is given in the annexure. Seven return and five risk ratios were calculated. BOX 01 below shows the list of return and risk ratios. Return ratios are related to profitability and efficiency. For Risk ratios, this study has only measured credit and capital, two very important, risks of commercial banks.

\section{Insert BOX 1 here}

Common size income statement and balance sheet were also prepared to see the impact of specific return and risk issues on the banks' operation. Mean of ratios and common size percentages were calculated for three generations individually, for Islamic banks and also for the entire banking industry during years 2001 to 2006. Common size income statement was prepared by dividing all the income statement items will Interest Income. Common size balance sheet was prepared by dividing all the balance sheet items, assets, liabilities and owners' equity, with total assets.

\subsection{Return Ratios}

An Earnings per Share (EPS) measures the net income every share, which consequences in direct income allocated to shareholders if $100 \%$ distributed in Annual General Meeting (AGM). No investor hates direct income to go up and therefore it has direct impact on the market price of the share as well. Therefore, it shows the operational and market efficiency for a company. Therefore, higher the EPS better seems to be the performance of the company. However, higher EPS would reduce Price Earnings multiples. However, obviously higher P/E ratio shows eagerness of the investors for the share of the company. Perhaps one of the best measures of investment-profitability relationship is Return on Asset (ROA). Higher the ROA, higher return on investment and the expected benefit. Another important measure of profitability is the Return on Equity (ROE) ratio, which is mainly investigated to see how much is the earnings for the shareholders. Higher ROE would motivate the investors to buy shares of the company, which will eventually increase the market value of the company. Net Interest Margin (NIM) measures the amount of operating income to earning asset. Higher the NIM ratio, higher is the quality of the management decision. Because higher operating income is the result of higher interest income or comparative lower interest expense, which is charged upon the earning assets such as Call Money, Short-term Investment, and loans and investment. Net Profit Margin (NPM) is nevertheless another measure of profitability, which is calculated by dividing net income after tax with interest income. NPM results in the measure of net profit on total revenue. Higher NPM ratio shows better expense and revenue management from the part of the management. Last Return Ratio, Efficiency Ratio, shows how total input and output in the banking process are managed. The ratio is calculated by dividing input (Expenses and Provisions) with the output (Net interest income and other operating income). Therefore, lower efficiency ratio satisfies the investors' with a positive node on the better quality of the management.

\subsection{Risk Ratios}

Banks manage risk. The birthplaces of these risks are credit disbursement, deposit collection, international commitments through Letter of Credit activities, changes in interest rates (rate of return) on loans and deposits, sudden breakdown of systems and operations. Capital Adequacy Ratio (CAR) measures the amount of capital reserve held for every unit of Risk-Weighted Asset (RWA). Higher percentage of CAR would not directly reduce the credit risk but would help to survive out of temporary credit disturbances since capital works as a cushion against risk. Non-Performing Loans (NPL) to Total Loans ratio indicates the level of direct credit risk. Higher Credit to deposit ratio shows that the management has been extremely efficient in deploying higher amount of deposit in earning asset. However, higher Credit to Total Asset ratio might increase the chances on being looser, otherwise with effective 
governance and control. Consequently, combination of Credit to Total Asset, Credit to Deposit and Non-Performing Loans to Total Loans ratio will determine the level of credit risk for any bank. For in-depth credit risk analysis, we have also considered provision for bad loans (Classified Loans) to Total Loans ratio. Higher the percentage of provision kept, lower is the risk to the investors. This would motivate the investors to deposit more with the bank. However, higher provision kept sometimes give negative signal to the markets regarding the increasing amount bad loans, which might consume way investor's funds.

The study has followed a simple method. After calculating the return and risk ratios for different generations of banks, we have calculated the mean and standard deviation of ratios for six years from 2001 to 2006. Coefficient of variance (CV) for both return and risk ratios were calculated using the following equation. CV measures the unit of standard deviation for per unit of mean, which will determine the riskiness of the variable. A ratio with higher $\mathrm{CV}$ indicates higher elasticity, therefore, higher risk.

$$
C V=\frac{\sigma_{i t}}{\mu_{i t}} \ldots \ldots \ldots \ldots \ldots \ldots \ldots \ldots
$$

In above equation (Equation Number 01), $\sigma_{i t}$ is the standard deviation of any ratio $\boldsymbol{i}$ for any specific time $\boldsymbol{t}$. $\mu_{i t}$ represents mean of any ratio $\boldsymbol{i}$ for any specific time $\boldsymbol{t}$. CVs' of different ratios can be ranked ( $*=$ highest to \# = lowest) to see which bank or category of banks are risky, less risky or highly risky. CV also gives future direction on how should these banks operate to get rid of the present situation. Same procedure has been followed for Common Size Income Statement and Balance Sheet figures (in decimal format). CV of Common Size statement figures were ranked for better interpretation of the data. The report was concluded reporting potential of generating more returns and riskiness of Islamic banks based on ranking of the mean ratios (return and risk ratios) and CV of ratios and $\mathrm{CV}$ of Common size figures.

\section{Results}

\section{(Insert Table 4 Here)}

\subsection{Mean and Standard Deviation of the Ratios (2001 to 2006)}

To analyze the return part of banks, this study has considered Earning per Share (EPS), Price Earnings Ratio (P/E), Return on Asset Ratio (ROA), Return on Equity (ROE), Net Interest Margin (NIM), Net Profit Margin (NPM) and Efficiency Ratio.

Table 04 shows that Banks in Generation 01 had the highest Mean EPS of 156.265 and the lowest mean EPS (42.780) is with Generation 03 Banks. Islamic banks had the highest mean P/E ratio of 185.74 times and Generation 03 was the lowest with 5.547 times. The Generation 03 Banks had the highest Mean ROA (1.5\%), ROE (2.42\%) and NPM (18\%), and the Generation 01 Banks had the lowest ROA and ROE ratios of $0.6 \%$ and $12.7 \%$ respectively. The Islamic Banks had the lowest mean NPM ratio of $8.4 \%$. The entire competing groups (G1, G2, G3, Islamic Banks and Industry Average) were indifferent on Net Interest Margin (NIM) ratio, which is close to Industry average (2.6\%). Since efficiency ratio shown in negative form, higher the efficiency ratio will reduce performance; Generation 02 Banks was in good position with the lowest Efficiency ratio (47.8\%) and Generation 01 Banks was in worse position with highest Efficiency ratio of $72.0 \%$. Islamic banks performed averagely with ROA, ROE and Efficiency ratio.

To analyze the Risk part of the banks, Capital Adequacy Ratio (CAR), Non-Performing Loans to Total Loans (NPL to TTL), Credit to Deposit, Credit to Total Asset and Provisions for Classified Loans to Gross Loan (Prov. For CL to Gross Loans) were undertaken.

From Table-04, Generation 03 Banks had the highest mean CAR and Credit to Deposit ratios, of $10.8 \%$ and $79.2 \%$ respectively, whereas Generation 01 Banks had the lowest CAR of $(9.0 \%)$, Credit to Deposit Ratio $(76.9 \%)$ and Credit to Total Asset Ratio (62.3\%) ratios. However, Generation 01 banks had the highest "NPL to TTL" Ratio and "Prov. for CL to Gross Loan" Ratio of $13.8 \%$ and $1.3 \%$ respectively. Islamic Banks were in moderate position in terms of every risk ratio, but have the highest position only in Credit to Total Asset ratio (67.9\%). As stated earlier, higher credit to total asset ratio is a cross-road ratio, which represents a positive sign since the earnings may increase but will be a negative one with the increase of credit/ default risk.

Islamic banks had the highest standard deviation of EPS (213), NPM (8.8\%) and P/E ratio (429) and moderate deviation (at par with the industry) in ROA, ROE, NIM and Efficiency Ratio. Islamic banks have been always doing better with Capital Adequacy Ratio, which shows the lowest standard deviation of $0.9 \%$. Except credit to deposit ratio (11.5\%), Islamic banks on average are performing moderate in all other risk ratios (NPL to Total Loans ratio, Credit to total asset ratio and provision for classified loans to total loan ratio).

\section{(Bring Table 5 Here)}




\subsection{Coefficient of Variance (CV) of the Ratios (2001 to 2006)}

Coefficient of Variance (CV) for different ratios is shown in Table 05. Higher CV signifies higher risk for per unit of mean. From the table of ' $\mathrm{CV}$ of Return Ratios', it is seen that the Generation -3 Banks have in overall best position with a lowest CV from among the options of Bank. In Generation-3 Banks, the CV of EPS, P/E, ROA, ROE, NIM and NPM ratios are $0.15,0.97,0.07,0.11,0.09$ and 0.08 respectively. The Islamic banks put in worst position with highest $\mathrm{CV}$ in EPS (1.91), P/E (2.31), ROA (0.70) and NPM (0.95) ratios. In case of Generation-1 Banks, it falls in best position with lowest CV in Efficiency ratio (0.13), but places in worst position with highest CV in ROE and NPM ratios, 0.44 and 0.44 respectively. Only Generation-2 Banks places in worst position with highest CV in Efficiency ratio, 0.63.

From the Table of 'CV of Risk Ratios', CV of Risk Ratios are almost relatively same with each other options and not vary deviates from the Industry Average, except 'NPL to TTL' and 'Prov. for CL to Gross Loan'. For both ratios, Generation-1 Banks are in worst position with highest CV 0.64 and 0.40 respectively. In case of NPL to TTL, Generation-2 Banks are in a best position with lowest CV (0.29), and in case of Prov. for CL to Gross Loan, Islamic Banks are in relatively good position with lowest $\mathrm{CV}, 0.25$.

\section{(Insert Table 8 Here)}

\subsection{Mean and Standard Deviation of Common Size Items}

\subsubsection{Balance Sheet}

Cash and cash equivalents are the highest with Islamic banks (23\%, which is $8 \%$ higher than the industry average), since they have limited freedom of investing their reserve funds in marketable securities. Unfortunately, the standard of cash and equivalent is the second highest with Islamic banks (5\% against an industry average of 4\%). This variation elucidates that customers withdraw fund very frequently, which may increase liquidity risk. Total loans and investment (investment for Islamic banks) is observed to be the lowest for all Islamic banks during 2001 to 2006 (70\% against an industry average of $74 \%$ ). Standard deviation of loans and investment is also higher than industry average ( $8 \%$ against an industry average of $7 \%$ ). This variation says that under competitive environment, Islamic banks would be in trouble with profitability ratios, which is already shown in Table 04 (Means and standard deviation of return ratios).

Islamic banks are mostly liability dependent ( $96 \%$ debt and only $4 \%$ of equity, whereas industry average of capital structure is $94: 6 \%$ ). This would create positive pressure on liquidity risk of the bank. Due to higher number of braches scattered throughout the country, Islamic banks' deposit amounted $87 \%$ compared a lower industry average of $82 \%$. However, the standard deviations of deposits and liabilities were on an average $1 \%$ higher than the industry averages for the same during 2001 to 2006.

\subsubsection{Income Statement}

For preparing common size income statement, we have divided all the items with interest income (Table 08). Let us compare Total operating income as a percentage of interest income with total operating expenses as a percentage of interest income for industry average and Islamic banks. The ratio is 2.29 times for the industry but 2.10 times for the Islamic banks (with the same level of standard deviations for both the industry and the Islamic banks). This means, for the same level of operating income, Islamic banks had higher level of operating expenses or vice versa. This is again pointing towards a possible reduction of profitability, which is supported by the data in Table 08 . Net income to interest income rate is $10 \%$ for Islamic banks, whereas the ratio is $4 \%$ higher for the industry. Generation 3 banks crossed the benchmark by another $3 \%$ (means, $17 \%$ is the net income to interest income ratio). The situation was even worse when the standard deviation of net income to interest income ratio was as high as $7 \%$ for the Islamic banks compared to only $3 \%$ for the industry and $2 \%$ for the third generation banks. One might argue that even if the net income to interest income ratio is the lowest but the retained earnings to interest income ratio is one of the highest for the Islamic banks. One answer could be that investors were deprived off the higher level of income or the Islamic banks saved larger amount for further development. However, the standard deviation for retained earnings to interest income ratio $(6 \%$ for Islamic banks and only $2 \%$ for the industry) has proved that Islamic banks should be more careful with investor management strategy. Investors should have been receiving higher amount of profit. Last but not the least, the provision for classified loans to interest income ratio was 3\% lower for the Islamic banks compared to industry average (8\%). This shows that amount invested was recovered at a higher level of success (standard deviation for provision against classified loan is only $1 \%$ ), since higher level of provision gives negative signal to the market.

(Insert Table 09 here)

\subsection{Coefficient of Variance (CV) of Common Size Income statement and Balance Sheet}

Islamic banks are in awful form due to the highest amount of variation in most of the balance sheet items. However, the risk is significantly lower with common size income statement (Table 09). Except cash and total deposit, Islamic banks were facing tremendous pressure in maintaining an optimal balance of assets, liabilities over 2001 to 2006. Interest expense to interest income ratio $(\mathrm{CV}=.08)$ and Retained earnings to interest income ratio $(\mathrm{CV}=0.58)$ were two places 
where Islamic banks were having trouble. However, with other income and expense figures, CV of Islamic banks were under control. This analysis concludes that Islamic banks should concentrate on interest expenses, dividend and equity management and asset management.

(Insert Table 10 here)

\subsection{Ranking the Mean of the Ratios (2001 to 2006)}

Islamic banks on average performed mediocre compared to other groups. However, the average $\mathrm{P} / \mathrm{E}$ ratio has been the highest for Islamic banks and Net Profit Margin was the worst with Islamic Banks. On an average for return ratios, Generation 3 banks can be said to be efficient compared to other groups and the Generation 1 banks are inefficient in most of the cases.

As stated earlier Islamic banks are distress with their risk ratios. They have the worst performance in 3 out of 5 risk ratios. Capital Adequacy ratio should be higher for all the banks to consume marginal credit risk. However, Islamic banks have had the lowest Capital Adequacy Ratio (CAR). Higher credit to total asset ratio escalates amount of credit risk. As a result, a lower credit to total asset ratio was expected. Percentage of credit to total asset for Islamic banks was approximately $68 \%$, which was the highest among all other groups. It is worth mentioning here that higher credit to total asset may increase profitability, nevertheless, we have considering potential credit risk of the banks and higher credit compared to asset growth may increase number of defaulters. Amount of Non-performing loans was also elevated for Islamic banks (second highest of 7.5\%, where highest was $13.8 \%$ and lowest was 5.3\%). In view of the fact that, credit to total asset and percentage of non-performing loans are giving bad indicators for Islamic banks, it is expected the banks should have higher provision (reserve) against classified (non-performing loans) loans. Unfortunately, provision against bad loans is the lowest for several banks in Bangladesh and Islamic banks were in that list. The percentage of provision to gross loan was only $0.6 \%$ for Islamic banks whereas the highest amount of reserve was $1.3 \%$ for generation 1 banks.

\section{Concluding Remarks}

\subsection{Summary of the Findings}

The following points came out while analyzing the findings of this study:

1. Revenue management of Islamic banking sector countenance trouble during 2001-2006. Even with higher level of EPS and P/E ratio; lower efficiency ratio, NPM and NIM ratios will raise questions against expected development of shareholders' value maximization. Moreover, majority of return indicators such as EPS, P/E, ROA, and NPM resulted strayed from the industry average.

2. Operating efficiency illustrated less variation even though interest expense (expenses due to profit paid to the depositors) has turned aside the highest. Change in cost of deposit is an usual approach of Islamic banking since it cannot be fixed. However, change in the amount of total interest expense surfaces the question of inefficiency.

Deviation with income statement of Islamic Banks was lower than that of the contestants, which shows less riskiness of operating results.

3. Investments and liabilities of Islamic banks appeared off-putting. It is furthermore unlikely that Islamic banks have invested in call money market while the conventional environment prevailing. Investment in loans and advances was the highest deviating factor along with borrowings, total liabilities, and total equity. Change in total equity has engrossed concentration because of the highest deviation of retained earnings each year. Even though the EPS was one of the highest, retained earnings has been very much low for the Islamic banking sectors representing less concern for owners. Deviation in loans and investment has occurred due to less awareness creation among the investors.

4. Due to unavailability of local capital market, Islamic banking sectors have been suffering from investing idle fund in liquid venture. The largest source of fund was deposit followed by a tiny portion of equity capital. Unless there is diversity of sources of fund for Islamic banks, there will be instability prevailing in all stock market related ratios like $\mathrm{P} / \mathrm{E}$ ratio, Return of Equity Ratio and capital adequacy ratio. Islami Bank Bangladesh Limited has recently issued a Mudaraba Perpetual Bond, however the performance of the bond as yet is below standard.

5. Lack of awareness and understanding clogged the ways of credit disbursement for Islamic banks. Credit to total asset ratio has been the lowest for Islamic banks compared to other generations and industry average. Islamic microcredit operation has been started long ago, which has been however mostly unnoticed by majority of the customers.

6. Islamic banks have performed poorly in terms of the percentage of non-performing loans, which has increased the requirement for income cut to escalate the amount of provision against classified loans (bad loans). 


\subsection{Discussions of the recommended guidelines}

Inconsistency in operation has been the biggest finding for Islamic banks in Bangladesh. Sudden change in loans and advances and less costly supply of fund will threaten the survival of Islamic banks against giant conventional counterparts. Even though change is inevitable for regular style of Islamic banking, however, inconsistency is the problem. To reduce these disparities of performance on common grounds, the following guidelines are recommended:

1. Increasing the efficiency of the working procedure by clearly stating the goals/targets along with the presence of effective incentive mechanism.

2. Establishing early warning system and training the employees/managers to provide feedback on possible shift in values with respect to riskiness in certain highlighted areas such as Net Income, Interest expense (profit paid to depositors/ investors), interest income (profit earned from investment) and loans and advances.

3. Hiring and developing efficient employees, not just anybody spirited by the virtue of Islam, but with education and experience in Banking, economics and finance.

4. Increase in interest expense and deviations in loans and advances give notions of changes in customer perception. Islamic banks must publicize their ideas to the people irrespective of whether Muslim or non-Muslim along with necessary awareness creation program, if possible training program using Electronic and Print Media, to increase public understanding. Research on customer preference should be carried out on a regular basis to oversee the disparity occurring in the mind of the people.

5. The purpose of rigorous and objective analysis to develop a quality-credit culture should be brought in. This will ensure justification of non-performing loans from the past year and will edify the mistakes to recover the situation for the next years. Establishment of an effective corporate governance culture along with shariah principle is a vital requirement to reduce the credit risk, since the rule of thumb for Islamic banking is the business guided by Shariah Principles not just by the efficiency of the practice.

6. Government should introduce a precise guideline for Islamic banks; however a separate law may provide better result, and they also should monitor the deviations with respect to industry. About the cost of deposit, which can be fixed for conventional banks very easily by the central bank, Government should provide an explicit procedure of deploying market forces into actions on common grounds for both Islamic and conventional banks. A separate money market mechanism for Islamic banks may result in lower idle fund in the balance sheet, which may also help to reduce liquidity crisis of Islamic banks.

7. Marketing programs should be increased to aware the market about the utility of the services offered by Islamic banks.

\section{References}

Ahmad, A. U. F., \& Hassan, M. K. (2007). Regulation and performance of Islamic banking in Bangladesh. Thunderbird International Business Review, 49(2), 251-277.

Ali, A., \& Howlader, R. A. (2005). Banking Law and Practice. Agami Prakashoni, Dhaka, Bangladesh.

Athanassopoulos, A.D., \& Labroukos, N.S. (1999). Corporate customer behavior towards financial services: empirical results from the emerging markets of Greece. International Journal of Bank Marketing, 17(6).

Bangladesh Bank. "Schedule Bank Statistics," Various Editions.

Bangladesh Bank. (2005). Annual Report of Bangladesh Bank, Bangladesh Bank, Dhaka, Bangladesh.

Bangladesh Bank. (2007). Press relies on new capital requirement for commercial banks by Banking Regulatory and Policy Department. [Online] Available: www.bangladesh-bank.org (Retrieved from January 2008).

Berger, A.N., \& Humphrey, D.D. (1997). Efficiency of financial institutions: International Survey and directions for future research. European Journal of Operation Research, 98, 175-212.

Bonin, J.P., \& B. Leven (1996). Polish Bank Consolidation and Foreign Competition: Creating a Market-Oriented Banking Sector. Journal of Comparative Economics, 23, 52-72.

Chapra, M. U. (1985). Towards a just monetary system. Leicester, UK: Islamic Foundation.

Gerlach, S., \& Wensheng, P. (2003). Bank lending and property prices in Hong Kong. HKIMR Working Paper, $12 / 2003$.

Gunay, E. N. O. (2004). The Impact of Deregulation on Market Structure and Performance in the Turkish Banking Industry. Economic Review, 15(2).

Harker, P.T., \& Zenios, S. A. (1999). Financial Institutions: Efficiency, Innovation, Regulations. In Press, Cambridge University Press, Cambridge, U.K. 
Hassan, M. K., \& Tariq, H. (1992). Performance evaluation of private sector commercial banks. Indian Journal of Economics, 73(289), 159-180.

Hempel, G. H., \& Simonson, D.G. (1999). Bank Management: Text and Cases. Wiley and Sons, $5^{\text {th }}$ Ed.

Huda, S., Chisty, K. K. S., and Rashid, M. (2007). An Evaluation of the Role of Technology and Relationship on Banking: Study in Bangladesh. BRAC University Journal, 4(2), 41-53.

IFSB website. (2008). Islamic financial services industry development: ten-year framework and strategies. Joint initiative by Islamic Development Bank (IDB), Islamic Financial Services Board (IFSB), Islamic Research and Training Institute (IRTI). Downloaded from the following link of IFSB [Online] Available: http://www.ifsb.org/index.php?ch=4\&pg=140 (Retrieved from January 1, 2008)

Jackson, W. (1975). Commercial Bank Regulation, Structure and Performance. The Journal of Finance, 30(3).

Johnston, B., \& Buttle, J. (2001). A Performance Analysis of Major Banks in Australia. Asia Money, A Report Published by Arthur Andersen.

Jiang, G., Tang, N., Law, E., \& Sze, A. (2003). Determinants of bank profitability in Hong Kong. Hong Kong Monetary Authority Research Memorandum. [Online] Available: http://www.info.gov.hk/hkma/eng /research/RM_on_Bank_Profitability.pdf

Kumbhakar, S.C, \& Sarkar, S. (2003). Deregulation, Ownership and Productivity Growth in the Banking Industry: Evidence from India. Journal of Money, Credit and Banking, 35(3).

Kwan, S. (2002). The X-efficiency of commercial banks in Hong Kong. HKIMR Working Paper, 12.

Mansur, I., Zangeneh, H., \& Zitz, M. S. H. (1993). The association between banks' performance ratios and market determined measures of risk. Applied Economics, Vol. 25, pp. 1503-1510.

Mangla, I. Y., \& Uppal, J. Y. (1990). Islamic banking: A survey and some operational issues. Research in Financial Survey, 2(179), 185- 215.

Soteriou, A., \& Zenios, S. A. (1999). Efficiency, Profitability, and Quality in the Provision of Banking Services. Working Paper in Department of Public and Business Administration, University of Cyprus, Nicosia, Cyprus.

Seiford, L. M., \& Zhu, J. (1999). Profitability and Marketability of the Top 55 U.S. Commercial Banks. Management Science, 45(9), 1270-1288.

Sarker, A. A. (1999). Islamic Banking In Bangladesh: Performance, Problems and Prospects. International Journal of Islamic Financial Services, 1(3).

Siddique, S.R., \& Islam, A.F.M.M. (2001). Banking sector in Bangladesh: Its contribution and performance. Journal of Business Research, 3, 63-73.

Shu, C. (2002). The impact of macroeconomic environment on the asset quality of Hong Kong's banking sector. Hong Kong Monetary Authority Research Memorandum. [Online] Available: http://www.info.gov.hk/hkma/eng/research/RM20-2002.pdf.

Tatje, G.E., \& Lovell, C.A.K. (1999). Profits and Productivity. Management Science, 45(9), 1177-1193. 
Annexure 01: List of Banks based on Generations and Religious principles

\begin{tabular}{|c|c|}
\hline \multicolumn{2}{|c|}{ First Generation Banks } \\
\hline \multicolumn{2}{|l|}{ AB Bank Limited } \\
\hline \multicolumn{2}{|l|}{ The City Bank Limited } \\
\hline \multicolumn{2}{|l|}{ United Commercial Bank Limited } \\
\hline \multicolumn{2}{|l|}{ National Bank Limited } \\
\hline AL Baraka Islamic bank (ICB Islamic Bank) & Islamic Bank \\
\hline \multicolumn{2}{|l|}{ IFIC Bank LIMITED } \\
\hline Islami Bank Bangladesh LTD & Islamic Bank \\
\hline \multicolumn{2}{|l|}{ Pubali Bank Ltd } \\
\hline \multicolumn{2}{|l|}{ Uttara Bank Ltd } \\
\hline \multicolumn{2}{|c|}{ Second Generation Banks } \\
\hline \multicolumn{2}{|c|}{\begin{tabular}{|l|l} 
Eastern Bank Limited & \\
\end{tabular}} \\
\hline \multicolumn{2}{|l|}{ National Credit \& Commerce Bank Limited } \\
\hline \multicolumn{2}{|l|}{ Prime Bank Limited } \\
\hline \multicolumn{2}{|l|}{ South East Bank Limited } \\
\hline \multicolumn{2}{|l|}{ Dhaka Bank Limited } \\
\hline Al-Arafah Islami Bank Limited & Islamic Bank \\
\hline Social Investment Bank Limited & Islamic Bank \\
\hline \multicolumn{2}{|l|}{ Dutch-Bangla Bank Limited } \\
\hline \multicolumn{2}{|c|}{ Third Generation Banks } \\
\hline \multicolumn{2}{|l|}{ Mercantile Bank Limited } \\
\hline \multicolumn{2}{|l|}{ Standard Bank Limited } \\
\hline \multicolumn{2}{|l|}{ One Bank Limited } \\
\hline EXIM Bank Limited & Islamic Bank (from 2003) \\
\hline \multicolumn{2}{|l|}{ Bangladesh Commerce Bank Limited } \\
\hline \multicolumn{2}{|l|}{ Mutual Trust Bank Limited } \\
\hline \multicolumn{2}{|l|}{ First Security Bank Limited } \\
\hline \multicolumn{2}{|l|}{ The Premier Bank Limited. } \\
\hline \multicolumn{2}{|l|}{ Bank Asia Limited } \\
\hline \multicolumn{2}{|l|}{ The Trust Bank Limited } \\
\hline Shahjalal Bank Limited & Islamic Bank \\
\hline \multicolumn{2}{|l|}{ Jamuna Bank Limited. } \\
\hline Brac Bank Limited & \\
\hline
\end{tabular}


Table 1. Performance Highlights of Banking Sector of Bangladesh

\begin{tabular}{|c|c|c|c|c|c|c|c|c|c|c|}
\hline \multirow{3}{*}{ Type } & \multicolumn{10}{|c|}{1998} \\
\hline & \multirow{2}{*}{$\begin{array}{l}\text { No of } \\
\text { Banks }\end{array}$} & \multicolumn{2}{|c|}{ Branch \% } & \multicolumn{2}{|c|}{ Deposit \% } & \multicolumn{2}{|c|}{ Credit $\%$} & \multirow{2}{*}{$\begin{array}{l}\% \text { of } \\
\text { NPL }\end{array}$} & \multirow{2}{*}{ CAR } & \multirow{2}{*}{ LRR } \\
\hline & & Rural & Urban & Rural & Urban & Rural & Urban & & & \\
\hline $\mathrm{NCB}$ & 4 & 63.81 & 36.19 & 29 & 71 & 18.88 & 81.12 & 35.6 & 5.2 & 24.4 \\
\hline DFI & 4 & 87.55 & 12.45 & 51 & 49 & 38.54 & 61.46 & 59.1 & 6.9 & 16.6 \\
\hline PCB & 30 & 27.15 & 72.85 & 10 & 90 & 2.17 & 97.83 & 26.3 & 9.2 & 24.8 \\
\hline FCB & 12 & 0 & 100 & 0 & 100 & 0 & 100 & 0.1 & 17.1 & 39.8 \\
\hline \multirow{3}{*}{ Type } & \multicolumn{10}{|c|}{2004} \\
\hline & No of & \multicolumn{2}{|c|}{ Branch \% } & \multicolumn{2}{|c|}{ Deposit \% } & \multicolumn{2}{|c|}{ Credit \% } & \multirow{2}{*}{$\begin{array}{l}\% \text { of } \\
\text { NPL }\end{array}$} & \multirow{2}{*}{ CAR } & \multirow{2}{*}{ LRR } \\
\hline & Banks & Rural & Urban & Rural & Urban & Rural & Urban & & & \\
\hline $\mathrm{NCB}$ & 4 & 63.37 & 36.63 & 24 & 76 & 11.98 & 88.02 & $\begin{array}{c}21.1 \\
5\end{array}$ & 4.1 & 22.8 \\
\hline DFI & 5 & 88.63 & 11.37 & 43 & 57 & 46.54 & 53.46 & $\begin{array}{c}23.3 \\
7\end{array}$ & 9.1 & 11.2 \\
\hline PCB & 30 & 25.81 & 74.19 & 5 & 95 & 2.28 & 97.71 & 4.67 & 10.3 & 23.1 \\
\hline FCB & 10 & & 100 & 0 & 100 & & 100 & $\begin{array}{c}-1.4 \\
5\end{array}$ & 24.2 & 37.8 \\
\hline
\end{tabular}

\section{Source: Bangladesh Bank Annual Report, Schedule Bank Statistics; Various editions}

$C A R=$ Capital Adequacy Ratio. LRR $=$ Liquid Reserve Ratio.

$N C B=$ Nationalized Commercial Bank. DFI = Development Financial Institutions.

$N P L=$ Non-Performing Loans. FCB = Foreign Commercial Bank.

$P C B=$ Private Commercial Bank.

Table 2. Islamic Bank Statistics in Bangladesh

\begin{tabular}{|c|c|c|}
\hline Factors & June 2006 & June 2007 \\
\hline No of Banks & 6 & 6 \\
\hline Conventional Banks providing Islamic Banking & 10 & 10 \\
\hline No of Branches with Islamic Banks & 308 & 330 \\
\hline Islamic Branches with Conventional Banks & 20 & 21 \\
\hline \% of Employees in Islamic Banking with Private Commercial & 27.73 & 27.73 \\
\hline Banks & & 10.73 \\
\hline \% of Eslamic Deposit in Industry Deposits & 10.73 & 14.3 \\
\hline \% of Islamic Deposits in Private Banks' Deposit & 9.67 & 23.6 \\
\hline \% of Islamic Credit in Industry Credits & 28.46 & 17.2 \\
\hline Inlamic Credits in Private Banks' Credit & 14.88 & 26.9 \\
\hline Iiquidity: Excess (+), Shortfall (-) \% of the Private Banks' & $19.08\left[8.19^{*}\right]$ & $20.8\left[13.5^{*}\right]$ \\
\hline
\end{tabular}

* Ratio (inside bracket) of Islamic Banks of all Banks in the Industry.

Source: Annual Report, Bangladesh Bank, Various Editions. 
Table 3. Return and Risk Ratios

\begin{tabular}{|c|c|c|c|c|c|c|c|c|c|c|}
\hline \multicolumn{11}{|c|}{ Return Ratios } \\
\hline \multirow{2}{*}{ Ratio } & \multicolumn{5}{|c|}{2001} & \multicolumn{5}{|c|}{2002} \\
\hline & G1 & G2 & G3 & IA & IB & G1 & G2 & G3 & IA & IB \\
\hline EPS & 256 & 234 & 37 & 216 & 414 & 53 & 11 & 38 & 29 & -186 \\
\hline $\mathrm{P} / \mathrm{E}$ & 4 & 69 & 2 & 41 & 5 & 728 & 3 & 2 & 244 & 1063 \\
\hline ROA & 0.01 & 0.01 & 0.01 & 0.01 & 0.01 & 0.00 & 0.01 & 0.01 & 0.01 & 0.00 \\
\hline $\mathrm{ROE}$ & 0.22 & 0.28 & 0.27 & 0.26 & 0.17 & 0.09 & 0.27 & 0.28 & 0.22 & 0.27 \\
\hline NIM & 0.06 & 0.03 & 0.03 & 0.04 & 0.03 & 0.03 & 0.03 & 0.03 & 0.03 & 0.02 \\
\hline NPM & 0.13 & 0.17 & 0.18 & 0.17 & 0.10 & 0.06 & 0.08 & 0.17 & 0.10 & -0.05 \\
\hline Efficiency & 0.65 & 0.53 & 0.50 & 0.55 & 0.66 & 0.83 & 0.29 & 0.50 & 0.50 & 0.52 \\
\hline Ratio & \multicolumn{5}{|c|}{2003} & \multicolumn{5}{|c|}{2004} \\
\hline EPS & 74 & -24 & 54 & 29 & -55 & 287 & 40 & 46 & 106 & 85 \\
\hline $\mathrm{P} / \mathrm{E}$ & 31 & 6 & 3 & 13 & 4 & 12 & 13 & 16 & 14 & 12 \\
\hline ROA & 0.00 & 0.01 & 0.01 & 0.01 & 0.00 & 0.01 & 0.01 & 0.02 & 0.01 & 0.01 \\
\hline ROE & 0.06 & 0.20 & 0.21 & 0.17 & 0.22 & 0.13 & 0.20 & 0.24 & 0.20 & 0.17 \\
\hline NIM & 0.02 & 0.02 & 0.03 & 0.03 & 0.02 & 0.02 & 0.03 & 0.03 & 0.03 & 0.02 \\
\hline NPM & 0.04 & 0.09 & 0.18 & 0.11 & 0.04 & 0.11 & 0.13 & 0.21 & 0.15 & 0.09 \\
\hline Efficiency & 0.83 & 0.01 & 0.39 & 0.39 & 0.55 & 0.63 & 0.98 & 0.70 & 0.70 & 0.58 \\
\hline Ratio & \multicolumn{5}{|c|}{2005} & \multicolumn{5}{|c|}{2006} \\
\hline EPS & 131 & 101 & 38 & 90 & 182 & 136 & 135 & 44 & 105 & 228 \\
\hline $\mathrm{P} / \mathrm{E}$ & 15 & 20 & 5 & 13 & 21 & 11 & 9 & 6 & 9 & 9 \\
\hline $\mathrm{ROA}$ & 0.01 & 0.01 & 0.01 & 0.01 & 0.01 & 0.01 & 0.01 & 0.02 & 0.01 & 0.01 \\
\hline $\mathrm{ROE}$ & 0.11 & 0.19 & 0.23 & 0.18 & 0.20 & 0.16 & 0.20 & 0.23 & 0.20 & 0.21 \\
\hline NIM & 0.03 & 0.03 & 0.03 & 0.03 & 0.03 & 0.03 & 0.03 & 0.03 & 0.01 & 0.03 \\
\hline NPM & 0.10 & 0.16 & 0.17 & 0.14 & 0.16 & 0.14 & 0.16 & 0.16 & 0.15 & 0.16 \\
\hline Efficiency & 0.72 & 0.55 & 0.45 & 0.57 & 0.51 & 0.66 & 0.51 & 0.44 & 0.52 & 0.47 \\
\hline \multicolumn{11}{|c|}{ Risk Ratios } \\
\hline \multirow{2}{*}{ Ratio } & \multicolumn{5}{|c|}{2001} & \multicolumn{5}{|c|}{2002} \\
\hline & G1 & G2 & G3 & IA & IB & G1 & G2 & G3 & IA & IB \\
\hline CAR & 0.09 & 0.12 & 0.10 & 0.11 & 0.09 & 0.09 & 0.10 & 0.09 & 0.09 & 0.07 \\
\hline NPL to TTL & 0.22 & 0.06 & 0.06 & 0.10 & 0.07 & 0.24 & 0.08 & 0.08 & 0.12 & 0.10 \\
\hline Credit to Deposit & 0.68 & 0.71 & 0.74 & 0.71 & 0.67 & 0.84 & 0.74 & 0.74 & 0.77 & 0.74 \\
\hline Credit to Total Asset & 0.50 & 0.58 & 0.56 & 0.55 & 0.61 & 0.65 & 0.63 & 0.63 & 0.63 & 0.66 \\
\hline $\begin{array}{l}\text { Prov. for CL to Gross } \\
\text { Loan }\end{array}$ & 0.01 & 0.01 & 0.01 & 0.01 & 0.01 & 0.01 & 0.01 & 0.01 & 0.01 & 0.01 \\
\hline & \multicolumn{5}{|c|}{2003} & \multicolumn{5}{|c|}{2004} \\
\hline CAR & 0.09 & 0.11 & 0.13 & 0.11 & 0.09 & 0.07 & 0.09 & 0.09 & 0.09 & 0.09 \\
\hline NPL to TTL & 0.19 & 0.07 & 0.06 & 0.10 & 0.09 & 0.09 & 0.08 & 0.07 & 0.08 & 0.11 \\
\hline Credit to Deposit & 0.79 & 0.72 & 0.70 & 0.73 & 0.66 & 0.71 & 0.79 & 0.88 & 0.80 & 0.81 \\
\hline
\end{tabular}




\begin{tabular}{|c|c|c|c|c|c|c|c|c|c|c|c|}
\hline $\begin{array}{c}\text { Credit to Total Asset } \\
\begin{array}{c}\text { Prov. for CL to Gross } \\
\text { Loan }\end{array}\end{array}$ & 0.64 & 0.59 & 0.58 & 0.60 & 0.58 & 0.61 & 0.65 & 0.71 & 0.66 & 0.70 \\
\hline \multirow{2}{*}{ CAR } & 0.00 & 0.01 & 0.01 & 0.01 & 0.01 & 0.01 & 0.01 & 0.01 & 0.01 \\
\cline { 2 - 12 }$y$ & 0.10 & 0.11 & 0.10 & 0.10 & 0.09 & 0.10 & 0.10 & 0.12 & 0.11 & 0.10 \\
\hline NPL to TTL & 0.04 & 0.05 & 0.02 & 0.10 & 0.04 & 0.05 & 0.03 & 0.03 & 0.02 & 0.05 \\
\hline Credit to Deposit & 0.79 & 0.89 & 0.86 & 0.85 & 0.91 & 0.80 & 0.89 & 0.83 & 0.84 & 0.93 \\
\hline Credit to Total Asset & 0.66 & 0.72 & 0.72 & 0.70 & 0.75 & 0.68 & 0.74 & 0.70 & 0.71 & 0.77 \\
\hline $\begin{array}{c}\text { Prov. for CL to Gross } \\
\text { Loan }\end{array}$ & 0.01 & 0.01 & 0.00 & 0.01 & 0.01 & 0.01 & 0.00 & 0.00 & 0.01 & 0.00 \\
\hline
\end{tabular}

Source: Authors' Own Construction from the Data.

G1 $=$ Generation 1, G2 = Generation 2, Generation 3, IA = Industry Average, IB = Islamic Banks EPS $=$ Earnings per Share, $\mathrm{P} / \mathrm{E}=$ Price Earnings Ratio, $\mathrm{ROA}=$ Return on Asset, ROE $=$ Return on Equity $\mathrm{NPM}=$ Net Profit Margin, $\mathrm{CAR}=$ Capital Adequacy Ratio, NPL $=$ Non-performing Loans, $\mathrm{TTL}=$ Total Loans $\mathrm{NIM}=$ Net Interest Margin, $\mathrm{CL}=$ Classified Loan, Prov. $=$ Provision 
Table 4. Mean and Standard Deviation of the Ratios (2001 to 2006)

Mean of Return Ratios

\begin{tabular}{|c|c|c|c|c|c|}
\hline Ratio & G1 & G2 & G3 & IA & IB \\
\hline EPS & 156.265 & 82.837 & 42.780 & 96.008 & 111.311 \\
\hline P/E & 133.594 & 20.102 & 5.547 & 55.550 & 185.740 \\
\hline ROA & 0.006 & 0.011 & 0.015 & 0.011 & 0.007 \\
\hline ROE & 0.127 & 0.223 & 0.242 & 0.203 & 0.207 \\
\hline NIM & 0.033 & 0.028 & 0.030 & 0.026 & 0.027 \\
\hline NPM & 0.099 & 0.132 & 0.180 & 0.139 & 0.084 \\
\hline Efficiency & 0.720 & 0.478 & 0.496 & 0.540 & 0.549 \\
\hline
\end{tabular}

Mean of Risk Ratios

\begin{tabular}{|c|c|c|c|c|c|}
\hline Ratio & G1 & G2 & G3 & IA & IB \\
\hline CAR & 0.090 & 0.104 & 0.108 & 0.102 & 0.087 \\
\hline NPL to TTL & 0.138 & 0.063 & 0.053 & 0.087 & 0.075 \\
\hline Credit to Deposit & 0.769 & 0.791 & 0.792 & 0.783 & 0.786 \\
\hline Credit to Total Asset & 0.623 & 0.653 & 0.651 & 0.643 & 0.679 \\
\hline Prov. for CL to Gross Loan & 0.013 & 0.006 & 0.006 & 0.008 & 0.006 \\
\hline
\end{tabular}

Standard Deviation of Return Ratios

\begin{tabular}{|c|c|c|c|c|c|}
\hline Ratio & G1 & G2 & G3 & IA & IB \\
\hline EPS & 95.395 & 94.321 & 6.525 & 68.819 & 213.148 \\
\hline P/E & 291.186 & 24.857 & 5.402 & 93.288 & 429.860 \\
\hline ROA & 0.003 & 0.003 & 0.001 & 0.002 & 0.005 \\
\hline ROE & 0.056 & 0.039 & 0.027 & 0.033 & 0.038 \\
\hline NIM & 0.014 & 0.004 & 0.003 & 0.011 & 0.006 \\
\hline NPM & 0.038 & 0.038 & 0.015 & 0.025 & 0.080 \\
\hline Efficiency & 0.092 & 0.323 & 0.108 & 0.100 & 0.066 \\
\hline
\end{tabular}

Standard Deviation of Risk Ratios

\begin{tabular}{|c|c|c|c|c|c|}
\hline Ratio & G1 & G2 & G3 & IA & IB \\
\hline CAR & 0.010 & 0.011 & 0.015 & 0.010 & 0.009 \\
\hline NPL to TTL & 0.089 & 0.018 & 0.024 & 0.036 & 0.028 \\
\hline Credit to Deposit & 0.061 & 0.082 & 0.072 & 0.056 & 0.115 \\
\hline Credit to Total Asset & 0.064 & 0.064 & 0.072 & 0.059 & 0.077 \\
\hline Prov. for CL to Gross Loan & 0.005 & 0.001 & 0.002 & 0.002 & 0.002 \\
\hline
\end{tabular}

Source: Authors' own construction from the Data.

$\mathrm{G} 1=$ Generation 1, G2 = Generation 2, Generation 3, IA = Industry Average, IB = Islamic Banks

$\mathrm{EPS}=$ Earnings per Share, $\mathrm{P} / \mathrm{E}=$ Price Earnings Ratio, ROA $=$ Return on Asset, $\mathrm{ROE}=$ Return on Equity $\mathrm{NPM}=$ Net Profit Margin, CAR $=$ Capital Adequacy Ratio, NPL $=$ Non-performing Loans, TTL $=$ Total Loans $\mathrm{NIM}=$ Net Interest Margin, $\mathrm{CL}=$ Classified Loan, Prov. $=$ Provision 
Table 5. Coefficient of Variance of the Ratios (2001 to 2006)

Coefficient of Variance (CV) of Return Ratios

\begin{tabular}{|c|c|c|c|c|c|}
\hline Ratio & G1 & G2 & G3 & IA & IB \\
\hline EPS & 0.61 & 1.14 & $0.15 \#$ & 0.72 & $1.91^{*}$ \\
\hline P/E & 2.18 & 1.24 & $0.97 \#$ & 1.68 & $2.31^{*}$ \\
\hline ROA & 0.41 & 0.23 & $0.07 \#$ & 0.16 & $0.70^{*}$ \\
\hline ROE & $0.44^{*}$ & 0.18 & $0.11 \#$ & 0.16 & 0.19 \\
\hline NIM & $0.44^{*}$ & 0.14 & $0.09 \#$ & 0.43 & 0.22 \\
\hline NPM & 0.38 & 0.29 & $0.08 \#$ & 0.18 & $0.95^{*}$ \\
\hline Efficiency & 0.13 & $0.68^{*}$ & 0.22 & 0.18 & $0.12 \#$ \\
\hline
\end{tabular}

Coefficient of Variance (CV) of Risk Ratios

\begin{tabular}{|c|c|c|c|c|c|}
\hline Ratio & G1 & G2 & G3 & IA & IB \\
\hline CAR & 0.11 & 0.10 & $0.14^{*}$ & $0.09 \#$ & 0.10 \\
\hline NPL to TTL & $0.64^{*}$ & $0.29 \#$ & 0.45 & 0.42 & 0.37 \\
\hline Credit to Deposit & 0.08 & 0.10 & 0.09 & $0.07 \#$ & $0.15^{*}$ \\
\hline Credit to Total Asset & 0.10 & 0.10 & 0.11 & $0.09 \#$ & $0.11^{*}$ \\
\hline Prov. for CL to Gross Loan & $0.40^{*}$ & 0.26 & 0.35 & $0.21 \#$ & 0.25 \\
\hline
\end{tabular}

Source: Authors' own construction from the Data.

G1 = Generation 1, G2 = Generation 2, Generation 3, IA = Industry Average, IB = Islamic Banks

EPS $=$ Earnings per Share, $\mathrm{P} / \mathrm{E}=$ Price Earnings Ratio, ROA $=$ Return on Asset, ROE = Return on Equity

NPM $=$ Net Profit Margin, CAR $=$ Capital Adequacy Ratio, NPL = Non-performing Loans, TTL $=$ Total Loans

$\mathrm{NIM}=$ Net Interest Margin, $\mathrm{CL}=$ Classified Loan, Prov. $=$ Provision

* Highest result of $\mathrm{CV}$, which represents a bad sign, \# lowest result of $\mathrm{CV}$, which represents a good signal 
Table 6. Common Size Balance Sheet

\begin{tabular}{|c|c|c|c|c|c|c|c|c|c|c|}
\hline \multirow{2}{*}{ Items } & \multicolumn{5}{|c|}{2001} & \multicolumn{5}{|c|}{2002} \\
\hline & G1 & G2 & G3 & IA & IB & G1 & G2 & G3 & IA & IB \\
\hline Cash \& Equivalent & 0.16 & 0.25 & 0.20 & 0.21 & 0.31 & 0.13 & 0.19 & 0.18 & 0.17 & 0.25 \\
\hline $\begin{array}{c}\text { Money at Call and Short } \\
\text { Notice }\end{array}$ & 0.05 & 0.06 & 0.06 & 0.06 & 0.01 & 0.05 & 0.04 & 0.04 & 0.05 & 0.01 \\
\hline Total Investment and Loans & 0.59 & 0.64 & 0.64 & 0.63 & 0.63 & 0.65 & 0.72 & 0.73 & 0.70 & 0.70 \\
\hline Fixed Assets & 0.02 & 0.01 & 0.01 & 0.01 & 0.02 & 0.02 & 0.01 & 0.01 & 0.01 & 0.02 \\
\hline Other Assets & 0.06 & 0.03 & 0.06 & 0.05 & 0.03 & 0.05 & 0.03 & 0.04 & 0.04 & 0.03 \\
\hline Borrowings & 0.03 & 0.06 & 0.09 & 0.06 & 0.00 & 0.01 & 0.03 & 0.03 & 0.03 & 0.00 \\
\hline Total Deposits & 0.76 & 0.83 & 0.76 & 0.79 & 0.91 & 0.78 & 0.85 & 0.83 & 0.83 & 0.90 \\
\hline Total Liabilities & 0.96 & 0.95 & 0.94 & 0.95 & 0.97 & 0.96 & 0.96 & 0.95 & 0.95 & 0.98 \\
\hline Total Equity & 0.04 & 0.05 & 0.06 & 0.05 & 0.05 & 0.04 & 0.04 & 0.05 & 0.04 & 0.02 \\
\hline \multirow[t]{2}{*}{ Statutory Reserve } & 0.01 & 0.01 & 0.01 & 0.01 & 0.01 & 0.01 & 0.01 & 0.01 & 0.01 & 0.01 \\
\hline & \multicolumn{5}{|c|}{2003} & \multicolumn{5}{|c|}{2004} \\
\hline Cash \& Equivalent & 0.14 & 0.18 & 0.13 & 0.15 & 0.24 & 0.13 & 0.15 & 0.11 & 0.13 & 0.22 \\
\hline $\begin{array}{c}\text { Money at Call and Short } \\
\text { Notice }\end{array}$ & 0.03 & 0.03 & 0.07 & 0.05 & 0.01 & 0.03 & 0.15 & 0.03 & 0.04 & 0.00 \\
\hline Total Investment and Loans & 0.75 & 0.69 & 0.70 & 0.71 & 0.60 & 0.77 & 0.74 & 0.83 & 0.78 & 0.72 \\
\hline Fixed Assets & 0.02 & 0.01 & 0.01 & 0.01 & 0.02 & 0.02 & 0.01 & 0.01 & 0.01 & 0.02 \\
\hline Other Assets & 0.05 & 0.04 & 0.03 & 0.04 & 0.04 & 0.05 & 0.04 & 0.03 & 0.04 & 0.05 \\
\hline Borrowings & 0.01 & 0.04 & 0.02 & 0.03 & 0.00 & 0.01 & 0.05 & 0.07 & 0.05 & 0.00 \\
\hline Total Deposits & 0.81 & 0.84 & 0.82 & 0.82 & 0.88 & 0.85 & 0.83 & 0.81 & 0.83 & 0.87 \\
\hline Total Liabilities & 0.96 & 0.95 & 0.92 & 0.94 & 0.97 & 0.95 & 0.95 & 0.93 & 0.94 & 0.96 \\
\hline Total Equity & 0.04 & 0.05 & 0.08 & 0.06 & 0.03 & 0.05 & 0.05 & 0.07 & 0.06 & 0.04 \\
\hline \multirow[t]{2}{*}{ Statutory Reserve } & 0.01 & 0.02 & 0.01 & 0.01 & 0.01 & 0.02 & 0.02 & 0.02 & 0.02 & 0.01 \\
\hline & \multicolumn{5}{|c|}{2005} & \multicolumn{5}{|c|}{2006} \\
\hline Cash \& Equivalent & 0.13 & 0.11 & 0.13 & 0.12 & 0.19 & 0.12 & 0.10 & 0.14 & 0.12 & 0.16 \\
\hline $\begin{array}{c}\text { Money at Call and Short } \\
\text { Notice }\end{array}$ & 0.02 & 0.03 & 0.01 & 0.02 & 0.00 & 0.01 & 0.01 & 0.01 & 0.01 & 0.00 \\
\hline Total Investment and Loans & 0.78 & 0.82 & 0.82 & 0.80 & 0.77 & 0.79 & 0.84 & 0.81 & 0.81 & 0.80 \\
\hline Fixed Assets & 0.02 & 0.01 & 0.01 & 0.01 & 0.01 & 0.02 & 0.01 & 0.01 & 0.01 & 0.01 \\
\hline Other Assets & 0.06 & 0.03 & 0.03 & 0.04 & 0.03 & 0.05 & 0.03 & 0.03 & 0.04 & 0.04 \\
\hline Borrowings & 0.02 & 0.05 & 0.03 & 0.03 & 0.03 & 0.01 & 0.02 & 0.03 & 0.02 & 0.03 \\
\hline Total Deposits & 0.84 & 0.82 & 0.84 & 0.83 & 0.83 & 0.85 & 0.84 & 0.85 & 0.85 & 0.83 \\
\hline Total Liabilities & 0.95 & 0.93 & 0.94 & 0.94 & 0.94 & 0.94 & 0.93 & 0.93 & 0.93 & 0.93 \\
\hline Total Equity & 0.05 & 0.07 & 0.06 & 0.06 & 0.06 & 0.06 & 0.07 & 0.07 & 0.07 & 0.07 \\
\hline Statutory Reserve & 0.02 & 0.02 & 0.01 & 0.02 & 0.01 & 0.02 & 0.02 & 0.02 & 0.02 & 0.02 \\
\hline
\end{tabular}

Source: Authors' own construction from the Data.

G1 = Generation 1, G2 = Generation 2, Generation 3, IA = Industry Average, IB = Islamic Banks 
Table 7. Common Size Income Statement

\begin{tabular}{|c|c|c|c|c|c|c|c|c|c|c|}
\hline \multirow{2}{*}{ Items } & \multicolumn{5}{|c|}{2001} & \multicolumn{5}{|c|}{2002} \\
\hline & G1 & G2 & G3 & IA & IB & G1 & G2 & G3 & IA & IB \\
\hline Interest Expense & 0.70 & 0.71 & 0.72 & 0.71 & 0.74 & 0.71 & 0.78 & 0.71 & 0.74 & 0.84 \\
\hline Total Operating Income & 0.76 & 0.55 & 0.63 & 0.63 & 0.50 & 0.73 & 0.46 & 0.62 & 0.58 & 0.38 \\
\hline Total Operating Expense & 0.34 & 0.20 & 0.24 & 0.25 & 0.21 & 0.41 & 0.22 & 0.24 & 0.28 & 0.24 \\
\hline $\begin{array}{c}\text { Provision Against Classified } \\
\text { Loan }\end{array}$ & 0.15 & 0.05 & 0.05 & 0.08 & 0.05 & 0.18 & 0.04 & 0.06 & 0.08 & 0.04 \\
\hline Total Provision & 0.19 & 0.08 & 0.09 & 0.12 & 0.09 & 0.20 & 0.06 & 0.08 & 0.10 & 0.05 \\
\hline Provision for Tax & 0.09 & 0.09 & 0.12 & 0.10 & 0.07 & 0.07 & 0.11 & 0.12 & 0.10 & 0.09 \\
\hline Net Profit / Loss After Tax & 0.13 & 0.17 & 0.18 & 0.16 & 0.13 & 0.06 & 0.08 & 0.17 & 0.10 & 0.00 \\
\hline Appropriation & 0.10 & 0.13 & 0.14 & 0.12 & 0.12 & 0.06 & 0.04 & 0.17 & 0.09 & 0.14 \\
\hline \multirow[t]{2}{*}{ Retained Earnings } & 0.07 & 0.08 & 0.08 & 0.08 & 0.04 & 0.08 & 0.14 & 0.05 & 0.10 & 0.21 \\
\hline & \multicolumn{5}{|c|}{2003} & \multicolumn{5}{|c|}{2004} \\
\hline Interest Expense & 0.71 & 0.76 & 0.60 & 0.69 & 0.81 & 0.71 & 0.73 & 0.68 & 0.71 & 0.77 \\
\hline Total Operating Income & 0.74 & 0.50 & 0.57 & 0.58 & 0.44 & 0.89 & 0.57 & 0.72 & 0.70 & 0.48 \\
\hline Total Operating Expense & 0.39 & 0.21 & 0.20 & 0.25 & 0.21 & 0.47 & 0.24 & 0.23 & 0.29 & 0.22 \\
\hline $\begin{array}{l}\text { Provision Against Classified } \\
\text { Loan }\end{array}$ & 0.20 & 0.03 & 0.07 & 0.09 & 0.06 & 0.12 & 0.06 & 0.09 & 0.08 & 0.07 \\
\hline Total Provision & 0.21 & 0.05 & 0.06 & 0.09 & 0.08 & 0.14 & 0.07 & 0.10 & 0.09 & 0.08 \\
\hline Provision for Tax & 0.09 & 0.13 & 0.14 & 0.12 & 0.10 & 0.18 & 0.12 & 0.18 & 0.16 & 0.10 \\
\hline Net Profit / Loss After Tax & 0.04 & 0.09 & 0.16 & 0.11 & 0.04 & 0.11 & 0.13 & 0.21 & 0.15 & 0.09 \\
\hline Appropriation & 0.03 & -0.02 & 0.19 & 0.07 & 0.09 & 0.10 & 0.01 & 0.24 & 0.11 & 0.15 \\
\hline \multirow[t]{2}{*}{ Retained Earnings } & 0.07 & 0.09 & 0.14 & 0.10 & 0.16 & 0.08 & 0.05 & 0.03 & 0.05 & 0.07 \\
\hline & \multicolumn{5}{|c|}{2005} & \multicolumn{5}{|c|}{2006} \\
\hline Interest Expense & 0.67 & 0.69 & 0.72 & 0.69 & 0.69 & 0.65 & 0.71 & 0.75 & 0.70 & 0.70 \\
\hline Total Operating Income & 0.90 & 0.62 & 0.53 & 0.68 & 0.51 & 0.83 & 0.61 & 0.49 & 0.64 & 0.48 \\
\hline Total Operating Expense & 0.47 & 0.23 & 0.20 & 0.30 & 0.21 & 0.48 & 0.21 & 0.19 & 0.29 & 0.18 \\
\hline $\begin{array}{c}\text { Provision Against Classified } \\
\text { Loan }\end{array}$ & 0.16 & 0.06 & 0.03 & 0.09 & 0.06 & 0.06 & 0.04 & 0.03 & 0.04 & 0.04 \\
\hline Total Provision & 0.18 & 0.09 & 0.07 & 0.11 & 0.06 & 0.07 & 0.07 & 0.06 & 0.07 & 0.05 \\
\hline Provision for Tax & 0.14 & 0.14 & 0.15 & 0.14 & 0.14 & 0.14 & 0.16 & 0.13 & 0.14 & 0.14 \\
\hline Net Profit / Loss After Tax & 0.10 & 0.16 & 0.17 & 0.14 & 0.16 & 0.14 & 0.17 & 0.15 & 0.15 & 0.16 \\
\hline Appropriation & 0.13 & 0.10 & 0.11 & 0.12 & 0.08 & 0.06 & 0.10 & 0.09 & 0.08 & 0.06 \\
\hline Retained Earnings & 0.05 & 0.06 & 0.09 & 0.07 & 0.07 & 0.10 & 0.09 & 0.08 & 0.09 & 0.11 \\
\hline
\end{tabular}

Source: Authors' own construction from the Data.

G1 = Generation 1, G2 = Generation 2, Generation 3, IA = Industry Average, IB = Islamic Banks 
Table 8. Mean of Common Size Items

\begin{tabular}{|c|c|c|c|c|c|}
\hline \multicolumn{6}{|c|}{ Mean of Common Size Balance Sheet (2001 to 2006) } \\
\hline Items & G1 & G2 & G3 & IA & IB \\
\hline Cash \& Equivalent & 0.14 & 0.16 & 0.15 & 0.15 & 0.23 \\
\hline Money at Call and Short Notice & 0.03 & 0.05 & 0.04 & 0.04 & 0.00 \\
\hline Total Investment and Loans & 0.72 & 0.74 & 0.75 & 0.74 & 0.70 \\
\hline Fixed Assets & 0.02 & 0.01 & 0.01 & 0.01 & 0.01 \\
\hline Other Assets & 0.05 & 0.03 & 0.03 & 0.04 & 0.04 \\
\hline Borrowings & 0.02 & 0.04 & 0.05 & 0.04 & 0.01 \\
\hline Total Deposits & 0.82 & 0.83 & 0.82 & 0.82 & 0.87 \\
\hline Total Liabilities & 0.95 & 0.95 & 0.94 & 0.94 & 0.96 \\
\hline Total Equity & 0.05 & 0.05 & 0.06 & 0.06 & 0.04 \\
\hline Statutory Reserve & 0.02 & 0.02 & 0.01 & 0.01 & 0.01 \\
\hline \multicolumn{6}{|c|}{ Mean of Common Size Income Statement (2001 to 2006) } \\
\hline Items & $\overline{\text { G1 }}$ & $\overline{G 2}$ & $\overline{G 3}$ & $\overline{\mathbf{I A}}$ & IB \\
\hline Interest Expense & 0.69 & 0.73 & 0.70 & 0.71 & 0.76 \\
\hline Total Operating Income & 0.81 & 0.55 & 0.59 & 0.64 & 0.46 \\
\hline Total Operating Expense & 0.43 & 0.22 & 0.22 & 0.28 & 0.21 \\
\hline Provision Against Classified Loan & 0.15 & 0.05 & 0.05 & 0.08 & 0.05 \\
\hline Total Provision & 0.17 & 0.07 & 0.08 & 0.10 & 0.07 \\
\hline Provision for Tax & 0.12 & 0.12 & 0.14 & 0.13 & 0.10 \\
\hline Net Profit / Loss After Tax & 0.10 & 0.13 & 0.17 & 0.14 & 0.10 \\
\hline Appropriation & 0.08 & 0.06 & 0.16 & 0.10 & 0.11 \\
\hline Retained Earnings & 0.08 & 0.09 & 0.08 & 0.08 & 0.11 \\
\hline \multicolumn{6}{|c|}{ Standard Deviation of Common Size Balance Sheet (2001 to 2006) } \\
\hline Items & G1 & G2 & G3 & $\mathbf{I A}$ & IB \\
\hline Cash \& Equivalent & 0.01 & 0.06 & 0.03 & 0.04 & 0.05 \\
\hline Money at Call and Short Notice & 0.02 & 0.05 & 0.02 & 0.02 & 0.01 \\
\hline Total Investment and Loans & 0.08 & 0.08 & 0.08 & 0.07 & 0.08 \\
\hline Fixed Assets & 0.00 & 0.00 & 0.00 & 0.00 & 0.00 \\
\hline Other Assets & 0.00 & 0.01 & 0.01 & 0.00 & 0.01 \\
\hline Borrowings & 0.01 & 0.01 & 0.03 & 0.02 & 0.02 \\
\hline Total Deposits & 0.04 & 0.01 & 0.03 & 0.02 & 0.03 \\
\hline Total Liabilities & 0.01 & 0.01 & 0.01 & 0.01 & 0.02 \\
\hline Total Equity & 0.01 & 0.01 & 0.01 & 0.01 & 0.02 \\
\hline Statutory Reserve & 0.00 & 0.00 & 0.00 & 0.00 & 0.00 \\
\hline \multicolumn{6}{|c|}{ Standard Deviation of Common Size Income Statement (2001 to 2006) } \\
\hline Items & G1 & G2 & G3 & IA & IB \\
\hline Interest Expense & 0.03 & 0.04 & 0.05 & 0.02 & 0.06 \\
\hline Total Operating Income & 0.08 & 0.06 & 0.08 & 0.05 & 0.05 \\
\hline Total Operating Expense & 0.05 & 0.02 & 0.02 & 0.02 & 0.02 \\
\hline Provision Against Classified Loan & 0.05 & 0.01 & 0.02 & 0.02 & 0.01 \\
\hline Total Provision & 0.06 & 0.02 & 0.02 & 0.02 & 0.02 \\
\hline Provision for Tax & 0.04 & 0.02 & 0.02 & 0.02 & 0.03 \\
\hline Net Profit / Loss After Tax & 0.04 & 0.04 & 0.02 & 0.03 & 0.07 \\
\hline Appropriation & 0.04 & 0.06 & 0.06 & 0.02 & 0.04 \\
\hline Retained Earnings & 0.02 & 0.03 & 0.04 & 0.02 & 0.06 \\
\hline
\end{tabular}

Source: Authors' own construction from the Data.

G1 = Generation 1, G2 = Generation 2, Generation 3, IA = Industry Average, IB = Islamic Banks 
Table 9. Coefficient of Variance (CV) of Common Size Items

\begin{tabular}{|c|c|c|c|c|c|}
\hline CV of Common Size Balance Sheet (2001 to 2006) \\
\hline Items & G1 & G2 & G3 & IA & IB \\
\hline Cash \& Equivalent & $0.11 \#$ & $0.35^{*}$ & 0.23 & 0.24 & 0.23 \\
\hline Money at Call and Short Notice & 0.50 & 0.91 & 0.62 & $0.46 \#$ & $1.20^{*}$ \\
\hline Total Investment and Loans & 0.11 & 0.10 & 0.10 & $0.10 \#$ & $0.11^{*}$ \\
\hline Fixed Assets & 0.11 & $0.06 \#$ & 0.15 & 0.07 & $0.22^{*}$ \\
\hline Other Assets & $0.06 \#$ & 0.19 & $0.34^{*}$ & 0.09 & 0.23 \\
\hline Borrowings & 0.54 & $0.32 \#$ & 0.58 & 0.42 & $1.41^{*}$ \\
\hline Total Deposits & $0.05^{*}$ & $0.01 \#$ & 0.04 & 0.02 & 0.04 \\
\hline Total Liabilities & 0.01 & 0.01 & 0.01 & $0.01 \#$ & $0.02^{*}$ \\
\hline Total Equity & 0.16 & 0.18 & 0.17 & $0.14 \#$ & $0.38^{*}$ \\
\hline Statutory Reserve & $0.13 \#$ & 0.18 & 0.23 & 0.16 & $0.28^{*}$ \\
\hline
\end{tabular}

CV of Common Size Income Statement (2001 to 2006)

\begin{tabular}{|c|c|c|c|c|c|}
\hline Items & G1 & G2 & G3 & IA & IB \\
\hline Interest Expense & 0.04 & 0.05 & 0.07 & $0.03 \#$ & $0.08^{*}$ \\
\hline Total Operating Income & 0.09 & 0.11 & $0.14^{*}$ & $0.08 \#$ & 0.10 \\
\hline Total Operating Expense & $0.13^{*}$ & $0.07 \#$ & 0.11 & 0.08 & 0.08 \\
\hline Provision Against Classified Loan & 0.33 & 0.26 & $0.42^{*}$ & $0.21 \#$ & 0.26 \\
\hline Total Provision & $0.33^{*}$ & 0.24 & 0.21 & $0.18 \#$ & 0.23 \\
\hline Provision for Tax & $0.36^{*}$ & 0.18 & $0.16 \#$ & 0.19 & 0.28 \\
\hline Net Profit / Loss After Tax & 0.38 & 0.31 & $0.11^{*}$ & $0.19 \#$ & 0.66 \\
\hline Appropriation & 0.46 & $1.02^{*}$ & 0.36 & $0.22 \#$ & 0.34 \\
\hline Retained Earnings & $0.22 \#$ & 0.38 & 0.48 & 0.26 & $0.58^{*}$ \\
\hline
\end{tabular}

Source: Authors' own construction from the Data.

G1 = Generation 1, G2 = Generation 2, Generation 3, IA = Industry Average, IB = Islamic Banks

$*=$ Highest result of $C V$, which represents a bad signal.

\# = Lowest result of $C V$, which represents a good signal 
Table 10. Mean Ranking of the Ratios

Mean of Return Ratios

\begin{tabular}{|c|c|c|c|c|c|}
\hline Ratio & G1 & G2 & G3 & IA & IB \\
\hline EPS & $156.265(1)$ & $82.837(4)$ & $42.780(5)$ & $96.008(3)$ & $111.311(2)$ \\
\hline P/E & $133.594(2)$ & $20.102(4)$ & $5.547(5)$ & $55.550(3)$ & $185.740(1)$ \\
\hline ROA & $0.006(5)$ & $0.011(2)$ & $0.015(1)$ & $0.011(3)$ & $0.007(4)$ \\
\hline ROE & $0.127(5)$ & $0.223(2)$ & $0.242(1)$ & $0.203(4)$ & $0.207(3)$ \\
\hline NIM & $0.033(1)$ & $0.028(3)$ & $0.030(2)$ & $0.026(5)$ & $0.027(4)$ \\
\hline NPM & $0.099(4)$ & $0.132(3)$ & $0.180(1)$ & $0.139(2)$ & $0.084(5)$ \\
\hline Efficiency** & $0.720(5)$ & $0.478(1)$ & $0.496(2)$ & $0.540(3)$ & $0.549(4)$ \\
\hline
\end{tabular}

Mean of Risk Ratios

\begin{tabular}{|c|c|c|c|c|c|}
\hline Ratio & G1 & G2 & G3 & IA & IB \\
\hline CAR & $0.090(4)$ & $0.104(2)$ & $0.108(1)$ & $0.102(3)$ & $0.087(5)$ \\
\hline NPL to TTL** & $0.138(5)$ & $0.063(2)$ & $0.053(1)$ & $0.087(4)$ & $0.075(3)$ \\
\hline Credit to Deposit** $^{* *}$ & $0.769(5)$ & $0.791(2)$ & $0.792(1)$ & $0.783(4)$ & $0.786(3)$ \\
\hline${ }^{1}$ Credit to Total Asset** & $0.623(1)$ & $0.653(4)$ & $0.651(3)$ & $0.643(2)$ & $0.679(5)$ \\
\hline${ }^{2}$ Prov. for CL to Gross Loan** & $0.013(5)$ & $0.006(3)$ & $0.006(2)$ & $0.008(4)$ & $0.006(1)$ \\
\hline
\end{tabular}

** A Higher ratio might bring bad result.

${ }^{1}$ Higher Credit to Total Asset ratio would increase the chances of default risk, but will also increase the profitability. Since we are considering risk with this, higher result will be taken as worse performance.

2 Higher amount of provision against classified loans give a bad signal to the market, since this may reduce profitability and it is a result of higher default risk. So, a higher figure will be considered as worse performance.

G1 = Generation 1, G2 = Generation 2, Generation 3, IA = Industry Average, IB = Islamic Banks

Source: Authors' own construction from the Data 
BOX 1. Return and Risk Ratios

\section{Return Ratios}

1. $\quad$ Earnings Per Share $=\frac{\text { Net Income }}{\text { No. of Share Outstanding }}$

2. Price Earning Ratio $(\mathrm{P} / \mathrm{E}$ Ratio $)=\frac{\text { Market Price Per Share }}{\text { Earnings Per Share }}$

3. $\quad$ Return on Asset $=\frac{\text { Net Income }}{\text { Total Assets }} \times 100$

4. Return on Equity $=\frac{\text { Net Income }}{\text { Total Equity }} \times 100$

5. Net Interest Margin $=\frac{\text { Interest Income }- \text { Interest Expenses }}{\text { Call Money }+ \text { ST Investment }+ \text { Loan \& Advances }} \times 100$

6. Net Profit Margin $(\mathrm{NPM})=\frac{\text { Net Income after Tax }}{\text { Interest Income }} \times 100$

7. Efficiency $=\frac{\text { Total operating expense }+ \text { Total provisions }}{(\text { Int. Inc }- \text { Int. Exp. })+(\text { Investment Inc. }+ \text { Commission }+ \text { Other Opt. Inc. })} \times 100$

\section{Risk Ratios}

8. Capital Adequacy Ratio $(\mathrm{CAR})=\frac{\text { Total Capital Reserve }}{\text { Total Risk Weighted Assets }} \times 100$

9. NPL to Total Loans $=\frac{\text { Bad Loans }}{\text { Total Loans }} \times 100$

10. Credit to Deposit Ratio $=\frac{\text { Total Loans }}{\text { Total Deposits }} \times 100$

11. Credit to Total Asset Ratio $=\frac{\text { Total Loans }}{\text { Total Assets }} \times 100$

12. Provision for Classified Loans to Gross Loans $=\frac{\text { Provision for Classified Loans }}{\text { Gross Loans }} \times 100$

Source: Hempel and Simonson (1999) 


\title{
The Impact of Spatial Externalities on the Economic Convergence in the Euro Mediterranean Countries
}

\author{
Amina NACEUR SBOUI \\ Faculty of economic sciences, Tunis El Manar University, Tunisia \\ Tel: 216- 97-439-064 E-mail: naceuramina@yahoo.fr \\ Mohamed Amine HAMMAS \\ Faculty of Economic Sciences of Sousse, Tunisia \\ Tel: 216 -22 -416- $443 \quad$ E-mail: hammasamine@yahoo.fr
}

\begin{abstract}
Recent models of economic growth have underlined the importance of external effects on the accumulation of factors of production (ROMER 1986, 1990; LUCAS 1988). The technology knowledge rises with stock of factors of production (human capital, physical capital, $\mathrm{R} \& \mathrm{D}$, etc.) to which all the producers contribute with identical manner. The idea is that the knowledge is considered as a free good and spread in entire economy. However, this new approach brings more explanation of economic growth; but it doesn't integrate the spatial dimension of these externalities.
\end{abstract}

In this paper, the analysis that we wish to present aims to demonstrate that the external effects on the accumulation of factors of production have a geographic dimension and they affect the regional convergence.

Adopting this new hypothesis, we derive an equation of convergence with external effects issue from the Mankiw, Romer \& Weil (1992) model, and we propose to estimate it with the recent methods of spatial econometrics to test the presence of these externalities and to estimate their effects on the economic convergence.

For the empirical validation, relying on a panel of 26 euro Mediterranean countries over the period 1995-2004, and using the matrix of distance and the matrix of contiguity to measure the interactions between these countries, we estimate the equation of convergence with spatial externalities derived from the model of Mankiw, Romer \& Weil (1992).

The results of estimation based on the integration of spatial dimension of externalities permit to appreciate better than the a-spatial growth theory, the effects of these externalities on the economic convergence in the case of economic integration in space. They allow to quantify a double effect of geographic spillovers and to valid the hypothesis that taking account of spatial externalities doesn't necessarily reduce the divergence between the North and the South Mediterranean countries. The reason of the persistence of this divergence is related to the absence of efficient interactions and coordination between these countries.

Keywords: External effects, Economic convergence, Spatial econometrics, Economic integration

\section{Introduction}

Recent models of endogenous growth have considered the importance of external effects on the accumulation of factor of production. A first approach (Romer, 1986; Lucas, 1988) tries to endogenous the technology by the "Marshallien externalities" on the stock of knowledge. The introduction of apprenticeship effects "learning by doing" permit to do of the knowledge a factor of production supplementary and to consider it as a joint output. The external effect proceeds from accrue of knowledge due to the increase of total stock of capital. Considered as a free good, meaning not perfectly appropriated by the producer, the knowledge is accessible freely and profit theoretically for all with the same manner.

A second approach (Romer, 1990; Aghion and Howitt, 1990) models explicitly the sector of research and its effects on the deepening of the technology innovation. The progress of technology proceeds then from a "production of technology" realised with a specialised activity of "R\&D" which is distinct from the production: 
- A first externality proceeds from the sector of « $R \& D »$ : each researcher has potentially to accede to the stock of accumulated knowledge in this sector for his own research.

- A second externality proceeds from the sector of production: with baying the intermediate goods, agents profit not only from this capital, but also from the increase of the technology incorporated in these goods of production.

These two explanations of technology progress, based on endogenous accumulation of knowledge, beget theoretically increasing returns to scale in the global level which can engender endogenous growth.

However, although this contribution, the theory of endogenous growth remains limited. Especially, because it doesn't takes into account of spatial dimension of these externalities and their role in explaining issues such as growth and economic convergence.

In this sense, the conjoint development of New Geographic Economy and the endogenous growth models in the 1990 years, have permit for economists to propose more appropriate approaches of problematic "innovation-localisation-growth" (Foray, 2000).

Essentially, the theoretical models of "New Geographic Economy-Endogenous Growth" (C.Baumont, 1995) support on the hypothesis of geographic dimension of externalities of knowledge for explaining the specificity of phenomenon of spatial concentration of innovation and dynamics of differentiated growth that proceeds.

Until the middle of 1990 years, this hypothesis hasn't any empirical validation. Thus, only lately those empirical studies had proposed to integrate the effects of spatial externalities on the regional growth (Amstrong, 1995; Rey and Montouri, 1999; López-Bazo et al, 1999). Their suggestions are consistent with predictions of endogenous growth models and new geographic economy that insist on the role of interactions between agents which are considered as the sources of agglomerations of activities of innovation in some regions and not in others (Fujita et al, 1999).

On this base, in our present work we consider that the external effects on the accumulation of factors of production (human capital and physical capital) are geographically burned and they influence the economic convergence.

For verifying it empirically, we privilege the methods of spatial econometrics which constitute a powerful tool to test the presence of spatial externalities and to estimate their impacts on the regional convergence.

Starting with this new approach, we adopt for our work the following structure:

- $\quad$ The first section will be reserved for developing the model of Mankiew, Romer and Weil (1992) which introduces in the function of production the external effects on the accumulation of production factors (human and physical capital stocks). We suggest that the equation of convergence derived from this model possess similarities with the specifications of spatial models used in spatial econometrics.

- $\quad$ On this base, in the second section, we will chow why these spatial models permit to test better the presence of spatial externalities and to estimate their effects on the economic convergence.

- In the third section, we will expose results of the empirical validation applied on a panel of 26 countries composed by fifteen counties of the European Union and the eleven Mediterranean south counties on the period 1995-2004.

- $\quad$ Finally, in the conclusion, we will resume the interpretations of results.

\section{Model of Mankiw, Romer and Weil (1992)}

In this section, we present the model growth with technological externalities of Mankiw, Romer and Weil (1992).

Formally, the model of M.R.W (1992) incorporates the human capital and physical capital in the function of production:

$$
y_{i t}=\mathrm{A}_{\text {it }} \mathrm{k}_{\mathrm{it}}^{\theta_{\mathrm{k}}} h_{i t}^{\theta_{\mathrm{h}}}
$$

Where, $y_{i t}$ is the level of income in region $\mathrm{i}$ and period $\mathrm{t}, \mathrm{k}_{\mathrm{it}}$ and $\mathrm{h}_{\mathrm{it}}$, the levels of physical capital and human capital and $\theta_{\ell}(\ell=\mathrm{k}, \mathrm{h})$ measures the average internal returns.

The level of technology $\mathrm{A}_{\mathrm{it}}$ in a region $\mathrm{i}$ reflect both an externality within the region $\mathrm{i}$ to investments in $\mathrm{k}$ and the technological interdependence across neighbouring regional economies. We have then,

$$
\mathrm{A}_{i t}=\Delta k_{i t}^{\delta_{k}} h_{i t}^{\delta_{h}}\left(k_{\rho i t}^{\theta_{k}} h_{\rho i t}^{\theta_{h}}\right)^{\gamma}
$$

Where, $\Delta$ is the level of exogenous technology, $\delta_{l} \quad(l=k, h)$ is the measure of external returns within the region to physical and human capital (caused by the effects of the accumulation of these factors in each region) and $\gamma$ measures the effect of spatial externalities between economies, that is assumed to be positive.

From this expression, we can observe that the M.R.W model considers, with a latent manner that the level of technology in a region depends on the accumulation of human capital and physical capital within a region i, but also on the 
accumulation of these factors in the neighbouring regions by the effect of spatial externalities. This chows that this model already predicts, but without demonstrates, that the external effects on the accumulation of factor of production are geographically burned.

Substituting [2] in [1], we obtain:

$$
y_{i t}=\Delta k_{i t}^{\left(\theta_{k}+\delta_{k}\right)} h_{i t}^{\left(\theta_{h}+\delta_{h}\right)} A_{\rho i t}^{\gamma}
$$

From this expression, we deduce a convergence equation, such as the dynamics in the proximity of the steady state is characterised by the following expression. (Note 1):

$$
\begin{aligned}
& g_{y}=\xi-\left(1-e^{-\beta T}\right) \ln y_{0}+\frac{\left(1-e^{-\beta T}\right) \gamma}{1-\left(\tau_{k}+\tau_{h}\right)} \ln y_{0 \rho}+\gamma g_{y \rho}+ \\
& \frac{\left(1-e^{-\beta T}\right)}{1-\left(\tau_{k}+\tau_{h}\right)}\left[\tau_{k}\left(\ln s_{k}-\ln (n+g+d)+\tau_{h}\left(\ln s_{h}-\ln (n+g+d)\right)\right)\right]
\end{aligned}
$$

Where, $\beta=\left(1-\tau_{k}-\tau_{h}\right)(n+g+d)$ is the spread of convergence, $\tau_{k}=\theta_{k}+\delta_{k}, \quad \tau_{h}=\theta_{h}+\delta_{h}$ et $\xi=(1+\gamma) g-\left(1-e^{-\beta T}\right)\left(1-\frac{\gamma}{1-\left(\tau_{k}+\tau_{h}\right)}\right)\left(\ln \Delta_{0}+g T\right)$

Equation [4] expresses that the growth in each region depends on the level of initial income in this region, as well as on the initial level and the growth of income in the neighbouring regions.

\section{Econometric specification}

The expression for growth equation [4] with externalities has much in common with the specifications defined in spatial econometrics. In fact, empirically, externalities across economies translate into dependence across the units of analysis.

Thus, under the assumption that there is information for $\mathrm{N}$ regions and $\mathrm{T}$ time periods, equation [4] could be rewritten as (including a well behaved error term):

$$
g_{y}=\alpha-\left(1-e^{-\beta}\right) \ln y_{0}+\lambda\left(1-e^{-\beta T}\right) W \ln y_{0}+\lambda W g_{y}+\varepsilon
$$

Where, for yearly data, gy denotes annual growth rates, a bold character represents a vector

$\left[\mathrm{N}^{*}(\mathrm{~T}-1) \quad \mathrm{x} 1\right.$ with the information for each region and time period $(\mathrm{t}=2, \ldots, \mathrm{T}$ for $\mathbf{g y}$ and $\mathrm{t}=1, \ldots, \mathrm{T}-1$ for $\mathbf{l n y}) . \mathrm{W} 1 \mathbf{g y}$ and W1Iny are the spatial lags for the growth rates and the initial level of income respectively. $\alpha$ collects any difference in the steady state across economies. It might be composed by variables approaching the factors including in [4]. Finally, $\mathrm{W} 1$ is a $\left[\mathrm{N}^{*}(\mathrm{~T}-1)\right] \mathrm{x}\left[\mathrm{N}^{*}(\mathrm{~T}-1)\right]$ matrix with the following general expression:

$$
W_{1}=\left[\begin{array}{ccccc}
W & 0 & 0 & . & 0 \\
0 & \mathrm{~W} & 0 & . & 0 \\
0 & 0 & \mathrm{~W} & . & 0 \\
\cdot & \cdot & \cdot & \cdot & \cdot \\
0 & 0 & 0 & . & \mathrm{W}
\end{array}\right]
$$

0 being a $(\mathrm{NxN})$ matrix of zeros and $\mathrm{W}$ a $(\mathrm{NxN})$ spatial matrix of weights.

This expression clearly indicates that technological externalities are associated to substantive phenomenon which implies that the growth in a region depends on the initial level of income and the initial and growth of income in 
neighbouring countries. Moreover, this expression explains why the empirical evidence based on the traditional spatial model selection procedure has shown preference for the spatial error specification. It is because the similarity between the expression in (5) and the spatial model of Durbin which derived from the spatial model with autocorrelation in errors.

We note that in the case of equation of convergence the spatial model with autocorrelation in errors is the following:

$$
g_{y}=\alpha-\left(1-e^{-\beta T}\right) \ln y+\varepsilon
$$

$$
\varepsilon=\lambda W_{1} \varepsilon+\mu
$$

Where, $\lambda$ is the parameter that expresses the intensity of spatial dependence between the residues of regression.

That in the spatial model of Durbin is:

$$
g_{. .}=\left(I-\lambda W_{1}\right) \alpha-\left(1-e^{-\beta}\right) \ln v+\lambda W_{1} g_{. .}+\lambda\left(1-e^{-\beta}\right) W_{1} \ln v+\mu
$$

The restrictions in the parameters involving growth rates and the initial conditions match those in our specification, but in the spatial model of Durbin the spatial lag of the variables affecting the steady state (summarised by $\alpha$ in the empirical specification) influences growth rates. If the spatial model of Durbin were to be correct, transitional dynamics for an economy would not only depend on the distance to its own steady-state but also on the distance of the neighbours to their steady state. In contrast, in our model, the latter distance does not exert any direct influence.

\subsection{Definition of weight matrix $W$ :}

The concept of weight matrix constitutes a fundamental element in Spatial Econometrics because it permits to model the interactions between observations. Generally, two principal conceptions are reserved to the determination of the elements of the weight matrix, respectively founded on the principle of contiguity and on the principle of distance.

The matrix of contiguity

The matrix of contiguity reposes on the sharing of a common frontier between spatial unities. Formally, a contiguity matrix represents each localisation of spatial system in line and in column. The "spatial weights" (elements of weight matrix) $w_{i j}$ of matrix of contiguity $\mathrm{W}$ are then defined by the following expression:

$$
w_{i j}= \begin{cases}1 & \text { if regions } \mathrm{i} \text { and } \mathrm{j} \text { are contiguiou } \mathrm{s} \text { for order } 1 . \\ 0 & \text { else. }\end{cases}
$$

Moreover, a same contiguity matrix can represent different arrangements of spatial units (Cliff et Ord, 1981, p. 21). Then, others weight matrices appear useful.

The matrix of distance

The matrix of distance reposes on the idea that two spatial units know high (respectively low) interaction that the distance between them is low (respectively high). Cliff and Ord $(1973,1981)$ are the first ones that used this type of specification, by combining a function of the reverse of the distance that separates two localisations and the relative length of their common frontier. However, recently the most current specifications in the empirical studies use expressions more simple for the spatial weights.

In our work, we carry a simple matrix of distance based on the reverse of the distances that separate spatial units. In this case the elements of this matrix $w_{i j}$ are defined as following:

$$
w_{i j}=1 / d_{i j}
$$

Where $d_{i j}$ is the distance that separate the centroids of countries $\mathrm{i}$ and $\mathrm{j}$.

However, the matrices of weights are standardised in lines for facilitating interpretation of spatial parameters after estimation. Thus, each line $\mathrm{i}$ of matrix of weight $\mathrm{W}$ is divided by the sum of elements $w_{i j}$ that compose it and the resulting spatial weights are: 


$$
w_{i j}^{s}=\frac{w_{i j}}{\sum_{j} w_{i j}}
$$

The standardisation of the matrix of weights permits to compare the spatial parameters issued from different models.

\section{Empirical evidence from the Euro Mediterranean countries}

In this section we estimate the equation of convergence with spatial externalities derived from Mankiw, Romer and Weil (1992) model. We will expose results of empirical validation on a specific sample of Euro Mediterranean countries that is composed from:

1) First, the fifteen countries of the European Union: Germany, France, Italy, Luxembourg, Netherlands, Greece, Spain, Portugal, Ireland, Denmark, Sweden, Finland, Austria, Belgium and United Kingdom.

2) Second, the eleven south Mediterranean countries: Algeria, Tunisia, Cyprus, Egypt, Israel, Lebanon, Jordan, Morocco, Turkey, Syria and Malta.

NB: for the reason of the absence of data availability, the country " Autonomy Palestinian Territory » will be excluded from the analysis.

The period of our analysis is 1995-2004. This period is particularly interesting for the analysis of the impact of spatial externalities on economic convergence, since it corresponds to crescent economic integration between the Euro Mediterranean countries, marked by acceleration of liberalisation of exchanges and by a widening of market. It corresponds also, after the reform of structural founds, to the existence of important regional political aiming to harmonise the potentialities of territories development.

The data that we use in this empirical validation are obtained from "World Indicator Data;W.I.D" version 2006. For panel data, we use thus the variable "growth of labour productivity between $\mathrm{t}$ and $\mathrm{t}-1, \mathrm{t}=2, \ldots, 10$ " as an endogenous variable. Annual data on labour productivity are obtained by dividing yearly data of "GDP at constant price 2000 " by yearly data of "number of population in employment".

Results of spatial dependence tests and results of estimation of spatial models will be plot using the contiguity matrix (equation 8) and distance matrix (equation 9).

\subsection{Estimation of absolute $\beta$-convergence model:}

Although our empirical specification incorporates the spatial dependence, the first step of our empirical work consists to estimate the absolute $\beta$-convergence model without any kinds of spillover:

$$
g_{y}=\alpha-\left(1-e^{-\beta T}\right) \ln y+\varepsilon
$$

\section{Our objective is to determine that the omission of introduction of spatial external effects constitute an insufficiency of absolute $\beta$-convergence model.}

We must note that in case of the estimation of a model with the method of panel data, the model can be with individual fixed effects (Within estimator) or with individual random effects (Estimator with GLS). The choice between these two models is based on the test of Hausman (1978), which is a test for specification of individual effects. The rule of decision of this test is the following: if the realisation of the statistic is higher than $\chi^{2}(\mathrm{~K})$. (Note 2 ) at $\alpha \%$ level (Note 3 ). , we reject the hypothesis null and we privilege the adoption of individual fixed effects and the Within estimator is unbiased. On the contrary, if the statistic of Hausman is smaller than $\chi^{2}(\mathrm{~K})$ at $\alpha \%$ level, we accept the hypothesis null and we privilege the adoption of random individual effects and the use of GLS estimator.

Results of estimation of the equation of convergence under the two specifications of panel are presented in the table 1.

- Results chow that for the two specifications the estimation of the speed of convergence is statistically significant at $5 \%$ level.

- The estimation of the model with random individual effects with the GLS method chows that the speed of convergence is more significant then in the case of the Within estimator (first column), this is explained by the fact that the GLS estimator uses the totality of information (within and between) and not only the intra individual information.

- We note that the test of Fisher is statistically significant indicating that the presence of individual effects. For a level of tolerance of $5 \%$, we remark that the value of the test of Hausman is law and not significant, indicating that the absence of the correlation between the regional specific effects and the explicative variables of model (the hypothesis $\mathrm{H}_{0}: \operatorname{corr}\left(\mu_{i}, X_{i t}\right)=0$ is not rejected). Thus, the estimators of the model with random effects are convergent (Mundlak, 1978). (Note 4). In this sense, we obtain a positive absolute convergence, but slaw because the speed of convergence in 
this model is $2.2 \%$. This value is near to $2 \%$ usually funded in the analysis of international convergence (Barro et Sala-I-Martin, 1995).

\subsection{Diagnostics of spatial dependence}

Spatial diagnostics are provided in table 2. We report five tests for spatial dependence: the Moran's I test, two Lagrange Multiplier tests for spatial error and spatial lag dependence ( $L M L A G, L M E R R)$, and two robust Lagrange Multiplier tests for spatial error and spatial lag dependence (RLMLAG and RLMERR) which are robust to the local presence of the other form of spatial dependence.

Results confirm the presence of spatial dependence in the equation of convergence. This chows that omission of introduction of spatial externalities constitutes an insufficiency of absolute $\beta$-convergence model. Details below explicit this confirmation:

- The first statistic reported is the Moran's I statistic for regression residuals (Cliff and Ord, 1981). This test is for the general presence of spatial dependence (Note 5), and does not allow us to discriminate between the spatial error and spatial lag models. The statistic is significant at the $5 \%$ level for all the standard regressions in Table 1, indicating that the residuals from the a-spatial regressions are spatially autocorrelated and that the standard models are misspecified.

- In order to discriminate between the two forms of spatial dependence (autoregressive spatial model or spatial model with autocorrelation in errors), we follow the decision rule suggested by Anselin and Florax (1995) and consider the Lagrange Multiplier (LM) tests for spatial error and spatial lag dependence and their robust counterparts. The four tests are significant at the $5 \%$ level. The test $L M E R R$ and its robust counterpart RLMERR (for spatial error autocorrelation) are higher than $L M L A G$ and its counterpart robust RLMLAG (for erroneously omitted spatial lag variable). This result chows that the equation of convergence with spatial autocorrelation in errors seems to be the more appropriate specification. In the next step of our work we present results of estimation of this specification.

\subsection{Estimation of absolute $\beta$-convergence model with spatial autocorrelation in errors}

In table 3 , we present results of estimation of absolute $\beta$-convergence model with spatial autocorrelation in errors (equation 6) in the case of random effects, with maximum likelihood method, using the matrix of distance (first column) and the matrix of contiguity (column 2). The interpretation of these results is as following:

- We note a slight increase of speed of convergence that attends $3.1 \%$ with the matrix of distance and $2.7 \%$ with matrix of contiguity. This result suggests that effects of proximity favour slightly the regional convergence process, but the letter remains relatively law.

- The estimation chows strong and positive spatial autocorrelation in error terms: $\hat{\lambda}=0,713$ with the matrix of distance and $\hat{\lambda}=0.614$ with the matrix of contiguity.

- Although the spatial parameter is high and statistically significant, the test of common factor is not significant, showing that the model with spatial autocorrelation in errors can be rewritten as a spatial model of Durbin constraint. (Note 6). This result confirms that our empirical specification (equation 8) resembles to the spatial model of Durbin constraint. On this base, it is than possible to estimate our empirical specification more efficiently, for analysing the impact of spatial externalities on economic convergence in Euro Mediterranean countries.

\subsection{Estimation of empirical specification}

Table 4 resumes results of estimation of the convergence equation with lag endogenous and lag exogenous variables (equation 8) in the case of random effects model, with maximum likelihood method. Interpretation of these results is the following:

- We note that parameters of model are positive and statistically significant and they are higher than values funded in the model with spatial autocorrelation in errors. This confirms that our empirical specification is the most appropriate to analysis the effect of spatial externalities on economic convergence in the Euro Mediterranean space.

- The estimation of this model permit to quantify a double effect of geographic spillovers: first, by the level of growth in neighbouring countries ( $\hat{\lambda}=0.930$ using the matrix of distance and $\hat{\lambda}=0.832$, using the matrix of contiguity). Second, by the level of initial labour productivity in neighbouring countries ( $\hat{\tau}=0.034$ (Note 7 ), using the matrix of distance and $\hat{\tau}=0.026$, using the matrix of contiguity).

This result confirms the theoretical predictions which suppose that the initial level of income in neighbouring countries affects the growth of a country by the effect of pecuniary and technological externalities. This effect can be considered us « supply-side externalities ». Also, growth in a country is high (respectively law), if the growth of neighbouring countries is also high (respectively law). This effect can be related to «demand-side externalities », as a consequence, for instance, of demand from neighbours for final goods or inputs produces in a country.

- $\quad$ Concerning the speed of convergence, we remark that its value doesn't increase significantly after the introduction of spatial externalities, as in the case of spatial model with autocorrelation of errors. 


\section{Conclusions}

In this paper, we analysed the impact of spatial externalities on the economic convergence in the Euro Mediterranean countries. We started by developing the model of Mankwi, Romer and Weil (1992) that introduces externalities between economies due to accumulation of human capital and physical capital. We have deduced from this model an equation of convergence that explains that the convergence to the steady state is related to externalities between countries.

To test the existence of these externalities and estimate their impact on economic convergence we are referred to recent methods of spatial econometrics.

For the empirical validation, relying on a panel of 26 euro méditerranean countrises over the period 1995-2004, we have estimated the equation of convergence with spatial externalities derived from the model of Mankiw, Romer \& Weil (1992). Following specificities of this sample we have exposed our empirical results on the base of contiguity matrix and distance matrix.

We have started our empirical analysis by estimating the absolute $\beta$-convergence model, our aim is to verify if the omission of spatial externalities constitutes an insufficiently of this model. Results of estimation have shown a low speed of convergence that takes value near to $2 \%$ usually funded in the analysis of international convergence (Barro and Sala-I-Martin, 1995). Besides, using the matrix of contiguity and the matrix of distance, the proceeding of research of spatial specification permit to confirm that the empirical specification resembles to the spatial model of Durbin, and thus we estimated our specification more efficiently.

The estimation of this model by the maximum likelihood method has shown that the growth in a country is positively affected by the investments and existents stocks in neighbouring countries. Also, results show that the introduction of spatial externalities hasn't affected the increase of speed of convergence in the Euro Mediterranean area.

These results have lines with theoretical conclusions evoked by "Geography-Growth synthesis" [Baumont and Huriot, 1999]. We think that the economic integration favour dynamic agglomeration by intermediate of regional interactions, but au contrary, the letter strengthens a cumulative agglomeration process.

Therefore, the political integration of markets can't favour the convergence between countries. The diminution of interaction costs (costs of transport and costs of transaction) makes more important the role of localised factors.

This accentuates the weights of initial conditions and contributes to the aggravation of cumulative divergence process and to persistence of diagrams "centre-periphery", that is traduced by a total geographical concentration of R\&D activities and of human capital and by a differentiated repartition of goods and services between countries. The specialisations of nations in innovation or in the fabrication of homogenous and traditional goods are flowed. Thus, the effects of economic integration in the Euro Mediterranean countries have engender an economic divergence process between the north and south countries due to the absence of sufficiently coordinate and interactions between them.

On this base, the efficacy of political integration amid the Euro Mediterranean space in sight of economic convergence will necessitate reinforcement of interactions between the north and south of Mediterranean, for example grace to a best application of Agreements of Barcelona and the New European Political of Neighbourhood and by the application of the proposition of the Union for the Mediterranean.

\section{References}

Abreu M. de Groot H.L.F. and R.J.G.M. Florax. (2005). Space and Growth: A Survey of Empirical Evidence and Methods. Région et Développement, 21, 13-44.

Acs Z and Varga A. (2002).Geography, endogenous growth and innovation. International Regional Science Review 25, 132 - 148 (Special issue on Regional Innovation Systems, edited by Z. Acs and Varga A).

Anselin L. (2001). Spatial Econometrics. In B. Baltagi (Szerk.) A Companion to Theoretical Econometrics. Oxford, Basil Blackwell, 310-330.

Anselin L and Rey SJ. (1991). Properties of tests for spatial dependence in linear regression models. Geographical Analysis, 23: 112-131.

Arbia G, Basile R and Salvatore M. (2003). Measuring spatial effects in parametric and nonparametric modelling of regional growth and convergence. mimeo, Univeristy G. D'Annunzio, Pescara, Italy.

Autant-Bernard et Massard Nadine. (2003)."Innovation and Local Externalities: Evidence and Ambiguities drawn from the Geography of Innovation".Working Paper CREUSET.

Autant-Bernard, C. (2001a). Science and knowledge flows: evidence from the French case. Research Policy, 30(7): 1069-1078.

Baumont C, Ertur C and Le Gallo J. (2001). A spatial econometric analysis of geographic spillovers and growth for 
European Regions, 1980-1995, LATEC - Document de travail - Economie \# 2001-04

Bernard A and Jones C. (1996). Productivity and convergence across U.S. States and industries. Empirical Economics, 21: 113-135.

Carlino G and Mills L. (1993). Are U.S. regional incomes converging? A time series analysis. Journal of Monetary Economics, 32: 335-346.

Chatterji M and Dewhurst J. (1996). Convergence clubs and relative economic performance in Great Britain: $1977-1991$. Regional Studies, 30: 31-40.

Ciccone, A. (1996). Dynamic externalities, spatial technology diffusion, and economic growth, University of California at Berkeley and University Pompeu Fabra, Mimeo. Journal of Common Market Studies, 33: 47-65.

Coe, D., and E. Helpman. (1995). International R\&D spillovers. European International Economic Review, 40, pp. 537-570.

Eaton, J., Kortum, S. (1999). International patenting and technology diffusion'. Economic Review, 39, pp. 859-887.

Fingleton B. (2003). Externalities, economic geography, and spatial econometrics: conceptual and modeling developments. International Regional Science Review, 26: 197-207.

Fingleton B. (2004). Regional economic growth and convergence: insights from a spatial econometric perspective, in Anselin L, Florax R and Rey S (Eds) Advances in Spatial Econometrics, Springer-Verlag, Berlin.

Fingleton B and López-Bazo. (2005). Empirical growth models with spatial effects. Manuscript.

Fingleton, B. and J.S.L. McCombie. (1998). Increasing returns and economic growth: Some evidence for manufacturing from the European Union regions. Oxford Economic Papers, 50, 89-105.

Florax, R. and H. Folmer. (1992). Specification and estimation of spatial linear regression models: Monte Carlo evaluation of pre-test estimators. Regional Science and Urban Economics, 22, pp. 404-432.

Keller, J. (1997). Are international R\&D spillovers trade-related? Analyzing externalities. Economics Letters, 53, pp. 227-232.

Le Gallo J. Ertur C. and Baumont C. (2003). A spatial econometric analysis of convergence across European regions, 1980-1995. In: Fingleton B (ed) European regional growth. Springer, Berlin, pp 99-129.

Le Gallo J. (2000). Econométrie spatiale 1 : Autocorrélation spatiale, document de travail du LATEC n²000-05, Université de Bourgogne, Dijon.

León-Ledesma MA. (2000). Economic growth and Verdoorn's law in the Spanish regions. International Review of Applied Economics, 14: 55-69.

López-Bazo E, Vayá E and Artís M. (2004). Regional externalities and growth: evidence from European regions. Journal of Regional Science, 44: 43-73.

López-Bazo E, Vayá E, Mora A, Suriñach J. (1999). Regional economic dynamics and convergence in the European union. Annals of Regional Science, 33: 343-370.

Mankiw, N.G., Romer, D. and D.N. Weil. (1992). A contribution to the empirics of economic growth, Quarterly Journal of Economics, 107, pp. 407-437.

Park, W.G. (1995). International R\&D spillovers and OECD economic growth. Economic Inquiry, 33, pp. 571-591.

Quah, D. (1996).Regional convergence clusters across Europe. European Economic Review, 40, pp. 951-958.

Raut, L.L. (1995). R\&D spillovers and productivity growth: evidence from Indian private firms. Journal of Development Economics, 48, pp. 1-23.

Ravallion, M. and J. Jalan. (1996). Growth divergence due to spatial externalities. Economics Letters, 53, pp. $227-232$.

Ravallion, M. and J. Jalan. (1996). Growth divergence due to spatial spillovers among randomly matched trade partners", National Bureau of Economic Research, nº 6065, Cambridge MA.

Rey, S.J., Montouri, B.D. (1999). U.S. regional income convergence: a spatial econometric perspective. Regional Studies, 33, 145-156.

Temple, J. (1999). The new growth evidence. Journal of Economic Literature, 37, 112-156.

Varga A. (2000). Local academic knowledge spillovers and the concentration of economic activity. Journal of Regional Science, 40, 289-309.

Varga A and Schalk H. (2004). Knowledge spillovers, agglomeration and macroeconomic growth. An empirical approach. Regional Studies, 38, 977-989. 


\section{Notes}

Note 1. Details on this transformation of convergence equation are given in the paper of López-Bazo E, Vayá E and Artís M (2004); Regional externalities and growth: evidence from European regions, Journal of Regional Science 44: 43-73.

Note 2. This is the number of freedom or also the number of exogenous variables.

Note 3 . This value is obtained from the table of $\chi^{2}$

Note 4. Details on the model with random effects and spatial dependence are presented in apendex .

Note 5. The test of Moran doesn't specify the alternative hypothesis for the absence of spatial autocorrelation.

Note 6. The test of the constraint of parameters is done with the test of ratio likelihood of common factor (Burridge, 1981).

Note 7. $\hat{\tau}=\hat{\lambda}\left(1-e^{-\hat{\beta}}\right)$

Table 1. Estimation of absolute $\beta$-convergence model (equation 11)

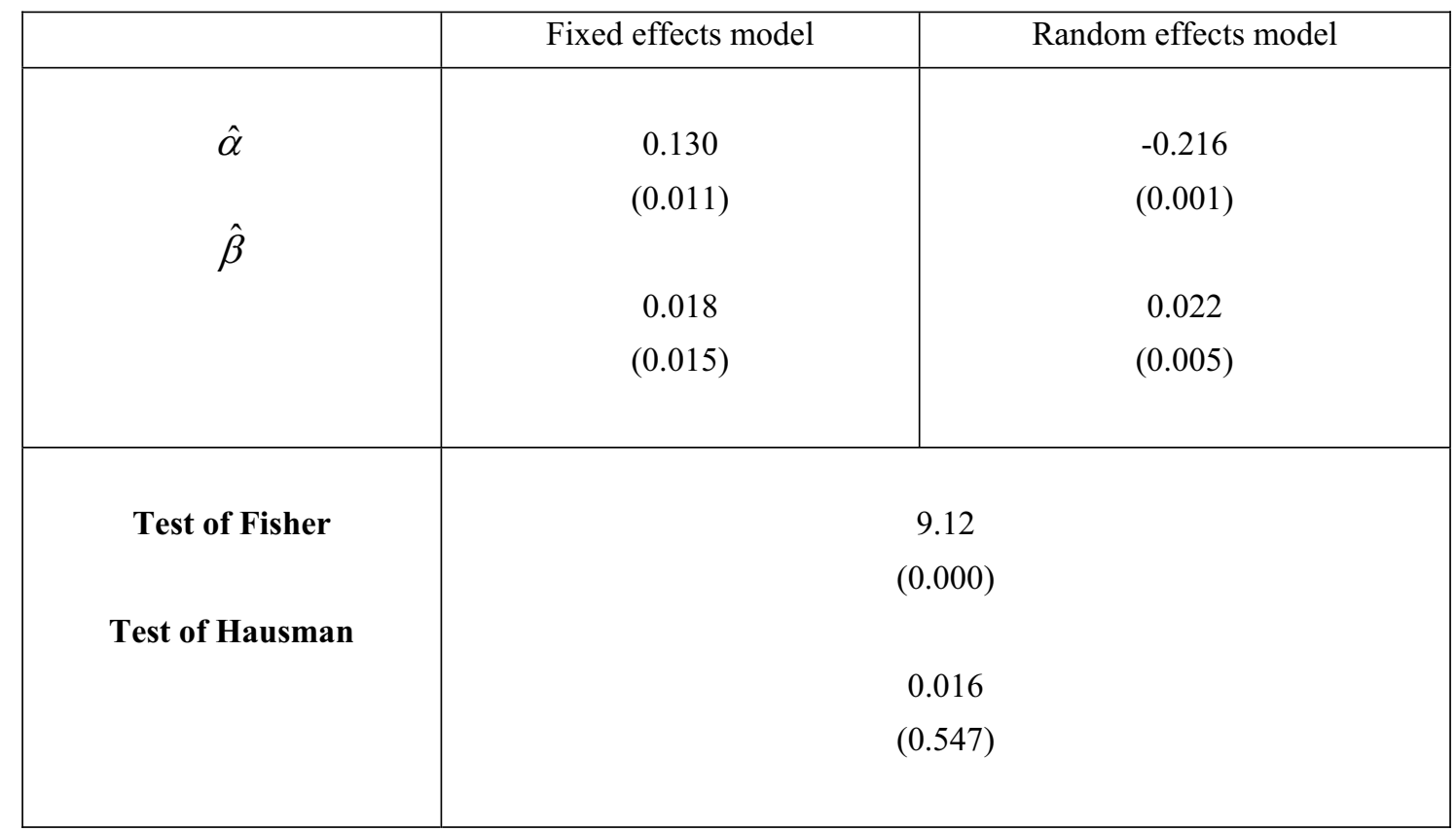

Note: $\mathrm{N}=26, \mathrm{~T}=10$; the values of critical probabilities are between parentheses.

Level of significantly $=5 \%$ 
Table 2. Tests of spatial dependence in absolute $\beta$-convergence model

\begin{tabular}{|c|c|c|}
\hline Tests & Distance matrix & Contiguity matrix \\
\hline \multirow{2}{*}{ MORAN } & 532.251 & 302.642 \\
& $(0.000)$ & $(0.000)$ \\
& 914.313 & 716.415 \\
& $(0.000)$ & $(0.000)$ \\
LMLAG & 641.632 & 402.637 \\
& $(0.000)$ & $(0.000)$ \\
RLMERR & 509.562 & 399.533 \\
& $(0.000)$ & $(0.000)$ \\
& & 202.222 \\
& 299.088 & $(0.000)$ \\
\hline
\end{tabular}

Note: The values of critical probabilities are between parentheses. Level of significantly $=5 \%$.

Table 3. Estimation of absolute $\beta$-convergence model with spatial dependence in errors: (equation 6)

\begin{tabular}{|c|c|c|}
\hline & Distance matrix & Contiguity matrix \\
\hline$\hat{\alpha}$ & 0.542 & 0.891 \\
$\hat{\beta}$ & $(0.001)$ & $(0.004)$ \\
$\hat{\lambda}$ & & 0.027 \\
& 0.031 & $(0.003)$ \\
& $(0.002)$ & 0.614 \\
& 0.713 & $(0.001)$ \\
Test of common factor & $(0.001)$ & \\
& & 0.031 \\
& & $(0.759)$ \\
& 0.035 & \\
\hline
\end{tabular}

Note: $\mathrm{N}=26, \mathrm{~T}=10$; Estimation by Maximum Likelihood method. The values of critical probabilities are between parentheses. Level of significantly $=5 \%$ 
Table 4. Estimation of empirical specification (equation 5)

\begin{tabular}{|c|c|c|}
\hline & Distance matrix & Contiduity matrix \\
\hline$\hat{\alpha}$ & -0.645 & -0.495 \\
$\hat{\beta}$ & $(0.002)$ & $(0.004)$ \\
& & \\
$\hat{\lambda}$ & 0.038 & 0.032 \\
& $(0.003)$ & $(0.003)$ \\
$\hat{\tau}=\hat{\lambda}\left(1-e^{-\hat{\beta}}\right)$ & 0.930 & 0.832 \\
& $(0.001)$ & $(0.003)$ \\
& & 0.026 \\
& 0.034 & $(0.001)$ \\
& $(0.001)$ & \\
\hline
\end{tabular}

Note: $\mathrm{N}=26, \mathrm{~T}=10$; Estimation by Maximum Likelihood method. The values of critical probabilities are between parentheses. Level of significantly $=5 \%$.

\section{APENDEX}

\section{Random effects model and spatial dependence}

The spatial autocorrelation can be incorporated in the random effects model in which the coefficients of regressions are supposed fixed (Anselin, 1988a ; Case, 1991 ; Baltagi et Li, 2002). In this model we have:

$y_{i t}=x_{i t}^{\prime} \beta+\varepsilon_{i t} \quad \mathrm{i}=1, \ldots \mathrm{N} ; \mathrm{t}=1, \ldots ., \mathrm{T}$

Where $y_{i t}$ is a vector $N T \times 1, i$ denotes the region and the period, $x_{i t}$ is a vector $k \times 1$ of observations relative to $k$ explicative variables and $\beta$ is a vector $k \times 1$ of parameters.

The term of error is supposed to incorporate the unobservable effects due to space (Hsiao, 1986; Baltagi, 1995):

$$
\varepsilon_{i t}=\mu_{i}+\phi_{i t} \quad \mathrm{i}=1, \ldots \ldots \mathrm{N} ; \mathrm{t}=1, \ldots ., \mathrm{T}
$$

$\mu_{i}$ is a vector $N \times 1$ of regional specific effects. The vector $N T \times 1$ of error terms $\phi_{i t}$ with mean null and variance $\sigma_{\varepsilon}^{2}$, is supposed normal, $\phi_{i t} \sim \mathrm{N}\left(0, \sigma_{\varepsilon}^{2}\right)$. The $\phi_{i t}$ are supposed independents of effects $\mu_{i}$ and explicative variables of model.

\section{The autoregressive spatial model:}

A first formulation of spatial dependence is the specification of autoregressive spatial model (cf. Florax et Folmer, 1992). If we consider an impalement of $T$ observations relative to each region, the random effects model with spatial dependence can be written under the following form:

$$
Y=\rho W^{1} Y+X \beta+Z \mu+\phi
$$

Where $Z=\left(I_{N} \otimes l_{T}\right)$ is a $N T \times N$ matrix of regional indicative variables, $l_{T}$ is a vector $T \times 1$ of 1 . The sign $\otimes$ is the kronecker product. $W^{l}=\left(W_{N} \otimes I_{T}\right)$ where $W_{N}$ is the $N \times N$. spatial weight matrix, standardized. $\rho$ is the spatial autoregressive coefficient.

The matrix of variances in the case of spatial autoregressive model presents the following structure:

$$
\Omega\left(\rho, \theta_{1}^{2}, \sigma_{\varepsilon}^{2}\right)=\sigma_{\varepsilon}^{2} M^{-1}(\rho)\left[Q+\theta_{1}^{-2} B\right] M^{\prime^{-1}}(\rho)
$$


Where $M(\rho)=\left(I_{N T}-\rho W_{1}\right), B=\left(I_{N} \otimes T^{-1} l_{T} l_{T}^{\prime}\right)$ and $Q=\left(I_{N T}-B\right)$ are respectively the $N T \times N T$ operators between and within and $\theta_{1}^{2}=\frac{\sigma_{\varepsilon}^{2}}{T \sigma_{\mu}^{2}+\sigma_{\varepsilon}^{2}}$.

The determinant and the reverse of $\Omega$ are respectively:

$$
\begin{aligned}
& |\Omega(.)|=\sigma_{\varepsilon}^{2}|M|^{2}\left|\theta_{1}^{2}\right|^{-T} \\
& \text { And } \quad \Omega^{-1}(.)=\sigma_{\varepsilon}^{-2} M_{1}^{\prime}\left[Q-\theta_{1}^{2} B\right] M_{1}
\end{aligned}
$$

\section{Spatial model with autocorrelation in errors:}

A second formulation of spatial dependence supposes that the errors $\phi_{i t}$ are spatially autocorrelated (cf. Florax et Folmer, 1992; Baltagi et Li, 1999):

$$
\phi=\lambda W \phi+v
$$

Where $\lambda$ is the coefficient of spatial autocorrelation. It catches the effects of spatial variables omitted in the model. The vector $N T \times 1$ of errors $v_{i t}$ is supposed normal, $v_{i t} \sim \mathrm{N}\left(0, \sigma_{v}^{2}\right)$. $v_{i t}$ are also supposed independents of the effects $\mu_{i}$ and the explicative variables of model.

In the case of spatial model with autocorrelation in errors, the matrix of variances possesses the following structure:

$$
\Omega\left(\lambda, \theta_{2}^{2}, \sigma_{v}^{2}\right)=\sigma_{v}^{2}\left\lfloor Q+\theta_{2}^{-2} B+\left(M^{\prime}(\lambda) M(\lambda)\right)^{-1}-I_{N T}\right\rfloor
$$

Where, $\theta_{2}^{2}=\frac{\sigma_{v}^{2}}{T \sigma_{\mu}^{2}+\sigma_{v}^{2}}, M(\lambda)=\left(I_{N T}-\lambda W_{1}\right)$

The determinant and the reverse of the matrix $\Omega($.$) can be written respectively ( c f$. Anselin, 1988 : 153-154) :

$$
\begin{aligned}
& \qquad|\Omega(.)|=\sigma_{v}^{2}\left|A_{N}\right|^{-2(T-1)}\left|\left(A_{N}^{\prime} A_{N}\right)^{-1}+\left(\theta_{2}^{-2}-1\right) I_{N}\right| \\
& \text { and } \Omega^{-1}(.)=\sigma_{v}^{-2}\left\{\left(A_{N}^{\prime} A_{N}\right) \otimes\left(I_{T}-\bar{J}_{T}\right)+\left[\left(A_{N}^{\prime} A_{N}\right)^{-1}+\left(\theta_{2}^{-2}-1\right) I_{N}\right]^{-1} \otimes \bar{J}_{T}\right\}
\end{aligned}
$$

where, $A_{N}=I_{N}-\lambda W$

\section{Estimation by the maximum likelihood method:}

The application of Ordinary Least Square (OLS) or Generalised Least Square (GLS) methods for estimation of models with spatial dependence leads to biased and not convergent estimators (cf. Dubin, 1988; Florax et Folmer, 1992). An appropriated method of estimation is the maximum likelihood (ML) (Anselin, 1988: 57-59).

The expression of log likelihood with spatial dependence is the following:

$$
L\left(\alpha, \beta, \theta_{j}^{2}, \sigma^{2}\right)=c_{0}-\frac{N T}{2} \ln \left|I_{N T}-\alpha W_{1 N T}\right|-\frac{1}{2} u^{\prime} \Omega^{-1}\left(\alpha, \theta_{j}^{2}, \sigma^{2}\right) u
$$

$c_{0}=-N T \ln (2 \pi) / 2$

We deduce the autoregressive spatial model for $\alpha=\rho, \mathrm{j}=1, \sigma^{2}=\sigma_{\varepsilon}^{2}$ and $u=M(\rho) Y-X \beta-Z \mu$. And the spatial model with autocorrelation in errors for $\alpha=\lambda, \mathrm{j}=2, \sigma^{2}=\sigma_{v}^{2}$ and $u=M(\lambda)(Y-X \beta-Z \mu)$.

The estimation of models with spatial dependence with the likelihood method necessitates an no linear optimisation and implies numeric calculations as mach harder and longer when the number of observations is important. In particular, 
one of difficulties in application of the ML resides in calculation of determinant of the Jacobean. An alternative proposed by Ord (1975) reposes on proper values of the weight matrix. Then,

$$
\left|I_{N T}-\alpha W_{1 N T}\right|=\left|I_{N}-\alpha W_{N}\right|=\prod_{i}\left(1-\alpha w_{i}\right)
$$

Where the $\omega_{i}$ design the proper values of the matrix $W_{N}$ and $\alpha=\{\rho, \lambda\}$. The identity [12] implies that the values of coefficients of spatial dependence must satisfy the condition: $\omega_{\min }^{-1} \leq \alpha \leq \omega_{\max }^{-1}$ where $\omega_{\max }=1$ in the case of weight matrices normalised. The advantage of this procedure is that we can determine the proper values of these matrices before the optimisation (since $W_{N}$ is supposed known). This reduces considerably the numeric calculation of likelihood of model, at least in the case of small samples. 


\title{
Study on the Disaster Harm and Pattern of Chinese Housing in
}

\section{Villages and Towns with Typical Building Structures}

\section{and the Countermeasures}

\author{
Feng Han \& Yachen Liu \\ School of Management, Shenyang Jianzhu University, Shenyang 110168, China \\ Tel: 86-24-2469-2209Ｅ-mail: hanf606@163.com
}

This paper is a research fruit of the project (2006BAJ04A08-10) funded by National Key Technology R\&D Program.

\begin{abstract}
Based on 499 effective questionnaires in China, this paper firstly analyzes and concludes the type characteristics, spatial distribution, and combined characteristics of typical village and town housing's building structure in China. Secondly, this paper studies the features and sorts of chief disasters in China and the harms on village and town housing. Finally, this paper summarizes the main factors that cause the disasters and the disaster pattern, and puts forward relevant countermeasures.
\end{abstract}

Keywords: Housing in villages and towns, Typical building structures, Harms of disaster, Disaster pattern

Some Chinese scholars have already studied the influencing factors that affect the safety of village and town housing (Huijun Gao, Guihua Xu \& Xiaoli Wu, 2002; Zijiang Yang, 2007; Jingang Yuan, 2006; Enping Jin \& Wei Ren, 2007) and sorts of main disasters that exert effects on village and town housing, including earthquake (Liqun Yao \& Hao Sun, 2000; Shuguang Wu \& Yejun Chang, 2001; Huijuan Wu, 2005), flood (Hailing Sun, 1999; Guihui Zhong, Shuguang Liu \& Donghui Huang, 2008), typhoon (Qiang Xu, 2004), and fire (Lizhen Wu, 2007). Based on these studies, this paper designs a questionnaire and completes a national survey. Finally get 499 effective questionnaires. In specific, 50 pieces are from Huabei, 84 from Huadong, 77 from Zhongnan, 51 from Xinan, 36 from Xibei, and 201 from Dongbei. Based on these questionnaires, this paper advances these opinions as follow.

\section{The typical building structure of China's village and town housing}

1.1 The type of China village and town housing's typical building structure

(1) The main characteristics of China's village and town housing construction

The primary characteristic of China's village and town housing construction is disordered construction management. Most houses are designed by owners. And construction materials are not qualified. Therefore, China's village and town housing has complicated structures.

(2) Define the basic type of China village and town housing's typical construction structure

Based on a wide survey on village and town housing in China, this paper starts from construction materials and bearing structure, classifying China village and town housing's typical construction structure into four types, namely earth-wood-stone structure, masonry structure, brick-concrete structure, and reinforced concrete structure.

\section{Define the basic type and the structural characteristics}

\section{a. Earth-wood-stone structure}

In construction, earth and stone are used to maintain the external structure. Wood is used to support the house vertically. It mainly includes earth-wood structure, wood-stone structure, and earth-wood-stone structure.

b. Masonry structure

It consists of bricks, stones, or sorts of blocks.

c. Brick-concrete structure 
It is to use bricks as a vertical bearing structure, reinforced concrete board as a horizontal bearing structure. If the block structure includes concretes, it also belongs to this type.

d. Reinforced concrete structure

The main bearing structure, such as pillars, beams, boards, stairs, and roofs, is made of reinforced concrete.

\section{The status of main structure}

In the 499 questionnaires, the earth-wood-stone structure occupies the largest proportion in villages and towns (31.66\%), then the masonry structure $(26.45 \%)$, and finally the brick-concrete structure $(30.26 \%)$. The reinforced concrete structure is not a dominating structure at present.

\subsection{The spatial distribution characteristics of China village and town housing's typical building structure}

According to the 499 questionnaires, the main village and town housing structure in different areas is various. Considering the percentage of dominating housing structure, Huabei is mainly brick-concrete structure, masonry structure, and earth-wood-stone structure; Huadong is mainly earth-wood-stone structure, then masonry structure and brick-concrete structure; Zhongnan is mainly masonry structure and earth-wood-stone structure, and then brick-concrete structure; Xinan is mainly earth-wood-stone structure, and then brick-concrete structure, masonry structure, and reinforced concrete structure; Xibei is mainly earth-wood-stone structure, then masonry structure; Dongbei is mainly brick-concrete structure, then masonry structure and earth-wood-stone structure (see Table 1).

\section{The disaster harms on China's village and town housing}

\subsection{The types and characteristics of disasters for China's village and town housing}

(1) Disasters' types and frequency of emergence

In China the village and town housing mainly faces these disasters, including earthquake, flood, fire, typhoon, sandstorm, wind-hail-snow disaster, and mountain landslide. The debris flow, termite, and tsunami serves as threats for small spatial areas (see Table 3). It reflects China's complicated natural conditions. Although some disasters are not popular, they exert significant harms on local areas.

Disasters have different frequencies of emergence. Usually, the most serious disaster for village and town housing in different areas happen every two or five years. The frequency of more than one time per year or one time per year is also common (see Table 4). The second serious disaster for village and town housing in different areas happen every 15 years, 5-10 years, more times every year, or one time every 2-5 years. The frequency of one time every two years or 5-10 years also accounts for a large proportion (see Table 5). Therefore, the most serious disaster has higher frequency and exerts more serious damages on housing. The second serious disaster happens every longer period. But combined with the most serious disaster, the second serious disaster can generate considerable pressure on village and town housing.

(2) Regional analysis of disasters

All disasters are regional. According to the number of disasters in questionnaires, we get these conclusions.

Main disasters in Huabei are flood, fire, sandstorm, and wind-hail-snow disaster, in Huadong flood, typhoon, fire, earthquake, and mountain landslide, in Zhongnan flood, fire, earthquake, termite, and wind-hail-snow disaster, in Xinan flood, earthquake, fire, wind-hail-snow disaster, and mountain landslide, in Xibei earthquake, fire, flood, sandstorm, and wind-hail-snow disaster, in Dongbei fire, flood, earthquake, wind-hail-snow disaster, and sandstorm (see Figure 2). In addition, we should notice that regional disasters may combine in different forms, which makes disasters be diversified and complicated in China.

\subsection{Disaster harms on village and town housing}

Different typical housing structure can resist disasters to a different degree. The earth-wood-stone can be ruined easily. More than one half earth-wood-stone structured housing has been damaged after disasters in $46.56 \%$ villages and towns (see Figure 3). Earthquake, flood, and fire are the most dominating disasters. The masonry structure and the brick-concrete structure are stronger than the earth- wood-stone structure. Here, the masonry structure mainly suffers from flood, fire, earthquake, and wind-hail-snow disasters. The brick-concrete structure mainly suffers from flood, fire, sandstorm, and wind-hail-snow disasters. The strongest is the reinforced concrete structure, which can resist almost all disasters to certain degree (see Figure 4).

\section{Disaster pattern of China's village and town housing}

\subsection{The meaning of disaster pattern and the main factors}

(1) The meanings of disaster pattern

Here it especially means all conditions after the disaster, including damages, ruins, and even human death. 
In this paper the disaster pattern especially means that sorts of factors contribute to the harms on village and town housing by certain mechanism.

(2) Main factors

In researches, this paper concludes that the main factors that cause disasters for village and town housing can be sorted into three aspects:

(1) Defects of village and town housing: seldom follow technological standards and can not resist disasters effectively.

(2) Grades of disasters: different grade means different harms.

(3) More key factors: people's recognition and capability of preventing disaster, guidance for housing construction, quality management and supervision evaluation.

\subsection{The typical disaster pattern for China's village and town housing}

(1) Poor consciousness of disaster prevention ------ short of subjectivity

This research especially focuses on the construction standards, housing construction workers, housing quality certificate and evaluation, and wealth insurance. Results are as follow:

(1) Almost $100 \%$ village and town housing does not follow any construction standard. In special, people do not combine the housing structure with the consciousness of disaster prevention. In China, many houses are built by local farmers, without geological researches and specialized designs. They build houses just according to subjective imagination. In the construction, no specialized workers but only local workers or friends and relatives join in. Houses are not qualified, not mention the disaster prevention in the technological aspect. Therefore, once there is a disaster, village and town housing will suffer a lot. People and wealth will be harmed seriously.

(2) Once houses are completed, there is no quality certification and evaluation. And there is no necessary maintenance, protection, and update. Only less than $10 \%$ research objects get the wealth insurance. The insurance covers a narrow scope, which is not effective.

Random construction leads to these defects of housing structure as follow:

(1) In housing structure construction, most materials are from local area and not qualified.

(2) There are regional disaster harms. And the disaster prevention capability is poor. For example, some village and town housing is full of straws, and wood, which indicates a fire risk. For some houses, because of carelessness in construction, they are easy to be ruined in earthquake.

(2) The complicated disaster

(1) Different disasters serve as different challenges for houses. A good example is the Wenchuan earthquake. Although we have already concluded that the earth-wood-stone structure is easy to be damaged, the wood structured house is a special example. In Wenchuan earthquake, many casualties are caused by the collapse of buildings. Some traditional wood structured houses are ruined but not collapse completely. Wood structured houses are flexible. The box structure can separate powers. Its light structure and strong flexibility can help it resist instant shocks and periodical damages. Therefore, in earthquake, it can absorb less power and still sit there due to its better flexibility.

(2) Many areas face more than two disasters. The disasters have different frequencies and harms, which means higher disaster prevention requirements for village and town housing structure. For example, if an area suffers from frequent earthquake, it should build more wood structured houses. But once there is flood, debris flow, or typhoon, the wood structure will suffer a lot. Therefore, for the village and town where there are more disasters, the housing structure is a problem.

(3) Disasters at different grades happen at different frequencies. High-grade disaster happens at a lower frequency. It is easy to be neglected. The disaster prevention measures and standards may be ignored. Therefore, once high-grade disaster happens, the harms are significant and cover a wider space.

(3) The guidance, management, and supervision evaluation system for village and town housing are not perfect.

This research focuses on village and town housing's guidance, management, and supervision evaluation. Results show that the construction and maintenance of village and town housing are short of perfect guidance, management, and supervision evaluation, which completely proves that in China the village and town housing construction guidance, management, and supervision evaluation system are extremely imperfect, short of rules and laws.

The three aspects mentioned above exert negative effects on each other in many fields, concerning housing structure construction and management, which finally causes the disaster pattern for China's village and town housing (see Figure 5). 


\section{Measures for improving the safety of China's village and town housing}

\subsection{Improve residents' consciousness of disaster prevention}

By means of periodical popularization, introducing the disaster prevention knowledge and the disaster harms on village and town housing, improve villagers' consciousness of disaster prevention. In building and designing houses, strengthen the disaster prevention capabilities by following present national standards or regional standards, emphasizing on the quality of houses. Keep pre-warning on the safety of houses. Lay more stresses on houses' maintenance, update, and re-construction.

\subsection{Set up local standards for village and town housing construction structure}

According to local economic development, set up standards for village and town housing construction structure, considering the disasters harms, people's income, and different typical structures. Take the uniqueness of village and town housing and construction workers into consideration, the standards should be easy to carry out.

\subsection{Perfect the village and town housing construction guidance, management, and supervision evaluation system}

The construction guidance is the key for village and town housing's structural design, technological application, and structural safety. The management system can insure the village and town housing's construction quality and materials' quality. The supervision and evaluation system can help to popularize the quality evaluation and condition evaluation of village and town housing, repairing and re-building the houses with poor safety more resonablly.

\section{References}

Gao, Huijun. Xu, Guihua \& Wu, Xiaoli. (2002). Potential problems of buildings in small towns and countries and the countermeasures. Development of Small Cities and Town, No.9, p.39-47.

Jin, Enping \& Ren, Wei. (2007). Problems of quality and safety of rural residential structure in Henan Province. Journal of Anhui Agricultural Sciences, No.22, p.121-142.

Song,Weixiang. (2007). Research on the earthquake resistance safety countermeasures of the rural building. Optimization of Capital Construction, No.3. p.27-29.

Sun, Hailing. (1999). Measures for reducing flood disasters in flood retention area. Hebei Water Resources, No.3, p.8-10.

$\mathrm{Wu}$, Huijuan. (2006). More stresses on the quality and safety of rural residential construction. Construction Science and Technology, No.1, p7.

Wu, Lizhen. (2007). On improving fire prevention in rural areas. Journal of Chinese People's Armed Police Academy, No.8, p7-14.

Wu, Shuguang \& Chang, Yejun. (2001). Study of structure formation optimization in the earthquake disaster. Journal of Anhui University of Technology, No.2, p23-24.

Xu, Qiang. (2004). Analyzing issues concerning disaster precaution of rural housing based on planning -With Wenzhou hit by the typhoon "Rananim" as an example. Development of Small Cities \& Towns, No.12, p6-17.

Yang, Zijiang. (2008). On the sustainable development of new counties' construction of buildings. Building Science Research of Sichuan, No.3, p56-8.

Yao, Liqun \& Sun, Hao. (2000). Earthquake hazards and houses safety management. Urban Earthquate Disaster and Reduction, No.4, p13-16.

Zhong, Guihui. Liu, Shuguang \& Huang, Donghui. (2008). Experimental study of pressure on village houses hit by floods. Urban Roads Bridges \& Flood Contro, No.12, p42-53. 
Table 1. Percentage of main village and town housing structure in different areas (\%).

\begin{tabular}{|l|l|l|l|l|l|l|}
\hline & Huabei & Huadong & Zhongnan & Xinan & Xibei & Dongbei \\
\hline $\begin{array}{l}\text { Earth-wood-stone } \\
\text { structure }\end{array}$ & 24.00 & 40.48 & 32.47 & 39.22 & 52.78 & 23.88 \\
\hline $\begin{array}{l}\text { Masonry } \\
\text { structure }\end{array}$ & 30.00 & 26.19 & 36.36 & 17.65 & 25.00 & 24.38 \\
\hline $\begin{array}{l}\text { Brick-concrete } \\
\text { structure }\end{array}$ & 36.00 & 20.24 & 23.38 & 25.49 & 13.89 & 39.80 \\
\hline $\begin{array}{l}\text { Reinforced } \\
\text { concrete structure }\end{array}$ & 10.00 & 13.10 & 7.79 & 17.65 & 8.33 & 11.94 \\
\hline Total & 100.00 & 100.00 & 100.00 & 100.00 & 100.00 & 100.00 \\
\hline
\end{tabular}

Table 2. Main disasters for village and town housing.

\begin{tabular}{|l|l|l|l|l|l|l|l|l|l|}
\hline & Earthquake & Flood & Fire & Typhoon & Sandstorm & $\begin{array}{l}\text { Wind-hail-snow } \\
\text { disaster }\end{array}$ & $\begin{array}{l}\text { Mountain } \\
\text { landslide }\end{array}$ & $\begin{array}{l}\text { Debris } \\
\text { flow }\end{array}$ & $\begin{array}{l}\text { Termite } \\
\text { Tsunami }\end{array}$ \\
\hline $\begin{array}{l}\text { Number of } \\
\text { questionnaires } \\
\text { in which it is } \\
\text { regarded as } \\
\text { the most } \\
\text { serious } \\
\text { disaster }\end{array}$ & 141 & 101 & 29 & 48 & 58 & 21 & 3 & 8 \\
\hline $\begin{array}{l}\text { Number of } \\
\text { questionnaires } \\
\text { in which it is } \\
\text { regarded as } \\
\text { the second } \\
\text { serious } \\
\text { disaster }\end{array}$ & & 129 & 85 & 34 & 49 & 79 & 52 & 14 & 9 \\
\hline
\end{tabular}

Table 3. Questionnaires and percentage of the most serious disaster's frequency of emergence.

\begin{tabular}{|l|l|l|l|l|l|l|l|}
\hline $\begin{array}{l}\text { Frequen } \\
\text { cy }\end{array}$ & $\begin{array}{l}\text { More than } \\
\text { one time } \\
\text { every year }\end{array}$ & $\begin{array}{l}\text { One time } \\
\text { per year }\end{array}$ & $\begin{array}{l}\text { One time } \\
\text { every two } \\
\text { years }\end{array}$ & $\begin{array}{l}\text { One time } \\
\text { every 2-5 } \\
\text { years }\end{array}$ & $\begin{array}{l}\text { One time every } \\
5-10 \text { years }\end{array}$ & $\begin{array}{l}\text { One time every } \\
5-15 \text { years }\end{array}$ & $\begin{array}{l}\text { One } \\
\text { every time } \\
\text { than } \\
\text { mears } \\
15\end{array}$ \\
\hline $\begin{array}{l}\text { Percenta } \\
\text { ge }(\%)\end{array}$ & 19.24 & 12.83 & 7.41 & 22.04 & 15.23 & 7.41 & 15.83 \\
\hline
\end{tabular}

Table 4. Questionnaires and percentage of the second serious disaster's frequency of emergence.

\begin{tabular}{|l|l|l|l|l|l|l|l|l|}
\hline $\begin{array}{l}\text { Frequen } \\
\text { cy }\end{array}$ & $\begin{array}{l}\text { More than } \\
\text { one time } \\
\text { every year }\end{array}$ & $\begin{array}{l}\text { One time } \\
\text { per year }\end{array}$ & $\begin{array}{l}\text { One time } \\
\text { every two } \\
\text { years }\end{array}$ & $\begin{array}{l}\text { One time } \\
\text { every } \\
\text { years }\end{array}$ & $\begin{array}{l}\text { One time every } \\
5-10 \text { years }\end{array}$ & $\begin{array}{l}\text { One time every } \\
5-15 \text { years } \\
\text { every } \\
\text { than } \\
\text { mears }\end{array}$ \\
\hline $\begin{array}{l}\text { Percenta } \\
\text { ge }(\%)\end{array}$ & 14.83 & 6.21 & 11.62 & 13.43 & 15.03 & 11.42 \\
\hline
\end{tabular}




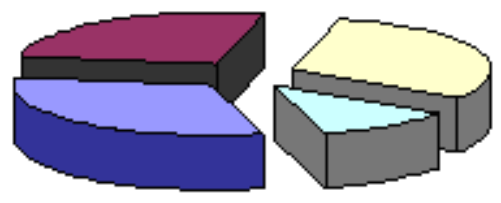

earth-wood-stone structure

masonry structure

$\square$ brick-concrete structure

reinforced concrete structure

Figure 1. Proportion of Different Type of Typical Village and Town Housing Construction Structure.

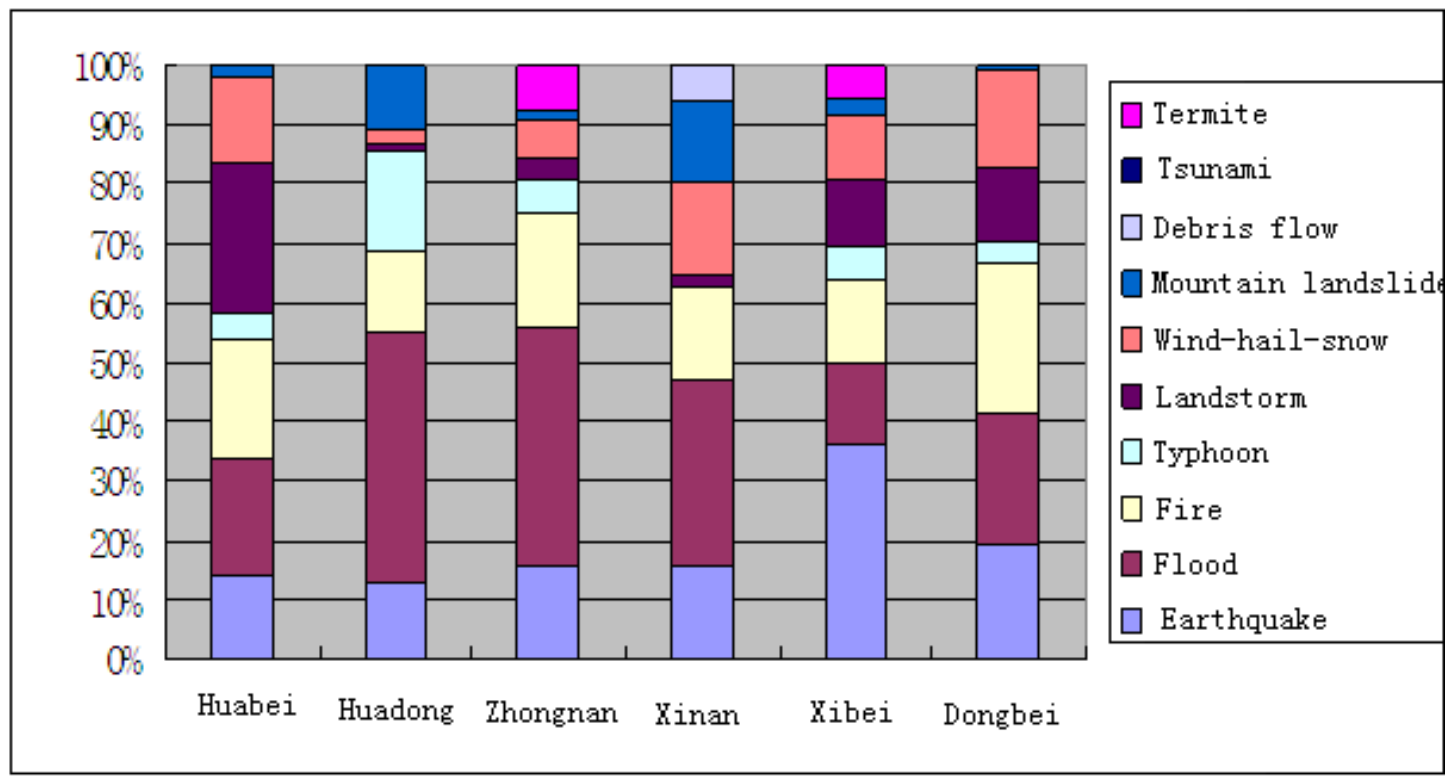

Figure 2. Distribution of Disasters that Exert most Serious Damages on Village and Town Housing.

Notice: Percentages in this figure is calculated from regional statistical data of "the most serious disaster for village and town housing".

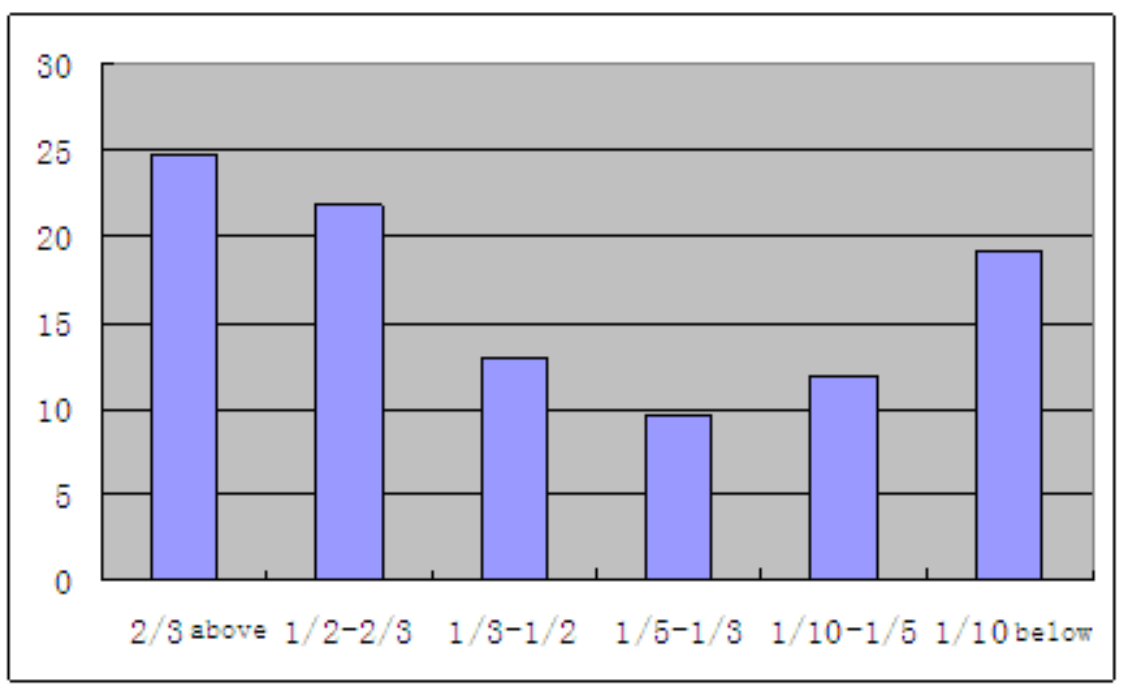

Figure 3. Percentage of Disaster Harms on Earth-Wood-Stone Structured Housing. 


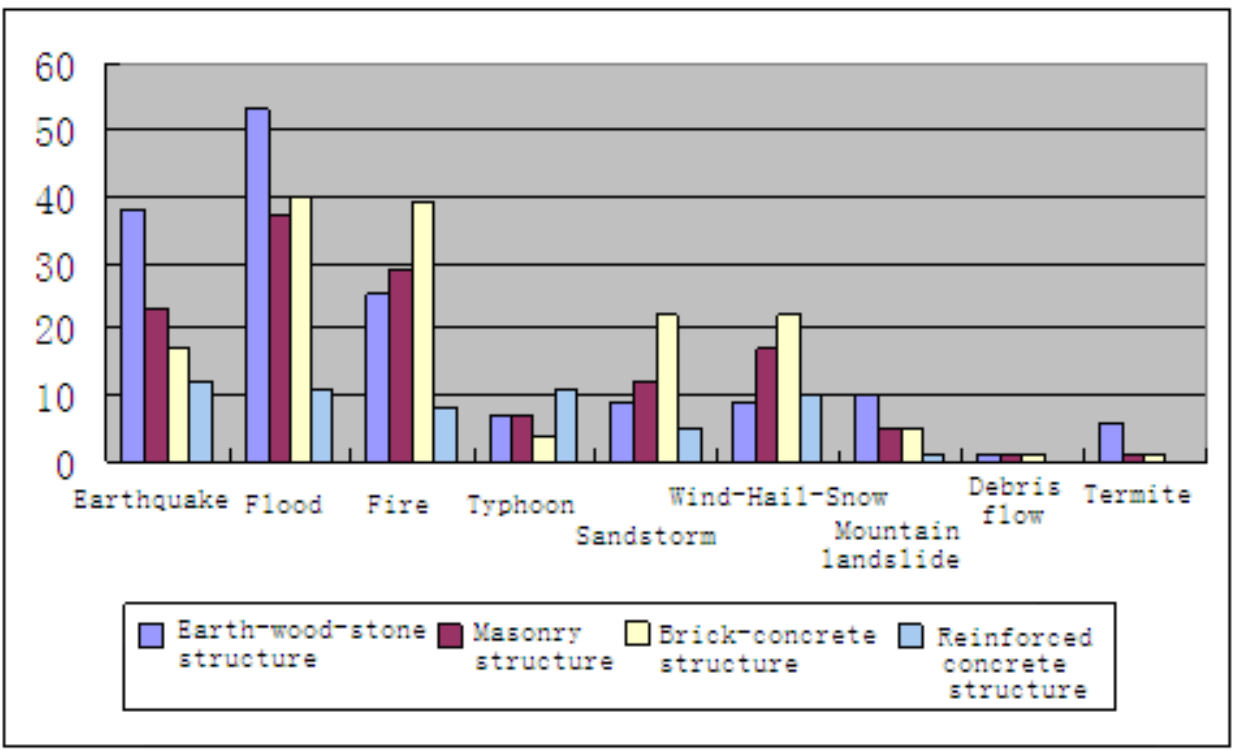

Figure 4. Comparison of Different Disaster's Harms on Typical Village and Town Housing.

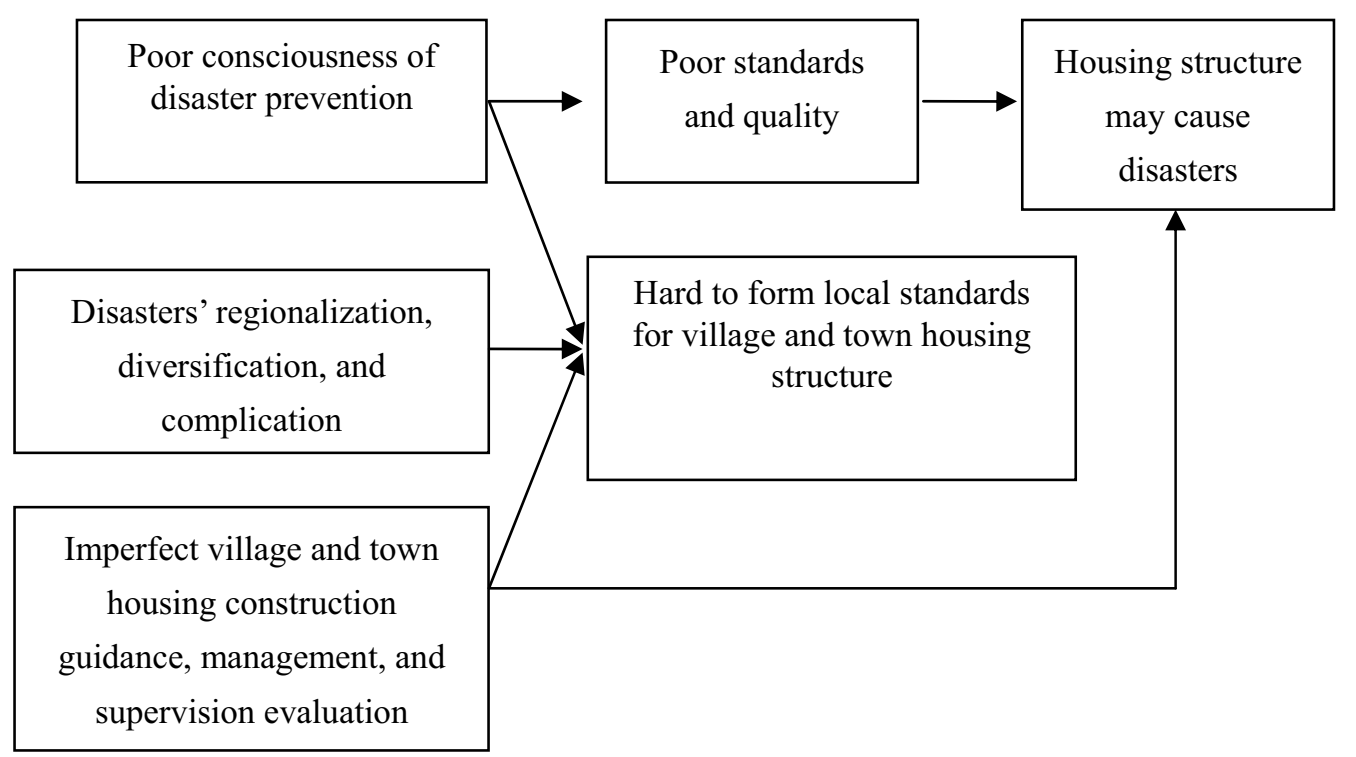

Figure 5. The Disaster Pattern for China's Village and Town Housing 


\title{
The Value and Effect of the Tourism Industry's Priority to Restoration
}

\section{and Rebuilding after Catastrophe}

\author{
Hejiang Shen, Limei Yuan, Yana Liu, Zhang Ying \& Wei Fei \\ College of Resources \& Environment Science, Hebei Normal University \\ Shijazhuang 050016, China \\ E-mail: Shen-hejiang@163.com
}

\begin{abstract}
The thing about the tourism industry's restoration and rebuilding after catastrophe has a great influence not only on sustainable development of tourism destination, as the tourism destination is concerned highly by public, but also on the social judgment on the accessibility of stricken area, except those, it even influences the works which are the restoration and rebuilding of the stricken area's various constructions and the important criterion, depending on that, the international community determines if the stricken area should be rebuilt completely. So, the restoration and rebuilding of stricken area after catastrophe has the great value and profound meaning on reducing the tourists' fear and worries about the area happened crisis, and exerting the tourism industry's effect on all-round social development, which spurs the relevant industries to be reconverted as before.
\end{abstract}

Keywords: Tourism industry, Restoration, Rebuilding, Catastrophe

\section{Objective vantage of the tourism industry's restoration and rebuilding after catastrophe}

Tourism industry has suffered a lot from the calamitous events' outburst is no doubt. But, "the tourism industry itself possesses great power for the recovery of elasticity instead of showing weakness", and "with the crisis controlled and eliminated effectively", "the tourism industry will burst into much more vitality and energy", therefore "the tourism industry is known as the industry with stronger recovery power by itself"[1]. According to that, to restore and rebuild the tourism industry after catastrophe has the objective vantage.

\subsection{The advantage of the tourism industry sell-repairing capability}

It is known to us, as the comprehension industry which takes the tourists as the core, that the tourism industry provides all kinds of services for tourists for their tourist activities relying on the tourism attractors. Basically, it is known as the economic sociocultural service-type business. Tourist activity becomes the key to this industry for the tourist plays the most important role. In the other hand, whether the tourist can make their tourist activities into truth smoothly or not becomes the key for the tourist industry's trouble-free running. The paroxysmal calamitous events not only lead to the discontinuing of the various tourist activities in tourist destination, but at once affect the tourists enter the tourist destination from the place where they live, those directly effect the tourism industry in the tourist destination "normal" operation, however, "with the crisis being eliminated gradually, the tourism industry will be soon recovery as before, which has shown its elasticity's level"[2]. So as the result of the crisis eliminated, objectively, the external safe factor to tourists realizing their tourist activities has been ready, if improving the speed to restore and perfect the various basic facilities, such as tourist communications, tourist hotel and tourist attraction, for developing the tourist activity in tourist destination, then the tourism industry will shows the powerful recovery ability. Just as,Frans Gallie, the secretary-general of WTO said that the tourism industry has the powerful recovery ability, and it will be more mature after experiencing one crisis.

\subsection{The comparative vantage of tourism industry's recovery and rebuilding}

Compared with the other industries, the tourism industry is one comprehension service industry, most important is that "it has the obvious comparative vantage"[3]. Compared with agriculture, steel industry and building material industry etc. which need long-term restoration and rebuilding and take the damage to local recourse and environment, tourism industry has the comparative vantage in restoration and post-disaster reconstruction. To restore and rebuild the tourism 
industry firstly has the much effect on promoting and furthering the development of related industries, and also set a good example to the other industries. In brief, bring the tourism industry's comparative vantage into full play has the magnitude to promote the society all-round development in tourism destination after catastrophe .

\subsection{The vantage of foundation of restoring and rebuilding the tourism industry in tourism destination}

The tourism industry's recovery and rebuilding has the certain vantages of foundation. Firstly, there are rich and unique tourism resources in tourism destination, on the basic of restoration of tourist attractions and evaluating the damage caused by catastrophe to tourist attractions, the tourist attractions may be opened to the public with measured strokes; secondly, the fairly perfect system of travel reception and supply built after long-term development and construction, the same as the first, on analyzing the damage caused by crisis to tourist system, may be perfected with measured stroke, therefore, the capability of travel reception should be recovered fast; Thirdly, according to the present industry structure in tourist destination, tourism industry usually is prioritized, even taken as the cornerstone industry. So, to rebuild the tourism industry after catastrophe is objectively necessary to perfect industry structure and adjust industrial pattern in tourist destination. Comparing with the tourism industry, either manufacturing or agriculture's development has much more limiting factors, furthermore, the added value and spur of this industry are also much lower, first developing the tourism industry not only optimizes industry structure, but also restores the damaged tourist resources and environmental deterioration so that improving and enhancing the tourist destination's ecological functions.

\section{The value of signal transmission effect of tourism industry's priority to recovery and rebuilding after catastrophe}

\subsection{Safety information transfer}

The basic value of effect embodied in tourism industry's recovery after catastrophe indicates to the public that the tourist destination has been one safe place, which is the fundamental, also the main factor to tourists to realize their tourist activities. Whether the tourist destination is safe or not has directly respect to the tourist's security of the lives and property, because which the tourist destination's accessibility has been influenced. It has been proved that the tourism industry doesn't exist without safety, and safety is the critical element to the tourism industry, if crisis, especially the catastrophe, happens to the tourist destination, which makes the tourists in passenger origin district always be fear and scared, at last, cancel the plan to travel to tourist destination. So the basic information of tourism industry's priority to recover and rebuild is to indicate to the world that the crisis has gone, the fear and hidden trouble caused by crisis has been removed, now the tourist destination is safe so the tourists can travel there relievedly. The effect produced by that information has the great value to recover the tourist's confidence and eliminate their fears.

\subsection{The transfer of tourist destination's true information}

The outburst of the disastrous crisis incident directly takes the enormous impact and great bodily injury to tourism industry. Although crisis takes partial failure to local tourism industry, it takes the global influence to tourism economy, whose "amplification effect" has gone beyond people's imagination, inducing public's psychological crisis in various degree, such as abandoning the choice to travel to this tourist destination, abandoning the investment to tourist destination and so on. As a result, the influence taken by crisis has certain extensibility, therefore, to eliminate all kind bodies' including investor, tourist, and etc. anxiety, to rebuild tourism industry, to show the public the practical action of rebuilding the tourism industry, to transfer the true information to public is regarded as the important tropism of tourism industry's rebuilding after catastrophe.

The transfer of tourist destination's true information mainly reflects the spirit of combating a nature disaster to save oneself displaying in tourism system, which will produces one vital effect on helping the tourist, tour investor and tour operator recover their confidence to tourism industry. So as to crisis happening to some areas produce global negative effect and immediate impact on tourism consumer's visiting and tourism investor's confidence. In result, rebuilding tourism industry has the critical compact on boosting investor's confidence or eliminating tourist anxiety on tourist consumption in order to reset their confidence. In addition, disastrous crisis incident happening make it be a huge and careful systematic engineering to rebuild the tourism industry. So in a sense, the work to rebuild the tourism industry also conveys the spirit of disaster resistance displaying in the progress of tourism system exerting and striving hard without any let up.

\section{The value of Promotion-Demonstration effect of rebuilding and recovering tourism industry firstly after catastrophe}

\subsection{The promotion effect of tourism industry}

Economically, tourism industry with high degree of association and strong promotion effect is "a inter-industrial and inter-regional industry, whose territorial scope covers tourism-generating region and tourism destination, the integration of those two regions forms the structure of spatial system of tourism industry, within this system, the related industries which fits the tourism demand including transportation industry, hospitality industry, scenic spot service industry, 
commerce, catering industry, entertainment industry, travel service industry and etc. make up the tourism industry"[4]. As a result, the economic multiplier effect tourism industry producing overpasses the other industries so that becomes a comprehension industry with strong promotion effect, whose comprehension and promotion directly promotes transportation industrial, communications', commercial, building industrial and energy industrial etc. development, with calculating, the income of tourism industry's increases 1yuan, which leads tertiary industry's income to increase over 4yuan. Thus its promotion effect to national economy is more obvious. Meanwhile, tourism industry also known as the industry to rich public, which expands the peasant's income channel and leads the peasants in tourism destination to increasing income, but supply the jobs to labors, accord with calculation, tourism industry indirectly offers five jobs for absorbing one employee. In one word, developing tourism industry expands the employment channel but also offers lots of job opportunities.

The outburst of the disastrous unexpected crisis incidents may cause multiple loss, even numerous industries may face a fatal strike. For example, Great Sichuan Earthquake caused disastrous loss in the districts such as Wenchuan, Qingchuan, Beichuan and Dujiangyan. With roundly unfolding the work of disaster relief and eliminating the effect crisis causing, resuming production and rebuilding the homes become the most important thing after the disaster. Thus, during the progress of rebuilding and recovering, being the cornerstone industry, new-type industry or the leading industry in tourist destination, it should play its role to lead other industries. It is a great meaning for promoting relevant industries' development and enlarging the job opportunity to public, and so on.

\subsection{Demonstration Effect of the Tourism}

Tourism industry known as Sunrise Industry or Smokeless Industry, under the theme of industrial structure adjustment and building conservation-oriented society, tourism industry becomes the one which is called the environment-friendly industry or energetic conservation-oriented industry. Therefore accelerating tourism industry development will has the congenital demonstration effect on sustainable utilizating resource, promoting the harmonious Co-existent between human beings and environment and changing economic growth mode.

The tourism industry's recovery and rebuilding can also show a good demonstrative effect, and it can be a dynamically developing leading industry in roundly recovering and rebuilding the stricken areas. With recovering and rebuilding the society and economics in tourism destination, tourism industry must be the harmonious industry which improves people's life and strengthens the stability of the society, and then the industry benefiting people which increases income and enlarges the employment. The destructed sceneries, the roads, communication facilities, tourists-receiving facilities and public facilities will be recovered with the primitively rebuilding of tourism, and will recover rapidly and develop better because of scientific arrangement.

\section{The Image-Showing Effect Value of the Post-Catastrophe Area}

Tourism is export oriented industry. Being the tour destination, its good surroundings, excellent service, pretty resources, and well-prepared service facilities etc. are of lot meanings for opening the tour destination, absorbing investment and strengthening the popularity of the destination. The occurrence of the catastrophe unexpectedly causes tremendous pessimistic effects on the fatal economic loss and the damage of the tour destination's brand image, which sends to the international society the information that it's been a dangerous place to go. However, after the catastrophe, building a good image, a safe destination and a reliable brand would be the main work. Absorbing more domestic and broad tourists to travel to the stricken area is most persuasive, and it the most important responsibility tourism industry can take.

Rebuilding the tourism industry priorly after catastrophe should be carried out gradually according to extent of the disaster after detailed investigation and carefully planning. Meanwhile the chargers should faithfully transmit the information of the disaster area and make it well known, and they also should develop and design some new tour products relating to catastrophe, carry forward the spirit of combating on the Earthquake Disaster in the stricken area, and build new brands. Therefore the primitive rebuilding of the tourism industry is very important, which would be a window to show the area and the national image to public and it also be the wind vane of the economic development and social order as well as the sign of eliminating the effect of the earthquake.

\section{References}

Shen, Hejiang \& Chen, Shurong. (2006). A comprehensive study of management of tourism industry crisis. Journal of Hebei Normal University, (6).

Tourism: The Preponderant Industry in After-Catastrophe Rebuilding-Sichuan Daily's Exclusive Interview on Shao Qiwei. (2008). Sichuan Daily, 6, 5.

Zhang, Guangrui \& Wei, Xiao'an. (2003). China's Tourism Effect of "SARS" And all-sided reviving, Social and Scientific Document Press, (8).

Zhang, Hui. (2002). Tour Economics, Tour and Education Press, (9). 


\title{
Evaluating Efficiency of Malaysian Banks Using Data Envelopment Analysis
}

\author{
Izah Mohd Tahir (Corresponding author) \\ Faculty of Business Management and Accountancy, University of Darul Iman Malaysia \\ 21300 Kuala Terengganu, Malaysia \\ Tel: 60-9-665-3863 E-mail: izah@udm.edu.my \\ Nor Mazlina Abu Bakar \\ Faculty of Business Management and Accountancy, University of Darul Iman Malaysia \\ 21300 Kuala Terengganu, Malaysia \\ Tel: 60-9-665-3767_E-mail: normazlina@udm.edu.my \\ Sudin Haron \\ President, Kuala Lumpur Business School \\ Suite 4-4-1 Jalan 4/50 Diamond Square Commercial Centre \\ Off Jalan Gombak, 53000 Kuala Lumpur \\ Tel: 60-3-4024-5011Ｅ-mail: sudin@klbs.com.my
}

\begin{abstract}
Data Envelopment Analysis (DEA) Approach is used to estimate the overall, pure technical and scale efficiencies for Malaysian commercial banks during the period 2000-2006. The results suggest that domestic banks were relatively more efficient than foreign banks. Our results also suggest that domestic banks' inefficiency were attributed to pure technical inefficiency rather than scale inefficiency. In contrast, foreign banks inefficiency is attributed to scale inefficiency rather than pure technical inefficiency. The study further examines whether the domestic and foreign banks are drawn from the same environment by performing a series of parametric and non-parametric tests. The results from the parametric and non-parametric tests suggest that for the years 2000-2004, both domestic and foreign banks possessed the same technology whereas results for 2005 and 2006 suggest otherwise. This implies that banks in recent years have had access to different and more efficient technology.
\end{abstract}

Keywords: Efficiency, DEA, Malaysia

\section{Introduction}

The banking system plays an important role in the economic development of any country. Commercial banks, which are the main component of the banking system, have to be efficient otherwise they will create maladjustments and impediments in the process of development in any economy. Technological advancements and globalisation have added to the pressure on the part of the banks to maintain market shares so as to survive and remain competitive. Competition from foreign banks as well from domestic banks themselves creates greater pressure. Commercial banks in Malaysia are of no exception. Therefore not only do commercial banks need to be profitable, but also efficient, since banks are exposed to intense competition both locally and globally. The basic benefit to enhanced efficiency is a reduction in spreads between lending and deposit rates and this will likely stimulate both greater loan demand for industrial investment and greater mobilization of financial savings through the banking system (Ikhide, 2000).

Past studies on bank efficiency and other financial institutions have focussed mainly in the USA (for example Aly et. al., 1990; Elyasiani and Mehdian, 1990; Kwan and Eisenbeis, 1996) and on other developed countries (for example Worthington, 1998 for Australian banking, Koetter, 2005 for German banking). Previous research that has focused on developing countries like Malaysia is still considered small. This motivates us to undertake this study to fill the gap and add to the existing literature. Our study uses unbalanced panel data of 22 banks over the period 2000-2006 and 
employs the non-stochastic approach-Data Envelopment Analysis (DEA) to estimate the technical and scale efficiency of Malaysian commercial banks. We also analyse the sources of inefficiency of these commercial banks, both domestic and foreign banks. The results of this study would be helpful to policy makers as well as scholars and researchers in finance and banking.

The paper is structured as follows: Section 2 will discuss efficiency measurement in banking followed by data and specifications of bank input and outputs in Section 3. Empirical findings are discussed in Section 4 while conclusions are drawn in Section 5.

\section{Efficiency Measurement in Banking}

In the banking literature, two major methods for the empirical estimation on bank efficiency are frequently used: parametric and non-parametric approaches. Parametric methods are considered more sophisticated compared to the non-parametric approach since the method is able to incorporate both input allocative and technical efficiencies. The two main methods frequently used are the Stochastic Frontier Approach (SFA) and the Distribution Free Approach (DFA).

The stochastic frontier approach (SFA), sometimes also referred to as the econometric frontier approach (EFA), was developed by Aigner, Lovell and Schmidt (1977), and Meeusen and Van den Broeck (1977). In this approach, the SFA specifies a functional form for the cost, profit or the production frontier and allows for random error. The SFA modifies a standard cost (production) function to allow inefficiencies to be included in the error term. The predicted standard cost function is assumed to characterize the frontier while any inefficiency is captured in the error term, which is by construction orthogonal to the predicted frontier. These assumption force any measured inefficiencies be uncorrelated with the regressors and any scale or product mix economies derived linearly from these explanatory variables (Ferrier and Lovell, 1990).

Another assumption needed in the SFA is to distinguish the inefficiencies from random components of the error terms. The random components include short term luck which place individual banks in relatively high or low cost positions and measurement error from excluded explanatory variables, misspecification etc. These two components are separated by assuming that inefficiencies are drawn from asymmetric half-normal distribution, and that random errors are drawn from a symmetric normal distribution. However, it is not possible to decompose individuals' residuals into inefficiency or random variation; therefore, estimating technical inefficiency by observation is impossible. Okuda et. al., (2003) used SFA to estimate the cost function of the Malaysian commercial banks from 1991-1997 and its impact on bank restructuring. The study observed economies of scale but not economies of scope and suggested that Malaysian domestic banks were making unproductive capital investments.

In the distribution-free approach (DFA), a functional form for the frontier is also specified but inefficiencies are separated from random error in a different way. Unlike the SFA, the DFA makes no strong assumptions regarding the specific distributions of the inefficiencies or the random errors. The identifying assumption is that efficiency of each bank is stable over time, while random errors tend to average out over time. The estimates of inefficiency for each bank in a panel data set is then determined as the difference between its average residual and the average of the bank on the frontier with some truncated measure performed to account for the failure of the random error to fully average out. The truncation procedure is similar to the TFA treatment of outliers. Therefore, the truncation procedure is used to remove some of the effects of the extreme observations by treating all the most efficient firms alike and, similarly, all the most inefficient firms alike. The DFA has been applied to banking by Berger (1993) in the study of the US banking industry. He found that the frequency distribution of inefficiencies appeared to be closer to the shape of symmetric normal distribution than an asymmetric half-normal distribution. Yildrim and Philippatos (2007) used both SFA and DFA to examine the cost and profit efficiency of banking sectors in twelve countries in Europe and found that the average cost efficiency level was 72 percent by DFA and 77 percent by SFA.

The second approach used in estimating bank efficiency, the non-parametric methods on the other hand, do not presume any explicit functional form for the frontier and construct it from the observed input-output ratios using mathematical programming techniques. The main method frequently used is the Data Envelopment Analysis (DEA).

DEA is rooted in the work of Farell (1957), who used the economic concept of the production frontier and the production possibility set to define technical and allocative efficiencies and later proposed measures of relative inefficiencies. DEA was first introduced by Charnes, Cooper and Rhoades (1978) to describe an application of mathematical programming to observe data to locate the frontier which can then be used to evaluate the efficiency of each of the organizations responsible for the observed output and input quantities.

DEA is based on the concept of efficiency that has been widely used in engineering and the natural sciences to measure the amount of work performed by a machine in relation to the amount of energy consumed in the process. The concept of DEA is similar to that of technical efficiency in the microeconomic theory of production. However, the main difference is that the DEA production frontier is not determined by some specific equation; instead it is generated from 
the actual data for the evaluated firms. Therefore, the DEA efficiency score for a specific firm is defined not by an absolute standard but is relative to the other firms under consideration. This feature differentiates DEA from the parametric approaches discussed earlier, which require a specific functional form. DEA also assumes that all firms face the same unspecified technology, which defines their production possibility set. The main objective of DEA is to determine which firms are operating on their efficient frontier and which firms are not. If the firm's input-output combination lies on the DEA frontier, the firm is considered efficient; and the firm is considered inefficient if the firm's input-output combination lies inside the frontier.

Consider a general situation where we have $\mathrm{n}$ decision making units (DMUs) and each consumes the same $\mathrm{m}$ inputs to produce the same s outputs. Precisely, $\mathrm{DMU}_{\mathrm{j}}$ uses $x_{i j}(I=1,2,3 \ldots, \mathrm{m})$ of input $i$ to produce $y_{r j}(r=1,2 \ldots \ldots, s)$ of output $r$ assuming that $x_{i j}>0$ and $y_{r j}>0$ (Seiford and Thrall, 1990). The specific DMU being evaluated has to solve the following optimization problem:

subject to the constraints:

$$
\operatorname{Maxh}_{0}=\sum_{r=1}^{s} u_{r} y_{r o} / \sum_{i=1}^{m} v_{r} x_{i 0}
$$

$$
\sum_{r=1}^{s} u_{r} y_{r j} / \sum_{i=1}^{m} v_{i} x_{i j} \leq 1, u_{r} \geq 0, v_{i} \geq 0
$$

for $i=1,2, \ldots, m ; r=1,2, \ldots s ; j=1,2, \ldots ., n$. where $\mathrm{h}_{\mathrm{o}}$ is the ratio of virtual outputs to virtual inputs, the $u_{r}$ 's and the $v_{j}$ 's are the variables and the $y_{r o}$ 's and the $x_{j o}$ ' $s$ are the observed output and input values of the DMU to be evaluated. A set of normalizing constraints guarantees that no DMU, including the one evaluated, can obtain an efficiency score that exceeds unity. Thus, DEA establishes a benchmark efficiency score of unity that no individual firm can exceed. If the efficiency score $h_{o}=1, \mathrm{DMU}_{\mathrm{o}}$ satisfies the necessary condition to be DEA efficient; otherwise it is DEA inefficient.

The basic DEA model (CCR model) implied the assumption of constant returns to scale. This assumption was later relaxed to allow for the evaluation of variable returns to scale and scale economies. Specifically, the efficient frontier may be derived using four alternative returns to scale assumptions; constant returns to scale (CR); variable returns to scale (VR), non-increasing returns to scale (NI); and non-decreasing returns to scale (ND). Yue (1992) defined the following assumptions. A bank exhibits increasing returns to scale (IRS) if a proportionate increase in inputs and outputs places it inside the production frontier. A bank exhibits constant returns to scale if a proportionate increase or decrease in inputs or outputs move the firm either along or above the frontier. A bank which is not on the frontier is defined as experiencing non-increasing returns to scale if the hypothetical bank with which it is compared exhibits either constant (CRS) or decreasing returns to scale (DRS). A similar definition applies for non-decreasing returns to scale. A firm which is efficient under the assumption of variables returns to scale (VRS) is considered technologically efficient; the VRS score represents pure technical efficiency (PT), whereas a firm which is efficient under the assumption of constant returns to scale (CRS) is technologically efficient and also uses the most efficient scale of operation. Aly et. al., (1990), suggests that from the measures of technical (T) and pure technical (PT) efficiency, it is possible to derive a measure of scale efficiency:

$$
\begin{aligned}
S=T / P T \text { or } \\
\\
S=C R S / V R S
\end{aligned}
$$

where $0 \leq \mathrm{S} \leq 1$ since $\mathrm{CR} \leq \mathrm{VR}$. If the value of $\mathrm{S}$ equals 1 , the firm is scale efficient and all values less than 1 reflect scale inefficiency. If scale inefficiency exists $(S<1)$, the source of inefficiency is the result of operating at either increasing $(N I<V R)$ or decreasing $(N I=V R)$ returns to scale.

There are a number of studies examining relative efficiency using DEA (Sufian and Abdul Majid 2007; Li 2006; Sufian 2006; Sufian 2004). Sufian and Abdul Majid (2007) analysed efficiency change of Singapore commercial banks during the period of 1993-2003. They found that commercial banks in Singapore exhibited an average overall efficiency of 95.4 percent. Li (2006) investigated the scale-efficiency and technology-efficiency of 14 Chinese commercial banks. She concluded that most banks have low comparative-efficiency. She also found that inefficient banks generally had input surplus. Sufian (2006) investigated the efficiency of non-bank financial institutions in Malaysia for the period 2000-2004. The study found that finance companies were more efficient than merchant banks and that the inefficiency was the result of pure technical inefficiency rather than scale inefficiency. Using DEA to examine the efficiency effects of bank mergers and acquisition in Malaysia, Sufian (2004) found that Malaysian banks exhibited a commendable overall efficiency level of 95.9 percent during 1998-2003 which indicates that the merger programme was successful. 


\section{Data and Specification of Bank Inputs and Outputs}

This study includes all commercial banks where data is available. 9 domestic banks and 13 foreign banks were included (See Table 1). The annual balance sheet and income statement used were taken from BANKSCOPE - Fitch's International Bank Database.

The evaluation of bank efficiency creates several problems which arise as a result of the nature and function of financial intermediaries, especially as banks are multi-product firms that do not produce or market physical products. One of the major problems in the study of bank efficiency is the specification of bank inputs and outputs. There has been long-standing disagreement among researchers over what banks produce. The most debatable issue is the role of deposits and, more specifically, whether they should be treated as inputs and/or outputs. Some researchers such as Elyasiani and Mehdian (1990), and Lang and Welzel (1996), treat them as inputs, but researchers such as Berger and Humphrey (1991), and Ferrier and Lovell (1990), treat deposits as outputs while other researchers such as Humphrey (1990) and Aly et. al., (1990) treat them simultaneously as inputs and outputs.

Generally, there are two ways of measuring bank outputs; the production approach and the intermediation approach. Under the production approach, banks produce accounts of various sizes by processing deposits and loans, and incurring capital and labour costs. Thus, in this approach, outputs are measured by the number of deposits and loan accounts or the number of transactions performed on each type of service provided, and costs are the operating costs needed to produce these products.

Under the intermediation approach, banks are treated as financial intermediaries that combine deposits, labour and capital to produce loans and investments. The values of loans and investments are treated as output measures; labour, deposits and capital are inputs; and operating costs and financial expenses comprise total cost.

The choice of input and output variables thus constitutes a major difficulty, which must be addressed carefully. Such choice however, will be influenced by a number of factors, such as, the selected concept of the banking firm and the questions under consideration. The availability of reliable information also has some effect on the measures used in published research on this topic. Moreover, whether products should be measured in terms of the number of accounts or dollar values depends on the various reasons being considered. For example, Kolari and Zardkoohi (1987), prefer to use dollar values for three reasons: Firstly, banks compete to increase the market share for dollar amounts, as opposed to the number of accounts; secondly, different accounts have different costs; for example, demand deposit accounts might be more costly to maintain than time deposit accounts (although, if these accounts were to have the same costs, then the use of the number of accounts would be equivalent); finally, banks are multi service firms and the dollar amount is the only common denominator; for example, securities investments cannot be measured in terms of number of accounts.

This study uses the intermediation approach to define bank inputs and outputs. Accordingly, two inputs and one output are used consisting of:

Y: Total Earning Assets

$\mathrm{X}_{1}$ : Total Deposits

$\mathrm{X}_{2}$ : Total Overhead Expenses

Table 2 presents the descriptive statistics of outputs and inputs used in the study.

\section{Empirical Findings}

All computation was performed using the DEAFrontier program. The efficiency of commercial banks in Malaysia was first examined by applying the DEA approach for each year by using a separate frontier for domestic and foreign banks. Table 3 reports the mean, standard deviation and extreme values of the various efficiency scores for the groups of banks: domestic and foreign banks for all years 2000-2006. For each year, our results suggest that domestic banks exhibited higher mean overall efficiency ( 88.7 percent) compared to their foreign counterparts ( 73.3 percent). Our results also suggest that domestic bank inefficiency were attributed to pure technical inefficiency rather than scale inefficiency. In contrast, foreign bank inefficiency is attributed to scale inefficiency rather than pure technical inefficiency.

The results for the pooled sample for domestic and foreign banks have in general confirmed our earlier findings that pure technical inefficiency is the dominant factor in influencing domestic bank inefficiency whereas scale inefficiency is the dominant factor in influencing foreign bank inefficiency. During the period 2000-2006, our results suggest that domestic banks exhibited a higher mean pure technical efficiency of 92.4 percent compared to foreign banks (91.5 percent). This suggests that domestic banks are managerially efficient in controlling costs compared to their foreign counterparts. During the period of study, domestic banks exhibited a mean overall efficiency of 88.7 percent, suggesting a mean input waste of 11.3 percent. On the other hand, mean overall efficiency for foreign banks was 73.3 percent, indicating an input waste of 26.7 percent. However, it is interesting to note that the degree of technical efficiency for domestic banks is lower than the degree of scale efficiency, which indicates that a portion of overall inefficiency is due to producing below the production frontier rather than producing on an inefficient scale. 
Figures 1 and 2 depict the mean overall, pure technical efficiency and scale efficiency for commercial banks according to ownership structure for the years 2000 to 2006.

Most of the technical inefficiency exhibited by the banks stem from operating at the wrong scale; ether operating at a scale that was too large (DRS) or operating at a scale that was too small (IRS). Since the major source of inefficiency in the Malaysian commercial bank is scale inefficiency, this study then examines further the trend in the returns to scale of Malaysian commercial banks. The results are reported in Table 4.

The results suggest that the share of scale efficient banks (CRS) was small. The share of scale efficient domestic banks has declined over the six year period; from 29 percent in 2000 to 22 percent in 2006. Similar results are found for foreign banks operating at efficient scale; 27 percent in 2000 declined to 8 percent in 2006.

Overall, the results suggest that a majority of domestic banks are operating in the region of increasing returns to scale. The number of domestic banks experiencing economies of scale (IRS) remained somewhat stable over the period even though the share has increased over the same period (29 percent in 2000 compared to 44 percent in 2006). Similarly, the number of banks experiencing diseconomies of scale (DRS) has remained somewhat stable but the share has declined (43 percent in 2000 compared to 33 percent in 2006). A majority of foreign banks are operating in the region of decreasing returns to scale. The share of foreign banks experiencing economies of scale (IRS) has declined from 27 percent in 2000 to 0 percent in 2006 whereas the share of banks experiencing diseconomies of scale (DRS) has increased from 45 percent in 2000 to 92 percent in 2006.

The results for all years (pooled sample) suggest that the share of domestic banks experiencing economies of scale is 46 percent and the share of domestic banks experiencing diseconomies of scale is 49 percent. A majority of foreign banks are operating at the diseconomies of scale, 93 percent compared to 3 percent operating at economies of scale.

After examining both the efficiency scores and sources of inefficiencies, we investigate further whether each group of bank, domestic and foreign banks, are drawn from the same population and whether these two groups possess the same technology:

$$
\begin{aligned}
& H_{0}=\text { Domestic banks and foreign banks are drawn from the same environment or technology } \\
& H_{l}=\text { Domestic banks and foreign banks are drawn from a different environment or technology }
\end{aligned}
$$

Both parametric (analysis of variance and $t$-test) and non-parametric (Mann-Whithey[Wilcoxon Rank-Sum] and Kolgomorov -Smirnov tests are used to test the null hypothesis that the two groups are drawn from the same population and have identical technologies. The results are presented in Table 5. From the results, we failed to reject the null hypothesis for the first five years (2000-2004) but not for the most recent years (2005 and 2006). This suggests that banks observed in recent years have access to different and more efficient technology compared to those banks in the first five years. Therefore we can conclude that from 2005 onwards, it is appropriate to separate the samples because these two groups of banks, domestic and foreign banks, have different technologies.

\section{Conclusion}

This study attempts to investigate the efficiency of Malaysian commercial banks during the period of 2000-2006. Using A non-parametric approach Data Envelopment Analysis (DEA) methodology enabled us to distinguish between technical, pure technical and scale efficiencies. We have run tests for each year, for domestic banks, foreign banks, and for all banks for all years.

The results suggest that the mean overall or technical efficiency improved during the period under investigation. Overall, for all the years (2000-2006), pure technical efficiency dominates the scale efficiency effects in determining the Malaysian commercial banks overall or technical efficiency. This is confirmed by the overall results (2000-2006), pure technical efficiency is 89.3 percent and scale efficiency is 79.4 percent.

During the period of study, we found that overall or technical efficiency of domestic banks was 73.3 percent, slightly higher than the foreign banks overall or technical efficiency (70.9 percent). The results suggest that domestic banks pure technical efficiency is lower than the degree of scale efficiency implying that during the period of study, domestic banks have been inefficient in controlling their costs rather than operating at the wrong scale. In contrast, foreign bank pure technical efficiency is higher than scale efficiency indicating that foreign banks were operating at the wrong scale of operations rather than producing below the production frontier.

Further investigation indicates that banks observed in recent years have access to different and more efficient technology compared to that in the first five years. Therefore we can conclude that from 2005 onwards, it is appropriate to separate the samples because these two groups of banks, domestic and foreign banks, have access to different technologies and environment. 
As a caveat, the results should be interpreted with caution since previous researches differ substantially regarding different estimation procedures. Further studies should use different estimation approaches allowing a comparison of results.

\section{References}

Aly, H. Y., Grabowski, R., Pasurka, C., \& Rangan, N. (1990). Technical, scale and allocative efficiencies in US banking: An empirical investigation. The Review of Economics and Statistics, 72: 211-218.

Aigner, D. A., Lovell, A.K., \& Schmidt, P. (1977). Formulation and estimation of Stochastic Frontier Production Models. Journal of Econometrics, 6:21-37.

Berger, A. N. (1993). "Distribution-Free" estimates of efficiency in the US banking industry and tests of the Standard Distributional Assumptions. The Journal of Productivity Analysis, 4:261-92.

Berger, A. N. \& Humphrey, D. B. (1991). The Dominance of inefficiencies over scale and product mix economies in banking, Journal of Monetary Economics, 28:117-48.

Charnes, A., Cooper, W.W. \& Rhoades, E. (1978). Measuring the efficiency of Decision Making Units, European Journal of Operational Research, 6:429-444.

Elyasiani, E. \& Mehdian, S. M. (1990). A Nonparametric Approach to measurement of efficiency and technological change: The Case of large U.S. commercial banks. Journal of Financial Services Research, 4 (2): 157-68.

Farell, M. J. (1957). The measurement of productive efficiency. Journal of the Royal Statistical Society 120, Part 111, Series A: 253-81.

Ferrier, G. D., \& Lovell, C. K. (1990). Measuring cost efficiency in banking: econometrics and linear programming evidence. Journal of Econometrics, 46:229-245.

Humphrey, D. B. (1990). Why do estimates of bank scale economies differ? Economic Review, Federal Reserve Bank of Richmond, September/October: 38-50.

Ikhide S. (2000). Efficiency of commercial banks in Namibia. Bank of Nigeria Occasional Paper, No. 4.

Koetter M. (2005). Measurement matters-input price proxies and bank efficiency in Germany, Discussion Paper Series 2: Banking and Financial Studies no. 01.

Kolari, J. \& Zardkoohi A. (1987). Bank Cost, Structure and Performance, Lexington, Mass: Lexington Books.

Kwan S. H., \& Eisenbeis R. A. (1996). An Analysis of Inefficiencies in Banking: A Stochastic Cost Frontier Approach. Federal Reserve Bank of San Francisco Economic Review, No. 2.

Lang, G., \& Welzel, P. (1996). Efficiency and technical progress in banking: Empirical results for a panel of German Cooperative Banks. Journal of Banking and Finance, 20: 1003-23.

Li, Z. (2006). The assessment analysis of efficiency of commercial banks based on DEA Model. International Management Review, 2(3): 60-66.

Meesun, W. \& Broeck, J.V.D. (1977). Efficiency Estimation from Cobb-Douglas Production Functions with Composed Error. International Economic Review, 18(2): 435-44.

Okuda, H., Hashimoto, H. \& Murakami, M. (2003). The estimation of Stochastic Cost Functions of Malaysian commercial banks and its policy implications to bank restructuring. Centre for Economic Institutions Working Paper Series, No. 2003-2.

Sufian, F. (2004). The efficiency effects of bank mergers and acquisitions in a developing economy: Evidence from Malaysia. International Journal of Applied Econometrics and Quantitative Studies, 1-4: 53-74.

Sufian, F. (2006). The efficiency of non-bank financial institutions: Empirical evidence from Malaysia. International Journal of Finance and Economics Issue 6 retrieved from www.eurojournals.com/finance.htm

Sufian, F. \& Abdul Majid, M.Z. (2007). Singapore banking efficiency and its relation to stock returns: A DEA Window Analysis Approach. International Journal of Business Studies, 15(1): 83-106.

Worthington A. C. (1998). The determinants of non-bank financial institution efficiency: A Stochastic Cost Frontier Approach. Applied Financial Economics, 8(3): 279-289.

Yildrim, H. S. \& Philippatos G. C. (2007). Efficiency of banks: Recent evidence from the Transition Economies of Europe, 1993-2000. The European Journal of Finance, 13(2):123-143.

Yue, P. (1992). Data Envelopment Analysis and commercial bank performance: A primer with applications to Missouri banks. Federal Reserve Bank of St. Louis January/February: 31-45. 
Table 1. List of Commercial Banks

\begin{tabular}{ll}
\hline Domestic banks & Foreign Banks \\
\hline Affin Bank Berhad & The Royal Bank of Scotland \\
Alliance Bank Malaysia Berhad & Bangkok Bank Berhad \\
AmBank Malaysia Berhad & Bank of America \\
CIMB Bank Berhad & The Bank of Nova Scotia \\
EON Bank Berhad & Bank of China (Malaysia) Berhad \\
Hong Leong Bank Berhad & Bank of Tokyo-Mitsubishi UFJ (Malaysia) Berhad \\
Malayan Banking Berhad & Citibank Berhad \\
RHB Bank Berhad & HSBC Bank Malaysia Berhad \\
Public Bank Berhad & United Overseas Bank (Malaysia) Bhd. \\
& Standard Chartered Bank Malaysia Berhad \\
& JP Morgan Chase Bank Berhad \\
& OCBC Bank (Malaysia) Berhad \\
& Deutsch Bank \\
\hline
\end{tabular}

Source: Bank Negara Malaysia

Table 2. Descriptive Statistics for Input and Output, 2000-2006 (In RM Million)

\begin{tabular}{clllllll}
\hline \multirow{2}{*}{ All Banks } & Variable & $\mathbf{N}$ & Mean & Median & Minimum & Maximum & Std. Dev. \\
\cline { 2 - 7 }$n$ & & & & & & & \\
$\mathrm{Y}$ & 147 & 28300.14 & 19669.00 & 508.90 & 189518.10 & 34256.54 \\
$\mathrm{X}_{1}$ & 147 & 24477.63 & 17172.50 & 190.10 & 164392.60 & 29819.88 \\
$\mathrm{X}_{2}$ & 147 & 1073.91 & 825.20 & 6.60 & 2784.00 & 1212.98 \\
$\begin{array}{r}\text { Domestic banks } \\
\mathrm{Y}\end{array}$ & 59 & 53196.17 & 38644.60 & 8826.00 & 189518.10 & 40747.25 \\
$\mathrm{X}_{1}$ & 59 & 46037.12 & 33733.30 & 6955.90 & 164392.60 & 35478.75 \\
$\mathrm{X}_{2}$ & 59 & 761.70 & 571.90 & 124.20 & 2784.00 & 572.60 \\
Foreign Banks & & & & & & \\
$\mathrm{Y}$ & 88 & 11608.48 & 3124.30 & 508.90 & 39324.00 & 12660.97 \\
$\mathrm{X}_{1}$ & 88 & 10022.98 & 2614.20 & 190.10 & 35417.30 & 11249.28 \\
$\mathrm{X}_{2}$ & 88 & 191.09 & 63.25 & 6.60 & 875.10 & 231.24 \\
\hline
\end{tabular}


Table 3. Descriptive Statistics of the Efficiency Measures, 2000-2006

\begin{tabular}{|c|c|c|c|c|c|c|c|}
\hline \multicolumn{4}{|c|}{ Domestic Banks } & \multicolumn{4}{|c|}{ Foreign Banks } \\
\hline 2000 & OE & PTE & SE & 2000 & $\mathbf{O E}$ & PTE & $\mathbf{S E}$ \\
\hline Mean & 0.949 & 0.970 & 0.978 & Mean & 0.861 & 0.963 & 0.896 \\
\hline Std. Dev & 0.052 & 0.035 & 0.022 & Std. Dev & 0.111 & 0.079 & 0.107 \\
\hline Minimum & 0.869 & 0.915 & 0.936 & Minimum & 0.723 & 0.741 & 0.730 \\
\hline Maximum & 1.000 & 1.000 & 1.000 & Maximum & 1.000 & 1.000 & 1.000 \\
\hline 2001 & OE & PTE & SE & 2001 & OE & PTE & SE \\
\hline Mean & 0.951 & 0.978 & 0.973 & Mean & 0.889 & 0.975 & 0.913 \\
\hline Std. Dev & 0.035 & 0.035 & 0.025 & Std. Dev & 0.089 & 0.060 & 0.082 \\
\hline Minimum & 0.893 & 0.908 & 0.935 & Minimum & 0.740 & 0.799 & 0.740 \\
\hline Maximum & 1.000 & 1.000 & 1.000 & Maximum & 1.000 & 1.000 & 1.000 \\
\hline 2002 & OE & PTE & SE & 2002 & OE & PTE & SE \\
\hline Mean & 0.968 & 0.975 & 0.993 & Mean & 0.792 & 0.939 & 0.845 \\
\hline Std. Dev & 0.036 & 0.035 & 0.005 & Std. Dev & 0.138 & 0.084 & 0.133 \\
\hline Minimum & 0.889 & 0.898 & 0.985 & Minimum & 0.609 & 0.762 & 0.609 \\
\hline Maximum & 1.000 & 1.000 & 1.000 & Maximum & 1.000 & 1.000 & 1.000 \\
\hline 2003 & OE & PTE & SE & 2003 & $\mathbf{O E}$ & PTE & SE \\
\hline Mean & 0.905 & 0.973 & 0.930 & Mean & 0.858 & 0.955 & 0.896 \\
\hline Std. Dev & 0.065 & 0.037 & 0.047 & Std. Dev & 0.134 & 0.071 & 0.106 \\
\hline Minimum & 0.833 & 0.913 & 0.869 & Minimum & 0.654 & 0.776 & 0.720 \\
\hline Maximum & 1.000 & 1.000 & 1.000 & Maximum & 1.000 & 1.000 & 1.000 \\
\hline 2004 & OE & PTE & SE & 2004 & OE & PTE & SE \\
\hline Mean & 0.945 & 0.984 & 0.961 & Mean & 0.855 & 0.958 & 0.891 \\
\hline Std. Dev & 0.053 & 0.025 & 0.044 & Std. Dev & 0.125 & 0.063 & 0.104 \\
\hline Minimum & 0.852 & 0.939 & 0.869 & Minimum & 0.680 & 0.802 & 0.728 \\
\hline Maximum & 1.000 & 1.000 & 1.000 & Maximum & 1.000 & 1.000 & 1.000 \\
\hline 2005 & OE & PTE & SE & 2005 & OE & PTE & SE \\
\hline Mean & 0.946 & 0.981 & 0.964 & Mean & 0.845 & 0.976 & 0.865 \\
\hline Std. Dev & 0.043 & 0.034 & 0.032 & Std. Dev & 0.137 & 0.049 & 0.124 \\
\hline Minimum & 0.886 & 0.895 & 0.919 & Minimum & 0.633 & 0.856 & 0.641 \\
\hline Maximum & 1.000 & 1.000 & 1.000 & Maximum & 1.000 & 1.000 & 1.000 \\
\hline 2006 & OE & PTE & SE & 2006 & OE & PTE & SE \\
\hline Mean & 0.935 & 0.987 & 0.947 & Mean & 0.845 & 0.989 & 0.854 \\
\hline Std. Dev & 0.045 & 0.021 & 0.042 & Std. Dev & 0.101 & 0.023 & 0.098 \\
\hline
\end{tabular}




\begin{tabular}{lccc|lcrrr}
\cline { 5 - 8 } Minimum & 0.886 & 0.940 & 0.886 & Minimum & 0.741 & 0.928 & 0.741 \\
Maximum & 1.000 & 1.000 & 1.000 & Maximum & 1.000 & 1.000 & 1.000 \\
\hline All & OE & PTE & SE & All & OE & PTE & SE \\
\hline Mean & 0.887 & 0.924 & 0.961 & Mean & 0.733 & 0.915 & 0.803 \\
Std. Dev & 0.049 & 0.054 & 0.036 & Std. Dev & 0.126 & 0.073 & 0.132 \\
Minimum & 0.788 & 0.807 & 0.862 & Minimum & 0.516 & 0.732 & 0.574 \\
Maximum & 1.000 & 1.000 & 1.000 & Maximum & 1.000 & 1.000 & 1.000
\end{tabular}

Note: $\mathrm{OE}=$ Overall efficiency, $\mathrm{PTE}=$ Pure technical efficiency, $\mathrm{SE}=$ Scale efficiency

Table 4. Developments in Returns to Scale (RTS) in Malaysian Commercial Banks According to Ownership

\begin{tabular}{clcccc}
\hline Year & Ownership & IRS & CRS & DRS & Total \\
\hline \multirow{2}{2}{000} & Domestic Banks & $2(29)$ & $2(29)$ & $3(43)$ & $7(100)$ \\
& Foreign Banks & $3(27)$ & $3(27)$ & $5(45)$ & $11(100)$ \\
\hline \multirow{2}{*}{2001} & Domestic Banks & $4(50)$ & $2(25)$ & $2(25)$ & $8(100)$ \\
& Foreign Banks & $4(36)$ & $3(27)$ & $5(45)$ & $11(100)$ \\
\hline \multirow{2}{*}{2002} & Domestic Banks & $3(38)$ & $2(25)$ & $3(38)$ & $8(100)$ \\
& Foreign Banks & $1(8)$ & $2(15)$ & $10(77)$ & $13(100)$ \\
\hline \multirow{2}{*}{2004} & Domestic Banks & $3(33)$ & $2(22)$ & $4(44)$ & $9(100)$ \\
& Foreign Banks & $0(0)$ & $4(31)$ & $9(69)$ & $13(100)$ \\
\hline \multirow{2}{*}{2005} & Domestic Banks & $4(44)$ & $2(22)$ & $3(33)$ & $9(100)$ \\
& Foreign Banks & $2(15)$ & $3(23)$ & $8(62)$ & $13(100)$ \\
\hline \multirow{2}{*}{2006} & Domestic Banks & $4(44)$ & $2(22)$ & $3(33)$ & $9(100)$ \\
& Foreign Banks & $1(8)$ & $3(23)$ & $9(69)$ & $13(100)$ \\
\hline \multirow{2}{*}{$(2000-2006)$} & Domestic Banks & $4(44)$ & $2(22)$ & $3(33)$ & $9(100)$ \\
& Foreign Banks & $0(0)$ & $1(8)$ & $12(92)$ & $13(100)$ \\
\hline & Domestic Banks & $27(46)$ & $3(5)$ & $29(49)$ & $59(100)$ \\
& Foreign Banks & $3(3)$ & $3(3)$ & $82(93)$ & $88(100)$ \\
\hline
\end{tabular}

Note: Figures in parentheses are in percentages 
Table 5. Summary of Parametric and Non-Parametric Tests

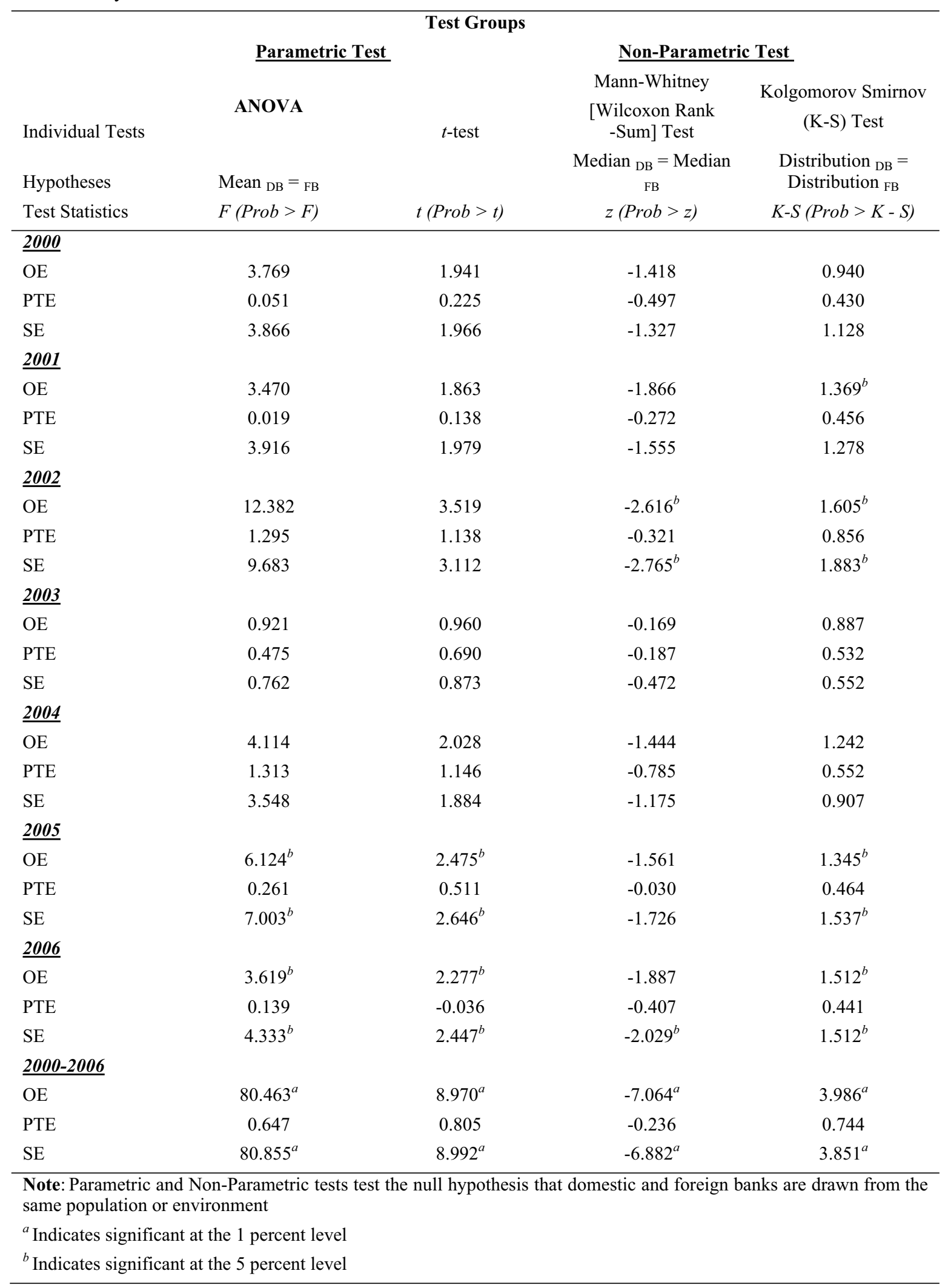



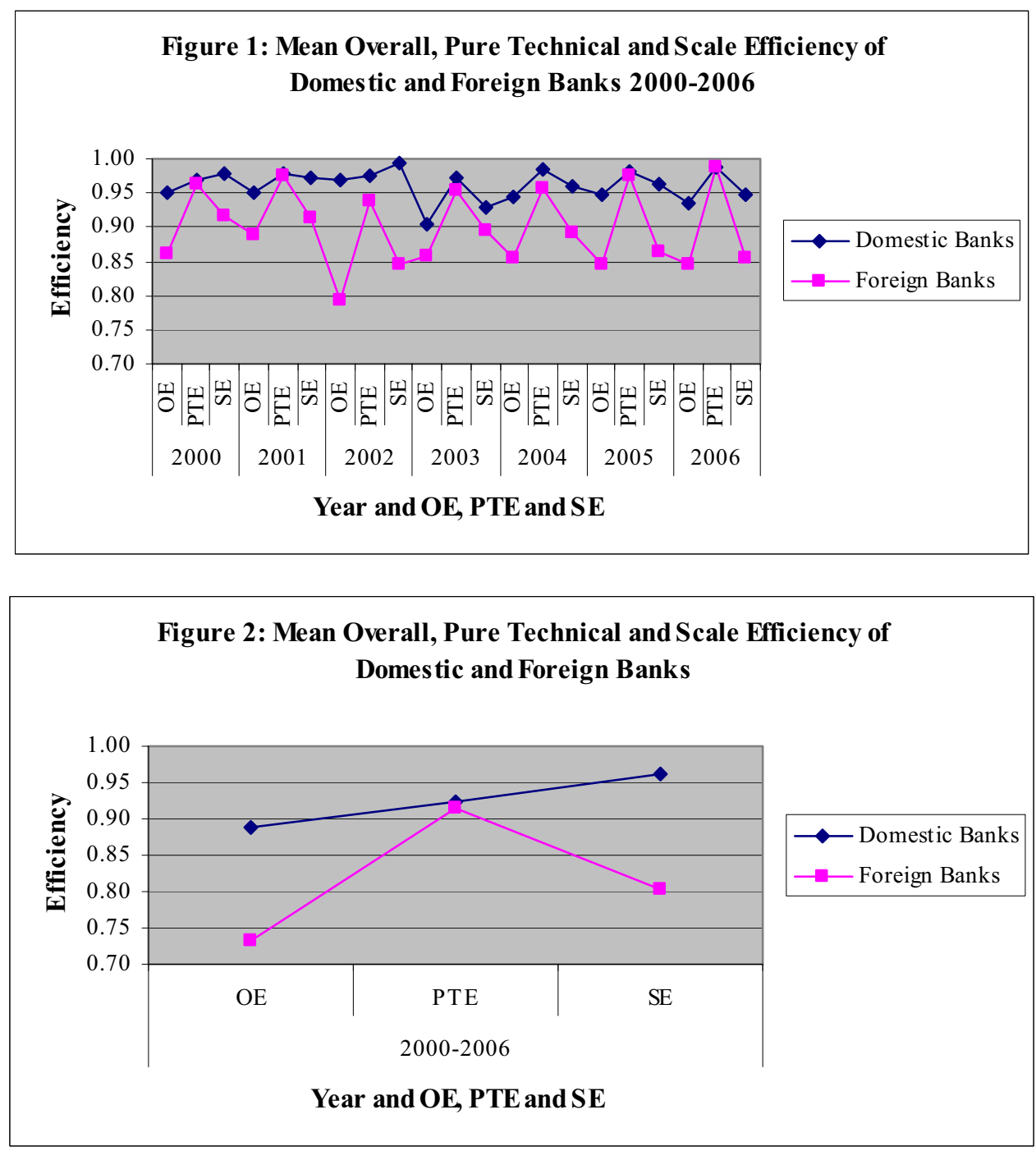


\title{
Cluster-mapping in China: the Empirical Evidence
}

\author{
Zhenming Sun \\ The O\&M Project Management, Sinoma SCC Project \\ Na Bi WU PO box 67105 \\ AL-HASSA 31928, Kingdom of Saudi Arabia \\ Tel: 96-6-532-076-880Ｅ-mail: masseyjamiesun@gmail.com
}

\begin{abstract}
A clear and precise exercise of cluster mapping may be viewed as the prerequisite for cluster identification and then for policy intervention designed to promote cluster development. In practice, there is no existing cluster mapping exercise widely accepted. However, there is no reason for stopping the endeavors to promote and standardize cluster mapping practice. This paper focuses on the review of cluster mapping exercises in China.
\end{abstract}

Keywords: Cluster, Cluster mapping, China, Empirical evidence

\section{Introduction}

For researchers and policy-makers, cluster identification is the initial step towards determining whether occurrence of business clusters is changing and in evaluating the possibility of endeavors to promote cluster formation (Perry, 2005). Unfortunately, so far, there is no agreed method to identify and map the distribution of business clusters. Even some strong advocators have to acknowledge that there are many handicaps to a kind of comprehensive and rigorous identification(Martin \& Sunley, 2003). Whatever researchers interpret and adapted the cluster definition in various ways, or they take various ways of information and various methods to identify clusters empirically, the outcomes that varying claims are made for the number of clusters exist and where they located (Martin \& Sunley, 2003). However, for example, if cluster applicants do not fit the categories identified in official statistics, it, thus, risks possible potentially large clusters being unrecognized. Such an example shown with a concentration of 54 domestic ceramic companies, encompassing more than 30,000 jobs in Beiliu City, Guangxi Province (Zhang, 2006). Official employment statistics allocated this sector among related industries. Once revealed, executives reportedly came together to work on issues of mutual interest, creating a stronger cluster. Consequently, to avoid misinforming executives about cluster status, measurement needs to be accuracy (Perry, 2005).

On the surface, a clear and comprehensive definition may be as a prerequisite for mapping clusters' frequency. However, all contemporary definitions for clusters ten to be short on explicit guidelines for cluster mapping (Perry, 2005). Porter (1998) defines cluster as "geographically proximate group of interconnected companies and associated institutions in a particular field, linked by commonalities and complementarities", which still offer seldom interpretation how to count clusters. Furthermore, a simplified concept, for example, " a regional cluster is an industrial cluster in which member firms are in close proximity to each other"(Enright, 1996). This simple concept poorly discuss on the issues how many activities constitutes a clusters and how close proximity must be, industrial categories and geographical boundaries can be adopted either to maximize or minimize the number of clusters counted (Perry, 2005).

Besides this, other four clustering-mapping strategies can be summarizes:

- One approach is to rely on " local experts", normally simply ask regional governmental agents $\mathrm{r}$ economic development agents to supply lists of regional clusters in their area which are then focused on more details (Martin \& Sunley, 2003).

- The development of cluster typologies may be considered as the second approach to cluster mapping.

- A third strategy for cluster mapping concentrates on the expected outcome of clusters. The main trend for individual studies of clusters to concentrates on successful stories is more likely to adopt outcome focus.

- The last mapping strategy is to use an input focus and seeks to identify clusters by the attributes that are expected to change firm behavior and performance. Generally, there are two basic attributes attached to clusters: one is 
connectedness, another is concentration.

Nevertheless, this is not the reason for stopping the endeavors to promote and standardize cluster mapping efforts. In the following section, this paper focuses on the review of cluster-mapping practices. Then, an evaluation of such practices is concluded.

\section{Cluster mapping in China}

There are really limited of cluster mapping concentration of Chinese manufacturing industries across the provinces or regions. Two cluster-mapping projects conducted in China, published in 2004 and 2005, share a stronger commitment to the conception of clusters as unique, local phenomena than Porter's cluster mapping project's emphasis on national industrial clusters (Ni, Hou, Jiang, \& Wang, 2005; Wang, Hou, \& Zhang, 2004). Both involve the use of location quotients (LQ). Furthermore, Wang, Hou \& Zhang (2004) specifically focus on Chinese auto manufacturing sector. So, with respect to such sector, direct comparison of the result may be possible due to the common base regions. Both studies conducted sought to identify geographically co-located activities whose interrelations reinforced their competitive advantage. In comparison to other countries such as French (Luxembourg, 2003) and the United Kingdom (Crouch \& Farrell, 2001) where the analysis is generally based on regional concentrations of industries defined at the five-digit SIC level, it defined at two or three-digit SIC level result in that Chinese national guoming jingji hangye fenglei yu daima (industrial identification and coding) system (GB/T4754-94) adapted two or three SIC. Therefore, it leads to that identification of clusters in China is problematic. In the study of $\mathrm{Ni}$ et al, for example, there are 47 cities where is the existence of transportation equipment manufacturing according the classification of GB/T $4754-94$. Based on the classification of manufacturing- transportation equipment manufacturing-ship floating device manufacturing, Dalian government classified into shipbuilding clusters. In comparison with Dalian, some regional governmental classified into of transportation equipment manufacturing clusters which includes tricycle manufacturing which should not classified into shipbuilding manufacturing sector, and it further weak the characteristics of clusters. Therefore, the denomination of clusters between regions based on the local requirement of development are various, which would seriously impact either the comparison of same types of clusters and distinguishing cluster or the cooperation across regions. Furthermore, such cluster mapping has two major limitations:

First, it assume is regions or nations are at the same level associated with labour productivity. One industry in some regions with a higher labour productivity, for example, will require less workforce than national average level of whole nation. In such situation, the coefficient of LQ might undervalue the clustering of this industry.

Second, the assumption is same in the terms of production and consumption model between local and national.

With the recognition of Porter's interpretation of clusters, Nevertheless, the analysis taken by Ni et al (2005) assumes clusters typically comprise linked activity from multiple industries. Hence, such efforts are given to seeking to build connections among industries. To the extent, they argue that business cluster has life cycle, and following the occurrence or closure of businesses, and the changes on local institutions, clusters evolve. Broadly, the tendency of cluster is further development. The development path can be divided into two stages (see the table 1). There is no difference from any cluster-mapping projects in other nations.

Another typical anecdotal cluster mapping project published in 2005 (Y. Zhu, 2005). A use of input-out data is to identify China business clusters. He suggests a method of descriptive approach to the analysis of industrial sectors. I $n$ particular, he lays out a means of using detailed information on national spatial industrial linkages that help identifying existing and potential clusters in China. Following the works of two researchers (Slater, 1977; D. Zhu, 2000),the functional linkages between individual industries are first estimated for Chinese economies. Such linkages can be shown to 'cluster' at the national level to present the linked re-aggregations of decimalized categories in the Standard Industrial Classification (SIC) system. When used in subsequent industrial sector analyses, the national clusters, in fact, has serve as templates for developing a strategic that is wholly distinct from the revealed through typical studies and data analyses that rely upon board the classification of GB/T 4754-94. The linkages are revealed by principal components factor analysis applied to the 1997 China input-output accounts. Interpretation of the consequence is guided by the objective to identify clusters based on separate industries with the tightest linkage to each other, allowing some cluster applicants to be interacted to other clusters as well. Specifically, Zhu (2000) identifies that there are 4 overall types, and 11 sub-types of business clusters in China. That is, business clusters is a system comprised by various industrial sectors. Such 11 sub-type business clusters comprise 96 industrial sectors, accounting for $78.2 \%$ with an output value of 16603.591 billion RMB and 83.1\% output value. By grouping those industrial sectors, that are most likely to interact with each other, both directly and indirectly, the cluster templates reveal relative specializations in various industries by exposing otherwise opaque extended functional chains. Hence, they are a valuable analytic tool for the design of economic development strategies that look forwards to exploiting or leveraging direct and indirect inter-sector linkages, or enhancing cross-regional cooperation. To some extent, guidance form such national analysis is judged better than an investigation of actual input-output linkages in the locality of interests. While local data reveal existing connectedness, they do not figure out gaps in functional linkages that may suggest potential development. 
Applied to one of recommendations of Zhu (2005), he argues that, for example, planting clusters and textile cluster seriously relying on condition of demand should the meet the existing demand, as well as creating new demand opportunities to promote China economic development. Similarly, applied to data from 1992 and 1997 provincial input-out tables, it shows that geographic agglomeration in industries with important comparative advantages, tightly supply linkages and high market potential (Batisse \& Poncet, 2003). They further claims that larger location quotients for industries experiencing high protection from interregional competition.

One more distinguish econometric contribution to the study of clusters are conducted by Chen (1996). In his study, he estimated sectoral value added as a function of capital, labour, and a function of factor multiplier that consists of five components, including agglomeration. Compared with machinery sector, the maximum impact of agglomeration on productivity in food sector is smaller (Chen, 1996). Following work of Chen (1996), Fan \& Scott (2003) proposes a framework similar to Chen's and on this basis seek to push the study of industrial concentration in China forward one more notch. Generally speaking, the procedure of their study can be divided into two phases (see table 2)

Applied to data from the second and the third national industrial censuses in 1980 and 1995, Wen (2004) examines the relocation and agglomeration after economic reform. His studies divided into two stages. Firstly, it looks 3-digit industrial locational Gini in 1995, aiming painting a picture of the spatial distribution of large and medium sized manufacturers to see whether their geographical locations reflect any economic rational. In the following stage, it concentrates on a historical comparison, based on the degrees of 2-digit all industrial enterprises concentration and attempts to analyses how Chinese manufacturing is re-located and concentrated. The results show that spatial location of Chinese manufacturing sectors have changed dramatically, with higher degree of geographical concentration for many industrial sectors and the relocation of some after 1978. That is say, the location of manufacturing sectors have shifted form an issue of war-preparedness between 1953-1978 to an economic preference after post-1978. To some extent, as a result of China economic reform, the relocation of industries reflects the industrial development policies taken in the period of economic period. In china, Labour mobility can facilitate both industrial agglomeration and industrial re-location. Industrial agglomeration can still be observed from 1980-1995, although the existing household registration system limits legal permanent migration form rural to urban areas and across regions. Furthermore, while numerous illegal migrants who can facilitate industrial concentration, substantial income inequality between regions, with a high average growth rate of real wage in eastern China. Wen (2004) claims costal regions such as Guandong, Jangsu, Shandong and Zhejiang have became home to many manufacturing industries result in preferential development policies. To some extent, Clams that Gini coefficients of 25 two-digit manufacturing industries in 1980, 1985 and 1995, and shows that the majority of such industries are highly concentrated, while chemical fibers, ferrous metal smelting and pressing, and non-ferrous metal smelting and pressing tend to disperse (Wen, 2004). In addition, Wen (2004) observe that the resource-based industries tend to be concentrated and many relatively footloose industries are agglomerated in costal China, while most of the industry sectors producing goods with higher transport costs are geographically dispersed. Wen (2004) also conclude both workforce and capital tend to flow from the interior to the costal provinces due to the reality that Chinese industrial agglomeration relies on both transaction agglomeration and production agglomeration with increasing return to scale in production.

A study conducted by (He, Wei, \& Xie, 2006) examine the spatial transformation of Chinese manufacturing sector between 1980-2003, and attempt to explore and explain degrees of geographical concentration with a particular certain to the impact of Chinese transition. They establish a panel dataset comprising of all two-digit manufacturing industries by provinces to examine the temporal tendency of geographical agglomeration of such industries from 1980-2003. Meanwhile, they focus on issues on investing the role of explanatory variables in changing the geographical concentration. Applied to data from Annual Report of Chinese Industrial Statistics from 1980-2003, they adopts Gini coefficient to examine 28 manufacturing industries in their study.

In the context of temporal trends of geographic concentration, the old industrial bases and interior provinces (Shanghai, Beijing, Sichuan, Hubei, liaoning, Jilin and Heilongjiang) in Mao's era appear a decrease of Gini coefficient of industrial gross output and value added. That is, since China economic reform, Costal provinces have gradually taken the advantages in attracting investment, improving technology, and expanding industries. Because the spatial pattern of industries of industries in inland provinces has been fairly stable since 1999, it implies that national strategy of Great Western Development launching in 1999 have reduced the regional inequality in such region. In China, due to a rapid growth in labour-intensive and light industries, provinces have represented less specialized since 1980, showing an overall pattern of convergence in provincial industrial structure. As the central government implemented more radical market reforms and open door policies in the early stage of 1990s, therefore, the overall provincial output specialization has been slowly increasing since mid-1990s. Moreover, in contrast to inner provinces, all industries in coastal provinces are more dispersed. In other words, it implies that costal areas are more economically developed and share similar locational advantages while the inner areas are still in the early stage of industrialization.

With respect to spatial pattern of industrial distribution, He et al (2006) claim that most highly concentrated industries 
are clustered in Guangdong, Jiangsu, Zhejiang, Shanghai and Shandong. For example, Guangdong, Zhejiang and Shanghai account for $74 \%$ market share in culture, education and sport goods sector; Jiangsu, Zhejiang, Shandong and Fujian account for $74 \%$ market share in chemical fibers sector. Owing to favourable policy treatment and preferential access to international market, globalized industries clustering in coastal region has emerged. For example, Guandong, Fujian and Zhejiang are responsible for $57 \%$ of value added in leather and fur products in 2003. Also, their analysis indicates that spatially clustering neighbouring provinces in some industries. For example, machinery and timber processing are clustering in Yangze River Delta. In addition, in China, industrial with large share foreign of foreign enterprises and export are move agglomerated than others, and analysis results also show that globalization forces have remarkably impacted the coastal shift of all industries. In 2005, a similar study is conducted by (Catin, Luo, \& Van Huffel, 2005). Based on the classification of Chinese industrial economic statistical yearbooks (30 groups of industries), they divide these 30 industries into two categories: 4 high-tech industries and other 26 industries (including two sub-categories -9 primary materials, energy and foodstuffs, and 17 labour intensive industries). They measure the degree of geographic concentration of an industry by calculating its Gini coefficient. The results are mixed. It shows that geographic concentration of activities differs across industries and regions (Costal /inland). Ultimately, they conclude that the distribution of activities in China is resulted in openness and industrialization.

The Gini index has been the most frequently used way of assessing the degree to which the regional distribution of one variable deviates from the regional deviates form the regional distribution of a 'neutral' yardstick. A choice of neutral comparison is able to impact the extent to which a separate activity is identified to be distributed unevenly. At the provincial level, a locality perspective indicates how the proportion of a locality's activity in a single industry compares with the provincial share of that industry and is assessed using some form of location quotient.

To identify clusters in Zhejiang Province, the overall concentration of products sales revenue was examined in conjunction with a measure to the industry's importance in individual localities(Liang et al., 2005). Applied to products sales revenue, Gini coefficients express the degree to which products sales revenue in an industry sector is unequally dispersed over localities. The localization of coefficient measures the level of industry concentration in a particular locality relative to the average sales revenues in the industry among all localities. To the extent a region with a high localization coefficient in an industrial sector that has a high Gini, that is, identifies a region demonstrating a especially high degree of concentration of an business activity that is unequally dispersed.

Generally speaking, based on the outcome of this cluster-mapping, Liang et al (2005) conclude that the degree of industry concentration in Zhejiang is high, and Zhejiang has made great progress in the programme of clusters-led growth. The 'high' must have a minimum Gini coefficient of 0.5. From the period between 1998-2003, the Gini coefficient in all industry sectors of Zhejiang is over 0.5. In term of spatial concentration, except timber processing and bamboo and rattan palm and grasses and other products manufacturing industry, Gini coefficient in each industry is higher than national average level, that is to say, there is a high degree of industry spatial concentration. More importantly, during the period from 1998-2003, the spatial concentration in Zhejiang manufacturing sector is gradually optimized. In Zhejiang, there are numerous examples of industries dominated by small firms that have high rates of spatial concentration. The majority of them are industries which is result in China economic reform after 1978. Apart from that, some of them are industries where firms are small due to a dependency on proximity to special-characteristic industrial districts. High-tech industry sector is comparatively higher concentrated.

Claims that cluster are significant tend to relate to regional natural elements and the changes of export situations. In comparison to other provinces, the impact of natural elements is weaker. However, there are still some clusters associated such cases. For example, the sales revenue of food processing sector accounts for $37.2 \%$ of the whole industry in the costal areas of Putuo District, Dinghai district and Beilun District. In addition, in some cases, claims appear to relate to business activities where the presence of a few leading firms in the region concerned can account for the concentration in Zhejiang.

Similarly, a cluster-mapping project is conducted in 2006(Zhang, 2006). Based on the data from Revenue Department, and the number of enterprises and employment in 2004 Shangxi Statistical Yearbook, Zhang(2006) uses two variables, namely, employment and the number of firms in particular industry with a three-digit SIC. Based on the result, Zhang (2006) claims that Coal-mining industry is with a highest localization ( $22.3 \%$ share of national output value). However, such industry sector comprise mainly of small firms, and most of them distributed dispersedly. In other words, it is not expected to represent clustering advantages. With respect to localization efficient of employment, claim appears to be distributed unevenly. Some industries have been developing with the formation of clustering. For example, the forging cluster in the county called Dingxiang comprise 683 firms with over 23000 employment, 30\% of total workforce in this area. Nevertheless, only a few industry sectors in Shangxi can be identified as cluster. For spatial concentration, they mainly distributed in big and small cities area and regions close to highways. 


\section{An evaluation of cluster-mapping projects}

Broadly speaking, cluster-mapping exercises are best designed as a two process (Perry, 2005). First of all, localities that potentially accommodate clusters should be identifies' secondly, profiles of potential clusters should be conducted to confirm that they qualify for inclusion and to determine how develop, if any, is made of the cluster by its prospective attendees. That is to say, such approach to cluster identification appears to point with some plausibility to a real connection between clusters, as well as economic development and growth. To some extent, the results is of particular interests result in concerns situations that are definitely distinguish from the use of individual case-study source found in the existing literature, which is mainly concentrated on developed high-income nations. With respect to the case of China, such analysis of Chinese industries sustains the argument that a positive relationship can be showed between clustering and economic growth. More importantly, industrial sectors and spaces are experiencing economic liberalization as those most prone to the formation of business clusters.

However, the extent, process and determinants of spatial distribution of industries in China still lack special attention (He et al., 2006). Nevertheless, limitations still exist and further study is expected.

(i) especially after access to WTO, however, the existing researches lack sufficient concerns about the impact of globalization and economic transition of the geographical patterns of industries (He et al., 2006).

(ii) Defects in Chinese industry Economy Statistical Yearbook. It only presents 20 manufacturing sectors by regions (provinces) after 1998, which leads to studies have to either stay on only 20 industry sectors or are confined to pre-1998. Also, it induces temporal compassion extremely difficult. In addition, due to a absence of coherent data, some studies are limited on the analyzing data under five year long, therefore, the temporal tendency of separate industry lacks a systemic investigation.;

(iii) An existence of theoretical argument on clusters and geographical agglomeration, hence, it is necessary to prove the theoretical literature associated with China and explore theoretical implication applied to Chinese situation.

\section{References}

Batisse, C. e., \& Poncet, S. (2003). Protectionism and industry localization in Chinese provinces. CERDI: Centre de Recherches et d'Etudes sur le D'eveloppement International. [Online] http://www.hiebs.hku.hk/events_updates/pdf/poncet.pdf.

Catin, M., Luo, X., \& Van Huffel, C. (2005). Openness, industrialization, and geographic concentration of activities in China. The World Bank in its series Policy Research Working Paper Series with number 3706.

Chen, Y. (1996). Impact of regional factors on productivity in China. Journal of Regional Science, 36(3), 417.

Crouch, C., \& Farrell, H. (2001). Great Britain: falling thourgh the holes in the network concept. In C. Crouch, P. L. Gales, C. Trogilia \& H. Voelzkow (Eds.), Local production system in Europe: rise or demise Oxford: Oxford University Press.

Enright M.J. (1996). Regional clusters and economic development: A research agenda, in Staber U., Schaefer N.V. and Sharma B., Business Networks: Prospects for Regional Development, DeGruyter, New York.

Fan, C.C. \& Scott, A. J. (2003). Industrial agglomeration and development: A survey of spatial economic issue in East Asia and a statistical analysis of Chinese regions. Economic Geography, 79, 295-319.

He, C., Wei, Y. D., \& Xie, X. (2006). Globalization, Institutional Change, and Industrial Location: Economic Transition and Industrial Concentration in China. Paper presented at the AAG Annual Meeting.

Liang, P., Chen, H., Lang, C., Lin, Y., Yuan, Y., \& He, T. (2005). Zhejiang chanyejiqun de jiben xianzhuang yiangxiang yinsu ji fazhan duice yanjiu. Hangzhou, Zhejiang Porvince.

Luxembourg. (2003). Trend Chart Policy Workshop“Innovative Hot Spots in Europe: Policies to promote trans-border clusters of creative activity” (Publication.: http://194.78.229.48/extranettrend/Upload/TCW14_policy_background_paper.pdf

Martin, R. and P. Sunley. (2003).Deconstructing clusters: chaotic concept or policy panacea? Journal of Economic Geography, 3: 5-35.

Ni, P., Hou, T., Jiang, M., \& Wang, C. (2005). Blue book of city competitiveness No.3. Beijing: Shehui Kexue Wenxian Chubanshe.

Porter, M. (1998). Clusters and the new economics of competition. Harvard Business Review, 76(6): 77-90.

Perry, M. (2005). Business Clusters: An International Perspective. Routledge, London.

Slater, P. B. (1977). The Determination of Groups of Functionally Integrated Industries in the United States Using a 
1967 Interindustry Flow Table. Empirical Economics, 2(1), 1-9.

Wang, J., Hou, F., \& Zhang, Y. (2004). Chanye Jiqun de shibie fangfa ji shizheng yanjiu . kexue xue yu kexuejishu guanli 11 .

Wen, M. (2004). Relocation and Agglomeration of Chinese Industry. Journal of Development Economics, 73, $329-347$.

Zhang, A. (2006). Shanxisheng zhongxiao qiyejiqun jujidu yanjiu. China industrial cluster, 31-41.

Zhu, D. (2000). Chanye jingjixue. Beijing Beijing ligong daxue chubanshe.

Zhu, Y. (2005). Zhongguo chanye jiqun fenxi.. Bejing Kexue jiaoyu chubanshe.

Table 1. Two development path of cluster presented by Ni et al (2005)

First Stage

Second Stage

\begin{tabular}{|c|c|}
\hline Germination & Renaissance \\
Development & or \\
Mature & Upgrading \\
Decline & Upgos \\
\hline
\end{tabular}

Table 2. The procedure of cluster-mapping project by Fan \& Scott (2003).

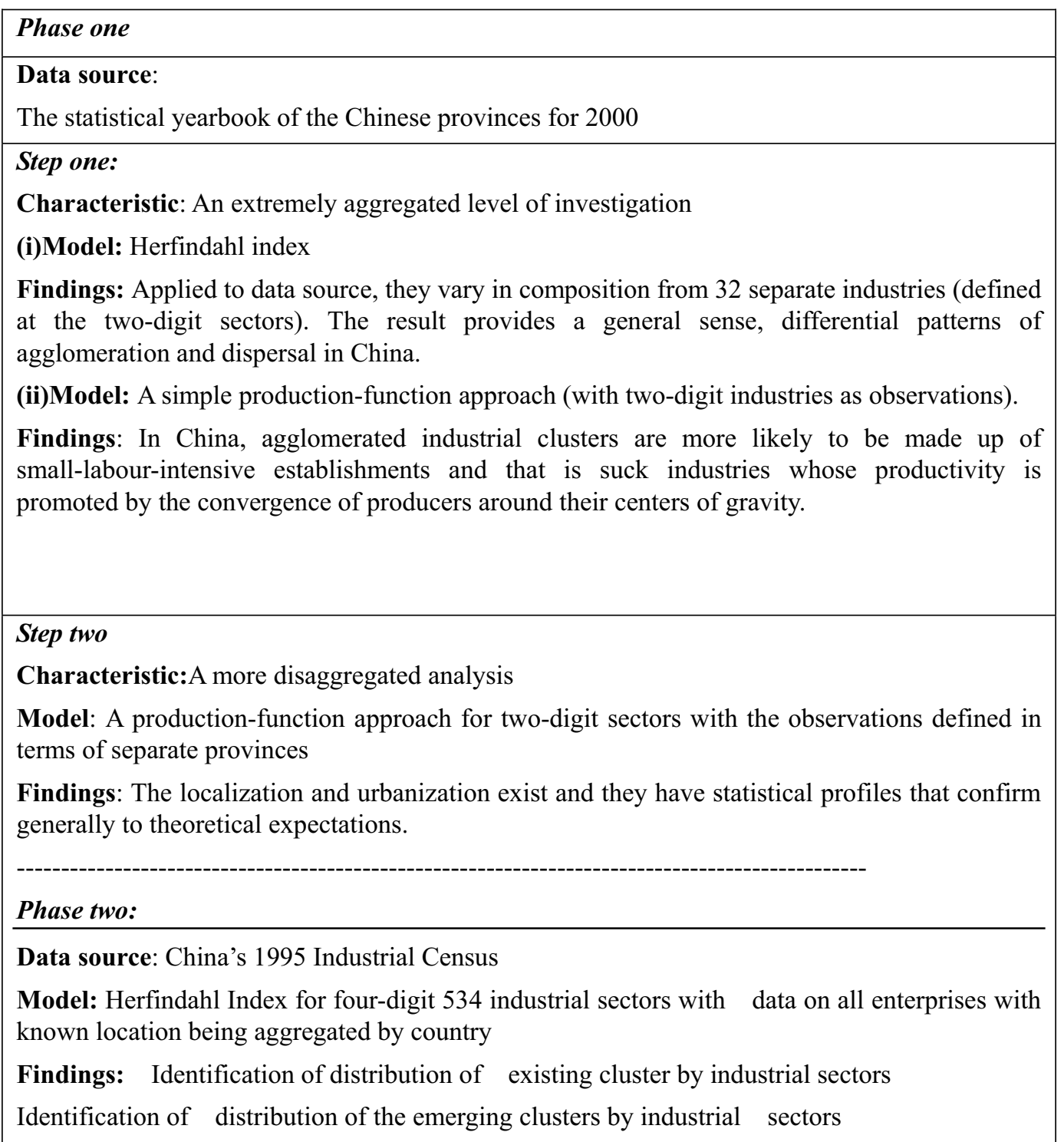

Source: Fan \& Scott (2003) 


\title{
On the Market Risks Prevention of China's Commercial Banks' Financial Product under the Financial Crisis
}

\author{
Mengchun Ding \\ School of Economics and Management, Changchun University of Science and Technology \\ Changchun 130022, China \\ Tel: 86-431-8203-0456_E-mail: dingmengchun312@163.com \\ Hongxin Li \\ School of Economics and Management, Changchun University of Science and Technology \\ Changchun 130022, China \\ E-mail: zc1050506@163.com
}

\begin{abstract}
The year 2009 faces significant changes of economy. In front of the global financial crisis originated from Wall Street sub-prime mortgage crisis, China will be affected inevitably. The financial products market of the banking industry suffers from serious test. Starting from the concept, the classification, the risks, and the development of China's commercial banks' financial products, this paper analyzes the market risks of China's commercial banks' financial products under the financial crisis and advances specific countermeasures for China's commercial banks dealing with crisis and defending market risks.
\end{abstract}

Keywords: Financial crisis, Financial product, Risk prevention

\section{The development of China's commercial banks' financial products}

Recently, along with the stable development of China's economy and the fast growth of residents' financial assets, traditional investment ways tend to be far from satisfying people's diversified financial needs. Channels for investment are narrow. People just make choice between the products (national debts and deposits) with no risks and low interests and the products (stocks) with high risks and high return. Banks' financial products can fill up the blank. Therefore, more residents have increasing needs for financial services. Banks' financial products and services keep in innovation. Financial products become more diversified. The financial market grows fast.

\subsection{The concept of banks' financial product}

Banks' financial product is designed and issued by commercial banks by analyzing and researching potential target customers group. Commercial banks invest the collected capitals into relevant financial market or buy financial products, and allocate the interests among investors according to contracts. Due to the different operations, commercial banks' personal financial business includes the financial consultant service and the comprehensive financial service. Here the "banks' financial product" means the comprehensive financial service. In nature, financial product belongs to financial investment. This attribute determines the risks of banks' financial product.

\subsection{The classification of banks' financial product and the characteristics of risks}

(1) RMB financial product

RMB financial product is sorted into the profit-guaranteed and the non-profit-guaranteed. The former includes the fixed profit type and the floating profit type. The later includes the principal-guaranteed type with non-guaranteed profit and principal type.

(2) Foreign currency financial product

Foreign currency financial product is sorted into the foreign currency-combined option investment product, the structured financial product connected with financial derivatives, and the financial product with fixed profit at prime rate. The first does not offer guaranties for principals but with higher profits. The second mostly offers guaranties for principals. The third offers fixed profits. 


\section{(3) QDII financial product}

QDII financial product is sorted into the principal guaranteed and the non-principal guaranteed. The former includes the fixed profit type and the related type (structured financial product). The later does not guarantee the return. The profits are completely floating.

Apparently, the principal guaranteed product has lower risks but may lose profits and other opportunity cost. For the non-principal guaranteed product, if investing in the asset with higher fluctuation, it may gain higher profits or suffer from larger losses.

\subsection{The development of China's commercial banks'financial product}

In 2004, the first money financial product of banks appeared. In Sep. 2005, in order to regulate the development of commercial banks' personal financial business, China Banking Regulatory Commission issued the Temporary Regulations on Administration of Commercial Banks' Personal Financial Service Management and the Direction for Risks Management of Commercial Banks' Personal Financial Service. Afterwards, the financial services of China's commercial banks step into a regulated and legal development way. In a short period, banks' financial services develop fast. In many commercial banks, the financial services have already turned into the growth point of middle services. The increment has surpassed the rise of deposits. In 2005, the sales of China's commercial banks' personal financial product reached 200 billion RMB. In 2006, the number was 600 billion RMB, 819 billion RMB in 2007, and exceeded 1000 billion RMB in 2008. The banks' financial product achieves fast development.

Because China's banking financial business has developed for a short period and laws and regulations are imperfect, it has confronted with a series of problems. For example, due to the financial crisis, in early 2008, the capital market suffers seriously, which indirectly causes the zero profit or negative profit of structured products. Afterwards, the wide prevail of financial crisis makes QDII product to the bad completely. Some experts agree that in the year 2009, the development of banks' financial product will be hard, which may make it to be mature and cool.

\section{The market risks of China's commercial banks' financial products under the financial crisis}

\subsection{The risks caused by financial products' excessive innovation}

China's commercial banks are lack of initiatives of product design and pricing. They fail to pay sufficient attention to product development and brand. All financial products are similar. As a result, these financial products have no core competitiveness. Therefore, all commercial banks have the problem of financial innovation. However, if the financial innovation can not be evaluated and controlled and the financial innovation only aims at profits, the innovation activities will bring about nothing but bubbles in financial market, and crises and disasters. American financial storm is resulted from the popularization of sub-prime mortgage crisis, what is caused by the excessive financial innovation of American financial institutions and the improper use of financial derivatives. The market subject does not consider the quality of assets but try to sell the new products by packaging, separating, or turning into securities after buying the derivatives. As a result, nobody cares about the real value of financial derivatives, which drives the extreme activities of short-profits pursuits, finally causing the serious financial market crisis. By learning from American financial crisis, we should re-examine the financial product innovation, making risks of financial product innovation under the control.

\subsection{Commercial banks' financial products face credit risks.}

Some commercial banks do not follow the principle of balancing the interests and the risks in designing financial products. They do not develop products and design investment combination in perspective of assets allocation. They do not predict the return of financial investment combination by scientific and reasonable methods. They do not set up relevant market risks supervising and examining indexes and the effective system for identifying, measuring, supervising, and controlling market risks. "They do not perform customer evaluation effectively." The regulatory department finds that some commercial banks do not evaluate customers' risks preferences or merely finish this task in form. They do not understand customers' financial conditions, investment goals, investment experiences, risks recognition, and risks acceptance exactly. They do not evaluate whether the financial product in promotion is right for a customer or not, not mention to inform the customer about the evaluation suggestions.

\subsection{Commercial banks' financial products face the compliance risk and the market risk}

Along with the enhancing macro economic adjustment and control, and the increasing problems in small and medium-sized banks, the assets pool financial product based on check assets and credit assets tends to rise. Under the background of global inflation pressure, US dollar continues to depreciate and foreign market is changeable, which make commercial banks' financial products face higher and higher risks.

\subsection{There are defects in some commercial banks' financial product system and personnel management}

Although it sets up the personal financial system, other systems do not change, what causes a series problems, affecting the development of personal financial services. Can not comprehensively consider personal financial services' each 
factor and ring, or make wide development and deep dig on personal financial services, no regular and unified operation and management procedures. Can not realize an overall risks management and control over personal financial services' each ring. Some commercial banks simply take the loan tellers, legwork people, and counter workers as customer managers without any training. Constrained by former thinking and work fields, these customer managers from different positions are lack of the comprehensive idea of financial services, financial service knowledge, and marketing techniques. They can not fulfill their work in a short period.

\section{The market risks prevention of China's commercial banks' financial products under the financial crisis}

\subsection{Make reasonable financial product innovations}

In commercial banks, the new product development leaders group, the scientific and technological department, and relevant operational departments should cooperate together to speed up the innovation of financial products based on researching and digging out customers' needs completely. As for some hot services, such as motor consumption loan, house consumption loan, and personal mortgage loan, commercial banks should simplify procedures, loosen conditions, and improve services in order to enlarge the market share, forming an advantage of scale. By means of the high-tech electric net, integrate and upgrade present products, taking bank card, online bank, and telephone bank as carriers. Supply valuable information and consultation for customers, improving the value of customers' assets. Understand the distance of financial services with foreign banks and make financial innovation. Enhance the depth and width of trans-bank cooperation, and integrate the financial services, such as banks, securities, insurance, funds, and trust, offering the comprehensive services.

\subsection{The financial products should be designed concisely, considering both return and risks.}

For banks, most customers are common. For these customers, the simpler the product is, the more the bank explains it for customers, and the better it is for the sell. The bank should reveal the risks of the financial product completely in issuing, fulfilling the obligation of informing risks. The bank must make it clear concerning the product's operational mechanism, the fee, and relevant articles that may be adjusted along with the change of market. The bank, as the issuer of financial product, should perfect the product design management mechanism, designing the financial product considering customers' interests and acceptance, developing the product and designing the investment combination in perspective of assets allocation, predicting the return of financial investment combination by scientific and reasonable prediction methods, and building relevant market risk supervision and examination indexes and the effective system of identifying, measuring, supervising, and controlling market risks.

\subsection{Banks should keep an eye on financial products' risks concerning basic assets}

One of important element caused the American financial crisis is the security extension of sub-prime mortgage loans. Risks are originated from the wide contract breach of sub-prime loans subjects, together with the exaggerate effect of financial derivates as a leverage. All these factors contribute to the happen of unprecedented crisis in American financial market. This crisis teaches us a lesion concerning the design of banks' financial products. Firstly, the basic assets in designing the financial product demand for higher credits. Besides, guaranties and insurance are inevitable. Secondly, the chain for basic assets securitization should not be too long.

\subsection{Honest and credit service}

Commercial banks operate credits. Credits are the base for commercial banks operations. Along with the development of financial market and the change of global financial environment, such a fundamental principle or moral standard for commercial banks has been neglected by foreign developed markets. Apply an entrance quality management system for the sellers of financial products. Promote the compulsory quality certification system for personal financial services. Set up the continuous training, trace evaluation and evaluation system, making relevant workers obtain necessary professional knowledge, industrial knowledge, and management ability. By informing them with relevant laws and regulations and necessary professional morals, regulate their behaviors in selling.

\subsection{Competitive human resource development}

Firstly, form a certification system for professional financial planners. The experts in domestic banks serving top customers by supplying personal financial services are not professional. There are not financial planners in a real sense. Secondly, train present financial consultants systematically and comprehensively. Make up a systematic training plan for financial consultants. Pick up excellent workers who master certain financial knowledge, know marketing skills, and understand customers' psychology as candidates. Besides, set up a horizontal associated training mechanism with securities and insurance industries. Help the candidates realize a purposeful communication about positions. Help them familiarize all businesses of banks as soon as possible in order to make them work independently. 


\section{References}

Huang, Lizhu. (2008). The enlightenment of USA sub-prime mortgage crisis for China's commercial banks. Financial News. Nov. $10^{\text {th }}$.

Jiang, Dingzhi. (2008). Speech in Tianmu Lake China-Europe Economic Forum. Oct. $25^{\text {th }}$.

Jin, Lixin. (2008). How much the effect of Wall Street financial crisis on Chinese banks' financial market. Financial News. Oct. $27^{\text {th }}$.

Li, Xiuye. (2009). Problems in commercial banks developing personal financial business and the countermeasures. [Online] Available: www.studa.net

Li, Yu. (2004). On the innovation personal financial management service. Commercial Research. No.17.

Ma, Weihua. (2009). A dialectical view on the effect of financial crisis on China's commercial banks. Shanghai Securities News. Feb. $2^{\text {ed }}$.

Meng, Yang. (2009). Global financial crisis changes view of financial, private banks gain chances for development. Financial News. Apr. $7^{\text {th }}$.

Xu, Qinghong., He, Bing \& Sun, Conghai. (2009). Banks' financial and risks management under the financial crisis. China Financial and Economic News. Feb. $24^{\text {th }}$. 


\title{
HRM Practices and Organizational Performance:
}

\section{An Empirical Analysis}

\author{
Kodjo Ezane Joseph (Corresponding author) \& Changjun Dai \\ Glorious Sun School of Business and Management, Donghua University \\ Shanghai 200051, China \\ E-mail: kodjo_ezane@yahoo.fr
}

\begin{abstract}
We theorize about the assessment of HRM practices on perceptions of firm performance through Monte Carlo Method (MCM), and the Hausman's Specification Test (HST) in the Ivorian framework. 320 enterprises were surveyed and factor analysis of 13 bundles of HRM practices was undertaken. The confirmation of the findings through simulation (MCM) permitted the examiner to authenticate the reliability of the results in using the HST. The results of this paper highlight that in the Ivorian context there are significant connections between HRM practices and firm performance; that the strategic alignment of HRM is also a driver for firm performance.
\end{abstract}

Keywords: Monte carlo method, Hausman's specification test, Human resource management, Firm performance, Côte d'Ivoire

\section{Introduction}

Monte Carlo Methods (MCM) are being utilized for a growing variety of issues. They have been used productively to handle deterministic problems and stochastic problems. There is indeed a great scope for ingenuity both in modeling of the problem and in developing special methods of simulation. Given a model and data in which fixed effects (FE) estimation would be appropriate, a HST tests whether random effects (RE) estimation would be almost as good. In a FE kind of case, the HST is a test of $\mathrm{H}_{0}$; RE would be consistent and efficient, versus $\mathrm{H}_{1}$ : that RE would be inconsistent (Note that FE would certainly be consistent). The result of the test is a vector of dimension $\mathrm{k}$ which will be distributed chi-square (k). So if the HST statistic is large, one must use FE. If the statistic is small, one may get away with RE. As the intention of this paper is to lay the emphasis on the influence of HRM practices on perceived firm performance in the Ivorian setting, we resort to MCM and HST to authenticate and test the reliability of the results.

\section{Literature Review}

Researchers have indicated a positive interconnectedness between bundles of HRM practices, such as, training (Bartel, 1994), information sharing (Kleiner \& Bouillon, 1998), employment security (Pfeffer, 1995; Delery \& Doty, 1996), strategic alignment of HRM to business strategy (Becker \& Gerhardt, 1996; Bjookman and Fey, 2000) and those researches that look into the influence of bundles of HRM mechanisms and the perceptions of enterprise performance (MacDuffie, 1995; Ichniowski et al. 1994). Studies have demonstrated that the investment in HRM practices and the Strategic alignment of HRM to corporate strategy is a driver for moving the enterprises from mediocrity to excellence.

\subsection{Human Resources' Development}

\subsubsection{The Investment in Technical and Non-Technical Training}

Training is a significant component of organizations' success even if it is not the end. Rather, training is characterized as a means to an end - the end being productive, efficient work organizations, populated by informed employees who see themselves as significant factors in the success of their organizations. The investment for enterprises in technical and non-technical training can positively impact the performance of organizations.

\subsubsection{The Employment Security}

Employment protection calls for a meaningful tool in the performance of high HRM practices (Pfeffer, 1995). Studies by Delery and Doty (1996); Bjookman and Fey (2000) have emphasized the significant correlation between 
employment security and organizational performance. By stimulating the congruence of employees, the security of employees goes along with their commitment to tie that congruence to the organization's goals. Enterprises that are able to provide their employees with job security will favor employees' congruence.

\subsubsection{The Career Management Programs}

Enterprises that care and have concern for employee development need to stimulate commitment through the enterprise to help the employees understand the organization's mission statement, vision, and values. The management of a career planning system (CPS) is to be efficient and effective as the enterprise's career management policies and employees' beliefs regarding their career need to be altered to satisfactorily meet up viable challenges. Enterprises that have a career management program for assisting the human resources (HRs) will favor their motivation and increase in productivity.

\subsubsection{The Promotion of the Workforce within Enterprises}

An employee that gets promoted is much more committed to the enterprise goals and objectives attainment. Nothing great can be achieved out of competency and employees need to work hard as much as possible to get the required skills to progress within the organization. When promotion takes place in enterprises, we should expect the ensuing: care and concern for the workers, trust in the HRs, and provision of personal growth opportunities. An atmosphere that stimulates and compensates employees brings the understanding of those employees to feel that they are also "living" in the enterprise.

\subsubsection{The Development of Human Resources in Abidjan}

Training is an essential tool for the management and development of HRs. The commitment to investments in development-oriented HRM practices is likely to improve an enterprise's ability to retain valuable HRs. Enterprises that offer such programs get more high-quality applicants. Promotion and career management programs (CMP) should be important for enterprises in Abidjan to stand for competitive edge. HRM practices that contribute to the development of managerial workers in Abidjan can be expected to be positively related to enterprise performance. That is why the researcher proposes that there is an outstanding correspondence between how enterprises value their managerial HRs and the performance of their enterprises in Abidjan (A1); that there is also an outstanding correspondence between how enterprises value their non-managerial HRs and the performance of their enterprises in Abidjan (A2).

\subsection{The Pay/Organization Issue}

\subsubsection{Team-Based Enterprises}

Seers (2004) holds that teams are the backbone of the flexible organizational designs required to cope with the new knowledge economy. Teams increase the likelihood that employees will be innovative, creative and able to quickly react to changing market needs and customer preferences for products and services (Anthony \& Buzzotta, 1993). Team-based organizations give employees, confidence to pool their ideas to come up with creative solutions to problems. Communication is difficult to take place in a power-distance enterprise.

\subsubsection{The Decentralized Decision Making}

The growing adoption of flat or non-hierarchical organizational structures (NHOSs) and the consequent empowering of employees to create effective workplaces suggest that delegation will become an increasingly popular managerial technique or leader behavior (Zhen \& Samuel, 2007). The NHOSs reduce status difference as hierarchical organizations ranks high on power distance. The reduction of status difference is part of the characteristics of high HRM practices emphasized by Pfeffer (1998).

\subsubsection{The Performance-Based Compensation System}

Studies (See for instance Huselid, 1995) have emphasized the optimistic correlation between perceptions of firm performance and the execution of good performance-based compensation system (PBCS). Hence, implementing a PBCS that attracts high-quality applicants (HQAs) is just such an important issue. A HQA is one who has the ability and disposition to produce more than a low-quality applicant. Correspondingly, Copeland (2002) admits that firms should be able to offer an equitable and original compensation so as to attract competent job-seekers.

\subsubsection{The Compensation Issue in Abidjan}

A review of literature (See for example Beugre, 2004) indicates that the compensation system in Côte d'Ivoire is based on salary, bonus and benefits. Few enterprises operating in Abidjan use pay as performance tool for their employees. The use of 360-degree feedback for objectivity and for better performance appraisal is altered by many considerations (nepotism, ethnicity...). In the business environment, compensation and bonus systems are extremely significant, as they attract and retain skilled and competent HRs. From the ongoing, we propose that there is a substantial link between managerial HRM practices that impact the design of work and a subsequent compensation scheme, and enterprise performance in Abidjan (A3); that a substantial link between non-managerial HRM practices that impact the design of work and a subsequent compensation scheme, and enterprise performance in Abidjan (A4) exists as well. 


\subsection{The Feedback System Issue}

\subsubsection{The Sharing of Information}

An enterprise that makes real a shared culture that is in actual fact unbreakable through information flow will be a competitive one. When the sharing of information is a vital component of the entire enterprise's culture, this can surely impact the effectiveness of the enterprise. When people work together, share ideas, and sometimes wrangle, they build on one another's ideas for the benefit of the enterprise. The lack of communication and information sharing disrupts works and brings about enterprise mediocrity.

\subsubsection{The Complaint Resolution Systems}

\subsubsection{The Problem of Injustice within Enterprises}

Conflicts often occur in enterprises or firms due to the lack of opportunity, ability, or motivation to communicate effectively. When parties lack the opportunity to communicate, they tend to use stereotypes to explain past behaviors and anticipate future actions (Steven \& Glinow, 2000). The complaint resolution system (CRS) in enterprises can help handle situations of conflicts that can distort work and negatively impact productivity, commitment, satisfaction and performance of enterprises. When complaints are dealt with delicateness, workers feel valued, supported, respected and dedicated. Complaints adequately settled make the workers be more inclined to keep up an elevated level of dedication, and congruence to the enterprises. To better understand the opinion of employees, the attitude surveys may be significant. The utilization of attitude survey has also been found beneficial as using such a survey helps top management understand the desires and ideas of employees.

\subsubsection{The Value of Attitude Survey}

Employees can be surveyed vis-à-vis their job satisfaction, opinions about supervisors, operating effectiveness, and training and development matters. Enterprises survey employee levels of job satisfaction as a measure of executive and enterprise performance. Performance appraisals (PAs) are a formal management system that provides for the evaluation of the quality of an employee's performance in an organization. The objectives of PAs are the following: provide feedback to employees about their performance; determine which employee gets promoted; encourage performance improvement; motivate superior performance; find out individual training and development wants or needs; develop overall enterprise performance.

\subsubsection{The Feedback Systems Issue in Abidjan}

Abhishek et al (2006) wrote that "knowledge sharing (KS) can be defined as team members sharing task-relevant ideas, information, and suggestion with each other". Liebowitz (1999) observes that KS is a central component of knowledge management (KM), as it helps in codifying the repository of available knowledge in an organization and increasing it overtime. Exchanging information supposes that information is exchanged and it gets to those who need it to do their work. When the workplace is an inciting one and there is a strong and effective information sharing system (ISS), it is essential for a given enterprise to operate well. Feedback by superiors on employee functional behaviors and personal praise confidently influence productivity and this paper acknowledges that there is a need to recognize that there is a constructive link between enterprise strategy and enterprise performance. It is against the ongoing that the investigator proposes that there is a great link between managerial HRM practices that make possible opinion and enterprise performance in Abidjan (A5); and that a great link is also effective between non-managerial HRM practices that make possible opinion and the performance of enterprise in Abidjan (A6).

\subsection{The HRM Strategy Alignment and the Strategy Alignment of HRM Issues in Abidjan}

Beugre (2004) indicates that the compensation system in Côte d'Ivoire is based on monetary compensation (salary, bonus) and benefits (health insurance and pension contributions). The performance-based compensation issue, the teamwork, the reduction of power-distance will help enterprises in Abidjan be competitive. The strategic alignment of HRM to business strategy leads to firm performance as it is admitted (See Guest, 1997) that those organizations that have a fit between strategy, structure and HRM policy will have significant performance and increase productivity. This paper admits that aligning HRM practices with corporate strategy can be a source of enterprise performance in Abidjan, as well. Hence we theorize that aligning the management of HRs with corporate strategy can bring about enterprise performance in Abidjan (A7).

\section{Methods}

\subsection{Data Collection and Method}

The platform which helped the researcher choose the sectors and the organizations is the "Repertoire des Entreprises Commerciales Industrielles et de Service: Annuaire: Chambre de Comerce et d'Industrie de Côte d'Ivoire, 2007" which contains information about the listed enterprises involved in our study. We identified a sample of 500 enterprises. But only 320 showed interest in the study which represented a $64 \%$ response. Questionnaires were disseminated in the 
enterprises. Questionnaire was designed depending upon the extensive literature review (Barney, 1991; Delany \& Huselid, 1996; Delery \& Doty, 1996; Eisenhardt, 1998; Forster, 2004; Bjookman \& Fey, 2000). We coded and analyzed the data. The commercial software package (SPSS, Version 11.0) permitted data coding, storage and analysis.

We used a predetermined draft for questionnaires. The conclusions of this modus operandi were 320 participants (117General Managers or Human Resource Managers or Personnel Managers), categorized as managerial HRs and 203 Production workers identified as non-managerial HRs. We noticed that there were 105 enterprises having between 20 and 399 workers, 195 having between 400 and 599 workers, 12 having between 600 and 900 workers, and 8 having over 900 workers.

\subsection{Measures}

\subsubsection{Control Variables}

Our research includes several variables to capture other organizational and environmental factors that are in conjunction with the adoption of HRM practices and enterprise performance. Our control variables include the size of the enterprises in the organizations. It was useful for the investigator as on a theoretical basis, significant organizations in terms of size utilize formal HRM practices than those who have "insignificant" number of workforce. The age of the enterprises was also important as there can be optimistic connection between enterprises' years of operations and the adoption of bundles of HRM practices.

\subsubsection{Independent Variables}

The information about the HRM practices is highlighted in Table 1. As HRM-strategy alignment leads to organizational performance (Becker \& Huselid, 1996), we need to stress that the strategic alignment (SA) of HRM practices to business strategy was focused on predisposed evaluation with a view to figure out how strategic HRM is appreciated in the enterprises under study. We considered HRM-strategy alignment and participants' perceptions about the effectiveness of the SA of HRM practices with their enterprise strategy, utilizing a likert scale that ranged from 1 " To little importance" and 5 "To a great importance" as studies (Becker \& Huselid, 1996; Bjookman \& Fey, 2000) used this kind of likert scale.

\subsubsection{Dependent Variables}

Studies have been carried out to find measures of perceptions of firm performance to correlate specifically with measure of enterprise performance. The variables were market share, quality of products or services, profitability, and sales growth. Each of the dependent variables is based on questionnaire items responses on likert scales like Bjookman \& Fey (2000); Becker and Huselid (1996) also ranging from 1 "Poor" to 5 "Exceptional" where on a biased foundation, the participants were asked to state how those variables were effective and efficient in their enterprises. The subjective basis of the assessment does not negate this measure as studies (See for example Youndt et al., 1996; Powell, 1992; Bjookman \& Fey, 2000) have indicated that biased of enterprise performance undeniably presents a relation with the objective assessments of the performance of enterprises. Therefore, the issue of biases is outweighed in this paper.

\section{Results}

We need to draw reasonable conclusions from the data collected. So, we found it essential to deal with a principal component factor analysis (Table 1) with varimax rotation about the different HRM practices considered in the extensive literature review.

(Insert Table 1and Table 2 about here)

Table 1 highlights the different factors identified for this research inquiry. Totally, we have three different factors. "Development factor" contains trainings (technical training (0.856); non-technical training (0.902); non-entry jobs filled from within enterprises (0.896); assisting in career planning (0.929); and job security (0.437). While "feedback factor" is composed of information sharing programs (0.931), complaint resolution system (0.916), and attitude surveys (0.851), the "pay/organization factor" deals with performance appraisals (0.826); group/company performance in pay ( 0.767$)$; teamwork (0.860); decentralized decision making (0.751); and interdepartmental communication (0.911). When we look at Table 1, we observe the results of the three different Cronbach's Alphas $(0.732 ; 0.672 ; 0.713)$. They imply that they are acceptable because they are in line with the credibility level of 0.70 emphasized by Nunnally (1999); Bjookman and Fey (2000); Price and Mueller (1986) in this kind of research. The correlation matrix (Table 2) presents the intercorrelations among the identified variables. The findings highlight that interconnectedness exits among the variables. As stated earlier, we need to test propositions. That is why we utilized regression analysis on enterprise performance in Table 3 and Table 4 as they respectively indicate the results of findings for model 1 (managerial workers) and model 2 (non-managerial workers). Regression equation that is used to test the research model for managerial workers (Table 3 ) is as under:

Equation 1: 


$$
\ln (P)_{i}=\lambda_{1}(L)_{i}+\delta^{\prime}{ }_{1} A E_{i}+\beta_{1}^{\prime} H_{i}+\gamma_{1}^{\prime} M D_{i}+\mu_{1}^{\prime} M P_{i}+\theta_{1}^{\prime} F D M_{i}+\varepsilon_{1 i}
$$

Enterprise Performance $=$ Coefficient $($ Number of employees $)+$ Coefficient $($ Age of enterprises $)+$ Coefficient (HRM-Strategy fit) + Coefficient (Manager development) + Coefficient (Manager pay/organization) + Coefficient (Feedback to managers) + Residuals

(Insert Table 3 about here)

The alignment of HRM strategy to corporate strategy was confidently in conjunction with enterprise performance as $\mathrm{p}$ value was inferior to 0.05 . Considerable associations were of use. As we need to substantiate theories, the researcher led regression analysis on enterprise performance (See Table 3). In Table 3, the model 1 highlights the outcomes of the regression analysis on enterprise performance and emphasizes the HRM practices for managerial workers. The model was acceptable because we have $R^{2}$ being 0.531 and Adjusted $R^{2}$ is 0.487 . The variable related to the management of employees also has a positive and significant coefficient.

Regression equation that is used to test the research model 2 for non-managerial workers (Table 4) is as follows:

Equation 2:

$$
\ln (P)_{i}=\lambda_{1}(L)_{i}+\delta^{\prime}{ }_{2} A E_{i}+\beta_{2}^{\prime} H_{i}+\gamma^{\prime}{ }_{2} E D_{i}+\mu_{2}^{\prime} E P_{i}+\theta_{2}^{\prime} F D E_{i}+\varepsilon_{2 i}
$$

Enterprise Performance $=$ Coefficient $($ Number of employees $)+$ Coefficient $($ Age of enterprises $)+$ Coefficient (HRM-Strategy fit $)+$ Coefficient (Employee development) + Coefficient (Employee pay/organization) + Coefficient (Feedback to employees) + Residuals.

(Insert Table 4 about here)

The model 2 (See Table 4) permits us to appreciate the contribution of the employees in terms of performance and the relation between the identified variables and organizational performance (OP) for non-managerial workers. The estimated models (model 1, table 3; model 2, table 4) have equal dependent variable: performance. The main variables are utilized in the regression analysis and this is important for this paper as preceding researches (See for instance, Guest, 1997; Bjookman \& Fey, 2000; Delany \& Huselid, 1996) have emphasized connections between HRM practices and firm performance. The correlation between bundles of HRM practices for the different categories of employees (managerial workers; non-managerial workers) and OP is remarkable and considerable. Additionally, the alignment of HRM practices to organizations' strategy was appreciably interrelated with OP. To put it in a nutshell, we notice that noteworthy and important relation existed between bundles of HRM practices for the two sorts of employees in our study. The employees with a good human potential are more productive and they bring appreciative and meaningful added value to the enterprises. The findings indicate that the level of employee pay is a decisive factor for the explanation of performance within the enterprise. The findings reveal the significant correspondence of the variable "variance explained" whatever the factor that is involved in. The "development factor", and the variables such as "job security", "technical training", "non-technical training", and "assisting in career planning" highlight an optimistic correspondence. When we change the reference factor by considering the "feedback factor", the correlation becomes much more important between that factor and the following variables: "Complaint resolution systems", "Information sharing programs", and "Attitude survey". As for the factor about "Pay/Organization", we observe new variables with a remarkable correlation between that factor and the variables of the model used. Except the variables "Information sharing programs", all the other variables are optimistically correlated with the "development factor". As for the "feedback factor", only two variables are negatively interrelated. Those variables are the ensuing: "Job security" and "Group/company performance in pay". With reference to the "Pay/organization factor", the variables of the model have an encouraging correspondence. The findings of this research are based on the different hypotheses.

To test our specific propositions, a factor analysis for separate practices for non-managerial workers was used as well (See Table 1); regression analysis was also effective (See Table 3 and Table 4). To confirm the findings from Table 1, Tables 3 and Table 4, a simulation approach (See Table 5) based on Monte Carlo Method (MCM) was important.

(Insert Table 5 about here)

Table 5 gives room to validate our various research hypotheses. The standard error (SE) values which are similar to the standard deviation (SD) and to the one of the coefficient of sensibility (CS) will bring us to appreciate the impacts of a variation on the explanatory variables about the performance of enterprises in the Ivorian setting. The results indicate that there is no very important deviation between the explanatory variables; that the distribution principles are therefore normal and stable. The most important deviation is seen from the variables such as "manager development" with 3.675 $\mathrm{SE}$ and the $\log$ of numbers of employees with $2.543 .10^{-2} \mathrm{CS}$. An interpretation of the results can be found in the difference in initial training of the managers. In our sample, we have important enterprises with important number of 
employees and the results point out that enterprises with high number of employees perform better than those with a smaller number of employees. This fact indicated above gives an explanation of the origin of the SE. The CS is a way to consider the nature of simulations of the explanatory variables about the performance of enterprises in Abidjan. From the MCM analysis, it can be observed that all the explanatory variables positively impact the performance of enterprises in the Ivorian setting. The variables related to the development of HRs, that is, "employee development" with $2.014 \mathrm{SE}$ and $2.45 .10^{-2} \mathrm{CS}$ and "manager development" with $3.675 \mathrm{SE}$ and $3.65 .10^{-1} \mathrm{CS}$ positively and statistically influence the performance of enterprises. Our results show that "managerial HRM practices" and "non-managerial HRM practices" variables have an optimistic influence on the performance of enterprise and that the "HRM-strategy alignment" variable with 1.690 SE and 3.17.10-2 CS influences the performance of enterprise. For the consistency of the findings of this paper, we conducted a credibility test using the Hausman's Specification Test (HST).

When we have a model with individual effects (IE), the first concern is to know how these IE must be specified. Should we adopt the hypothesis with fixed effects (FE) or the hypothesis with the random effects (RE)? One of the problems that can occur with the model with RE comes from the probable correlation between the explanatory variables and the IE. On the economic plan, this correlation points out the influence of the structural individual specifications on the determination of the level of the explanatory variables. The HST (1978), or $m$-statistic, can be used to test hypotheses in terms of bias or inconsistency of an estimator and can be applied to many issues of specification in econometrics. However, its application the most known is the Specification Test of IE in panel. Therefore, the HST is used to discriminate the FE and RE. The general idea about the HST is both simple and interesting. Let's suppose that the inquirer tries to test the probable existence of a correlation or a defect of specification. Furthermore, let us admit that we have two sorts of estimators for the parameters of the model to be studied. The first estimator is supposed to be the non-biased estimator with minimum variance with the right null hypothesis of specification of the model (no correlation). Besides, with the alternative hypothesis of bad specification, this estimator is supposed to be biased. We suppose that the second estimator is non-biased in both cases. As such, there will be a need to compare a vector of dimension by a matrix of variance, covariance among the two estimators to be able to determine whether the specification is correct or not. If the distance is statistically null it means that the specification is correct and we then choose the first estimator. If the distance is significant it means that the model is not well specified. The hypothesis that is tested concerns the correlation of the IE and the explanatory variables. The random effects refer to the fact that the results of analysis are not caused by the variables of the model. The fixed effects highlight that the results of the findings are the consequence of the choice for the variables. The test for the hypothesis is as follows:

$\mathrm{H}_{0}$ : Consistency and efficiency of RE

$\mathrm{H}_{1}$ : Existence of $\mathrm{FE}$

Under $\mathrm{H}_{0}$, the statistic $\mathrm{H}$ of this test has a chi-square distribution with $\mathrm{k}$ degrees of freedom, $\mathrm{k}$ being the number of the explanatory variables:

$$
H=\frac{\left(\hat{\beta}_{1}-\hat{\beta}_{2}\right)}{\operatorname{Var}\left(\hat{\beta}_{1}\right)-\operatorname{Var}\left(\hat{\beta}_{2}\right)}
$$

Where $\hat{\beta}_{1}$ and $\hat{\beta}_{2}$ represent the estimators of the generalized least squares (GLS) and within. The statistics test follows (as we stated earlier) a chi-square with $\mathrm{k}$ degrees of freedom where $\mathrm{k}$ is the number of estimated coefficients. An important or interesting value of this statistics $\mathrm{H}$, associated with a critical probability (the level of probability that we fix) for a very weak $\mathrm{H}_{0}$ is conducive to the rejection of the null hypothesis. Hence, we test whether RE estimation will be good. To conduct the HST, we utilized STATA, Version 9 (Table 6).

(Insert Table 6 about here)

$$
\text { Ch } 2(13)=(b-B)^{\prime}\left[\left(V_{b}-V_{B}\right)^{-1}\right](b-B)=275.44
$$

Pro $>$ Chi2 $=0.0000$

In the estimation of the chi-square, we have two methods to verify our hypotheses' test. The first hypothesis test consists in calculating the value of chi-square that we compare to a theoretical value of chi-square in the "chi-square table". If from this operation, the value that is calculated is superior to what is tabulated; we then reject the null hypothesis. If the opposite happens, we subsequently accept the null hypothesis. The second hypothesis test consists in fixing a level of probability that we compare with what is calculated (p-value). If the p-value is inferior to the level that we fixed, the null hypothesis is not validated. If this is not the case, then, the null hypothesis is to be accepted. In our case, we used the second approach. As a consequence, the commercial software package (STATA, Version 9.0) that was utilized for the test of credibility gave us the two values and that is why we have both of them in our table and analysis. The probability of rejecting the null hypothesis $\mathrm{H}_{0}$ is given by the following: 
Pro $>$ Chi2 $=0.0000$

The level of significance is $5 \%$, and even $1 \%$. Therefore, we can reject $\mathrm{H}_{0}$ without any risk of mistaking. This brings the researcher to positively appreciate the hypothesis $\mathrm{H}_{1}$ for the existence of FE. The model that the research accepted for estimation is the model with FE. Therefore, the findings of this research inquiry confirm the validity of our model and the results that this investigation highlights.

\section{Discussion and Conclusion}

The findings make it clear that investing in HRM leads to organizational performance. The different results indicate that there is a couple of significant correlation between the practices of HRM and the performance of enterprise. As Guest (1997) has emphasized the relationship between HRM practices and enterprise performance, our findings are in line with those results in the context of enterprises located and operating in Abidjan. It could be observed that the different identified factors did not highlight the same results for the investment in HRM practices and perception of enterprise performance. The findings draw attention to noteworthy connection of the variable "variance explained" whatever the factor that is involved in. The "employee development" factor and the variables such as "technical training", "non-technical training", "non-entry jobs filled from within", "assisting in career planning" and "job security" all have a high and positive correlation with the enterprise performance. When we change the reference factor by considering the "feedback factor", the correlation becomes much more important between that factor and the following variables: complaint resolution system", "information sharing programs", and "attitude survey". Additionally, in taking into account the "pay/organization" factor, we observe new variables with a remarkable correlation between that factor and the variables of the models used in this investigation. The results of this paper also indicate that there is a correspondence between the alignment of HRM to corporate strategy and the performance of organization. As a consequence, our different propositions (A1; A2; A4; A5; and A7) are all verified and confirmed by our results. This investigation implies that the investment in HRM practices is a driver for enterprise performance; that all the HRM practices are not compulsory to value or consider as there should be HRM practices for managerial HRs and HRM practices related to the management of non-managerial HRs. Knowing which HRM practices bring about enterprise performance in the Ivorian context for the two types of workers will help top leaders make their organization be effective and efficient in not wasting time to find out how to boost their enterprise performance.

This investigation admits some limitations. The size of the sample used in this paper will be for us, a premature way of asserting that the management of HRs in the participating enterprises is similar to many other enterprises. The sample is not sufficient to reflect the realistic picture of the enterprises established and operating in Côte d'Ivoire through the evaluation of the influence of HRM practices on OP. Consequently, this paper suggests directions for possible prospective researches. Accordingly, a longitudinal study should be carried out all through the country for a much more considerable assessment of the connection between HRM practices and the performance of enterprises in Côte d'Ivoire. Questionnaire techniques were utilized to collect the data with a view to analyze them and draw conclusions. For prospective research, it will also be interesting to do with forum discussions or group discussions. This study purely gives us an idea about the assessment of HRM practices enhancing performance in some industrial enterprises in Abidjan, Republic of Côte d'Ivoire. Since there is in this article a constrained conclusion for an optimistic link between the alignment of HRM practices with business strategy and OP, the research inquirer thinks that there should be much more important development of refined measures of organizations strategy to give a hand in investigating the substance of HRM practices for enterprises in Abidjan, to attain maximum performance. This paper makes important contributions to the perception of the correspondence between HRM and OP in Abidjan (Republic of Côte d'Ivoire), a West African country with a developing economy.

\section{References}

Becker, B and Gerhardt, B M. (1996). The Impact of human resource management on organizational performance: Progress and Prospect. Academy of Management Journal, 39:4, 779-801.

Beer, M., Spector, B., Lawrence, P., Mils, Q., and Walton, R. (1984). Managing Human Assets, New York: Free Press.

Beugre, C.D. (2004). Human Resource Management in Ivory Coast, in Kamoche, K., Debrah, Y., Horwitz, F., and Muuka, G.K. (eds), Managing Human Resources in Africa, Routledge.

Bjookman, I and Fey, Carl. (2000). The Effects of HRM Practices On MNC Subsidiary Performance In Russia, SSE/EPI Working Paper Series in Business Administration, N0. 6.

Delaney, J T \& Huselid, M., A. (1996). The Impact of human resource management practices on perceptions of organizational performance. Academy of Management Journal, 39: 4, 949-969.

Delery, J E and Doty, D H. (1996). Codes of theorizing in strategic human resource management: Tests of universalistic, contingency, and configurationally performance predictions. Academy of Management Journal, 39: 4, 802-835. 
Eisenhardt, Kathleen. (1998). Agency and institutional — theory explanations: The case of retail states compensation, Academy of Management Journal, 31: 488-511.

Fey, Carl F.,Pontus Engstrom, \& Ingmar Bjookman. (1999). Effective HRM practices for foreign firms in Russia. Organizational Dynamics, Autumn: 69-80.

Flachaire E. (2003). Methodes de Simulations”, Working Paper, Universite de Paris I Panthion-Sorbonne.

Forster, N. (2004). Maximum Performance: A Practical Guide to Leading and Managing People at Work. Cheltenham: Edward Edgar.

Freedman D.A. (1984). “On Bootstrapping Two-Stage Least-Squares Estimates in Stationary Linear Models”. Annales of Statistics, Vol. 1, pp. 827-842.

Guest, D. E. (1997). Human Resource Management and Performance: A Review and Research Agenda.The International Journal of Human Resource Management, 8:3 June. Pp 263-276.

Hausman, J. A. (Nov.1978). Specification Tests in Econometrics. Econometrica, Vol. 46, pp. 1251-1271.

Jones, G. \& Patrick Wright. (1992). An economic approach to conceptualizing the utility of HRM practices. In K. Rowland \& G. Ferris (Eds.) Research in personnel and human resource management, 10: 271-300.

Lloyds, T.B. (July 2005). "The Impact of HRM and Work Climate on Organization Performance”, BNEDT, p. 1.

Mac Kinnon J.G. (2002). Boostrap Inference in Econometrics. Canadian Journal of Economics, Vol.35, pp. 615-645.

Ngo, Hang-Yue, Daniel Turban, Chung-Ming Lan, and Siu-Yun Lui. (1998). HRM practices and firm performance of multinational Corporations: Influences of country of origin. Journal of International Management, 9:632-652

Nunnally, Jeffrey. (1998). Psychometric theory, New York: McGraw Hill.

Pfeffer, J. (1998). Seven practices of successful organizations. California Management Review, Vol. 40 No. 2, pp. 96-124.

Powell Thomas C. (1992). Organizational alignment as a competitive advantage. Strategic Management Journal, 13: 551-558.

Price, J.K., and Mueller, C.W. (1986). Handbook of Organizational Measurement, Marshfield, Mass: Pitman.

Snell, Scott A. (1991). Executive use of HMR controls to improve firm performance: Modeling effect of administrative information. Academy of Management Best Papers Proceedings, 277-281.

Wright Patrick M., Blaine McCormick, Scott Sherman, \& and Gary C. McMahan. (1999). The role of human resource practices in petro-chemical refinery performance. International Journal of Human Resource Management, 10: 551-571.

Wright, Patrick M., and Rogers, E. W. (1998). Measuring Organizational Performance in Strategic Human Resource Management: Problems, Prospects, and performance Information Markets, Human Resource Management Review, Vol. 8 (3), pp311-331.

Youndt, Mark A., Scott A. Snell, James W. Dean, And David P. Lepak. (1996). HRM, manufacturing and firm performance, Academy of Management Journal, 39: 836-866. 
Table 1. Results of Principal Component Factor Analysis with Varimax Rotation

\begin{tabular}{|c|c|c|c|}
\hline Variables & $\begin{array}{c}\text { Development } \\
\text { Factor }\end{array}$ & $\begin{array}{c}\text { Feedback } \\
\text { Factor }\end{array}$ & $\begin{array}{c}\text { Pay/organization } \\
\text { Factor }\end{array}$ \\
\hline Technical training & 0.856 & 0.634 & 0.303 \\
Non-technical training & 0.902 & 0.582 & 0.582 \\
Non-entry jobs filled from within & 0.896 & 0.399 & 0.592 \\
enterprises & & & \\
Assisting in career planning & 0.929 & 0.626 & 0.303 \\
Job security & 0.437 & -0.517 & 0.435 \\
Information sharing programs & -0.302 & 0.931 & 0.525 \\
Complaint resolution system & 0.531 & 0.916 & 0.297 \\
Attitude survey & 0.475 & 0.851 & 0.042 \\
Performance appraisals & 0.547 & 0.411 & 0.826 \\
Group/company performance in & 0.301 & -0.304 & 0.767 \\
pay & & & 0.860 \\
Teamwork & 0.630 & 0.659 & 0.751 \\
Interdepartmental communication & 0.444 & 0.492 & 0.911 \\
Eigen Value & 2.825 & 2.515 & 2.445 \\
Vecentralized decision making & 19.735 & 17.375 & 16.795 \\
\hline Cronbach Alpha & 0.732 & 0.672 & 0.713 \\
\hline
\end{tabular}

Table 2. Results from the Correlation Analysis

\begin{tabular}{|c|c|c|c|c|c|c|c|c|c|c|}
\hline Variables & 1 & 2 & 3 & 4 & 5 & 6 & 7 & 8 & 9 & 10 \\
\hline 1. PERFORMANCE & 1 & & & & & & & & & \\
\hline 2. Manager Development & $0.422 * *$ & 1 & & & & & & & & \\
\hline 3. Manager Pay/Organisation & $0.947 * *$ & $0.293 * *$ & 1 & & & & & & & \\
\hline 4. Manager Feedback & $0.247 * *$ & $0.905 * *$ & $0.213 * *$ & 1 & & & & & & \\
\hline 5. Employee Development & $0.693 * *$ & $0.955^{*}$ & $0.613 * *$ & $0.208 * *$ & 1 & & & & & \\
\hline 6. Employee Pay/Organisation & $0.972 * *$ & $0.448 * *$ & $0.239 * *$ & $0.801 * *$ & $0.093 * *$ & 1 & & & & \\
\hline 7. Employee Feedback & $0.615 * *$ & $0.326^{* *}$ & $0.492 * *$ & $0.446^{* *}$ & $0.056^{* *}$ & $0.735 * *$ & 1 & & & \\
\hline 8. HRM-Strategy Fit & $0.428^{*}$ & $0.485^{*}$ & $0.145^{*}$ & 0.983 & $0.450 * *$ & $0.118^{* *}$ & $0.875^{* *}$ & 1 & & \\
\hline 9. \#Years Enterprise in Côte d'Ivoire & 0.431 & 0.300 & $0.636^{* *}$ & $0.550 * *$ & 0.897 & $0.585^{*}$ & $0.366^{*}$ & 0.628 & 1 & \\
\hline 10. Log of \# Employees & $0.768 * *$ & $0.762 * *$ & $0.271 * *$ & 0.145 & $0.269 *$ & $0.273 * *$ & 0.778 & -0.968 & 0.901 & 1 \\
\hline
\end{tabular}

$$
\text { Note: } \quad \mathrm{N}=320,{ }^{*} \mathrm{p}<0.05 ; * * \mathrm{p}<0.01
$$


Table 3. Regression Analysis on Enterprise Performance for Managerial Workers

\begin{tabular}{|c|c|}
\hline Independent Variables & Model 1 \\
\hline Log of number of employees & $0.231^{*}$ \\
Age of enterprise in years & 0.128 \\
HRM - strategy fit & $0.144^{*}$ \\
Manager development & $0.205^{*}$ \\
Manager pay/organization & -0.075 \\
Feedback to manager & $0.252^{*}$ \\
$\mathrm{R}^{2}$ & 0.531 \\
Adjusted $\mathrm{R}^{2}$ & 0.487 \\
$\mathrm{~F}$ & $10.56^{* * * *}$ \\
\hline $\mathrm{N}$ & 320 \\
\hline
\end{tabular}

Note: a. Dependent variable=enterprise performance, b. Standardized regression

Coefficients are shown, c. ${ }^{*} \mathrm{p}<0.05, * * * * \mathrm{p}<0.01$

Table 4. Regression Analysis on Enterprise Performance for Non-Managerial Workers

\begin{tabular}{|l|c|}
\hline \multicolumn{1}{|c|}{ Independent variables } & Model 2 \\
\hline Log of number of employees & $0.134^{*}$ \\
Age of enterprise in years & 0.052 \\
HRM - strategy fit & 0.099 \\
Employee development & $0.351^{*}$ \\
Employee pay/organization & $0.123 * * * *$ \\
Feedback to employees & 0.093 \\
$\mathrm{R}^{2}$ & 0.504 \\
Adjusted $\mathrm{R}^{2}$ & 0.395 \\
$\mathrm{~F}$ & $12.912 * * * *$ \\
\hline $\mathrm{N}$ & 320 \\
\hline
\end{tabular}

Note: a. Dependent variable=enterprise performance, b. Standardized regression

Coefficients are shown, $\mathrm{c}{ }^{*} \mathrm{p}<0.05, * * * * \mathrm{p}<0.01$

Table 5. Simulations Results from Monte Carlo Methods

\begin{tabular}{|c|c|c|}
\hline Independent Variables & \multicolumn{2}{|c|}{ Monte Carlo Methods } \\
\hline Log of number of employees & 2.543 & $\begin{array}{c}\text { Coefficient of } \\
\text { Sensibility }\end{array}$ \\
Age of enterprise in years & 1.518 & $2.21 .10^{-2}$ \\
HRM - strategy fit & 1.690 & $-3.31 .10^{-1}$ \\
Employee development & 2.014 & $3.17 .10^{-2}$ \\
Employee pay/organization & 1.776 & $2.45 .10^{-2}$ \\
Feedback to employees & 2.312 & $1.06 .10^{-1}$ \\
Manager development & 3.675 & $2.39 .10^{-1}$ \\
Manager pay/organization & 1.641 & $3.65 .10^{-1}$ \\
Feedback to manager & 2.128 & $2.11 .10^{-2}$ \\
\hline N & & $2.72 .10^{-1}$ \\
\hline
\end{tabular}


Table 6. Results of the Credibility Test: The Hausman's Specification Test (HST)

\begin{tabular}{|c|c|c|c|c|}
\hline \multicolumn{5}{|c|}{---- Coefficients ---- } \\
\hline & (b) Fixed & $\begin{array}{c}\text { (B) } \\
\text { Random }\end{array}$ & $\begin{array}{c}\text { (b-B) } \\
\text { Difference }\end{array}$ & $\begin{array}{c}\text { Sqrt (diag } \\
\left.\left(\mathrm{V}_{-} \text {b-V_B }\right)\right) \\
\text { S.E. }\end{array}$ \\
\hline Technical training & $\begin{array}{c}0.0053989 \\
2\end{array}$ & $\begin{array}{c}-0.082022 \\
47\end{array}$ & 0.08742139 & 0.00048740 \\
\hline Non-technical training & $\begin{array}{c}-0.014457 \\
83\end{array}$ & $\begin{array}{c}0.2208101 \\
7\end{array}$ & -0.23526800 & 0.01408882 \\
\hline $\begin{array}{l}\text { Non-entry jobs filled from within } \\
\text { enterprises }\end{array}$ & $\begin{array}{c}0.0529661 \\
0\end{array}$ & $\begin{array}{c}-0.384845 \\
89\end{array}$ & 0.43781199 & 0.00046771 \\
\hline Assisting in career planning & $\begin{array}{c}-0.259259 \\
26\end{array}$ & $\begin{array}{c}-0.046851 \\
39\end{array}$ & -0.21240787 & 0.00800000 \\
\hline Job security & $\begin{array}{c}-0.003755 \\
55\end{array}$ & $\begin{array}{c}-0.301285 \\
63\end{array}$ & 0.29753009 & 0.11111111 \\
\hline Information sharing programs & $\begin{array}{c}0.0148760 \\
3\end{array}$ & $\begin{array}{c}0.0028427 \\
0\end{array}$ & 0.01203333 & 0.00048540 \\
\hline Complaint resolution system & $\begin{array}{c}0.0081461 \\
9\end{array}$ & $\begin{array}{c}-0.001110 \\
19\end{array}$ & 0.00925638 & 0.00004052 \\
\hline Attitude survey & $\begin{array}{c}-0.005783 \\
02\end{array}$ & $\begin{array}{c}0.0491397 \\
5\end{array}$ & -0.05492277 & 0.00218341 \\
\hline Performance appraisals & $\begin{array}{c}-0.004569 \\
58\end{array}$ & $\begin{array}{c}0.2196950 \\
1\end{array}$ & -0.22426459 & 0.15772871 \\
\hline Group/company performance in pay & $\begin{array}{c}0.0249777 \\
0\end{array}$ & $\begin{array}{c}0.0716212 \\
6\end{array}$ & -0.04664356 & 0.10840704 \\
\hline Teamwork & $\begin{array}{c}0.0609523 \\
8\end{array}$ & $\begin{array}{c}-0.085065 \\
06\end{array}$ & 0.14601744 & 0.01425373 \\
\hline Decentralized decision making & $\begin{array}{c}-0.782178 \\
22\end{array}$ & $\begin{array}{c}-0.226355 \\
46\end{array}$ & -0.55582276 & 0.00112893 \\
\hline Interdepartmental communication & $\begin{array}{c}-0.008332 \\
36\end{array}$ & $\begin{array}{c}-0.074021 \\
50\end{array}$ & 0.06568914 & 0.00179351 \\
\hline
\end{tabular}

Note: $\mathrm{b}=$ consistent under $\mathrm{H}_{0}$ and $\mathrm{H}_{1}$

$\mathrm{B}=$ inconsistent under $\mathrm{H}_{1}$, efficient under $\mathrm{H}_{0}$ 


\title{
Study on China's Sustainable Development of Rural Micro-credit
}

\author{
Lixin Tang \\ School of Management, Yangtzeu University \\ Jingzhou 434023, China \\ E-mail: tanglixin@yeah.net
}

\begin{abstract}
Rural micro-credit, which has been passed for 15 years in our China, gained great social and economic benefits, while its sustainability is still facing the challenges. This passage reviews the development course of rural micro-credit, points out the problems that existed and puts forward the corresponding suggests.
\end{abstract}

Keywords: Micro-credit rural area construction

\section{Introduction}

Micro-credit is a way of poverty alleviation. Micro-credit, as the name implies, is small amount of inputs, with the nature of the funds as a loan and the implementation of credit. Micro-credit is a financial service that targets to the poor, which core elements doesn't aim at small, but that the credit is an unsecured loan in order to ensure effective use of funds and return. At the micro-credit operation, it takes direct-to-home, the group UNPROFOR, the whole loan-to-zero also, a series of measures such as strict management. Micro-credit first introduced in Bangladesh in 1976, which also called "Meng-mode", has got the national organizations' authorization these years. The 2006 Nobel Peace Prize winner Muhammad Yunus and the Grameen Bank's biggest contribution was to open the financial means to assist the poor, while some can be self-financing their own sustainable development, and continuing to serve the more poor better. We introduced this mode into China in 1992, and made experiments at a dozen provinces and municipalities, including Yunnan Shanxi and so on, which got remarkable social and economic benefits. Micro-credit is positively advocated and implemented in our China.

\section{The development procedure of Micro-credit in China}

Micro-credit has been passed for 15 years in China from the time that Rural Development Institute Chinese Academy of Social Sciences, Duxiaoshan, has applied soft loans from GB Trust Fund in 1993.The procedure can be divided into 4 periods:

The first period (1993 1996), the source of the fond mainly depend on the international donation and soft loans without government fond basically, the key is GB-style micro-credit project.

The second period (1996 2000), at this stage, Government agencies and Financial institutions carried out Policy-oriented poverty alleviation projects of micro-credit for Operation of institutions with the help of International aid funds at the same time.

The third period (2000 2005), Rural formal financial institutions was Full-scale intervening and various projects entered into the stage of the institutionalization of the building. From 2000, at the People's Bank under the impetus of, rural credit cooperatives, as the formal financial institutions, was beginning to promote micro-credit comprehensively. Obvious characteristic at this stage is that under the support of central bank refinancing, rural credit cooperatives carried out small farmer credit on the basis of in strengthening the letter of the user, credit the construction villages and towns. From the start in 2002, government started to release independent start-up loans for re-employment of laid-off unemployed workers in state-owned enterprises learning from the experiences of rural credit cooperatives.

The forth period (2005 nowdays), Beginning in December 2005, suppliers of rural micro-credit were diversified, and tried the way of commercial and market-oriented to develop. Initially, it is a micro-credit organization of commercialization of sustainable development, its basic characteristic is only loans, and not deposits, operating independently and assumption of the risk is its commercial principle. RiShenglong, in jinzhongpingyao, is the first small loan company in China. By the end of 2006, CBRC relaxed the policy of market access to rural financial 
institutions, and allowed private capital to pilot in loan companies, village banks, and rural cooperatives. March 2007, China issued guidance on the development of rural micro-credit carried out in banking and financial institutions and made specific provisions on small loan business. June 2007, China postal savings bank micro-credit business was started in Henan province. After careful selection, Xingxiang and other three cities were chose as the place to make experiments, and chose ten middle developed County such as Changheng in Xingxiang. May 2008, CBRC and central bank published the guidance on the pilot of rural micro-credit united, small loan companies as corporate, its legitimacy was confirmed. Zhejiang province decided to start small loan company pilot.

At this stage of our country, Microfinance institutions including the following several categories:

The first category is the micro-credit of rural Credit Cooperatives. So far, the micro-credit of rural Credit Cooperatives has many features, such as wide coverage, large volume of business, and large volume of business.

The second category is the micro-credit of postal savings bank. Recently, postal savings bank is the financial institution which covers the largest the rural market, the scale of bank self-dots and post agent network is up to 37000 , the coverage of the network is wide, sources of funding is sufficient, and its cost is low relatively. Just because of bank self-dots' distribution characteristics, this kind of micro-credit may become one of the dominant forms of micro-credit.

The third category is the wholesale microfinance of China Development Bank and Agricultural Development Bank and other Policy banks. Policy-oriented financial institutions loan the fond to Rural Credit Cooperatives, Postal savings bank and other Microfinance institutions, which has the nature of poverty alleviation.

The forth category is the micro-credit of non-profit non-governmental organizations, such as the Microfinance institutions that established by China Foundation for Poverty in 2000. Its source of funds is single which mainly depends on the donations of non-profit non-governmental organizations.

The fifth category is microfinance institutions that created by private and absorbed public deposits to some degree.

The sixth category is commercial micro-credit companies. They generally register at the Trade and Industry Department, not absorb public deposits, and undertake business loan, their business object is small and medium-sized rural enterprises not general farmers, Pilot micro-credit companies of Central bank belongs to this kind.

The seventh category is the micro-credit of village bank and rural non-governmental capital mutual aid organizations. The number of this mode is small, and exists in pilot framework of CBRC nowadays.

China's rural micro-credit has been achieving great achievements. December 26, 2007 to 27, "China's rural micro-credit in international forums" was held ceremoniously in Haikou, the theme is "Micro-credit, Serve for Sannong". At Forum, all kinds of microfinance institutions introduced much successful experience, however, we generally felt that China's rural micro-credit is in the "low period". Among in 240 million farmers, there are 120 million farmers need loan, well, $67,000,000$ are general credit cooperatives. Recently, there're about 300 micro-credit organizations, but lots of them are unsustainable. That is, China's rural micro-credit is in the experimental stage and the unique technology doesn't come into being, we have to analysis in depth.

\section{The challenge that China's rural micro-credit's development faced}

\subsection{Channels of sources of funding are narrow}

State-owned commercial bank loans permissions has been taken, Substantial deposits absorbed by Grass-roots business organizations can only be deposited to superior bank, this causes lots of the county's fond runs into cities, the injection of agricultural credit isn't sufficiently. Pilot micro-credit companies face lacking money, whereas, village bank is bad at absorbing deposits in short time; Second, Postal savings have a foot in the local deposits, and Rural Credit Cooperatives have another, lacking money is a big challenge. From the overall situation, various credit subjects' fond aren't enough, supporting "Sannong" is not within our power.

\subsection{Micro-credit's high risk and high cost influence its sustainable development}

Compared with other industries, agriculture has the features of instability, property of weakness, and externalities. Farmers are the users of micro-credit, which lack effective assets, in this way ability to regain loans greatly relies on production and operation situation of farmers and the degree of personal credit. Second, because micro-credit are mainly used in plant industry, aquaculture and other small-scale production and operations which are closely related to natural conditions, the unpredictability of natural disasters add the risk of micro-credit's callback. The cost of micro-credit is certainly high owing to conducting loaning to single family.

\subsection{Rural micro-credit granting management is imperfect that affects the sustainability of loan}

At the procedure of releasing farmers small loans, because of lacking unified operational management methods and working procedures, not strict system, and confusing the different concept and content of farmers ratings, credit and lending, this causes unconditional credit and lending when farmers gained credit rating, the view that rating decides every thing, and confusion of basic conditions (credit) and lending conditions. At the process of operation, it based on 
subjective judgments, there are too many variables and difficult to control, as well, the use of the loans is too flooding. On the level of rural productivity, its risk is difficult to control and expected recovery rate is more difficult to achieve if we release excessive rural consumer loans.

\subsection{The service related to credit is lagging seriously}

Because publicity is not in place, some farmers view loan as the fond of poverty alleviation, risk their own strengths and needs to follow the trend of loaning. Some places' investment failed and its loans couldn't be return at the process of industrialization of agriculture's structural adjustment, as the result of not understanding technology and blinding investment.

\section{Some advice to the sustainability of micro-credit}

\subsection{Adopt Community Investment Act to solving the lack of fond}

It's not enough that the fond of micro-credit is only supplied by the local saving, between 1980s and 1990s, our countryside have made great contribution to the city building, the urban-rural gap is gradually expanding, now we can conduct industry-financed agriculture and city-financed rural. Outboard experience does have community investment act, it formulates that Commercial Banks have to invest a certain proportion of funds to the countryside. Thailand, for example, formulates that no matter which Commercial Bank, $20 \%$ of the fond must be invested to the rural, and it can be invested by itself or commissioned to others to invest, Central One document in 2005 has proposed this idea, but at that time, this idea referred to county's fund community investment, according to the idea of Thailand and USA, it covered all over the country already. If we have such a compulsory mechanism, maybe the problem of rural finance can have a greater ease.

\subsection{Perfect risk transfer and guarantee mechanisms, enhance the comprehensive agricultural support capacity and the overall disaster response capacity}

I suggest that when we are establishing and improving the government-led security system in agriculture, we can establish micro-credit guarantee funds for special projects which are used to subsidy the main body of rural micro-credit's a certain proportion of the loss, and institutionalize and standardize micro-credit project eligibility and the method of subsidization.

\subsection{Make farmers micro credit interest rates market-oriented}

Micro credit is different from banks generally loan processing. The former has the feature of small quantity and high cost, the key to profitability for microfinance institutions is loan pricing and cost management, that is, interest rate pricing need to cover the cost of credit. However, China's relevant laws stipulate that more than four times the benchmark interest rate belong to Usury and this is a contradiction. If micro-credit wants to achieve the goal of sustainable commercial, its lending rate must be much higher than that of general commercial banks. Giving full consideration to the cost of funding sources, loan management costs, farmer affordability and the situation of funding needs in rural areas, we should calculate breakeven point with adding normal profit to come up with the reasonable level of interest rates of micro credit. Nowadays, interest rates can be higher relatively, in this way the farmers can undertake to make up the higher loan cast. But it is not good if the interest rates is much too high, one way to reduce interest rates is to give preferential treatment at aspects such as tax and so on, the nation can subsidy some. But the more important one is competition, at a place should not result in monopolization, there should be 2 or 3 agencies doing it together, and the interest rates will decline naturally, this is international experience, that is to take step by step approach to do market-oriented reforms towards micro-lending rate.

\subsection{Improve the credit rating system and set up a farmer credit record}

Giving credit rating system provisions on law to avoid randomness of farmer credit limit, and establishing scientific criteria for rural micro-credit system, with applicability of progressive lending, are propitious to set up good rural credit system. We can refer to "Tax-credit rating management methodologies" issued by State Administration of Taxation in July 2003 and "Agricultural Development Bank of China enterprise credit rating loans provisional Ways" issued in May 2002, and classify farmers credit into four agricultural level ABCD, refine the specific criteria of all level, and carry out the job of farmers credit rating regularly. We should conduct rural research in depth, set up a sound farmer economic file, and prevent the risk of users to assess the false record. We need to set up barriers at the respect of conditions, quality, and rates and so on for discreditable farmers, and strengthen credit awareness of farmers. At the same time, Local Government should take part in it positively, strengthen the rural credit system construction, and promote the formation of rural credit system through strengthening supervision of the use and recycling of the farmer loans and controlling and eradicating situation of escaping debt.

\subsection{Issue policies that are good to promote the development of micro credit, especially the development of poverty} alleviation micro credit

Micro credit's large-scale development needs our nation's help. We should advocate pilot at different places and 
institutions, encourage moderate competition, and award for the excellent, fine the bad. Firstly, we should issue policies to encourage the development of micro credit from the micro-level, such as provisional management method, it gives people legal identity; we should give channels and financial support for the poverty alleviation micro credit institutions from the concept level, and establish wholesale funding agencies and organizations which only serve for them, such as policy banks, they conduct the job of issuance, management and supervision. Secondly, we have to offer the support of the quality of personnel management and training opportunities, and conduct the training of micro-credit project to make them learn the new technology, especially learn how to adjust themselves' breeding, cultivation and production methods to meet the demand of the market. It is important to improve the abilities of adjusting market, applying new technologies and loans, as well, improving the success rate of investment projects and reducing the risk of micro-credit are vital. At last, we should encourage microfinance institutions to establish industry self-regulatory mechanism, now industry self-regulatory organizations are incompact, we call one of them Micro-credit to promote the network, in fact, it is the predecessor of loose organizations, and we can encourage this kind of organizations to be self-disciplined.

In all, the solution of rural issues is a complex systems engineering, farmers, especially medium low-income farmers, are the vulnerable groups of society, country should not only offer assistance in policy, but also give the capital and administrative support, moreover, we need to put in true feelings. And then, we have to continuous improved China's rural micro-credit market and micro-credit operation efficiency and quality to promote the sustainable development of micro-credit.

\section{References}

Bu, Yanhong. (2008). Post Bank Micro credit Development of the characteristics and advantages. Commercial Banks, (2): 63-64.

China's rural micro-credit in international forums, record of the third unit. Sina Finance. [Online] Available: http://www.sina.com.cn (Retrieved from December 26, 2007)

Guo, Peiqing. (2007). The research of "Yunus microcredit model". Western financial, (8): 23-26.

Zhang, Jie. (2007). Rural micro-credit risk prevention and management. Price monthly, 11: 86-87. 


\title{
Awareness of Eco-label in Malaysia's Green Marketing Initiative
}

\author{
Nik Ramli Nik Abdul Rashid \\ Faculty of Business Management, Universiti Teknologi MARA Perlis \\ 026000, Arau Perlis, Malaysia
}

Tel: 60-4-9874-252Ｅ-mail: nikramli@perlis.uitm.edu.my

\begin{abstract}
Consumer awareness of the environment and preference for more environmentally benign products appears to be growing steadily around the developed world and also some developing countries. The Malaysian government too has responded very positively to this challenge. In 1996 Standards and Industrial Research Institute of Malaysia (SIRIM) lunched the national eco-labeling program verifying products according to environmental criteria such as Environmentally Degradable, Non-toxic Plastic Packaging Material, Hazardous Metal-Free Electrical and Electronic Equipment, Biodegradable Cleaning Agents and Recycled Paper. Federal Agriculture Marketing Authority (FAMA) has the Malaysia Best logo for environment friendly agriculture product and the Malaysian Energy Commission for energy efficient electrical products. But is the Malaysia consumer ready for the eco-label? Taking into consideration the infancy stage of the Malaysia green marketing initiative, traditional approach to evaluating local consumer receptiveness to the eco-label might not be suitable. This paper approaches the introduction of eco-label with two perspectives in mind. Firstly, while earlier studies from the western scholars use eco-label as a part of the augmented product, this study introduces eco-label as a separate moderating variable. Secondly, the choice of employees working in ISO14001 certified organization as the study population explore a potentially conducive place to initiate a systematic effort in developing a green consumer community. The result is very encouraging. This study has clearly shown that, with some exposure to environmental related experiences (such as those who were working with organization implementing the EMS) Malaysian consumer would indeed react positively to the eco-label. In fact, for situation that requires them to consider environmental aspects of a product that they wish to purchase, the eco-label will definitely be the crucial factor that will push them to make the right purchase choice.
\end{abstract}

Keywords: Eco-label, Environmental attitude, Knowledge of environmental issues, Green products, ISO14001

\section{Introduction}

The Product Certification Program, Malaysia's national labeling program, was launched in 1996 by the Standards and Industrial Research Institute of Malaysia (SIRIM). It is a single-attribute, seal-of-approval product certification program. As of March 1997, SIRIM's certification activities were delegated to a fully owned subsidiary SIRIM Quality Assurance Services (SIRIM QAS). This eco-labeling scheme would verify products according to environmental criteria such as Environmentally Degradable, Non-toxic Plastic Packaging Material, Hazardous Metal-Free Electrical and Electronic Equipment, Biodegradable Cleaning Agents and Recycled Paper.

Another relatively more active eco-labeling scheme is for agricultural products; one promoted by the Agricultural Department and Federal Agriculture Marketing Authority (FAMA), known through its SALM and Malaysia's Best logo, respectively. SALM (Skim Amalan Ladang Baik Malaysia) is a national program implemented by the Department of Agriculture to recognize and certify farms which adopt good agricultural practices (GAP), operate in an environmentally friendly way and yielding products that are of quality, safe and suitable for human consumption. Only agricultural produces from these certified farms could apply for the Malaysia Best eco-label.

There is also an eco-label that relates to efficient use of energy endorsed by the Malaysian Energy Commission. The commission was set up in 2001 to regulate and promote energy efficiency (EE) in line with national policies with the cooperation of interested stakeholders. The energy commission has established an energy labeling scheme for household appliances to assist Malaysian consumers. With the Energy Rating Label consumers will see the appliance energy performance at a glance and help them to compare products. Even though at the moment the Energy Rating Label is only used for refrigerators, the Energy Commission will expand its promotional efforts to encompass other energy efficient household appliances in the future. These encouraging developments could be evidence that the 
Malaysian business sector are not far behind in responding to challenges arising from demand made from the consumers for environmentally friendly products.

However, according to Chen (2003) these developments might not be originating from local causes because industries have only become more environment-conscious due to export market demand for environment-friendly goods or complying with instruction from oversea head office. Searching through literature also found very few studies done on the respond of local consumers toward the use of eco-label in purchase decisions. Taking into consideration the above discussion, the main question for this study is could Malaysian consumer awareness of an eco-label strengthen the preference they would give for the corresponding environment friendly product? The research framework consisting of all relevant variables is depicted in Figure 1 and will be elaborated further in the following section.

\section{(Insert Figure 1)}

\section{Literature Review}

\subsection{Eco-labels}

Eco-labels refer to a product's collective overall environmental performance (Giridhar, 1998). They are indicators of the environmental performance of a product, developed to try to prevent consumers from being confused over claims of environmental friendliness (Childs and Whiting, 1998). A sound eco-label program would look at the entire life cycle of the product including production, distribution, use and disposal. The first of such programs was the Germany's Blue Angel program, which began in 1978. A number of programs have been developed in other countries: The Swan (Nordic Eco labeling), Environmental Choice (Canada 1988), Eco Mark (Japan 1989), Green Seal (US 1990), Eco-Mark (India 1991) and Eco-label (EU 1993).

Eco-labels are potentially attractive instruments informing consumers (including institutions and governments that consume input materials and products) about the environmental impact of their purchasing decisions, while simultaneously providing producers with a tool for extracting market place preference and thus market share. Generically eco-labels can be classified into 2 categories: a) self-declaration claims and b) independent third-party claims. Self declaration claims are placed on a product by the manufacturer, retailer or marketer and may be made on a single attribute or an overall assessment of the product. Product claim could include "environment friendly"', "ozone friendly", "organic", "pesticide-free", "degradable", and "recyclable" which are usually described on the packaging. However, these claims are usually not independently verified. Independent third-party claims on the other hand are based on compliance with predetermined criteria, which are independently verified by a competent authority. The criteria are usually built on a product life-cycle approach.

A study by Teisl, Roe and Hick (2002) provided market-based evidence that consumers can respond positively to eco-labels and consequently contributed to the increased market share of the product concerned. Thogersen (2002) in a rather extensive study involving respondents from 4 different countries, found that large majority of them pay attention to eco-labels at least sometimes. Grankvist, Dahlstrand and Biel (2004) also found that information about environmental outcomes (which were either negative or positive) provided by eco-labels did influence product preference, especially those with strong concern for the environment. Apart from that, they also noted that women, graduate and young respondents showed positive attitude toward eco-labeled products. Loureiro and Lotade (2005) have identified consumers especially in much developed countries have shown their willingness to pay higher premium for eco-labeled products.

However, there are also some studies that highlighted the disagreement on whether or not eco-labeling or environmentally sound labeling programs may be effective tools to motivate consumer's response (Wessells et al., 1999). While discussing the strength and weaknesses of eco-labeling scheme Erskine and Collins (1997) concluded that, in practice, it would be very difficult to have a workable and effective eco-labeling scheme that could clearly contribute to improving the environment. Some studies even reported a weak correlation between environmental concern and the choice of eco-labeled product (Magnusson et al., 2001). Even consumer who know and trust a relevant environmental label will not use it due to information overload (Jacoby, 1984).

Thus, the above discussion showed that the use of eco-label in itself does not ensure positive response from the respondents. It seems to suggest that the use of eco-labels in assisting the eventual purchase decision can be influenced by other exogenous factors such as source credibility (Cary, Bhaskaran and Polonsky, 2004; Erskine and Collins, 1997; Nilsson, Tuncer and Thidell, 2004), the strength of the environmental concern (Grankvist, Dahlstrand and Biel, 2004), and availability of eco-labeled product on the retail shelf (Thogersen, 2000).

An observation common for all of the above studies is that the eco-labels are discussed as part of the augmented product and treated as a dependent variable. This is understandable taking into consideration the relatively advance stage of environmental awareness among western society and the easy availability of eco-labeled product in the retail outlets. This situation would not be applicable for a society who is relatively still unaware of the concept of a green product, much more for eco-labeled product. Thus, rather than focusing on eco-labels products as dependent variable, this study 
have attempted to uncover the independent role of eco-label moderating the relationship between predictor variables to its purchase decisions.

\subsection{Attitudes toward environmental protection}

Environmental attitude is defined as a learned predisposition to respond consistently favorable or unfavorable manner with respect to the environment. Overall, there has been consistent empirical evidence supporting a positive association between environmental attitude and behavior. These studies have also indicated that even if people have little knowledge about the environment they would still exhibit strong emotional attachment to environmental wellbeing (Ling-yee, 1997). Attitude, as opposed to knowledge and behavior, is the most significant predictor of consumers' willingness to pay more for ecologically favorable products (Laroche et. al., 2001). Some studies have also indicated that even though people have little knowledge about the environment they still exhibit strong emotional attachment to environmental wellbeing (Dispoto, 1997; Li Ling-yee, 1997). This study follows earlier studies in conceptualizing attitude toward environmental protection as a unidimensional construct (Noe and Snow, 1990; Minton and Rose, 1997; Sharifah et al., 2005).

\subsection{Environmental Knowledge}

The state of one's knowledge about an issue impacts significantly upon his or her decision making process. The importance of knowledge and the impact of lack of knowledge in the decision-making process have been demonstrated in numerous studies (Laroche et. al 2001; Verdugo, 1996, and Oskamp et al., 1991). This study has initially conceptualized consumer knowledge as having two dimensions, namely Knowledge of Environmental Issues and Knowledge of Green Product Features. The factor analysis of the 20 items measuring perceived knowledge of selected environmental issues were carried out and resulted in 3 dimensions (Table 1). The first factor consist of perceived knowledge respondents had concerning attributes of green products such as "no animal testing, natural ingredient cosmetics, wood product from sustainable forest, organic vegetables, ozone friendly aerosols, biodegradability and unleaded petrol". The second factor consists of respondent's perceived knowledge of general environmental issues such as "vanishing wildlife habitat, destruction of the rain forest, the greenhouse effect and pollution from pesticides". The last factor (concrete knowledge) consist of respondent's perceived knowledge regarding "waste management, hazardous waste and recycled material" which seems to be relevant issues related to their actual activities at their workplace or factory.

\section{(Insert Table 1)}

\subsection{Green Purchase Intention}

Green purchase intention (PI) is conceptualized as the probability and willingness of a person to give preference to products having eco-friendly features over other traditional products in their purchase considerations. The green product used for this study was the energy-saving bulb as compared to the traditional tungsten bulb. A detailed and graphical description of the two products was provided for comparison and the respondents were required to give their preferred product choice.

\section{Methodology}

The population for this study is employees of organizations that have successfully adopted the environmental management system ISO14001 since 1996. Questionnaires were either sent by "express mail" or delivered by hand to the environmental management representative (EMR), who would then be asked to randomly select 15 employees from their organization to be respondents for the survey. A total of 526 employees were then finally selected. The entire data collection period took approximately ten weeks to be completed. There are justifications for using this population. Firstly, due to the early stage of the green marketing initiatives in this country. Secondly, organization implementing the EMS would be a potentially conducive place to initiate a systematic effort in developing a green consumer community.

\section{Findings and Interpretation}

\subsection{Moderating Effect of Awareness of Eco-Labels Variables}

Hierarchical regression analysis was used to test the moderating effect of consumers' perception of eco-labels between concern for environmental protection and purchase intention. Based on the suggestions of Sharma et al. (1981), a three-step hierarchical regression analysis was conducted to test for a moderating effect. The independent variables were entered in the first step, the moderator variable was entered in the second step, and lastly the interaction between the moderator and the independent variables were entered. If the interaction term is statistically significant, a moderator effect is then present. The results of the analyses are discussed as below.

\section{(Insert Table 2)}

Table 2 above shows the results of the hierarchical regression analysis of the moderating effect of Awareness of Eco-Label between Environmental Attitude and Knowledge with Purchase Intention. The adjusted $\mathrm{R}^{2}$ and the F change 
are significant from step 1 to step 2 and from step 2 to step 3 with the introduction of the interaction terms indicating the moderating effect of eco-label awareness. For the interaction effect, the results indicated that the interaction between attitude and label awareness is significant $(\beta=.71, \mathrm{p}<.01)$. The interaction between knowledge of green product (knowledge $B$ ) and label awareness is also significant $(\beta=.49, \mathrm{p}<.05)$ as also with the interaction between concrete knowledge (knowledge $C$ ) and label awareness $(\beta=-.52, \mathrm{p}<.01)$. Lastly, the interaction between knowledge of environmental issues (knowledge $A$ ) and label awareness was found to be not significant.

Before final decision could be made the line graph was use to further analyze the effect of the moderating variable on the relationship between dependent and independent variables. Looking at Figure 2, it could be concluded that the relationship between Attitude toward Environmental Protection and Purchase Intention is decisively moderated by consumers' awareness of the relevant Eco-Label for the chosen product used in this study. The effect of high awareness of the eco-label in influencing the purchase of a green product is very strong for respondents having positive attitude toward the protection of the environment. The relationship is also positive for respondents with low awareness of eco-label, but as can be seen from the slope (beta), the effect on purchase intention is very much lower. The result indicated that the effect of attitude toward environmental protection on purchase intention is a crucial prerequisite, and can be further enhanced with the existence of an eco-label.

\section{(Insert Figure 2)}

Thus, we could now conclusively state that the higher the awareness of eco-label the stronger the relationship between attitude toward environmental protection and intention to purchase a product with environmental friendly features.

\section{(Insert Figure 3)}

The above Figure 3 displays the moderating effect of awareness of eco-label on the relationship between knowledge of green products and purchase intention. Respondents that have high awareness of eco-label (energy star) show a higher and positive inclination to purchase a green product (energy saving bulb) if they have better knowledge of them. Whereas respondents that have low awareness of eco-label show a negative relationship (i.e. though they would have more knowledge of the green product it would not influence them in their purchase). Thus, this clearly shows the influence awareness of eco-label has on the confidence of the respondents when making a purchase for a green product. It could also show that awareness of the relevant eco-label would help consumers distinguish between green products and ordinary products when they are confronted by a purchase decision making situation.

One other observation from the results is that respondents with high awareness of eco-label do not have as high beta as expectedly so (as compared to those having low awareness of the eco-label). This situation would probably be explained by the existence of other factors contributing to this relationship, namely as mentioned earlier, the role of attitude toward environmental protection. It could also be due to the fact that in the present circumstances the use of eco-label is very much limited, either from the perspective of the consumers or much so on the part of the manufacturer (marketer) when using these eco-labels in their marketing initiatives. In conclusion we could state that the higher the awareness of eco-label the stronger the relationship between knowledge of green product feature and intention to purchase a product with environmental friendly features.

Finally, the Figure 4 below shows the moderating effect of awareness of eco-label on the relationship between concrete knowledge and purchase intention. Respondents that have high awareness of eco-label show a stronger and positive inclination to purchase a green product (energy saving bulb) when they are more exposed to actual efforts in environmental protection at the workplace. In other word, consumer that has acquired knowledge of environmental protection through their own experience has higher intention to purchase a green product, only if they are made more aware of the environment friendly features of the product by the corresponding eco-label.

\section{(Insert Figure 4)}

On the other hand respondents that have low awareness of eco-label will show a negative relationship (i.e. even though they would have more knowledge arising from actual experience from the workplace, it would not influence them in their purchase intention, since there were no eco-label to inform them of the green features of the product). This clearly shows the impact of eco-label on the confidence of the respondents when making a purchase for a green product. Thus, we could now conclusively state that the higher the awareness of eco-label, the stronger the relationship between concrete knowledge and intention to purchase a product with environmental friendly features.

\section{Conclusions and Suggestion for future study}

This study have suggested that a person having some concern for the environment would have a stronger preference for purchasing a green product, if he is made much more aware of its environmental friendly features through the use of an eco-label.

The importance of an educational program directed toward the community at large, explaining the significance of an eco-label in any consumer purchase decisions, should be carried out hand-in-hand with the general effort to increase 
awareness for the need to protect the environment. It is very surprising indeed, even after launching a national eco-label since 1996, the level of consumer awareness regarding the local eco-labels is almost negligible. Effort in marketing the eco-label by the regulating authorities (government and SIRIM) should be on both ends of the marketing process, the producer and the final consumers. Another interesting finding, especially within the Malaysia's context (where the awareness for green products is still low) is that this study has been able to uncover some limited aspects of Malaysian consumers' reaction to the use of eco-label in their purchase intention for products with environment friendly features. Overall, this study has shown the positive moderating effect of awareness of eco-label between knowledge of green product and consumer intention to purchase. Two conclusions could be made with regard to this interesting result. Firstly, it shows that consumer need more information and to be made much more aware about products with green labels. The emphasis on giving clear information about eco-labels would be two-prong, as it would not only familiarize them with the labels itself but also their knowledge of green products. Failure to do this would mean they were handicapped as to making the best choice that would fulfill their intention to purchase a product with environment friendly feature, due to their inability to effectively discern between green and traditional products. Secondly, it seems that even for those consumers with high knowledge of green product and high awareness of corresponding green label, a positive response as is hoped for from them is not necessarily secured. There seems to be another missing element that could surge their intention of purchasing the product to a higher level. It could be assumed that the most relevant missing factor would be the trust in the eco-label itself. Future studies should be carried out, especially so for local third party eco-labels (such as SIRIM, Malaysia Best etc) and determine whether this assumption is true or otherwise.

As a final conclusion to the question of whether Malaysian consumers are ready for the eco-label? This study has clearly shown that, with some exposure to environmental related experiences (such as those who were working with organization implementing the EMS) Malaysian consumer would indeed react positively to the eco-label. In fact, for situation that requires them to consider environmental aspects of a product that they wish to purchase, the eco-label will definitely be the crucial factor that will push them to make the right purchase.

\section{References}

Bohlen, G., Schlegelmilch, B.B., \& Diamantopoulos, A. (1993). Measuring Ecological Concern: A Multi-construct Perspective. Journal of Marketing Management, 9, 415-430.

Cary, J., Bhaskaran, S., \& Polonsky, M. (2004). Green Marketing and EMS: Assessing potential consumer influence on EMS development in fresh food chains. A report for the Rural Industires Research and Development Corporation. No:04/175. Australian Government.

Chen, S.S. (2003). General activity of Life Cycle assessment in Malaysia. Environmental and $\quad$ Energy Technology Centre, SIRIM Berhad. Malaysia.

Childs, C. \& Whiting, S. (1998). Eco-labeling and the Green Consumers. Working papers from Sustainable Business Publications series. The Sustainable Business Initiative, Department of Environmental Science, University of Bradford, West Yorkshire. [Online] Available: http://www.brad.ac.uk/acad/envsci/SB/init.htm

Dispoto, R.G. (1997). Interrelationship among measures of environmental activity, emotionality, and knowledge. Educational and Psychological Measurement, 37(4), 451-459.

Erskine, C.C. \& Collins, L. (1997) Eco-labeling: Success or Failure. The Environmentalist, 17, 125-133.

Giridhar, T.R. (1998) Eco-labelling: A comparative analysis. Chemical Business, 12(7), 95.

Grankvist, G., Dahlstrand, U., \& Biel, A. (2004). The impact of environmental labeling on consumer preference: Negative versus positive labels. Journal of Consumer Policy, 27, 213-230.

Jacoby, J. (1984). Perspective of information overload. Journal of Consumer Research, 11, 569-573.

Laroche, M., Bergeron, J. \& Barbaro-Forleo, G. (2001). Targeting consumer who are willing to pay more for environmentally friendly products. Journal of Consumer Marketing, 18(6), 503-520.

Li, Ling-yee (1997). Effect of collectivist orientation and ecological attitude on actual environmental commitment: The moderating role of consumer demographic and product involvement. Journal of International Consumer Marketing, 9(4), 31- 54.

Loureiro, M. L., \& Lotade, J. (2005). Do fair trade and eco-labels in coffee wake up the consumer conscience? Ecological Economics, 53(1), April, 129-138.

Magnusson, M.K., Arvola, A., Koivisto Hursti, U.K., Aberg, L. \& Sjoden, P.O. (2001). Attitudes toward organic foods among Swedish consumers. British Food Journal. 103, 209-227.

Minton, A.P., \& Rose, R.L. (1997). The effects of environmental concern on environmentally friendly consumer behavior: an exploratory study. Journal ofBusiness Research. 40, 37-48. 
Nilsson, H., Tuncer, B., \& Thidell, A. (2004). The use of eco-labeling like initiatives on food products to promote quality assurance - is there enough credibility? Journal of Cleaner Production, 12, 517-526.

Noe, F.P., \& Snow, R. (1990). The new environmental paradigm and further scale analysis. Journal of Environmental Education, 21, 20-26.

Oskamp, S., Harrington, M.M., Edwards, T.C., Sherwood, D.L., Okuda, S.M. \& Swanson, D.C. (1991) Factors influencing household recycling behavior. Environment and Behavior, 23, 494 - 519.

Teisl, M.F., Roe, B., \& Hicks, R.L. (2002). Can Eco-labels Tune a Market? Evidence from Dolphin Safe Labeling. Journal of Environmental Economics and Management, 43, 339-359.

Sharifah A. Haron, Laily Paim, \& Nurizan Yahaya. (2005). Toward sustainable consumption: An examination of environmental knowledge among Malaysia. International Journal of Marketing Research, 18, 426-436.

Sharma, S., Durand, R. M. \& Gur-Arie, O. (1981). Identification and Analysis of Moderator Variables. Journal of Marketing Research, 18(3), 291-300.

Thogersen, J. (2002). Promoting “Green" Consumer Behavior with Eco-Labels. New Tools for Environmental Protection: Education, Information and Voluntary Measures (editors: Dietz and Stern). National Academy Press. Washington DC.

Thogersen, J. (2000). Knowledge barriers to sustainable consumption. In P. F. Bone, K. R. France, \& J. Wiener (Eds.), Marketing and public policy conference proceedings 2000. 10, 29-39. Chicago: American Marketing Association.

Wessells, C. R., Johnston, R. J., \& Donath, H. (1999). Assessing Consumer Preferences for Ecolabeled Seafood: The Influence of Species, Certifier, and Household Attriobutes. American Journal of Agricultural Economics, 81(5), 1084-1089.

Verdugo, C. V. (1996). A structural model of reuse and recycling in Mexico. Environment and Behavior, $28,664-696$. 
Table 1. Factor Analysis for Perceived Environmental Knowledge

Factor Loading

\begin{tabular}{lll}
1 & 2 & 3 \\
\hline
\end{tabular}

Knowledge of Green Products
a. Biodegradability
$\begin{array}{lll}.63 & .18 & .19\end{array}$
b. Wood product from sustainable forest $\quad \begin{array}{lll}.76 & .22\end{array}$
c. No animal testing
.77

$.17 \quad .05$
d. Ozone friendly aerosols

$.72 \quad .21$
e. Organic vegetable
.76

$.30 \quad .03$
f. Natural ingredient cosmetics
.76
g. Minimum packaging materials
h. Unleaded petrol

$\begin{array}{lrrrr} & .76 & .22 & .16 \\ .61 & .23 & .31 & \end{array}$

\section{Knowledge of Environmental Issues}
a. Greenhouse effects
$\begin{array}{lll}.29 & .75 & .29\end{array}$
b. Pollution from pesticides
$.30 \quad .75$
$.75 \quad .23$
c. Destruction of rainforest
.34
.79
d. Vanishing wildlife habitat
$\begin{array}{lll}.33 & \mathbf{8 0} & .09\end{array}$

\section{Concrete Knowledge}
a. Hazardous waste
.06
.24
.83
b. Waste Management
$.07 \quad .20$
.86
c. Recycled materials

$\begin{array}{lll}.27 & .29 & .62\end{array}$

Eigen values

$\begin{array}{lll}9.79 & 2.52 & 1.27 \\ 26.50 & 23.72\end{array}$

17.73

Percentage of variance .92

Kaiser-Meyer-Olkin .00

Bartlett's Test of Sphercity

$.91 \quad .91$
cross factor loading)

$.91 \quad .91$
cross factor loading)

.81

Reliability

(Note: 5 items were dropped due to cross factor loading) 
Table 2. Moderating effect of Awareness of Eco-Label on the Relationship between Ecological Concern and Purchase Intention

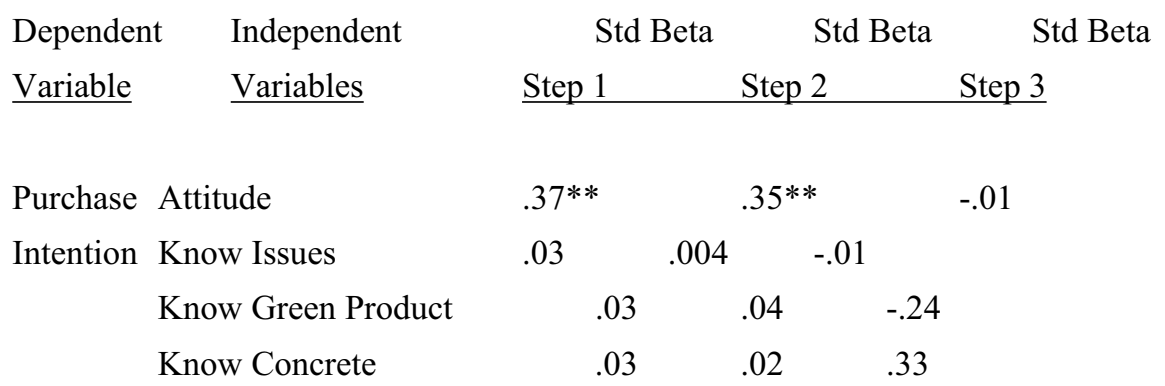

\section{Moderating}

Awareness of Eco Label

\section{Interaction Terms}

Attitude X Label Aware

Knowledge A X Label Aware

Knowledge B X Label Aware

$.49 *$

Knowledge C X Label Awareness

\begin{tabular}{lllll} 
Adjusted $\mathrm{R}^{2}$ & \multicolumn{1}{c}{.15} & \multicolumn{2}{c}{.16} & \multicolumn{1}{c}{.19} \\
$\mathrm{R}^{2}$ change & .15 & \multicolumn{2}{c}{.013} & \multicolumn{2}{c}{.034} \\
F change & 22.83 & & 7.80 & 5.29 \\
Sig. F change & & .000 & .005 & .000 \\
\hline
\end{tabular}

$p<01 * *, \quad p<05$ * 


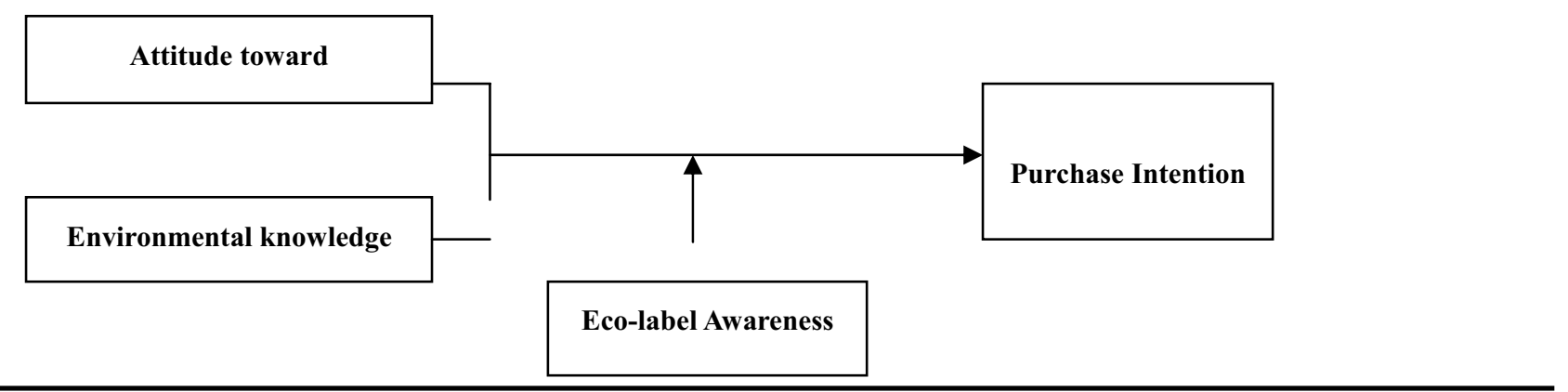

Figure 1. Research framework

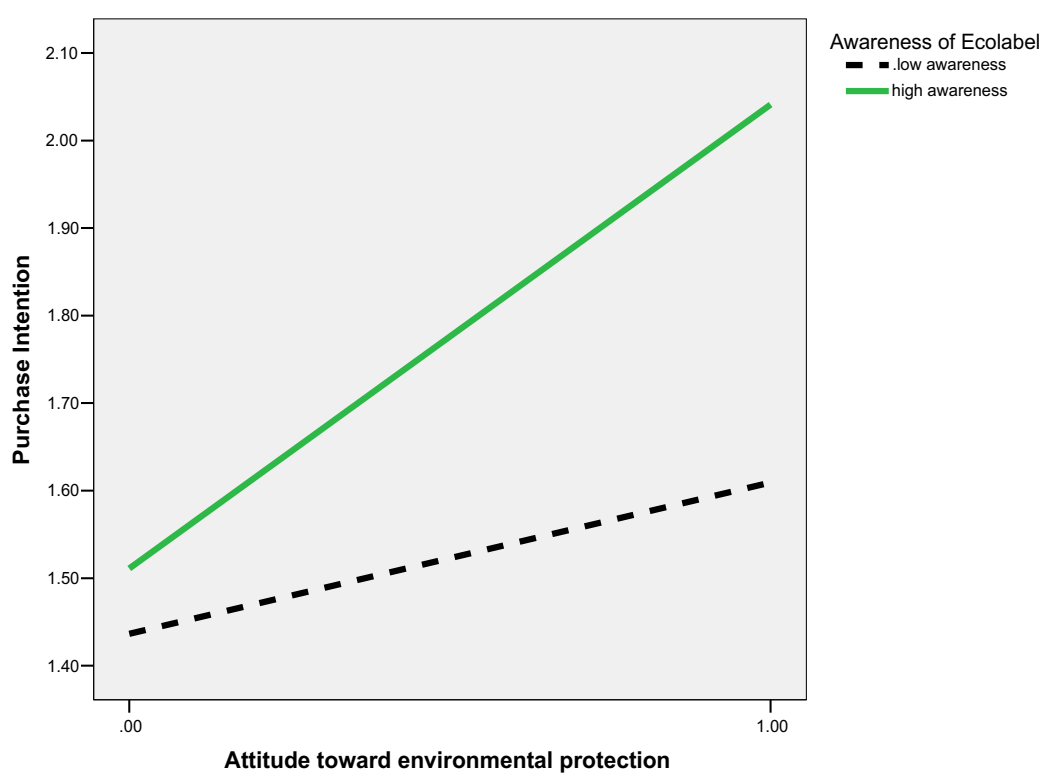

Figure 2. The impact of label awareness on the relationship between attitude toward environmental protection and purchase intention 


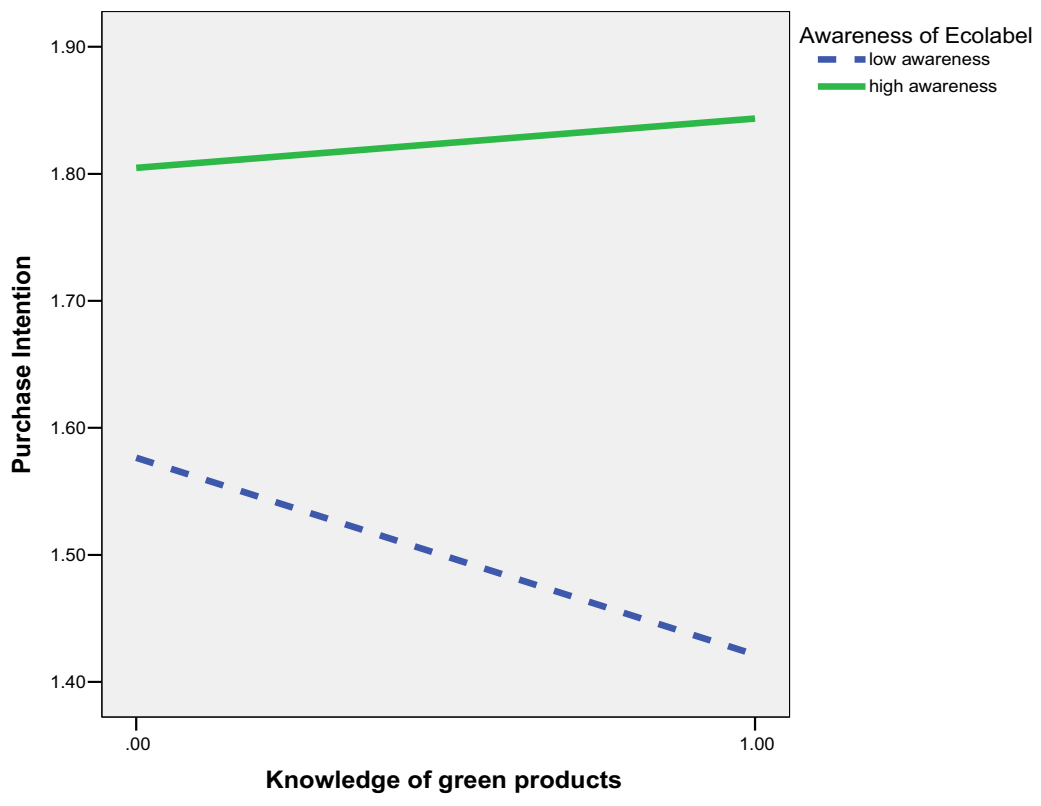

Figure 3. The impact of awareness of eco-label on the relationship between knowledge of green products and purchase intention

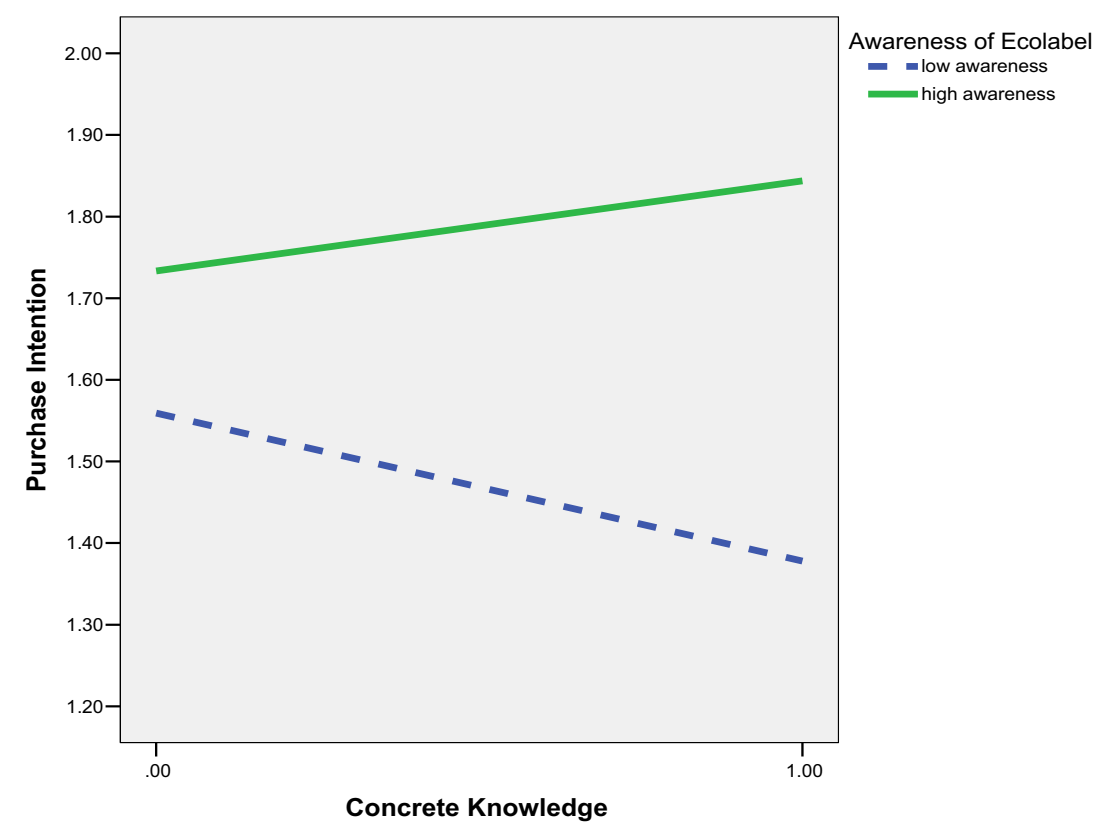

Figure 4. The impact of awareness of eco-label on the relationship between concrete knowledge and purchase intention 


\title{
Study on Online Financing Based upon
}

\author{
Internet and E-commerce
}

\author{
Chengfeng Long \\ School of Business Administration, North China Electrical Power University \\ Beijing 102206, China \\ Tel: 86-10-8462-3371_E-mail: longcf2001@sina.com
}

\begin{abstract}
Online financing is a brand-new financial management mode based on Internet and e-commerce. Vigorous development of Internet is foundation and indispensable technical support for online financing, and unfolding of e-commerce calls for implementation of online financial management, while "Accounting Law" and "Accounting Standards for Enterprises" in China offers an appropriate law environment for online financing. In terms of space, online financing realizes coordination, convergence and remoteness of management; in terms of time, it realizes online dynamic management, which improves work efficiency and quality of financing personnel to a great extent. Development and construction of an enterprise's online financial management system mainly contains the following four parts: feasibility analysis of implementing online financing, system programming and design, implementation, operation, assessment, maintenance, and improvement of system.

According to statistic data from Chinese Internet information center, by the end of June 2008, the number of Chinese netizens had attained 253 million, popularizing rate of Internet $19.1 \%$, and number of online shopping users had reached 63.29 million. Vigorous development of Internet and e-commerce has brought huge strike on financial management of an enterprise. Original financial management mode targeting at capital flow can not adapt to operation and management requirements of modern enterprises, which calls urgently for corresponding revolution. At the beginning of the $21^{\text {st }}$ century, proposing and unfolding of online financing brought into a brand-new mode based on e-commerce for financial management, and became a hotspot in the field of financial research.
\end{abstract}

Keywords: Online financing, Internet, E-commerce

\section{Background of and causes for online financing}

Online financial management is a functional and brand-new financial management system that is based on computer network technology, targeting at integrating and realizing e-commerce of an enterprise, centered with financial management, coordinating finance and business, supporting e-commerce, and providing financial accounting, and management under Internet circumstance. It is a key component of e-commerce, which is applied into e-commerce based on financial accounting and management on Internet platform.

\subsection{Vigorous development of Internet is foundation and indispensable technical support for online financing}

According to statistic data from Chinese Internet information center, by the end of June 2008, the number of Chinese netizens had attained 253 million, and the scale had reached the first in the world. By the end of June 2008, popularizing rate of Chinese Internet had reached 19.1\%. Among the 15 countries that had the highest Internet popularizing rate, China mounted up with a speed of $20 \%$. All the above information indicates that Chinese Internet development has entered a brand-new phase, and has laid solid and favorable foundation for various management modes based on Internet.

\section{Insert Figure 1 here}

Insert Figure 2 here

As a tidal wave in IT, network has brought huge strike on financing and management information system. The fact that Internet changes transmission of information necessarily results in a leap of the system in the process of information collection and transmission, which means this convenient and fast online information transmission makes possible online financing. Therefore, development of Internet is foundation and indispensable technical support for online financing. 


\subsection{Unfolding of e-commerce calls for implementation of online financial management}

With improvement of overall online shopping environment in China, increasing tendency of online shopping market is more obvious. Currently, the number of online shopping users has reached 63.29 million, and $25.0 \%$ of netizens are in favor of online shopping which is within the first ten online applications.

\section{Insert Table 1 here}

In online shopping, especially $\mathrm{C} 2 \mathrm{C}$ online shopping, online payment means and utilization of online bank have been rather universal. And $\mathrm{B} 2 \mathrm{C}$ online shopping also gets more and more enriched in terms of online payment means. Development of both of these two online applications is able to promote online shopping.

The open environment of Internet and e-commerce has brought huge strike on traditional business flow. There appear some limitations to the regional financial management mode targeting at capital flow, including information distortion, information lagging, information repetition and loose supervision, etc.. Therefore, it can not adapt to operation and management requirements of modern enterprises, which calls urgently for corresponding revolution. In an e-commerce situation, function of traditional financial management should go towards diversification; method of management towards responsiveness, practicalness, adaptability and convergence; working means of management towards computerization, remote management, online management, online office, and mobile office; management target from capital flow to information handling of the overall economic activity.

\subsection{Law environment for implementation of online financing has taken initial shape}

"Accounting Law" put into force on July $1^{\text {st }}$ 2007, and the new "Accounting Standards for Enterprises" put into force on January $1^{\text {st }} 2007$ offer an appropriate law environment for online financial management. Firstly, these two statutes established legal position of electronic bill of document for the first time, which enabled online financial management to have laws to follow. Secondly, they added inner system of accounting treatment for electronic trade, such as management system of online settlement, etc., which enabled online financing to be legally guaranteed as part of e-commerce. Thirdly, they promoted unification of accounting systems of various industries and regions, which made possible different city coordinating treatment of online financial management.

\section{Functions and advantages of online financing}

In comparison with traditional financial management, functions and advantages of online financial management are mainly displayed in the following:

\subsection{In terms of space, online financing realizes coordination, convergence and remoteness of management}

2.1.1 Coordination of financial processing and business processing. Development and prevalence of Internet has connected financial department and other business departments, so they can share common information, which, in turn, realizes coordination of financial information and business information. Coordination of these two are displayed in three aspects: firstly, business coordination of inner organization, such as online purchasing, online sale, storage management, online service, online checking on work attendance, and online salary management; secondly, coordination with supply chain, such as online enquiry, online reminder, customer relationship management, etc.; thirdly, coordination with relative social departments, such as online bank, online insurance, online tax declaration, and online securities investment, etc..

2.1.2 Remoteness of financial management. Online financing system breaks through spatial limitations of traditional financial management, and enables management to extend to any node in the world. So quite a lot of remote processing functions get implemented without difficulty, such as remote reporting, remote account rendering, and remote audit, etc., which intensifies financial supervision of director units on their sub-branch institutions.

2.1.3 Convergence of financial management. In recent years, with increasingly vehement market competition, and with requirements for risk control and capital management, financial management mode has begun to transfer from distributed management to converged management. Appearance of Internet has made possible information convergence, which differs from information convergence of traditional financial management after the event, and which is a sort of dynamic and real time information convergence. This sort of information convergence is capable of achieving information sharing, and information transparency.

\subsection{In terms of time, online financing realizes online dynamic management}

2.2.1 Dynamic accounting enables calculation to achieve real time after the event. Online financing is able to practically and conveniently display various dynamic financial reports that reflect enterprise operation and capital status, enriching accounting information and improving value of accounting information.

2.2.2 Online management enables financial management to transfer from static state to dynamic state. In the online financing situation, online database contains information of all online enterprises. An enterprise can carry out online fund procurement, online different city transfer, online securities investment, online foreign exchange trade, online 
financial audit and online business enquiry, etc.. Real time information feedback provides comprehensive, timely, accurate, safe and reliable financial information data for financial decision-making of an enterprise.

\subsection{In terms of efficiency, online financing improves work efficiency and quality of financing to a great extent}

2.3.1 Online financing realizes computerization of financial working method. Financial personnel can have mobile and online office at any time and in any place. Financial personnel and enterprise directors can use mobile terminal network to inquire about all sorts of financial data, and carry out online instant decision-making control.

2.3.2 Online financing realizes electronification of settlement payment. In the online financing situation, online payment and settlement based on currency electonification get implemented comprehensively. Electronic bill of document and electronic currency enables capital to turn over with an accelerated speed, which in turn improves efficiency of settlement payment.

2.3.3 Online financing reduces cost of management expenses. The fact that online financing adopts EDI reduces data transmission and processing time to a great extent, economizes expenses in paper for documents, printing and copy, storage and mailing, etc., and, thereby, reduces management expenses considerably.

2.3.4 Online financing improves quality of work by financial personnel. Advanced accounting means of online financing enables complicated accounting process to be completed with computer system, which is fast, and accurate in data. Work which took a great deal of manpower and time can now be finished within a blinking moment, so our major energy may be used into data analysis and control of production operating process, and may accordingly and timely adjust and perfect windage or loophole in inner accounting and management. Online financing improves work quality of financial management considerably.

\section{Development and construction of online financing system}

For implementation of online financing, financial software development corporation also plays an important role in addition to enterprises. For large and medium-size enterprises, if they are qualified to set up their own perfect intranet, they may confirm implementation plans of their own online financing by themselves; while for a large majority of medium and small-size enterprises, if they are not qualified or there is no need for establishing by themselves, they may resort to financial software corporations. As a key step in managing capital flow of an enterprise, changes of financial management tend to come down to the following aspects: collection and processing of basic data, business flow, organizational structure of an enterprise, management system and mode, investment decision-making and operating, as well as maintenance, etc.. In the establishment of a system, it should be promoted step by step from easy to difficult, and from simple to complicated. In detail, development and construction of online financial management system of an enterprise primarily contains the following four parts: feasibility analysis of implementing online financing, system programming and design, implementation, operation, assessment, maintenance, and improvement of system.

\subsection{Feasibility analysis of implementing online financial management system}

If an enterprise intends to develop and apply online financial management system, we should have a comprehensive grasp of its overall situation, conduct deep and meticulous investigation, and analyze feasibility of its implementation, since it is an important aspect in system construction. It contains the following: whether implementation of online financial system fits into strategical target of the enterprise, what financial information demand is lacking inside and outside the enterprise, impacts of online financing on industrial status and competition advantages of the enterprise, and economic feasibility and risk analysis based on online financing investment.

In the feasibility analysis of implementing online financial information system, what should be primarily ensured is that implementation of this project will be more helpful for the realization of the overall strategical target of an enterprise, and for the coordinated development with informationization of other departments. Otherwise, implementation of online financial management would become an "isolated information island" once again, not able to play its deserved role. Meanwhile, after confirmation of industrial status and competition advantages of the enterprise, an analysis of the system implementation may make clear whether it will enhance its industrial status and competition advantages. An analysis of investment benefits of the system establishment should take direct benefit and indirect benefit into consideration.

\subsection{System programming and design of online financing}

After feasibility analysis on implementation of online financing, an enterprise can conduct programming and design of online financing based on qualifications of the enterprise. On the basis of earlier investigation and demand analysis, an enterprise should conduct comprehensive design and improvement on its financial report flow, inner accounting system, standard coding, and software system, and conduct overall programming on its fund source, investment scale, construction progress and technical plan. To design network structure on the basis of business design and also to make clear how to put this into practice. In the course of system programming, an enterprise should conduct "comprehensive programming" from an overall point of view, and unify standards, so as to leave space and room for further 
improvement.

3.2.1 Business design. At the phase of business design, an enterprise should firstly make clear design principles of a system, and make an assessment on status quo of its financial management system. Then the enterprise can design an overall structure of online financial management system. According to different vertical directions of management levels, the system can be classified into three levels, namely, accounting system, analysis and control system, and strategy support system of online financial management.

3.2.2 Network design. An enterprise should provide instructions for system design according to its characteristics, so as to realize online financial management system. If the number of online business management system intranet is too large, and positions are too separated, an enterprise should adopt multi-layer structure to realize real time transmission of information in the design process of the entire network. This kind of structure enables network to be have high reliability, strong expansibility, large throughput, and clear configuration, convenient to maintain and manage. In the process of network design, an enterprise should also consider the following aspects: selection of appropriate operation system, database management system, generic cabling, software and hardware, anaphase management and maintenance of network, as well as resolution of network safety issue. Safety issue should be put in the first place in the design of the entire network.

\subsection{Implementation of online financial management system}

After preparation of the first two phases, online financial management enters a development phase of substantiality. For an enterprise, implementation of online financial management system should be finished through two steps: on one hand, to establish financial online system within an enterprise, and to realize inner informationization of an enterprise, which is an information system used within an enterprise for production, operation and management, and which is able to realize coordination of inner management; on the other hand, to realize contact outside an enterprise through Internet, which can accomplish coordination of an enterprise with supply chain, customers and relative departments outside the enterprise, which can achieve resource sharing of financial information to a greater extent. The primary task of an enterprise during its process of implementation is to set up inner network and to connect it successfully into Internet.

\subsection{Operation, maintenance, assessment, and improvement of online financial management system}

As core information of an enterprise, normal operation and regular maintenance of financial information is rather important. In its daily operating, an enterprise should use a CD to clone the system environment, and take measures of automatical backup and virus prevention, so that the system can be automatically recovered when in abnormal conditions. Establishment and perfection of safety purview can ensure perfect safety of the system. To set up technically supporting centers, and remote maintenance system, and to maintain corporations of all regions ever and again according to coverage scope of business in an enterprise. After a certain period of operating, an enterprise should ask relative personnel for systematic assessment according to definite standards, and put forward further direction and measures for improvement.

As a new-born business, online financing has huge space for development. On the part of inner enterprise, online financing will be further integrated with management information system, and become an important component of an enterprise; while on the part of exterior enterprise, the target is to wholly integrate e-commerce. With the tendency that Internet will become part of social life and work, online financial management will become an indispensable mode and system of e-commerce and enterprise management.

\section{References}

Li, Ping \& Xu, Pu. (2007). Online Financial Management Mode Based onInternet/Intranet. China Management Informationization, April.

Tian, Yuzhi. (2008). Developing Direction of Online Financial Management in Enterprise Group. Friend of Science Amateurs, Vol. 2.

Yan, Liping. (2005). Financial Mangement in Internet Times. Research on Finance and Accounting, Vol. 4. 
Table 1. Utilization rate of online shopping and its changing situation

Source: Information center of Chinese Internet

\begin{tabular}{c|c|c|c}
\hline \hline $\begin{array}{c}\text { Online } \\
\text { shopping }\end{array}$ & $\begin{array}{c}\text { December } \\
2007\end{array}$ & $\begin{array}{c}\text { June } \\
2008\end{array}$ & $\begin{array}{c}\text { Changing } \\
\text { situation } \\
\text { within a } \\
\text { half year }\end{array}$ \\
\hline Utilization rate & $22.1 \%$ & $25.0 \%$ & $2.9 \%$ \\
\hline $\begin{array}{c}\text { scale(ten } \\
\text { thousand) }\end{array}$ & 4,641 & 6,329 & 1,688 \\
\hline
\end{tabular}

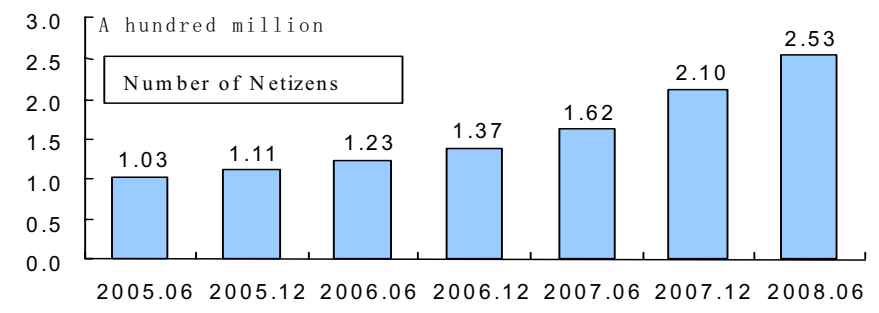

Figure 1. Number increasing situation of Chinese Netizens

Source: Information center of Chinese Internet

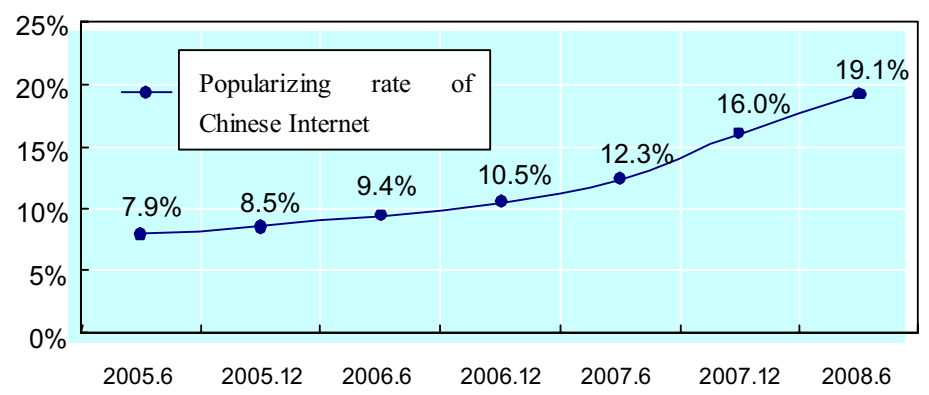

Figure 2. Popularizing rate of Chinese Internet

Source: Information center of Chinese Internet 


\title{
Research on Homogeneous Structure of Manufacturing Industry from the Angle of the Division of Labor
}

\author{
Dongjun Mao \\ Graduate School of Chinese Academy of Social Sciences \\ Beijing 100102, China \\ E-mail: maodongjun@gmail.com
}

\begin{abstract}
After near thirty years development, the Yangtze River Delta region (includes Jiangsu, Shanghai, Zhejiang) has been one of the places with fastest economy development and strongest economy power in China. Meanwhile, the economic integration in Yangtze River Delta region, especially the industry integration was proposed twenty years ago. In this paper, from the labor division angle the author has analyzed the homogeneous phenomenon of manufacturing industry in Yangtze River Delta region based on amounts of basic researches. By means of demonstration analysis with computation measures, the author has advanced relevant policy suggestions.
\end{abstract}

Keywords: Yangtze River Delta region, Manufacturing industry, Homogeneous industry structure, Labor division

\section{Introduction}

Since China socialist market economy reform in 90s 20 century, with the economic globalization background, the Yangtze River Delta region has attracted amounts of domestic and foreign capitals due to its predominant position, nice developing foundation and favorite policies. All industries, mainly the secondary industry in this region, have stepped into the fast-speed development path. And its average GDP increasing rate is higher than the country average rate with 2 to 3 point. The Yangtze River Delta region has become an important economy driver in China with its increasing economic status inside and outside.

In the rapid economic developing process, conflicts and problems are in existence, especially the homogeneous phenomenon of industry structure (mainly manufacturing industry) among the two provinces and one city. The homogeneous industry structure means certain similarity and common inclination of regional industry structure in its dynamic development and evolvement process, chiefly the industry homogeneous structure in areas. The arrangement of industry structure in one country or region determines its economic strength, while the reason of industry structure determines its development speed and stability.

\section{Documents review}

Scholars, both inside and outside, have carried out analyzing researches on this issue from different point of views. From the government point of view, Huang Youhe (2000), Hu Rongtao, Zhang Xuying, Su Mingwu (2002), Xu Jianming (2003), Yao Xianguo and Xie Xiaobo (2004) have presented the causes of homogeneous industry structure in Yangtze River Delta region. Their researches have been based on the game analysis between the local government and the central government, between the local governments. From the industry cluster point of view, Ni Shugao (2004) has analyzed the present industry structure in Yangtze River Delta region. In his opinion, the different industry frameworks originated from the transfer of various systems are due to the negative influences of the local economy on the industry cluster. According to Hong Yinxing, Liu Zhibiao (2003) and Chen Jianjun's (2004) researches, the numerous similarities in the chief outer variables which determine economic behavior, such as resources, technologies and traditional cultures, in different minor areas of the Yangtze River Delta region determine that the behaviors of economy subjects have high similarities, which will lead to similar industry structures in different areas. The cutthroat competition existed in region economy is coming from system and market frame, but not the homogeneous industry structure issue. Zhang Lei and Zhang Minglong (2003) have performed quantitative measurement to the local relations in Yangtze River Delta region by means of Euclidean Distance and concluded that the competitive local relations have surpassed the compensated local relations in this region.

Liang Qi (2004) has calculated the present regional industry labor division index in China based on the Paul Krugman's 
formula. With the regional labor division index $\left(S_{j k}=\sum_{i=1}^{n}\left|\frac{q_{i j}}{q_{j}}-\frac{q_{i k}}{q_{k}}\right|\right)$ he calculated the labor division differences in various regions in China between 1997 to 2000. In her opinion, the regional specialization is deepening and with China socialist market economy reform process the market mechanism will exert a more powerful influence on resources allocation. Wang Hao and Feng Yao (2004) have proposed to build integrated property right market to regulate the property right business and to decrease costs, advancing the utilization efficiency of property right. The property right can serve as a tie to allocate resources reasonably and to speed up economic development and to drive the regional economic integration. They also insist to restrict the cutthroat competition in different regions. The economy structure adjustment, reasonable labor division and strong cooperation can help to realize the transfer from administrative economy to regional economy, and to advance the integration process in Yangtze River Delta region. Based on demonstration analysis of the relationship between industry development and region in Yangtze River Delta, Wang Yizhi, Wang Zhen, Gu Liying (2000) have presented the industry integration thought. That is to construct integrated factor market and commercial and trade circulation system to drive industry integration in Yangtze River Delta region. Meanwhile a series of policy innovation can help to build a more active policy system. In Zhang Haiyan and Chen Yufang's (2004) opinion, the evolvement of regional industry structure is influenced directly or indirectly by the flow of transnational capitals, the form of global market system, the net system of global production labor division, and the transnational flow of technology and labor, under the economy globalization. Based on the analysis of European economic integration and the present situation in Yangtze River Delta region, Zhou Zhenhua (2002) and Wang Xiaohui (2004) have proposed some measures to speed up regional economic integration.

Judging from the above researches, these scholars have investigated this issue and have presented relevant conclusions and policy suggestions chiefly from the government angle, from the industry competition angle and from the local relation angle, but seldom from the labor division angle. In this paper the author has mainly used the economy new classical school theory represented by Yang Xiaokai and Huang Youguang for reference. Beginning with labor division, the author has performed basic investigation on this issue and with the panel data model he has carried out demonstration analysis, filling up the research empty in this field.

\section{Theory model and relevant analysis}

The new classical school, represented by Yang Xiaokai and Huang Youguang, using the inframarginal analysis method, has made Adam Smith's labor division theory revival by combining with Coase's transaction-cost theory and has been modified to explain and analyze economic phenomenon. Its key point is that labor division is the result of exchange. Labor division and specialization can speed up knowledge accumulation and bring about profit increase. Otherwise, coordinate labor division requires costs (namely transaction costs) and the deepening of the labor division leads to the increase of transaction costs which is decided by the transaction mechanism efficiency. The advantages of labor division conflict with the increase of transaction costs what constitutes basic restriction of labor division evolvement. In this conflict, the deepening of labor division is determined by the relative balance between transaction costs and labor division profits, showing a self-evolving process.

Meanwhile, they discussed the inner relevancy of labor division, specialization and industry structure adjustment.

Along with constant improvement of transaction efficiency, labor division evolvement is appearing. Economy development, trade, industry structure adjustment and market structure change are different sides of this evolvement. With the decrease of transaction costs, labor division level and production efficiency have been improved constantly. The regional trade economy has been changed toward the specialized production economy based on inter-dependence. As a result, the whole region will gain benefits from specialization and the level of industry regional integration will be improved further. Labor division and specialization are the two sides of one coin. They connect with each other closely. Where there is labor division, there is corresponding specialization. Industry structure is the result of labor division and specialization. Labor division and its corresponding specialization can lead to two results. One is the variety of products. The other is the singularity of production (specialization). The two are defined relatively from the social scope and the enterprise angle. The variety of products and their proportion determined by production consumption and living consumption have formed industry structure. The singularity of enterprise production demands other enterprises' coordination and cooperation in material, parts and sale. As a result, this will form industry structure for certain period.

The constant evolvement and advancement of industry structure is also the result of labor division and specialization. 
Industry structure adjustment is to coordinate and to deepen labor division and specialization. Labor division and specialization are natural evolving processes. Correspondingly, it is the constant evolving and optimizing process of regional industry structure which is based on obeying the labor division and specialization evolvement laws. Labor division and specialization are in favor of improving and advancing product quality, adjusting and upgrading consume structure what will serve as structure strategic adjustment foundation. Regional labor division------specialization------industry structure adjustment has been the inevitable process of regional economy development and the eternal driver of economy increase.

General equilibrium model of transaction efficiency and labor division evolvement

Assumption: the consumer---producer muster is $\mathrm{M}$ continuum. It means a large population in economy. Each consumer---producer follows the utility function. $U=\left(x+k x^{d}\right)\left(y+k y^{d}\right)$.

Hereinto, $\mathrm{x}$ and $\mathrm{y}$ are respectively the self-support numbers of products $\mathrm{x}$ and $\mathrm{y} \cdot \mathrm{x}^{\mathrm{d}}$ and $\mathrm{y}^{\mathrm{d}}$ are respectively the numbers of two products purchased from the market. The 1-k is the iceberg transaction cost index. Or $\mathrm{k}$ is an outer transaction efficiency index, representing transaction condition. The $\mathrm{k}$ is related with base facilities, citizen level, transportation condition and general policy environment.

The production function and restriction of each consumer---producer is:

$$
x+x^{s}=l_{x}^{a} \quad y+y^{s}=l_{y}^{a} \quad(a>1) \quad l_{x}+l_{y}=1
$$

The $\mathrm{x}^{\mathrm{s}}$ and $\mathrm{y}^{\mathrm{s}}$ are respectively the sale numbers of two products. The $\mathrm{l}^{\mathrm{i}}$ is the individual labor share in producing $\mathrm{i}$, and it represents relevant specialization level. The budget restriction is:

$p_{x} x^{s}+p_{y} y^{s}=p_{x} x^{d}+p_{y} y^{d}$

$\mathrm{P}^{\mathrm{i}}$ is the price of product $\mathrm{i}$. And there is non-negative restriction.

Wen theorem: According to the optimal decision, a corporate does not sale more than one product type, and does not sale or buy same product type, and does not buy or produce same product type.

Therefore, three models should be taken into considerations.

Self-support model: defined by $x, y, l_{x}, l_{y}>0, x^{s}=x^{d}=y^{s}=y^{d}=0$. The number of all the self-support products is positive. And the number of all the trade products is zero. The decision-making issue is:

$\operatorname{Max}$

$\operatorname{lax}_{x, y, l_{x}, l_{y}} u=x y$

s.t. $x=l_{x}^{a} ; y=l_{y}^{a} ; l_{x}+l_{y}=1$

Add all the restrictions to the utility function and the target function has been changed into: $\operatorname{Max}_{l_{x}} u=l_{x}^{a}\left(1-l_{x}\right)^{a}$.

Then, $\frac{d u}{d l_{x}}=a l_{x}^{a-1}\left(1-l_{x}\right)^{a}-a l_{x}^{a}\left(1-l_{x}\right)^{a-1}=0$.

Here, $l_{x}=\frac{1}{2}$. So $u=2^{-2 a}$. It is the self-support real per capita income.

Specialization model $(\mathrm{x} / \mathrm{y})$ : means producing $\mathrm{x}$ in specialization, sales $\mathrm{x}$ and buys $\mathrm{y}$. Defined by $x, x^{s}, y^{d}, l_{x}>0$, 
$x^{d}=y^{s}=y=l_{y}=0$. Then the decision-making issue is:

$\underset{x, x^{s}, x^{d}}{\operatorname{Max}} u=x k y^{d}$

s.t. $x+x^{s}=l_{x}^{a} ; l_{x}=1 \quad$ (The budget restriction is: $p_{y} y^{d}=p_{x} x^{s}$ )

Add the restriction to utility function, delete $l_{x}, x$ and $y^{d}$, then the result is:

$\underset{x^{s}}{\operatorname{Max}} u=\left(1-x^{s}\right) k \frac{p_{x} x^{s}}{p_{y}}$

Because $\frac{d u}{d x^{s}}=0$, the optimal decision is $x^{s}=\frac{1}{2}$. So $y^{d}=\frac{p_{x} x^{s}}{p_{y}}=\frac{p_{x}}{2 p_{y}}, u_{x}=\frac{k p_{x}}{4 p_{y}}$.

Specialization model $(\mathrm{y} / \mathrm{x})$ : means producing $\mathrm{y}$ in specialization, sales $\mathrm{y}$ and buys $\mathrm{x}$. According to the corner point

solution method in solving model $(\mathrm{x} / \mathrm{y})$, it is easy to get the equilibrium solution of model $(\mathrm{y} / \mathrm{x}): \quad y^{s}=\frac{1}{2} ; x^{d}=\frac{p_{y}}{2 p_{x}}$; $u_{y}=\frac{k p_{y}}{4 p_{x}}$

That is:

\begin{tabular}{|c|c|c|c|c|c|}
\hline Model & $\begin{array}{c}\text { Corner point } \\
\text { demand }\end{array}$ & $\begin{array}{c}\text { Corner point } \\
\text { supply }\end{array}$ & $\begin{array}{c}\text { Self-support } \\
\text { number }\end{array}$ & $\begin{array}{c}\text { Specialization } \\
\text { level }\end{array}$ & $\begin{array}{c}\text { Indirect utility } \\
\text { function }\end{array}$ \\
\hline Self-support model & 0 & 0 & $l_{x}=l_{y}=\frac{1}{2}$ & $u=2^{-2 a}$ \\
\hline Specialization model & $y^{d}=\frac{p_{x}}{2 p_{y}}$ & $x^{s}=\frac{1}{2}$ & $x=\frac{1}{2}$ & $l_{x}=1, l_{y}=0$ & $u_{x}=\frac{k p_{x}}{4 p_{y}}$ \\
\hline Specialization model & $x^{d}=\frac{p_{y}}{2 p_{x}}$ & $y^{s}=\frac{1}{2}$ & $y=\frac{1}{2}$ & $l_{x}=0, l_{y}=1$ & $u_{y}=\frac{k p_{y}}{4 p_{x}}$ \\
\hline
\end{tabular}

If choosing specialization model $(\mathrm{x} / \mathrm{y})$, iff $u_{x} \geq u_{A}$ and $u_{x} \geq u_{y}$, then $\frac{p_{x}}{p_{y}} \geq \frac{2^{2-2 a}}{k}$ and $\frac{p_{x}}{p_{y}} \geq 1$. If choosing specialization model $(\mathrm{y} / \mathrm{x})$, iff $u_{y} \geq u_{A}$ and $u_{y} \geq u_{x}$, then $\frac{p_{x}}{p_{y}} \leq 2^{-2+2 a} k$ and $\frac{p_{x}}{p_{y}} \leq 1$. If ensuring both, merely $k>k_{0} \equiv 2^{2-2 a}$ and $\frac{p_{x}}{p_{y}}=1$. 
If choosing self-support model, iff

$u_{x}<u_{A}$ and $u_{x}<u_{A}$, and $\frac{p_{x}}{p_{y}} \in\left[2^{-2+2 a} k, \frac{2^{2-2 a}}{k}\right]$, then $k<k_{0} \equiv 2^{2-2 a}$.

Then we can get the following conclusion. If there are reasonable labor division and specializing production between two regions, with rational industry structure and low homogeneous trend, there is a critical value scaled by transaction efficiency, namely $k=2^{2-2 a}$. That is, the labor division's precondition between two regions is $k>2^{2-2 a}$. Profits from labor division in two regions are higher $(1-k)$ than transaction costs. Contrarily, the optimal decision is to perform transaction and labor division within respective region, but not between regions. Then, the homogeneous phenomenon in industry structure is inevitable between two regions.

In the next figure the shadow EFGCJ represents labor division profits. It shows that if the transaction costs are smaller than this shadow, the specializing division will appear. Otherwise, the optimal choice is to self-support.

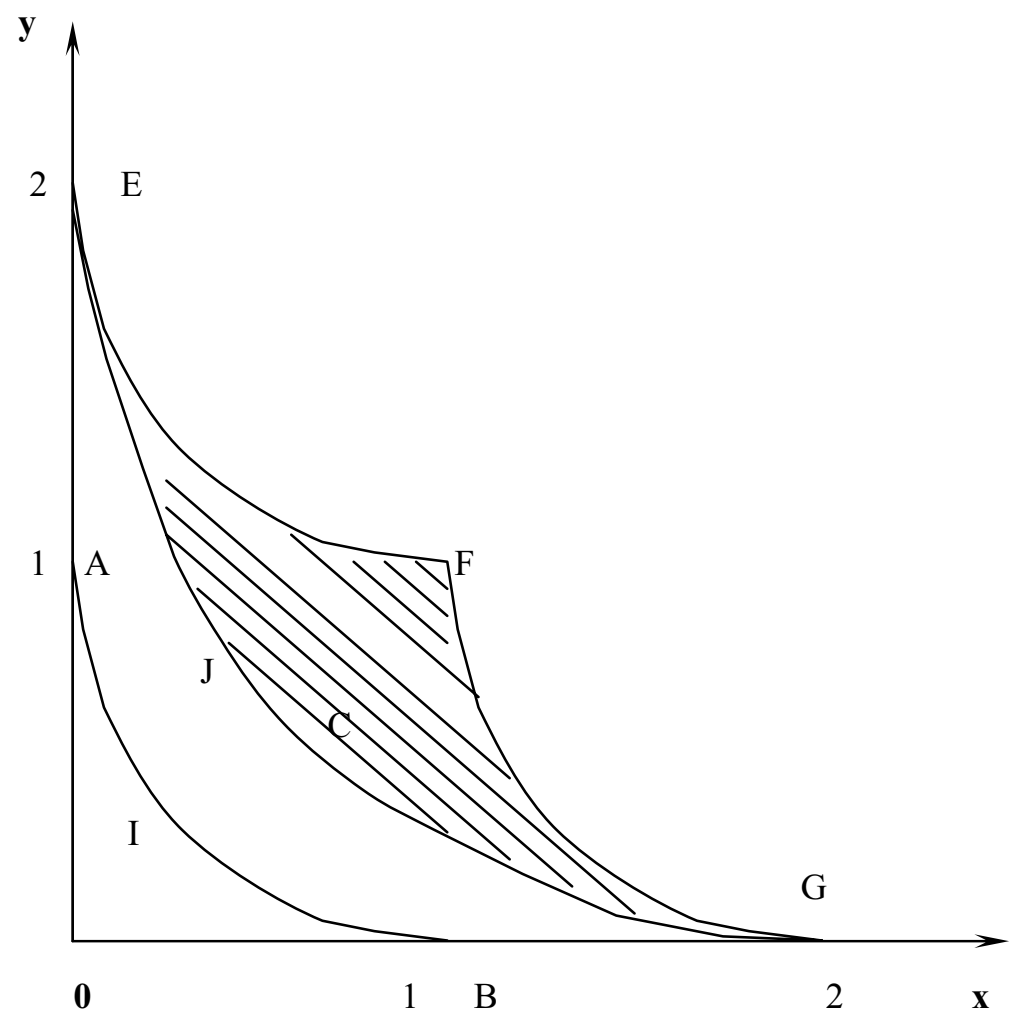

If the transaction costs are increasing and finally surpass critical value, the labor division and cooperation will be changed from formerly within respective region to presently between two regions. Correspondingly, the industry structure in two regions is becoming more reasonable, and the industry homogeneous trend is becoming lower.

In this equilibrium model, the transaction efficiency is determined by two factors. (1) Hard conditions: nature and geography, transport technology and tools, traffic and living facilities, information conditions. (2) Soft conditions: legal tradition and property right, credit and social capital, education and personnel resources, policy and common service level, social stability, competitive bank system, openness level and trade system. Communicating technology and electronic business could greatly decrease transaction costs and promote general transaction efficiency. Government and relevant policy, laws and measures could decrease transaction costs, being important factors that influence transaction efficiency. Education level, literature degree, personnel resources training also could decrease transaction costs and increase transaction efficiency. 
This analysis frame, the critical value for transaction efficiency, $k=2^{2-2 a}$, is unknown which can not be calculated properly. But the marketization changing index system includes quantitive analysis on the deciding factors of the transaction efficiency. Therefore, taking the marketization changing index as reference criterion to value transaction efficiency is reasonable. Scholars and specialists may take various methods and index to calculate or predict, but the results merely have relative meaning. It is not the results themselves that matter, but the changing trend which is reflected by the results sequence.

In this paper, the author adopted mainly the marketization quantitive index, aiming to reflect the general marketization process trend and to take it as reference index to value the transaction efficiency change. Using marketization index to value transaction efficiency change trend can broaden the model's application and explanation strength. Meanwhile it can provide theory basis for constructing a quantitive model.

\subsection{Data}

This paper is mainly based on the measure system by Xu Minghua (1999). It also uses some thoughts by Chen Zongsheng (1999), Fan Gang and Wang Xiaolu (2000), especially by Hong Yinxing and Liu Zhibiao (2001) for reference. They have set a series of reasonable measure index which can reflect characteristics of Yangtze River Delta region when they have tried to measure this region's marketization level. The index in this paper is just as following.

(1) Ownership pattern: proportion of non-state-owned economy to gross output value of industry, proportion of non-state-owned economy to social fixed assets investment, proportion of employment in non-state-owned economy to whole economy,. (2) Government function transfer and government efficiency increase: proportion of the margin between tax, turned profits of state-owned enterprise and government allowance to finance income, proportion of infrastructure and enterprise reengineer expenditure in finance to policy allowance, proportion of non-state budget capital to infrastructure expenditure, proportion of government financial income to GDP, ratio of GDP to government expenditure, proportion of government expenditure to total consume, proportion of government or social party workers to total workers. (3) Commodity market growth: proportion of export value to gross output value of industry, proportion of consumable commodity retail sales to gross output value of industry and agriculture, wholesale and retail spot number per 10,000 capita. (4) Factor market growth: proportion of non-state financial education outlay to total education outlay, proportion of contract worker number to total worker number, number of job-hunting agency per 10,000 capita, proportion of finance and insurance to tertiary-industry, proportion of tertiary-industry transportation to total transportation, proportion of non-state-owned enterprise loans to short-term loans in finance agency, proportion of floating population in tertiary-industry to total floating population, proportion of stock market value to GDP, proportion of listing company number to total industry and agriculture company number, proportion of real estate industry to tertiary-industry. (5) Open-door to the outside world: foreign trade dependence degree, foreign capital utility per capita. (6) Human: private company number per 10,000 capita in city and county, number of private company investor per 10,000 capita in country and city, family Engel coefficient of country resident, family Engel coefficient of citizen.

Data of above index are chiefly abstracted from "Statistics Compilation of Fifty-year In China", "China Statistics Annual", "Shanghai Statistics Annual", "Zhejiang Statistics Annual", "China Finances Annual", "China Banking Annual", "China Market Statistics Annual", "China Labor Statistics Annual", "China Industrial Economy Annual". The time span is from 1990 to 2005.

According to the universal industry structure homogeneous coefficient $S(X, Y)=\frac{\sum_{i=1}^{n} X_{i} Y_{i}}{\sqrt{\sum_{i=1}^{n} X_{i}^{2} \sum_{i=1}^{n} Y_{i}^{2}}}$ ("i" refers to the industry sector of No.i. " $n$ " refers to the number of industry sector. $X_{\mathrm{i}}$ and $\mathrm{Y}_{\mathrm{i}}$ refer to the proportion of the No. i industry sector value to gross output value of manufacturing respectively in certain region and in whole country.), the industry homogeneous coefficient in Yangtze River Delta region can be obtained by calculation. The marketization degree can be

valued by composite index method (

$$
K=\frac{1}{\sum_{i=1}^{n} w_{i}}\left(\frac{a_{1}}{a_{0}} w_{1}+\frac{b_{1}}{b_{0}} w_{2}+\ldots+\frac{n_{1}}{n_{0}} w_{n}\right)
$$

). The final value could be used to

reflect the marketization trend in Yangtze River Delta region and could be used for reference of weighing transaction 
efficiency change. Using marketization index for valuing transaction efficiency changes could broaden the model's application and explanation. Meanwhile it serves as theory base for next quantitive model and regression analysis.

\subsection{Regression analysis and results}

Based on the data of marketization index and industry homogeneous index $S(X, Y)$, make regression analysis on them and the result is:

$$
\begin{gathered}
\mathrm{Wstr}=0.9496-0.0126 \mathrm{Wmar}+[\mathrm{AR}(1)=0.5337] \\
(7.8132)(-2.6253)
\end{gathered}
$$

$R^{2}=0.8623 \quad D W=2.1128$

Apparently, along with the marketization process in Yangtze River Delta region (namely the transaction efficiency increase, the deepening of region division), the industry structure homogeneous phenomenon is showing a weaker trend and the regional industry structure is more reasonable. Based on the Panel Data model and analysis on six factors index we can conclude that the influences of them on industry structure homogeneous phenomenon in the process of marketization.

Take industry homogeneous coefficient $\mathrm{X}$ as dependent variable, six factors in marketization, that is $X_{1}$ (ownership pattern), $X_{2}$ (government function transfer and government efficiency increase), $X_{3}$ (commodity market growth), $X_{4}$ (factor market growth), $X_{5}$ (open-door to the outside world), $X_{6}$ (human), as independent variables, we can build the following model.

$$
Y=\alpha+\beta_{1} X_{1}+\beta_{2} X_{2}+\beta_{3} X_{3}+\beta_{4} X_{4}+\beta_{5} X_{5}+\beta_{6} X_{6}+u_{i t}
$$

\begin{tabular}{|c|c|c|c|c|c|c|c|}
\hline Variables & \multicolumn{2}{|c|}{ R-squared } & \multicolumn{2}{|c|}{ Adjusted R-squared } & F-statistic & \multicolumn{2}{|c|}{ Durbin-Watson stat } \\
\hline Values & \multicolumn{2}{|c|}{0.9692} & 0.8665 & \multicolumn{2}{|r|}{173.8697} & \multicolumn{2}{|c|}{2.0484} \\
\hline & $\bar{C}$ & $\mathrm{X} 1$ & $\mathrm{X} 2$ & $\mathrm{X} 3$ & $\mathrm{X} 4$ & $\mathrm{X} 5$ & $\mathrm{X} 6$ \\
\hline JS & 1.0043 & $\begin{array}{l}-\mathbf{0 . 4 3 2 6} * * \\
(-2.5341)\end{array}$ & $\begin{array}{c}\text { * } \\
-\mathbf{0 . 0 6 5 7 *} \\
\quad(-12.6362)\end{array}$ & $\begin{array}{l}\text { 0.0746* } \\
(3.1953)\end{array}$ & $\begin{array}{l}-\mathbf{0 . 0 1 9 8 *} \\
(-5.7317)\end{array}$ & $\begin{array}{l}\mathbf{- 0 . 0 0 9 5 *} \\
(-4.9051)\end{array}$ & $\begin{array}{l}\mathbf{0 . 0 1 2 1} \text { * } \\
(7.5661)\end{array}$ \\
\hline SH & 0.7563 & $\begin{array}{l}-\mathbf{0 . 0 4 2 4} \% \\
(-3.3658)\end{array}$ & $\begin{array}{c}\mathbf{- 0 . 0 2 3 1} * * * \\
(-1.9294)\end{array}$ & $\begin{array}{l}\mathbf{0 . 0 7 1 5 * *} \\
(2.4418)\end{array}$ & $\begin{array}{c}\mathbf{- 0 . 0 4 5 0} * * * \\
(-1.9785)\end{array}$ & $\begin{array}{l}\mathbf{- 0 . 0 0 1 6 *} \\
(-3.1966)\end{array}$ & $\begin{array}{c}\mathbf{0 . 0 0 2 5} * * * \\
(1.8895)\end{array}$ \\
\hline $\mathrm{ZJ}$ & 0.7982 & $\begin{array}{c}-\mathbf{- 0 . 3 6 3 9} * * \\
(0.0410)\end{array}$ & $\begin{array}{l}-\mathbf{0 . 1 6 6 2 *} \\
(-3.6493)\end{array}$ & $\begin{array}{l}\text { 0.0401* } \\
(8.7473)\end{array}$ & $\begin{array}{c}\mathbf{- 0 . 0 1 2 9 *} \\
(-11.9283)\end{array}$ & $\begin{array}{l}-\mathbf{- 0 . 0 1 1 9 *} \\
(-11.928)\end{array}$ & $\begin{array}{l}\mathbf{0 . 0 0 3 4} \text { * } \\
(4.1651)\end{array}$ \\
\hline
\end{tabular}

Program in SAS and check by Hausman, the function result is as following.

\section{Conclusion}

From the analysis results of panel data model, we can conclude that, among the six marketization factors, $X_{1}, X_{2}$, $X_{4}$ and $X_{5}$ are in negative correlation with the homogeneous trend of manufacturing industry structure in Yangtze 
River Delta region, whereas $X_{3}$ and $X_{6}$ are in positive correlation with it.

The ownership reform has driven the development of non-state economy. Along with the market economy system reform, the government function has been changed constantly and its efficiency has been greatly improved. Clear property right ensures enterprises independent right in investment and in decision-making, which contribute to constructing a modern enterprise system. In a sense, it has destroyed the construction repetition phenomenon resulted in too much government interference. The growth of factors market and the development of open door to the outside world have broaden the enterprises' invest resources. The enterprises can take part in global cooperation and attract high quality capital to weak the homogeneous trend of industry structure in Yangtze River Delta region.

As one of the most developed region in China, the Yangtze River Delta region has attracted amounts of foreign investors with its thriving commodity market and frequent transaction. The competition in market is extremely severe. Accompanied with the competition, the chief manager of enterprise will make micro-decision which accords with the aim of pursuing maximum profits as a "reasonable man". Furthermore, the resources and environment are similar in the two provinces and one city. It is easy to cause construction repetition in market which will result in higher homogeneous degree of industry structure in regions. Generally speaking, along with the market reform in Yangtze River Delta region, the transaction efficiency is increasing continuously what greatly pushes the labor division and cooperation between regions and effectively decreases the regional homogeneous trend of industry structure.

\section{References}

Chen, Jianjun. (2004). Industry homogeneous structure and industry location in Yangtze River Delta region. China Industrial Economy, 2.

Chen, Zongsheng., Wu, Zhe., \& Xie, Siquan. (1999). Research on Marketization of China Economy Mechanism. Shanghai People's Publishing House.

Hong, Yinxing., \& Liu, Zhibiao. (2003). Economy Development Model and Mechanism in Yangtze River Delta Region. Tsinghua University Press.

Huang, Youhe. (2000). Game analysis on industry homogeneous structure and revelation. China Business and Market, 2 .

Liang, Qi. (2004). Labor division in China manufacturing, local specialization and international comparison. Journal of World Economy, 12.

Ni, Shugao. (2004). Pushing the cluster expanding and conformity in Yangtze River Delta region. Shanghai Economic Review, 6.

Song, Tao. (2005). Dark clustering analysis on industry division in Yangtze River Delta region. Statistics and Decision-making, 7.

Wang, Bin. (2001). Analysis and Research on International Region Industry Structure. SJPC.

$\mathrm{Xu}$, Jianming. (2003). Game analysis and countermeasure on Yangtze River Delta's regional economic development. Shanghai Economic Review, 10.

Yang, Xiaokai \& Huang, Youguang. (1999). Specialization and Economic Organization------a New-Classical Micro-Economics Frame. Economic Sciences Press.

Yang, Xiaokai. (2003). Economics------New Classical Economics and Neoclassical Economics Frame. China Social Sciences Press.

Yao, Xianguo \& Xie, Xiaobo. (2004). Analysis of local government's competitive behavior in economic integration of Yangtze River Delta region. Journal of Zhejiang Provincial Party School, 3.

Zhang, Lei \& Zhang, (2003). Minglong. Regional economy analysis on Yangtze River Delta. Shanghai Economic Review, 11.

Zhou, Zhenhua. (2002). Discuss on the win-win regional economic conformity in Yangtze River Delta region. Journal of Social Sciences, 6. 


\title{
How Option Markets Affect Price Discovery on the Spot Markets: A Survey of the Empirical Literature and Synthesis
}

\author{
Afef ANSI (Corresponding author) \\ IHEC-Carthage School of Management, Tunis University \\ The High Institute of Business Administration of Gafsa \\ oucine IBN GADDOUR Street, Sidi Ahmed ZARROUG \\ fsa 2112, Tunisia \\ Tel: 216- 93- 80- 58 -27 E-mail: afefansi@yahoo.fr \\ Olfa BEN OUDA \\ IHEC-Carthage School of Management, Tunis University \\ Tel: 216- 98- 64- 80-64Ｅ-mail: benoudaolfa@yahoo.fr
}

\begin{abstract}
The aim of this paper is to survey a wide range of empirical papers on option markets to address the extent to which option markets affect price discovery on the spot market. The theoretical prediction that informed traders should sometimes trade in the option market has been examined empirically by several authors. The existing empirical evidence for such a view, however, is mixed. One group of researchers support the hypothesis that information reflects in option market first and find a significant lead for the option market. Another group of researchers support the hypothesis that information reflects in stock markets first and trading activities in option markets are not significant. Since there is no consensus among the empirical studies on this issue, it leaves us with some open theoretical and empirical issues.
\end{abstract}

Keywords: Option market, Informed traders, Spot market, Price discovery

\section{Introduction}

Increasing trading activity in and, in fact, the very existence of organized stock option markets shows that many investors do in fact trade in the derivatives markets. This attest to the economic benefits that these financial contracts provide. In complete markets, option trading should convey no new information to market participants because options are derivative securities and are then redundant [Black and Scholes (1973) and Merton (1973)]. This is logical since the spot and the option markets should reflect simultaneously the arrival of information.

However, in the absence of market completeness, informed traders may prefer to trade options instead of the underlying stocks for a couple of reasons. First, authors such as Black (1975) ${ }^{1}$ and Mayhew, Sarin, and Shastri (1995), among others, argue that reduced transaction costs and increased financial leverage may induce informed traders to trade in the option market instead of the stock market, to which we must add the lack of short sales constraints in these markets. Second, Back (1993) and Cherian (1993) point out that investors that bet on volatility can only do so in the options market. Nevertheless, what might dissuade investors from engaging in the above practices is a possible preference to trade in the underlying asset market, which offers a higher level of liquidity than the options market.

To what extent is the informational role of options theoretically justified? To what extent has it been supported by empirical work? This topic has been the focus of much study. To our knowledge, neither the theoretical models nor the empirical studies ${ }^{2}$ provide a definitive answer about this. The purpose of the present article is to provide a comprehensive review especially of the empirical literature on this issue. There is considerable academic discussion relating to the dynamics of the interaction between stock and option markets (see Easley, O'Hara, and Srinivas, 1998 among others). However, conflicting results have been obtained.

Understanding where informed traders do trade also has important impacts on the industry, which will benefit both the 
academic and financial communities. The latter include investors who trade in both shares and derivatives, as well as those who are active in only one market. For instance, if the findings show that the option market contributes significantly to price discovery, this indicates that some information is first reflected in that market, and movements in these markets will be of interest to investors watching for signals about future price movements. Further, an understanding of where informed traders choose to trade and the factors influencing this choice, are relevant to market makers and regulators (for example, in helping to prevent illegal insider trades). For example, a knowledge of the 'informative-ness' of orders will aid option market makers in managing the risks from adverse selection. In addition, an analysis of the origin of information-based trading activity will be of relevance to both policy makers and exchange regulators.

In this paper we provide a comprehensive analysis of the empirical literature on the informational linkage between the option and stock markets. The evidence on market interrelationships, however, is inconclusive as to which of the two markets reflects new information earlier. This paper contributes to the literature in several ways. It is not, of course, the first one that provides a summary of previous empirical research in this field but to the best of our knowledge, this is the first paper to provide a more recent literature and a Schema that makes a synthesis of the literature in the light of both the approach used and the empirical results found.

In contrast to the abundance of empirical research, there are relatively few analytical models that examine the impact of option trading on stock and option prices. Before we present the empirical literature review, we like to address some theoretical framework issues first. The theoretical motivation for analyzing the effect of option trading on underlying asset prices comes from the growing literature on how to incorporate conditioning information in asset-pricing models ${ }^{3}$. This is the central focus of all information-based models, which differ in their modeling approach but coincide in incorporating information into stock prices as the result of informed and uninformed trading. Two major references in this vein are Glosten and Milgrom (1985) and Easley and O'Hara (1987).

The consideration of derivatives introduces a new market to the scene, thus enriching the existing literature, since it adds to the relationship involving trading, prices and private information a new type of asset that may incorporate further information and thereby affect the pre-existing relationships. Some studies that include derivatives in these relationships are: Grossman (1988), Back (1993), Biais and Hillion (1994), Brennan and Cao (1996), Easley, et al (1998) and John, et al (2003), among others.

The remainder of this article is organized as follows. Section2 describes the background of the literature. In section3, we review the empirical literature on the lead-lag relationship. In section4, we present the factors affecting market performance and review the empirical literature examining the information-share approach. In section5, we review the more recent empirical literature applying different approaches to different markets. Finally, section6 concludes the paper and discusses some avenues for further research on the interaction between option and cash markets.

\section{The background of the literature}

As soon as the emergence of the first option markets in the middle of $1970 \mathrm{~s}^{4}$, many authors have examined the microeconomic and macroeconomic effects induced by the introduction of new contracts. Since then, the availability of new high-frequency databases has served to deepen these studies. Two lanes were mainly borrowed. The first consists in studying the impact of the introduction of contracts on liquidity, return or volatility of the underlying asset.

The second group of empirical studies has focused on how the option markets affect the process of price adjustment and the dissemination of information. It consists, more specifically, in estimating the speed at which new information is reflected in the price, through lead-lag relations. It allows in particular, to analyze which of the two markets reflects new information earlier and to study which market will bear the orders of informed investors ${ }^{5}$.

Concerning the impact of options on the characteristics of the underlying asset, three effects have mainly been studied: the impact of option introduction on liquidity, on price dynamics, or even on the underlying asset volatility. In all cases, the idea is to compare the situation of two samples of stocks: one whose securities used as underlying assets of option contracts, the other not. It can be either of two different groups made up of stocks with similar characteristics observed on the same period (longitudinal study), or in a single group, observed before and after the introduction of option contracts (cross-sectional study) ${ }^{6}$. The broad conclusions that have been drawn from these studies are that options listing leads to a reduction in the volatility of stock returns, a reduction in stock bid-ask spreads, and an increase in the informativeness of stock prices?

The aim of the second area of research which will be the subject of the next sections is to study, continuously, the links between derivative and cash markets. Overall, these studies do not allow concluding that the options market incorporates new information more promptly. In other words, that it plays a leading role in the disclosure of information. 


\section{Lead-lag relationship: The survey of the empirical literature}

Why might informed traders prefer to trade in the option markets? As argued by Black $(1975)^{8}$, informed investors may be attracted by the high leverage achievable through options. A number of authors have developed "sequential-trade" models, where informed traders can trade in either the stock or option market (Biais and Hillion (1994), Easley, O'Hara, and Srinivas (1998) and John et al (2003), among others). These papers suggest that the amount of informed trading in option markets should be related to the depth or liquidity of both the stock and option markets, and the amount of leverage achievable with the option ${ }^{9}$. In short, informed traders should sometimes trade in the options market. This theoretical prediction has been examined empirically by several authors. The existing empirical evidence for such a view, however, is mixed. Table 1 provides a summary of previous empirical research in this field. Schema 1 makes a synthesis of the literature in the light of both the approach used and the empirical results found.

\subsection{Lead-lag relationship between stock prices and option prices}

\subsubsection{From closing prices to intraday data}

Manaster and Rendleman (1982) investigate this issue by using the observed option prices to calculate Black and Scholes implied stock prices. The implied stock prices are then compared with observed stock prices. Based on their examination of daily closing data on individual stock options from April 1973 to June 1976, Manaster and Rendleman (1982) conclude that the implied prices and then option prices contain information regarding equilibrium stock price that is not fully reflected in observed stock prices. They reject the hypothesis that implied stock prices provide no information regarding the future movements of observed stock prices. Furthermore, they report that it takes up to one day for stock prices to adjust. However, the use of closing price data seriously undermines the interpretation of their results. Closing option and stock transactions do not always take place at the same time ${ }^{10}$. Therefore, it is possible that additional information contained in closing option prices merely reflects more recent rather than better information.

Although the quality of data of Manaster and Rendleman (1982) is relatively poor, Bhattacharya (1987) confirms their trading strategy results by using intraday transaction data. In order to examine the intraday lead/lag relation between the markets, he uses observed bid/ask call prices to compute implied bid/ask stock prices, which are, in turn, compared to actual bid/ask stock prices to identify arbitrage opportunities. The stock is considered underpriced (overpriced) if the implied bid (ask) is higher (lower) than the actual ask (bid). Rather than simply testing for statistical relationships, Bhattacharya (1987) measures the profitability of trading strategies using a simulated trading strategy based on these arbitrage signals. Although he finds none of the intraday trading strategies generate significantly positive profits, he confirms the Manaster and Rendleman (1982) trading strategy results that option markets tend to lead stock markets by documenting statistically significant excess returns for overnight holding periods.

A critical aspect of the methodology employed in both Manaster and Rendleman (1982) and Bhattacharya (1987) papers is that it tests only whether option prices contain leading information relevant to the stock market, not whether the stock market might also lead the option market ${ }^{11}$. Anthony (1988) takes another approach by examining the interrelation between common stock and call option trading volume from January 1, 1982 to June 30, 1983. The study, using Granger causality tests via the conventional vector-autoregression (VAR), examine whether trading in the option market causes trading in the stock market (or vice versa). He concludes that "...trading in call options leads trading in the underlying shares with a one day lag". He finds weak evidence that option market volume leads stock market volume. However, his results are subject to the same caveats as Manaster and Rendleman (1982) due to the non simultaneity of the closing times for the two markets.

Stephan and Whaley (1990) examine intraday relations between price changes and trading volume of options and stocks for a sample of firms whose options were traded on the Chicago Board of Options Exchange (CBOE) during the first quarter of 1986. Their approach circumvents the two major problems of the previous studies. First, by using transaction-by-transaction data, they avoid the biases inherent in the non simultaneity of closing prices in the two markets. Second, the analysis focuses directly on the lead/lag relation between the intraday price changes in the stock and option markets rather than indirectly through simulating a trading strategy.

Breaking the data into five-minute intervals, they transform observed call price changes into implied stock price changes using a Roll-style American option formula, and then use multivariate time series regression analysis to estimate directly the lead/lag relations between the price changes in the stock and option markets ${ }^{12}$. Unlike the previous studies, they find evidence that price changes in the stock market lead the option market by as much as fifteen minutes, and stock trading volume leads option trading volume by slightly longer than that.

However, Chan, Chang and Johnson (1993) report that this result vanishes when quote midpoints are used, rather than transaction prices. They argue that the Stephan and Whaley (1990) result is biased due to infrequent trading, different price discreteness rules in the stock and option markets, and the fact that a one-tick change in the stock price corresponds to an option price change that is less than one tick. They conclude that neither market leads. Vijh (1990) and Srinivas (1993) examine this linkage issue indirectly by looking at how option prices move with option trades. Vijh 
(1990) concludes that the price effect of large option trades is small, therefore suggesting that option trades are not informative ${ }^{13}$. Srinivas (1993) argues that this is due to a bias in Vijh's sample selection and presents evidence that option trades are informative. Krinsky and Lee (1997) find that Stephan and Whaley's (1990) result seems to reverse around the time of earnings announcements, with options leading stocks in these periods, but like Chan, Chang and Johnson (1993), they find no significant lead-lag relationship in quote midpoints.

More recently, Diltz and Kim (1996) and O'Connor (1999) examine the lead-lag relationship between stocks and options quotes using an error correction model that recognizes that the observed stock price and the option-implied stock price are cointegrated. Diltz and Kim (1996) suggest, from daily data for eight firms negotiated on the CBOE in the first quarter of 1986 that the causality is bi- directional ${ }^{14}$. However, O'Connor (1999), using the TORQ database for 19 firms during November and December, 1990, finds that the stock market tend to lead the option market, and that the lead time is cross-sectionaly related to various measures of option liquidity and trading costs. Stucki and Wasserfallen (1994) find the same result. They conclude that the Swiss stock market lead the Swiss Options and Financial Futures Exchange (SOFFEX) by ten minutes on average.

\subsubsection{How to circumvent problems raised by using intraday data?}

All these empirical studies, among others of lead-lag relations between the option and stock markets compare option and stock transaction prices, quotes, or volume changes using fixed intervals. The use of intraday data is a priori more accurate ${ }^{15}$. Nevertheless, the use of intraday data also raises new problems since those data are more prone to infrequent trading (i.e. asynchronous prices) and to measurement error ${ }^{16}$. To our knowledge, three adaptations for asynchronous trading have been proposed. DeJong and Donders (1995) propose an econometric solution. They estimate the true returns taking into account the asynchronous and non-trading problems. Bruand and Gibson-Asner (1998) use a VAR model and a Granger's test to be free from the pricing model. They select only the contemporaneous trades on each market to cancel the asynchronous trading and filter the time series with a unit-root test.

Finucane (1999) employs a new methodology involving the construction of variable-length return intervals, for call options and the underlying stocks. The method is designed to detect leads that are shorter than five minutes, and accurately measure lead lengths. Allowing the length of the return intervals to vary with the frequency of market activity avoids potential biases created by the presence of intervals with no trading activity, and allows for the unambiguous identification of leads that previous studies classify as contemporaneous price changes. He constructs his data set in event time, and he defines price changes as changes in bid-ask quote midpoints. He models the option price change as a linear function of two lagging and leading stock price changes, and estimates the model using the Generalized Method of Moments. Examining data from November and December 1990 on ten firms, Finucane (1999) finds evidence that stock price changes lead option price changes, but also that option price changes lead stock price changes. To assess the length of the relationships, he increases the minimum of time between the quote changes he uses until the disappearance of any relationships. He concludes that stock prices lead option prices by no more than six minutes, and option prices lead stock prices by no more than three minutes.

\subsection{Lead-lag relationship between stock indices and stock index options}

While the aforementioned studies come to conflicting conclusions as to whether the stock market leads the option market, they consistently find no significant lead for the options market. This conclusion applies to the individual stock market not the index options market where the underlying is not a traded asset. Fleming, Ostdiek and Whaley (1996) examine the interactions between the S\&P500 index, options and futures contracts on this index. They conclude that the derivatives markets lead systematically the spot market, while the futures market precedes the options market, in particular due to a more important liquidity, and therefore to less high transaction costs on the former.

De Jong and Donders (1998) examine the Dutch market. As previously, the futures contracts lead both the options and the index by about 10 minutes. The relationship between the options market and the spot market is not unidirectional. Finally, Booth so and Tse (1999), examining the relationship between the German derivative markets and the DAX index, find cross linkages among the three markets. In particular, they conclude that the spot market lead the options market. In the case of French markets, Capelle-Blancard and Vandelanoite (2002), using Granger linear and non-linear causality tests between European options and the CAC40 index, find that the spot market leads the options market.

\subsection{The information in option volume for stock prices}

A number of authors, while providing indirect evidence of informed trading in option markets, take a slightly different approach. For example, Mayhew, Sarin, and shastri (1995) find evidence that informed traders migrate between stock and option markets in response to changes in the option margin requirement. Using trade and quote data, Easley, O'Hara and Srinivas (1998) test whether option market volume leads stock price changes ${ }^{17}$. Their analysis is based on 44 trading days, October and November 1990, on 50 firms. They use the technique of causality testing proposed by Granger (1969), and Granger and Newbold (1977) to investigate the relationship between option volume and stock price changes, if one market leads the other, and if so for how long ${ }^{18}$. They find strong evidence that options markets are a 
venue for information based trading, and that properly defined option market volumes associated with "positive news" and "negative news" have predictive power for stock price movements ${ }^{19}$.

On the other hand, Chan, Chung and Fong (2002), also using trade and quote data for 14 firms for the first quarter of 1995, calculate signed volume and quote-midpoint returns for five-minute intervals. In order to examine the dynamics of price movements and order flows for stocks and their options, they specify a vector autoregression of stock returns, call option returns, put option returns, stock signed volume, call option signed volume, and put option signed volume. They then estimate the model by performing a separate ordinary least squares regression for each of these variables on the lagged values of all six variables. They find that stock returns lead call and put returns by at least three lags (15 minutes), and option returns lead stock returns by only one lag (5 minutes). They also find that signed stock volume leads stock and option returns by one lag, but contrary to the results reported by Easley, O'Hara and Srinivas (1998), signed option volume does not lead stock returns.

There is also evidence that options volume contains before the announcement of important firm specific news. For example, Amin and Lee (1997) find that a greater proportion of long (or short) positions are initiated in the options market immediately before good (or bad) earnings news on the underlying stock. In a similar vein, Cao, Chen and Griffin (2005) examine the relative information content of stock and option volume prior to takeover announcements ${ }^{20}$. They document abnormal trading activity in option markets prior to takeover announcements, for a sample of 78 events between 1986 and 1994. In time-series regressions they find that during the benchmark period, lagged stock volume imbalances are more informative of next-day returns and that lagged call volume imbalances are not related to returns. However, in the pre-announcement period, option imbalances become significant predictors of next day stock returns. In addition, these authors test the performance of trading strategies based on moving-average trading-volume triggers. They find that strategies based on abnormal option volume tend to be profitable, while those based on abnormal stock volume do not, supporting the conclusion that option market plays an important role in information revelation.

Using daily records of CBOE trading volume for all CBOE listed options from January 1990 through December $2001^{21}$, Pan and Poteshman (2006) have two main goals. The first is to determine whether option volume is informative for future stock prices. The second is to provide evidence on key features of information-based theoretical models. They find that Long-short stock portfolio formed from a put-call volume ratio get 40 basis points the next day and 100 basis points over the next week with very large t-statistics. Contrarily to Cao, Chen and Griffin (2005) and Chan, Chung and Fong (2002) who find that during "normal" times, stock volume not option volume predicts underlying stock returns, they produce strong evidence that option volume contains information about the future movements of underlying stock price. In addition they find that: (a) option volume is more predictive on stocks with higher concentrations of informed investors, (b) the volume of more levered options contains more information about future stock prices, and (c) option volume of full-service customers is most informative while there is no information in option volume of firm proprietary traders.

\section{Factors affecting market performance and information-share approach}

An emergent stream of the literature has delved into the microstructure of options markets in order to more closely understand the relation between information transmission in the two markets, leverage, and liquidity-related variables like spreads and volume. For example, Lee and Yi (2001) test to see if the greater leverage and lower trading costs make options more attractive to informed traders or if the relative lack of anonymity in options markets discourages large investors from trading options. Using a sample of relatively active stocks and their options, the authors find that the adverse selection component of the bid-ask spread decreases with option delta, implying that options with greater financial leverage attract more informed investors. Anand and Chakravarty (2003) have also found that in option markets, "stealth trading" (the propensity of informed traders to fragment trades into certain size classes) is a function of leverage and the underlying liquidity of the option contract.

The literature also indicates that moneyness affects informed traders' choice among different options. In a significant departure from a conventional analysis of the options markets, de Jong, Koedijk, and Schnitzlein (2001) use an experimental approach to examine the implications of asymmetric information for informational linkages between a stock and its traded call option. Their main finding is that an insider trades aggressively in both the option and the stock with most trades directed to the asset that affords the most profitable trading opportunity. Thus, they suggest informed traders use in-the-money (ITM) options to increase their trading profits because ITM are more sensitive to underlying equity price changes than other options. They also find that trades in the stock market imply quote revisions in the options market and vice versa. Hence, price discovery takes place in both markets.

Kaul, Nimalendran, and Zhang (2004) examine the relation between adverse selection in the underlying stock and spreads on options of different strike prices. Their main finding is that adverse selection costs are highest for at-the-money or slightly out-of-the-money options. The authors argue that this result is consistent with the trade-off between high leverage and transaction costs. Chen, Lung, and Tay (2005), using daily data of all the firms included in 
the S\&P500 index and their corresponding options negotiated on the CBOE in a period of approximately 7 years beginning on November 1st of 1995 and ending on December 31st of 2002, analyze the informational role of stocks and options across different option moneyness for firms with different degrees of information asymmetry ${ }^{22}$. They argue that informed traders, in deciding where to place their trades, are not entirely indifferent to option moneyness, degree of information asymmetry, and option liquidity. They discover feedback relations between trades in out-of-the money options and the underlying stocks. Moreover, they conclude that some informed traders are probably attracted to these options because of their higher liquidity, lower premiums, and higher delta-to-premium ratios.

Another strand of literature provides direct evidence of price discovery in the option market. The authors consider that lead-lag analysis tends to lump together permanent price changes, which represent new information entering the market, and transitory changes, which may result from mispricing or temporary order imbalances. They argue that if we are interested in knowing where informed trading occurs, we should focus on only the permanent component. To the best of our knowledge, Chakravarty, Gulen and Mayhew (2004) is the first paper to measure directly the percentage of price discovery across the stock and option markets, and to provide direct evidence of price discovery in the option market. Moreover, the authors investigate whether the relative rate of price discovery in the two markets is a function of firm characteristics that can be identified in a cross-sectional analysis.

To accomplish these objectives, Chakravarty, Gulen and Mayhew (2004) use a modification of Hasbrouck's (1995) "information share" approach ${ }^{23}$. Their results are consistent with theoretical arguments that informed investors trade in both stock and option markets, suggesting an important informational role for options. Indeed, based on five years of stock and options data for 60 firms, they estimate the option market's contribution to price discovery to be about 17 percent on average. Option market price discovery is related to trading volume and spreads in both markets, and stock volatility. Price discovery across option strike prices is related to leverage, trading volume, and spreads.

\section{More recent literature: different approaches to different markets}

In order to more closely investigate price discovery in options markets, the more recent studies apply a wide range of approaches. Richard, Yusif, and Liuren (2006) apply a portfolio approach to analyze price discovery in the United States stock and stock options. The authors consider that option prices vary with not only the underlying asset price, but also volatilities and higher moments. Hence, they use a portfolio of options to seclude the value change of the portfolio from the impact of volatility and higher moments. They find that price discovery on the directional movement of the stock price mainly occurs in the stock market. However, the options market becomes more informative during periods of significant options trading activities. Furthermore, Yusif and Liuren (2008) study price discovery in the United States stock options market. They describe the International Securities Exchange ${ }^{24}$ and present a comparison of the different exchanges' market-making systems along several dimensions, including the size of the typical bid-ask spread, how much a trade in each market contributes to a general updating of prices across the whole market, and how frequently trades are executed inside the quoted bid-ask spread ${ }^{25}$. Their results indicate that the electronic marketplace performs very well relative to the more traditional trading floors on all of these dimensions.

On the other hand, a number of authors study price discovery in Asian option markets. For example, by applying the method of open interest and volume-based predictors (Bhyan and Yan, 2002), Kedar and Mishra (2007) study the informational role of the options market in predicting the future price index in the underlying cash market in India. To explore the above relationship, daily data for both price as well as non-price variables, for two different sub-periods have been employed. Their findings confirm that the open-interest-based predictors- for both the periods-are found to be significant in predicting the future price in the underlying cash market. Nevertheless, during the recent sub-period, the trading volume shows some more impact when compared to open interest in the matter of price prediction in the cash market.

In the case of Korea, Hee, Jangkoo, and Doojin (2008) examine if informed trading is present in the index option market by analyzing the KOSPI $200^{26}$ options, the most actively traded derivative product in the world. The authors utilize the spread decomposition model developed by Madhavan, Richardson, and Roomans (1997) and then use the adverse-selection cost component of the spread estimated by the model as a proxy for the degree of informed trading ${ }^{27}$. They find that adverse-selection costs constitute a nontrivial portion of the transaction costs in index options trading. Approximately one-third of the spread can be accounted for by information asymmetry costs. Moreover, their regression analysis shows that option-related variables are significantly associated with estimated information asymmetry costs, even when controlling for proxies for informed trading in the index futures market.

Usually in the case of emerging markets, Wen-Liang, Chin-shen, and Shu-fang (2008) investigate the relative rate of price discovery in Taiwan between index futures and index options, proposing a put-call parity (PCP) approach to recover the spot index embedded in the options premiums ${ }^{28}$. Consistent with the trading-cost hypothesis, a dominant tendency is found for futures and a subordinate but non-trivial price discovery from options. More recently, Chang, Hseih, and Lai (2009) investigate the information content of options trading using a unique dataset to examine the predictive power of the put and call positions of different types of traders in the Taiwan option market. They find that 
options volume, as a whole, carries no information on Taiwan spot index changes. On the other hand, however, there is strong evidence to show that the trading in which institutional investors do engage has significant predictive power on the underlying asset returns.

\section{Conclusions}

In summary, there is no consensus among the empirical studies on the direction of information flow between the stock and option markets. Likewise, it is not clear where the informed traders choose to place their trades. However, we can make a synthesis of the literature in the light of both the approach used and the empirical results found. Indeed, several authors have provided indirect evidence consistent with the theoretical prediction that informed traders should sometimes trade in the option market (see, for example, Easley, O'Hara, and Srinivas (1998), Cao, Chen, and Griffin (2000), and Pan and Poteshman (2003)).

Given this corroborative evidence that informed traders use option markets, there is surprisingly little direct evidence that new information is reflected in option prices before stock prices (see Manaster and Rendleman (1982), Stephan and Whaley (1990), Vijh (1990), Chan, Chung, and Johnson (1993), Finucane (1999), and Chan, Chung, and Fong (2002)). The authors focus on which market leads (or lags) in terms of information arrival, through Granger lead-lag regressions and similar techniques.

While these studies come to conflicting conclusions as to whether the stock market leads the option market, they consistently find no significant lead for the options market. This conclusion applies to the individual stock market not the index options market where the underlying is not a traded asset (see for example, Fleming, Ostdiek and Whaley (1996)).

In order to circumvent the problem diagnosed in the lead-lag analysis that it tends to lump together permanent price changes and transitory changes, Chakravart, Gulen and Mayhew (2004) among others, provide direct evidence of price discovery in the option market. They find that options have an important informational role. In addition, they conclude that the relative rate of price discovery in the two markets is a function of firm characteristics. More recently, empirical studies examine if informed trading is present in some emerging option markets by applying mixed approaches.

The most important implication of the above literature survey is that it leaves us with some open theoretical and empirical issues. First, it raises doubts on the validity of most contingent claims pricing models which value options with a dynamic replicating strategy. From a conceptual perspective, it is clear that derivatives can no longer be treated as redundant securities. Second, on one hand, recent empirical evidence may help to determine whether there are further factors, such as firm or news characteristics, that might help to explain the complex relationships between informed trading volume, news, option prices and stock prices. Factors that might drive an informed trader to choose one market over another are liquidity, leverage, and transaction costs, and the type of market mechanism.

On the other hand, the majority of research focuses on directional information and on mature options markets such as the CBOE. In future research it would be interesting to explore information about the future volatility of underlying stocks and to understand information flow and price discovery in the emerging options market for two reasons. First, the typical emerging market usually has different trading regulations from mature markets. It would be informative to examine whether the regulations in a particular emerging market encourage or discourage informed trading activities in options market. Second, an emerging market is less efficient than a mature market, and insider trading regulations are lax. Hence, all else equal, trading in an emerging market provides more profitable opportunities for informed traders.

\section{References}

Amin, K., \& Lee,C. (1997). Option Trading and Earnings News Dissemination. working paper, University of Michigan. Anthony, J. (1988). The interrelation of stock and options market trading-volume data. Journal of Finance, 43, 949-964. Back, K. (1993). Asymmetric information and options. Review of Financial Studies, 6, 435-472.

Bessembinder, H., Chan.K., \& Seguin. P. (1996). An empirical examination of information, differences of opinion, and trading activity. Journal of Financial Economics, 40, 105-134.

Bhattacharya, M. (1987). Price changes of related securities: The case of call options and stocks. Journal of Financial and quantitative Analysis 22, 1-15.

Bhuyan, R. (2002). Information, alternative markets, and security price processes: A survey of literature. Working Paper.

Bhuyan, R., \& Yan, Y. (2002). Informational role of open interests and volumes: Evidence from option markets. Paper presented at Twelfth Annual Asia-Pacific Futures Research Symposium held in Bangkok, Dec. 3-4, 2001.

Biais, B., \& Hillion, P. (1994). Insider and Liquidity trading in stock and options markets. Review of Financial Studies, $74,743-780$. 
Black, F., \& Scholes, M. (1973). The pricing of options and corporate liabilities. Journal of Political Economy, 637-655.

Black, F. (1975). Fact and fantasy in use of options. Financial Analysts Journal, 31, 36-41.

Blasco, N., Corredor, P., \& Santamaria, R. (2006). Does informed trading occur in the options market? Some revealing clues. working paper, University of Zaragoza.

Booth G.G., So, R.W., \& Tse, Y. (1999). Price discovery in the German equity index derivative markets. Journal of Futures Markets, 19(6). 619-643.

Brennan, M., \& Cao, H. (1996). Information, trade, and derivative securities. Review of Financial Studies, 9, 163-208.

Brennan, M., \& Subrahmanyam, A. (1995). Investment analysis and price formation in securities markets. Journal of Financial Economics, 38, 361-381.

Bruand, M. \& Gisbon-Asner, R. (1998). The effects of newly listed derivatives in a thin stock market. Review of derivatives Research, 2 (1), 59-86.

Cao, C., Chen, Z. \& M. Griffin. (2005). The informational content of option volume prior to takeovers. Journal of Business, 78, 1073-1109.

Capelle-Blancard, G. (2001). Les marchés à terme d'options : organisation, efficience, évaluation des contrats et comportements des agents. Thèse de doctorat, Université Paris I Panthéon-Sorbonne.

Capelle-Blancard, G., \& Vandelanoite, S. (2002). Relations intrajournalières entre l'indice CAC40 et les options sur indice : quel est le marché préféré des investisseurs informés?. Annales d'économie et de Statistique, №66, 2002.

Chakravarty, S., Gulen, H., \& Mayhew, S. (2004). Informed Trading in Stock and Option Markets. Journal of Finance, 59 (3), 1235-1257.

Chan, K., Chung, P., \& Fong, W. M. (2002). The informational role of stock and option volume. Review of Financial Studies, 15, 1049-1075.

Chan, K., Chung, P., \& Johnson, H. (1993). Why option prices lag stock prices: A trading-based explanation. Journal of Finance, 48, 1957-1967.

Chan, K., Chung, P. \& Johnson, H. (1995). The intraday behaviour of bid-ask spreads for NYSE stocks and CBOE options. Journal of Financial and Quantitative Analysis, 30, 329-346.

Chan, K. C., Chang, Y., \& Lung, P.P. (2009). Informed trading under different market conditions and moneyness: Evidence from TXO options. Pacific-Basin Finance Journal, 17(2), 189-208.

Chang, C.C., Hsei, P.F., \& Lai, H.N. (2009). Do informed option investors predict stock returns? Evidence from the Taiwan stock exchange. Journal of Banking \& Finance, 33(4), 757-764.

Chen, C.R., Lung, P.P., \& Tay, N.S.P. (2005). Information flow between the stock and option markets: Where do informed traders trade. Review of Financial Economics, 14, 1-23.

Cherian, J. (1993). Option pricing, self-fulfilling prophecies, implied volatilities and strategic interaction. Unpublished Ph.D. dissertation, Cornell University.

Conrad, J. (1989). The price effect of option introduction. Journal of Finance, 44(2), 487-498.

Damodaran, A., \& Joseph, L. (1991). The effects of option listing on the underlying stocks' return process. Journal of Banking and Finance, 15, 647-664.

De Jong, C., Koedijk, K.C.G., \& Schnitzlein, C.R. (2001). Stock market quality in the presence of a traded option. working paper, Erasmus University.

De Jong, F., \& Donders, M. (1998). Intraday lead-lag relationships between the futures, options and Stock Markets. European Finance Review, 337-359, 1(3).

Diltz, J., \& Kim, S. (1996). The relationship between stock and option price changes.The Financial Review, 31,499-519.

Easley, D., \& O’Hara, M. (1987). Price, trade size and information in securities markets. Journal of Financial Economics, 19, 69-90.

Easley, D., O’Hara, M., \& Srinivas. P. (1998). Option volume and stock prices: Evidence on where informed traders trade. Journal of Finance, 53, 431-465.

Fedenia, M., \& Grammatikos, T. (1992). Options trading and the bid-ask spread of underlying stocks. Journal of Business, 65(3), 335-351. 
Franke, G., Stapleton, R., \& Subrahmanyam, M. (1998). Who buys and who sells options: The role of options in an economy with background risk. Journal of Economic Theory, 82, 89-109.

Figlewski, S., \& Webb, G. (1993). Options, short sales, and market completeness. Journal of finance, 48, 89-109.

Finucane, T.J. (1999). A new measure of the direction and timing of information flow between markets. Journal of Financial Markets, 2(2), 135-151.

Fleming, J., Ostdiek B., \& Whaley, R. E. (1996). Trading costs and the relative rates of price discovery in the stock, futures, and option markets. Journal of Futures Markets, 16, 353-387.

Glosten, L.R., \& Milgrom, P.R. (1985). Bid, ask and transaction prices in a specialist market with heterogeneously informed traders. Journal of Financial Economics, 14, 71-100.

Granger, C. (1969). Investigating causal relations by econometric models and cross-spectral methods. Econometrica, 37(3), p. 424-438.

Granger, Clive, W. J., \& Peter, N. (1977). Forecasting economic time series. Academic Press, New York.

Grossman, S. (1988). An analysis of the implications for stock and future price volatility of program trading and dynamic hedging strategies. Journal of Business, 61, 275-298.

Hasbrouck, J. (1995). One security, many markets: Determining the location of price discovery. Journal of Finance, 50, 1175-1199.

Hee.J.A., Jangkoo, K., \& Doojin.R. (2008). Informed trading in the index option market: The case of KOSPI 200 options. Journal of Futures Markets, 28(12), 1118-1146.

Ho, T., \& Stoll, H. (1983). The dynamics of dealer markets under competition. Journal of Finance, 83, $1053-1074$.

Jennings, R., \& Starks, L. (1986). Earnings announcements, stock price adjustment, and the existence of option markets .Journal of Finance, 41(1), 107-125.

John, K., Koticha, A., \& Subrahmanyam, M. (2000). The micro-structure of options markets: informed trading, liquidity, volatility and efficiency. Working paper, New York University.

John, K., Koticha, A., \& Subrahmanyam, M. (2003). Margin rules, informed trading in derivatives and price dynamics. Working paper, New York University.

Jones, C., Kaul, G., \& Lipson, M. (1993). Information, trading, and volatility. Journal of Financial Economics, 36, 127-154.

Kaul, G., Nimalendran, M., \& Zhang, D. (2004). Informed trading and option spreads. Working paper, University of Michigan.

Kedar, N.M., \& Mishra, R.K. (2007). Informational role of non-price variables: An empirical study of the Indian options market. The Icfai Journal of Applied Finance, 13(2), 32-45.

Kraus, A., \& Smith, M. (1996). Heterogeneous beliefs and the effect of replicatable options on asset prices. Review of Financial Studies, 9, 723-756.

Krinsky, I., \& Lee, J. (1997). Quarterly earnings announcements and the lead/lag relationship between the stock and option markets. Working paper, McMaster University.

Kyle, A. (1985). Continuous auctions and insider trading. Econometrica, 53, 1315-1335.

Jason, L., \& Cheong, H.Y. (2001). Trade size and information-motivated trading in the options and stock markets. Journal of Financial and Quantitative Analysis, 36, 485-501.

Jun, L., \& Jun, P. (2003). Dynamic derivative strategies. Journal of Financial Economics,

forthcoming.

Madhavan, A., Richardson, M., \& Roomans, M. (1997). Why do security prices change? A transaction-level analysis of NYSE stocks. Review of Financial Studies, 10, 1035-1064.

Manaster, S., \& Rendleman, R. (1982). Option prices as predictors of equilibrium stock prices. Journal of Finance, 37 , 1043-1057.

Mannaï, S. (1995). De la microstructure en général et de la liquidité en particulier: théories et études empiriques sur le Monep. Economica.

Mayhew, S., Sarin, A. \& Shastri, K. (1995). The allocation of informed trading across related markets: an analysis of the impact of changes in equity-option margin requirements. Journal of Finance, 505, 1635-1653.

Mayhew, S. (2000). The impact of Derivatives on Cash Markets: What Have We Learned?. Working Paper. 
Merton, R.C. (1973). The Relationship between Put and Call option Prices: Comment. Journal of Finance, 31, 369-381.

Nandi, S. (1994). Asymmetric information about volatility and options markets: Theory and evidence. Working paper, Washington University.

Neal, R. (1987). Potential and actual competition in equity options. Journal of Finance, 42, 511-532.

O'connor M. (1999). The cross-sectional relationship between trading costs and lead/lag effects in stock and option markets. Financial Review, 34, 95-118.

Pan, J., \& Poteshman, A. (2006). The information in option volume for stock Prices. Review of Financial Studies, 19(3), 871-908.

Richard, H., Yusif, S., \& Liuren, W. (2006). Price discovery in the U.S. stock options markets: A portfolio approach. Review of Derivatives Research, 9(1), 37-65.

Ranaldo, A. (2000). Intraday trading activity on financial markets: the Swiss evidence. Thesis, University of Fribourg.

Ross, S. A. (1976). Options and efficiency. Quarterly Journal of Economica, 90(1), 75-89.

Sims. (1972). Money, income and causality. American Economic Review, 62, 540-552.

Skinner, D.J. (1989). Options markets and stock return volatility, Journal of Financial Economics, 23, 61-78.

Srinivas, P. S. (1993). Trade size and the information content of option trades. Working paper, Cornell University.

Stephan, J, \& Whaley, R. (1990). Intraday price change and trading volume relations in the stock and stock option markets. Journal of Finance, 45, 191-220.

Stoll, H. \& Whaley, R. (1987). Expiration day effects of index options and futures," Financial Analysts Journal, 43, 16-28.

Stucki, T. \& Wasserfallen, W. (1994). Stock and option markets: the Swiss evidence. Journal of Banking and Finance, 18, 881-893.

Vandelanoite, S. (2002). Les modalités de transaction et d'incorporation de l'information sur les marchés financiers. Thèse de doctorat, Université Paris I Panthéon-Sorbonne.

Vijh, A. (1988). Potential biases from using only trade prices of related securities on different exchanges. Journal of Finance, 43, 1049-1055.

Vijh, A. (1990). Liquidity of the CBOE equity options. Journal of Finance, 45, 1157-1179.

Wen-Liang, G.H., Chin-Shen, L., \& Shu-Fang, Y. (2008). Price discovery in the options markets: An application of put-call parity. Journal of Futures Markets, 28(4), 354-375.

Yusif, E.S., Liuren, W. Winter. (2008). Price discovery in the U.S. stock options market. The Journal of Trading, Winter .

\section{Notes}

Note 1. "Since an investor can usually get more action from a given investment in options than he can by investing directly in the underlying stock, he may choose to deal in options when he feels he has an especially important piece of information" ( Black[1, p. 61]).

Note2. Empirical studies contribute to the understanding of why options are relevant in actual markets, by providing the unambiguous evidence that stock option trading contributes to price discovery in the underlying stock market.

Note 3. Most derivative pricing models assume complete markets where derivatives are redundant securities and hence not traded in equilibrium. But when traders with private information about the underlying stock can choose to trade the stock or the option, then options prices and trades contain valuable information and are no longer redundant.

Note 4. Since Ross (1976) first suggested that option introductions impact upon the value of the underlying asset, much research has focused on examining the validity of this hypothesis both through theoretical and empirical analysis.

Note 5. Note that if the first type of approach deals with comparative static, the second refers rather to a continuous analysis.

Note 6. The results of these studies should however, be considered with caution. Indeed, it is difficult to distinguish the effects caused directly by the existence of options, from those resulting from the events that have led to the introduction of these contracts.

Note 7. For evidence on the reduction in volatility, see Conrad (1989) and Skinner (1989); on the reduction in bid-ask spreads, see Damodaran and Lim (1991) and Fedenia and Grammatikos (1992); and on improved efficiency, see Damodaran and Lim(1991) and Jennings and Starks (1986)... 
Note 8. This idea is well explained in section 1.

Note 9. In addition, Capelle-Blancard (2001) presents a model in which some investors are privately informed about the stock value and others are privately informed about volatility. His results suggest that when there is greater uncertainty, there is likely to be more price discovery in the stock market and less in the option market.

Note 10. The option market closes at 3:10 PM (CST), ten minutes after the close of the stock market.

Note 11. Bhattacharya recognizes this problem but does not perform the simulations in the reverse way. Although he shows that option price changes have some predictive power, his results do not preclude the possibility that the stock price changes predict option price changes.

Note 12. Stephan and Whaley (1990) are the first to use both an intraday interval (5minutes) and a bi-directional test. Since the relation can be bi-directional (each market can lead the other and they can interact), it is preferable to use a causality test in the Granger's (1969) and Simms' (1972) meaning.

Note 13. Vijh (1990) argues further that Manaster and Rendleman (1982)'s methodology suffers from the bid-ask bias as well as the nonsynchroneity. He concludes that not accounting for the bid-ask bounce and the nonsynchroneity between stock and option prices in an ex post study can give the impression that the option prices lead the stock prices even when the tow are in equilibrium.

Note 14. They find evidence both for the stock market leading the option market and the option market leading the stock market.

Note 15. The last option trade or quote occurring in a particular interval is used as the representative price for that interval, and if no trade or quote is registered during a particular interval, transactions from previous intervals are typically applied to the empty intervals.

Note16. Measurement error caused by missing observations will affect the consistency and efficiency of coefficient estimates.

Note 17. They investigate the informational role of transactions volume in options markets.

Note 18. Dividing the trading day into five-minute intervals, they regress stock price changes on lagged option volume, and vice versa.

Note 19. Signed volume is calculated by first classifying trades as buyer or seller-initiated according to their location within the prevailing bid-ask spread, then lumping long call volume together with short put volume (volumes associated with "positive news"), and short call volume with long put volume (volumes associated with "negative news").

Note 20. The authors consider that takeover announcements are ideal events for studying information discovery in the security price formation process.

Note 21. A unique feature of their dataset is that the daily trading volume for each option is broken down into 16 categories defined by 4 trade types (open buy, open sell, close buy, and close sell) and 4 investor classes (firm proprietary traders, public customers of discount brokers, public customers of full-service brokers, and other public customers).

Note 22. Unlike some previous studies that find information to flow unilaterally from equity to options markets, they control for the above factors.

Note 23. The information-share approach measures the contribution of the innovation in the price process in one market (say the option market) to the total variance of the innovation in the permanent component of the price vector spanning both (stock and option) markets.

Note 24. In 2000, the International Securities Exchange (ISE) was launched, with an entirely different all-electronic trading arrangement. The ISE model has proven highly successful, making the exchange the most active market for individual stock options within only a few years.

Note 25. Meaning that the quoted spread did not fully reflect the best prices available at that exchange.

Note 26. The KOSPI 200 Index is the Korea Composite Stock Price Index. It is a capitalization-weighted index of 200 Korean stocks which make up 93\% of the total market value of the Korea Stock Exchange. The index was developed with a base value of 100 as of January 3, 1990.

Note 27. Their approach is similar to that applied by Kaul, Nimalendran, and Zhang (2004).

Note 28. The PCP approach offers the benefits of reducing model risk and alleviating the burden of volatility estimation. 
Table 1. Summary of empiricul reseurch in the links between option and cush markets

\begin{tabular}{|c|c|c|c|c|}
\hline Authors & Markets, Products and period & Data & Methodology & Results and criticisms \\
\hline Mannster-Rendlemun (1982) & $\begin{array}{c}\text { CBOE } \\
\text { Stock options } \\
\text { From } 04 / 73 \text { to } 066 / 76\end{array}$ & Duily closing prices & Simulated trading strategy & $\begin{array}{c}\text { Options lead by one day } \\
\text { Biased results due to difference } \\
\text { in closing times }\end{array}$ \\
\hline Bhattacharyu (1987) & $\begin{array}{c}\text { CBOE } \\
\text { Stock options } \\
\text { From } 06 / 73 \text { to } 08 / 78\end{array}$ & Intraday transuctions & Simulated trading strategy & $\begin{array}{l}\text { Options lend stocks by one doy } \\
\text { Corroborative result with } \\
\text { M\&R(1982) }\end{array}$ \\
\hline Anthouy (1988) & $\begin{array}{c}\text { CBOE } \\
\text { Stock options } \\
\text { From } 01 / 82 \text { to } 06 / 83\end{array}$ & Deily closing volumes & $\begin{array}{c}\text { ARIMA } \\
\text { Linear causality }\end{array}$ & $\begin{array}{l}\text { Options market lead stock } \\
\text { market by one day }\end{array}$ \\
\hline Stephum-Whaley $(19 \%)$ & $\begin{array}{c}\text { CBOE } \\
\text { Stock options } \\
\text { From } 01 / 86 \text { to } 03 / 86\end{array}$ & Intraday transuctions & Multivariute unalysis & $\begin{array}{l}\text { Stock market lead the options } \\
\text { market by as much as } 15 \\
\text { minutes }\end{array}$ \\
\hline Chan-Chung-Jotnson (1993) & $\begin{array}{c}\text { CBOE } \\
\text { Stock options } \\
\text { From 01/86 to 03/86 }\end{array}$ & Intraday quotes & Linear causality & $\begin{array}{l}\text { The lead of S\&W (1990) } \\
\text { disuppears with quotes }\end{array}$ \\
\hline Stucki-Wusserfallen (1994) & $\begin{array}{c}\text { SOFFEX } \\
\text { Stock options } \\
\text { From } 0189 \text { to } 12 / 89\end{array}$ & Intraday transuctions & Linear causality & Cush murket lead by 10 minutes \\
\hline Diltz-Kim (1996) & $\begin{array}{c}\text { CBOE } \\
\text { Stock options } \\
\text { From } 01 / 86 \text { to } 03 / 86\end{array}$ & Duily quotes & Error Correction Model & Bidirectional ceusality \\
\hline$\sigma^{\prime}$ Connor $(19 y 9)$ & $\begin{array}{c}\text { CBOE } \\
\text { Stock options } \\
\text { From } 11 / 90 \text { to 12/90) }\end{array}$ & Intraday quotes & Error Cortection Model & $\begin{array}{l}\text { Stock market lend the options } \\
\text { market }\end{array}$ \\
\hline $\begin{array}{l}\text { Fleming-Ostdick-Whaley } \\
\text { (1996) }\end{array}$ & $\begin{array}{c}\text { CBOE } \\
\text { Index options }\end{array}$ & Initraday quotes & Limear causality & $\begin{array}{l}\text { Option market lead the cash } \\
\text { market }\end{array}$ \\
\hline
\end{tabular}


$03 / 91$

\begin{tabular}{|c|c|c|c|c|}
\hline Detong-Donders (1998) & $\begin{array}{c}\text { AEX } \\
\text { Index options } \\
01 / 92 \text { to } 07 / 92 \cdot 01 / 93 \text { to } 06,093\end{array}$ & Intraday quotes & Cointegnation tests-MCE & $\begin{array}{l}\text { Symmetrical relutionship of } \\
\text { index und options }\end{array}$ \\
\hline Bruand-Gibson Asner (1998) & $\begin{array}{c}\text { SOFFEX } \\
\text { Stock options } \\
\text { From } 01 / 89 \text { to } 12 / 89\end{array}$ & $\begin{array}{l}\text { Simultaneous intraday } \\
\text { transuctions }\end{array}$ & Test VAR und Granger & $\begin{array}{l}\text { Results unstable acoording to the } \\
\text { features of options and to the } \\
\text { undertying }\end{array}$ \\
\hline Finueune $(1999)$ & $\begin{array}{c}\text { CBOE } \\
\text { Stock options } \\
\text { From 11/90 to 12/90 }\end{array}$ & $\begin{array}{l}\text { Intraday quotes } \\
\text { Every quote change is } \\
\text { registered to calculate } \\
\text { real time returns }\end{array}$ & Linear cuusality by $\mathrm{GMM}$ & $\begin{array}{l}\text { Lead of the cush market } \\
\text { The minimum is a few seconds } \\
106 \text { minutes }\end{array}$ \\
\hline Booth.50.7se (1999) & $\begin{array}{c}\text { DTB } \\
\text { Index options } \\
\text { From } 01 / 92 \text { to } 03 / 94\end{array}$ & Intraday quotes & Vur Enor correction model & $\begin{array}{c}\text { The cash market lend the options } \\
\text { market }\end{array}$ \\
\hline $\begin{array}{l}\text { Capelle-Bluncird-Vundelanoite } \\
\qquad(2002)\end{array}$ & $\begin{array}{c}\text { MONEP } \\
\text { Index options } \\
\text { From } 01 / 97 \text { to } 12 / 99\end{array}$ & Intriday transnctions & $\begin{array}{l}\text { Granger linear causality } \\
\text { Grunger non lineur cuusality }\end{array}$ & $\begin{array}{c}\text { The cash market lend the options } \\
\text { market }\end{array}$ \\
\hline Easley.0'Hura-Sinivis (1998) & $\begin{array}{c}\text { CBOE } \\
\text { Stock options } \\
\text { From } 10,90 \text { to } 11 / 90\end{array}$ & $\begin{array}{c}\text { Intraday transaction } \\
\text { volumes }\end{array}$ & $\begin{array}{l}\text { Bivariute ARIMA } \\
\text { Linear cuusality }\end{array}$ & $\begin{array}{l}\text { Options murket is a venue for } \\
\text { information based trading }\end{array}$ \\
\hline Chan-Chung.fong (2002) & $\begin{array}{c}\text { CBOE } \\
\text { Stock options } \\
\text { From 01/95 to 03/95 }\end{array}$ & $\begin{array}{l}\text { Intraday transaction } \\
\text { volumes/ } \\
\text { intraday quotes }\end{array}$ & Test VAR und Granger & $\begin{array}{l}\text { Stock volumes lead option } \\
\text { returns } \\
\text { Option volumes have no } \\
\text { predictive content for stock } \\
\text { prices }\end{array}$ \\
\hline
\end{tabular}




\begin{tabular}{|c|c|c|c|c|}
\hline Pan-Poteshuman (2006) & $\begin{array}{c}\text { CBOE } \\
\text { Stock options/lndex options }\end{array}$ & Deuly volumes & $\begin{array}{c}\text { Cross-sectional unalyses } \\
\text { (univariatebivariate regressions) }\end{array}$ & $\begin{array}{l}\text { Options murket leads stock } \\
\text { murket }\end{array}$ \\
\hline & From $01 / 90$ to $30 / 2004$ & & & $\begin{array}{l}\text { Index option have no predictive } \\
\text { content }\end{array}$ \\
\hline Cuo-Chen-Girffin (2005) & $\begin{array}{c}\text { CBOE } \\
\text { Stock options } \\
78 \text { events between } 1986 \text { and } 1994\end{array}$ & Intraday transiction wolumes & $\begin{array}{c}\text { ARIMA } \\
\text { Lineur cususality }\end{array}$ & $\begin{array}{l}\text { Option market pluys un importan } \\
\text { role in information revelation } \\
\text { during pre-announcement penod }\end{array}$ \\
\hline Kaul-Nimaldrun-Zhang (2004) & $\begin{array}{c}\text { CBOE } \\
\text { Stock options } \\
\text { (02295 }\end{array}$ & Intraday trade and quotes data & $\begin{array}{l}\text { Develop und test a model of } \\
\text { option spread: OLS regression } \\
\text { und ordered Probit models }\end{array}$ & $\begin{array}{l}\text { Presenve of strategie trading by } \\
\text { informed investors in the options } \\
\text { murket }\end{array}$ \\
\hline $\begin{array}{l}\text { Chaknuvarty-(iulen-Mayhew } \\
\qquad(2004)\end{array}$ & $\begin{array}{c}\text { CBOE } \\
\text { Stock options }\end{array}$ & Intraday trade and quotes data & Cointegration vector & $\begin{array}{l}\text { An important informational role } \\
\text { for options }\end{array}$ \\
\hline & From 1988 to 1992 & & & \\
\hline
\end{tabular}




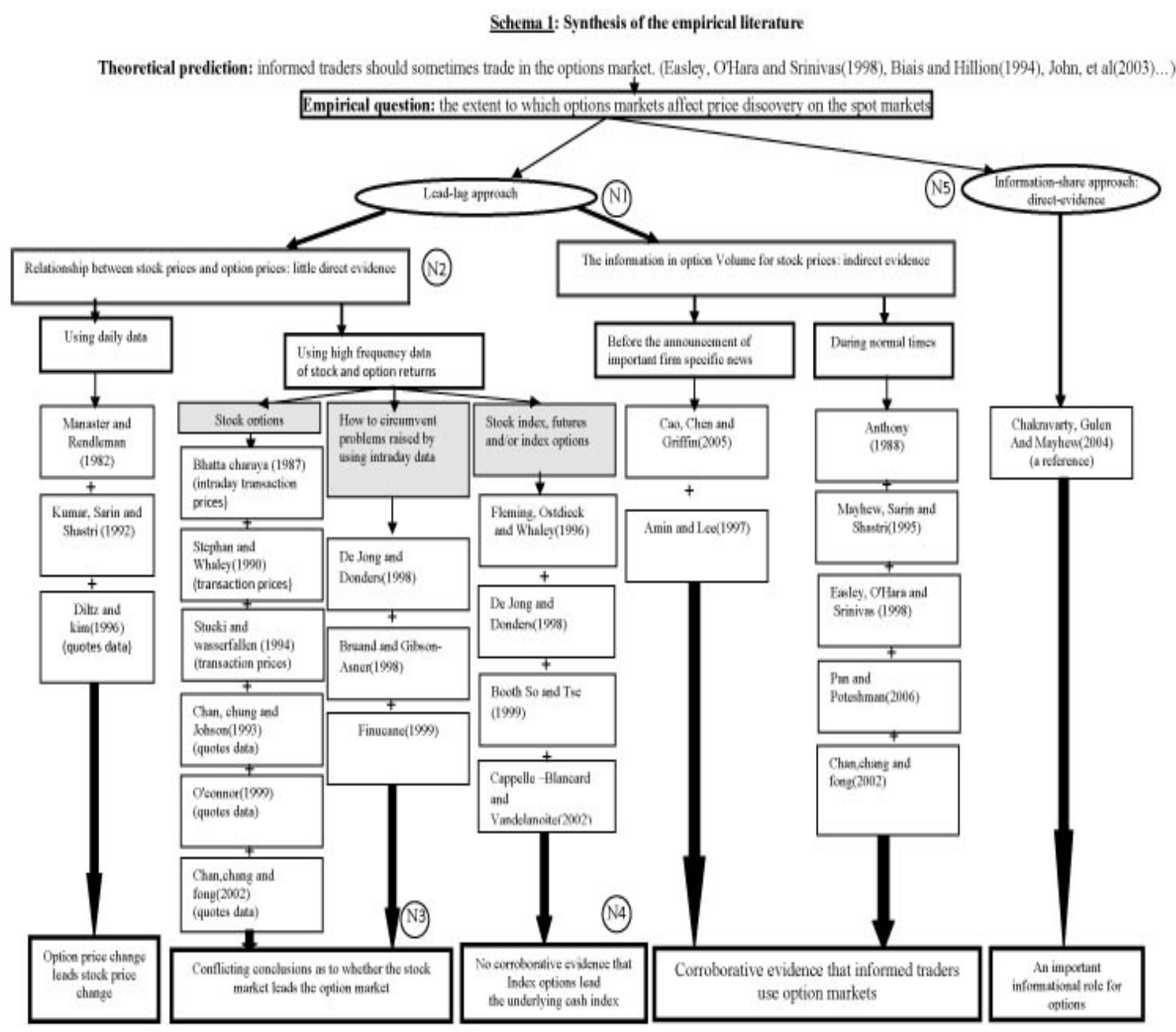

\section{Schema 1 notes}

N1: There is a substantial body of empirical research focusing on which market leads (or lags) in term of information arrival, through Granger lead-lag regressions and similar techniques.

N2: There is surprisingly little evidence that new information is reflected in option prices before stock prices.

N3: While these studies come to conflicting conclusions as to whether the stock market leads the option market, they consistently find no significant lead for the options market. This conclusion applies to the individual stock market, not the index options market where the underlying is not a traded asset.

N4: The authors have reported that the underlying index is not a traded asset. Thus, it may be composed of stale prices.

N5: The information-share approach measures the contribution of the innovation in the price process in one market (say the option market) to the total variance of the innovation in the permanent component of the price vector spanning both (stock and option) markets. 


\title{
Research on Risks of Chinese Commercial Banks'
}

\section{Independent Innovation}

\author{
Mingyou Wang, Jian Gui \& Jingting Ma \\ Shenyang University, Shenyang 110044, China \\ E-mail: gweijean@126.com
}

\begin{abstract}
Since the 90s in last century, financial innovation tends to be different under the condition of loose regulation and the revolutionary progress of information technology. The competition in the finance industry becomes severe and financial institutions lay more stresses on innovations, not only concerning the product innovation but also the services. However, risks come. The bankruptcy of many American financial institutions in last year deserves more attentions from China's commercial banks that should emphasize on financial innovations. Only by strengthening the internal and external supervision and regulation, can it reduce commercial banks' innovation risk.
\end{abstract}

Keywords: Commercial bank, Innovation risk, Management of risk

Since the 90s last century, commercial banks in western countries have paid more attentions on financial innovations that concern not only financial products but also financial institutions, financial system, and financial services. In a short period, these financial innovations have actualized better effects. In a sense, their independent innovations have been improved to a great degree. However, the financial crisis indicates that the commercial banks in western countries produce risks as they make innovations. They neglect innovation risks. As China's commercial banks learn innovation experiences from western countries' commercial banks and evaluate their innovation abilities, they should care about the control over risks. The independent innovation effect of commercial banks should exclude the expenses on risks. The stronger the ability of controlling risks is, the smaller the risk is, and the stronger the ability of independent innovation is.

\section{The relationship between financial innovations and risks}

The financial innovation concept is mainly derived from Joseph Schumpeter's economic innovation concept. Financial innovation means to change present financial system and adopt new financial tools in order to gain potential profits that can not be obtained by present financial system and financial tools. It is a slowly-continued development process driven by a desire for profits. The birth of new things is always accompanied with uncertainties and randomness. Risk is a byproduct of innovation. Financial innovation risks concern two aspects, namely the stock risk and the increment risk.

For the stock risk, financial innovation is the best way for improving the asset structure and defending risks. China's commercial banks mostly focus on traditional operations. Liabilities mainly locate on public deposits and savings. Assets are mainly loans for enterprises. However, the irrational loan structure, term limits, and rates structure lead to bad liquidity of loans. As a result, banks that mainly depend on interests from loans operate hard due to the poor-quality assets. These banks face higher risks. By developing new businesses, banks can speed up the circulation of capitals. On one hand, it can improve the safety of assets by higher profitability and liquidity. Then, banks can actualize the maximum effect of total assets. On the other hand, it can separate banks' assets as much as possible, which can help to escape from higher risks caused by centering in few customers, reducing banks' losses and improving banks' assets quality and governance level. Foreign financial development history also shows that financial innovation and exploration is the best choice for financial institutions adapting to the changeable economic environment and avoiding risks. For risks increment, it is better to develop financial innovation with a precondition of pre-analysis and prediction and strict control. As banks develop the money credit business, some unfavorable factors may cause that cashes fail to flow back or realize added value, which may lead to the loss of banks' assets. Therefore, to strengthen the risk management is the necessary and main content for banks' businesses. So, in making innovations, banks should take the development speed, the operational efficiency, and the risk prevention into consideration at the same time (Guangcheng Zhu, 2007, p46). 


\section{Problems in Chinese commercial banks' innovation}

In China the financial innovation has started from the implementation of reform and opening-up policy. After twenty years, it has realized marvelous achievements, constructing a general central banking system, completing the institutional fame, forming a banking system that takes four state-owned commercial banks and more than ten stock commercial banks as the main body, and completing a financial corporate system in which multiple ownership structure and multiple financial institutions coexist. Meanwhile, loosen the market entrance standards for foreign bank branches and insurance industry, building an exchange market, and speeding up the opening-up process.

However, by reviewing China's financial innovation, we can find that there are four main problems.

Firstly, financial innovation lags behind economic development. The finance can not catch up with the development of economy, which results in that former regulations and system can not meet new conditions. After China's entry to WTO, few researches probe into new financial products. Systematic innovations lag behind. A so-called vacuum brand appears (Le Fu \& Xianning Zeng, 2007, p78-79).

Secondly, financial tools are few. Presently, more innovations are for debts but less for assets. China's financial institutions focus on debts as they make innovations before. Because the loans operate in a seller market, where the competition is not so serious, financial institutions have no sufficient internal motivations and external pressures for innovations. The few financial tools and narrow financing channels lead to higher debts for enterprises and more pressures for banks.

Thirdly, information technology lags behind and fails to match up with financial innovation. As information network technology has been applied to the banking fields, China's commercial banks depend on information technology more and more. However, presently China's computer network technology can not catch up with world latest level. Commercial banks can not offer comprehensive electric information services for customers. Besides, banks' financial innovations can not cooperate with information technology well. It lacks a deepening data analysis marketing system (Ling Xiong, 2007, p65-66).

Fourthly, the personnel are not qualified due to the short of innovative consciousness and ability.

\section{Risks for Chinese commercial banks' innovation}

The blindness of financial innovation brings about risks. After the WTO entry, China speeds up the process of financial opening-up. In order to pursue for fast development, it is possible for the blindness of financial innovation, which may lead to uncertainty risks. At present, foreign banks' financial innovations focus on derivatives, financial futures, and financial business. China's financial industry lags behind foreign banks in many aspects, especially at the operational level. If introduce foreign banks' business mode, business way, and financial products blindly, it may exert negative effects on the innovation of China's grass-roots financial institutions, causing new financial risks, and affecting the steady operation and development of grass-roots financial institutions. In China, financial innovation is still at the imitation stage that does not care about profits. The popular joint insurance products have been stopped now, what means insurance companies could not estimate the risks and profits of these products precisely. As a matter of fact, these series of innovations are mainly from imitating foreign products simply. It may produce greater risks (Hongwei Zhang, 2006, p56-58).

Insufficient scientific and technological innovation generates electric risks. Today China's financial network develops well. Electric associated banks, payment and liquidity system, and bank credit register and consultant system begin to work mostly. But compared with foreign commercial banks' network construction, it still lags behind. Especially for online banks and telephone banks, there are greater potentials. In China, the development of capital market in some areas is imperfect. The internal management structure of financial institutions needs to be perfected further. And the equipped system, laws, and regulations are not perfect. Scientific and technological development may face higher risks in some areas. On one hand, computers may fail to operate properly objectively. On the other hand, crimes may take advantages over computers. Electric risks are systematic, concerning a large sum of money. Once there is an electric risk, the financial institution or even the whole financial industry may fall into a threat.

Unqualified personnel may bring about risks. Many factors contribute to the innovation risks. One of most important factor is the personnel. Today China lacks comprehensive talents who are familiarized with business and management, which causes a low development of financial institutions and poor innovation abilities. The potential risks are huge. It is impossible to guarantee the practical effect of financial innovation.

\section{Measures for reducing risks for Chinese commercial banks' independent innovation}

At present, it is an urgent to strengthen commercial banks' innovation risks management, guaranteeing the stable development of banks. In the innovation process, it is better to balance the market risks, the liquidity risks, and the credit risks. In the market risks aspect, shorten the combination term of monetary bonds, decrease the estimation value losses, and make best use of financial derivatives management transaction and non-transaction exchange risks. In the 
liquidity risks management aspect, pay more attention to and manage assets-liabilities term effectively, and exert the effects of currency swap on commercial banks' exchange businesses. In the credit risks management aspect, control the sum of loans, optimize the credit-loan structure, and enhance the risks supervision and entrance-exit mechanism.

Financial regulation and supervision is to implement restrictions on financial institutions' operations, prices of capitals, market entrance, and branches by legislation and management rules, aiming at stabilizing the whole financial system and insuring the safety of financial institutions' operations. Effective financial regulation and supervision can maintain credits, guarantee the stability of payment system, protect investors' interests, and driving the faire competition among financial institutions (Kunlin Zhu, 2009, p64-65).

\subsection{Strengthen the exterior financial regulation and supervision}

(1) Build and perfect the law support system for financial regulation and supervision. The effective operation of financial innovation and financial supervision should be guaranteed by perfect and transparent financial law system. Besides, it needs a set complete equipped implementation rules.

(2) Apply a strict market entrance system. The market entrance supervision is a powerful defense for preventing financial innovation risks. For the register and approval of financial innovation tools, trade institutions, exchange membership, and brokers, it is necessary to execute strict examination. Control financial innovation risks and guarantee the positive development of financial market.

(3) Build the financial innovation risks pre-warning system. By learning developed countries' successful experiences in reducing financial innovation risks, considering the practical conditions and risks features of finance industry in China, build a risks pre-warning system that is right for China's financial innovation.

\subsection{Strengthen the internal financial regulation and supervision}

(1) Build and perfect the internal control system for innovative financial tools trade. Establish the responsibilities and rights of innovative financial tools' participators. Build an information system to supervise, control, and manage the trade risks. Execute a comprehensive internal control and check. Exert the internal supervision function effectively.

(2) The financial innovation subject can determine the proportion of off-balance sheet business to total assets based on self scale, capitals, and capabilities. Control the off-balance sheet position. Enhance the statistical calculation and check on the off-balance sheet business. Once find problems in off-balance sheet business, manage it effectively and properly.

(3) Strengthen the management of outside branches. Establish the business scope and approval limits of foreign branches.

(4) Concerning the organizational arrangement, set up an independent risks management department, separating business innovation from risks management and decision properly, and achieving a balance.

\section{References}

Fu, Le \& Zeng, Xianning. (2007). Probe into the present conditions and future development of Chinese financial innovation. Enterprise Economy, No.10, p. 78-79.

$\mathrm{Hu}$, Qingkang. (2006). Modern Money and Banking. Shanghai: Fudan University Press. P. 108.

Xiong, Ling. (2007). On problems and countermeasures for Chinese financial innovation. Commercial Culture, No.5, p.65-66.

Zhang, Hongwei. (2006). Thoughts on strategies of dealing with financial innovation risks. Financial Theory and Practice, No.11, p. 56-58.

Zhu, Guangcheng. (2007). Chinese commercial banks' financial innovation and risk prevention. Market Modernization, No.3, p. 46.

Zhu, Kunlin. (2009). China's financial innovation risks and the prevention. Commercial Times, No.7, p. 64-65. 


\title{
An Empirical Assessment of Hotel Departmental Managers
}

\section{Turnover Intentions: The Impact of Organizational Justice}

\author{
Salleh Mohd Radzi, Siti Zuraini Alan Ramley, Mohd Salehuddin, Zulhan Othman \& Mohd Hairi Jalis \\ Faculty of Hotel \& Tourism Management, Universiti Teknologi MARA (UiTM) \\ Malaysia \\ E-mail: mohdsa02@salam.uitm.edu.my
}

\begin{abstract}
This paper investigates the relationship between organizational justice (OJ) and turnover intentions (TI) among the lower and middle-level hotel departmental managers. Organizational justice, comprising three-dimensional measures of distributive justice (DJ), procedural justice (PJ), and interactional justice (IJ) was measured through inferential statistics. Distributive justice and procedural justice had a significant negative effect on managers' turnover intentions while interactional justice did not support the proposed relationship. The perceptions of fairness of reward allocation and procedure received in organizations prompt the lower and middle hotel departmental managers to reciprocate their turnover intention behaviour. These research findings offer some insight for the hotel top management into how to prevent their valuable managers from leaving the organization.
\end{abstract}

Keywords: Organizational justice, Distributive justice, Procedural justice, Interactional Justice, Turnover intentions

\section{Introduction}

Most of the academic scholars share a common view on turnover intention (Hellman, 1997; Hom and Griffeth, 1995; Griffeth, Hom \& Geatner, 2000; Price, 2001. It generally refers to an individual's perceived probability of leaving an employing organization, or the willingness of an individual to voluntarily permanently withdraw from the organization. Empirical studies have shown that turnover intentions are the best immediate predictor of actual turnover behaviour (Griffeth, Hom \& Geatner, 2000; Price, 2001; Hemdi, 2006; Samad, 2006). There is, in fact a strong and significant positive relationship between turnover intentions and the actual turnover (Lambert, Hogan, \& Barton, 2001; Mor Barak, Nissly, \& Levin, 2001; Price; 2001; Samad, 2006). This relationship supports the attitude-behavior theory, which holds that an individual's intention to perform a specific behaviour is the immediate determinant of the actual behaviour (Ajzen \& Fishbein, 1980). Mor Barak et al. (2001) and Price, (2001) noted that many studies have used turnover intentions as a proxy in measuring actual turnover.

One of many reasons that cause an individual turnover intention is closely related to organizational justice which denotes the fairness and evaluation of treatment received by an individual in the organization (Cropanzano \& Greenberg, 1997). It is, in other words, associated with the ways in which employees determine whether they have been treated fairly in their jobs or other work-related outcomes (Moorman, 1991). Considerable attention has been devoted to the dimensionality of organizational justice, leading to the conclusion that employees distinguish three forms of justice (Niehoff and Moorman, 1993) (1) distributive justice (fairness of the outcomes that the employee receives); (2) procedural justice (fairness of the procedures used to determine those outcome allocation decisions) and(3) interactional justice (fairness of communications or interpersonal treatment that accompanies an organization's formal procedures).

Distributive justice refers to the employees' perception of fairness in the workplace by comparing their inputs/outcomes received from the organization (Niehoof \& Moorman, 1993). Greenberg (2001) said distributive justice highlights the employees' response to the fairness of the treatment or distribution of rewards such as pay, promotions, bonuses, job security and layoffs received from the organization. Distributive justice may also be important in predicting personal-level outcomes such as pay satisfaction (Linda \& Ping, 1996; Sweeney \& McFarlin, 1993), job satisfaction (Samad, 2006; Yusof \& Shamsuri, 2006) and to have a significant negative influence on turnover intentions (Aryee \& Chay, 2001; Dailey \& Kirk, 1992; Lee, 2000; Loi, Ngo, \& Foley, 2006). Procedural justice on the other hand reflects the extent to which employees perceive that the outcome allocation decisions were fairly made in relation to the 
organization's formal procedures and treatment given in enacting those procedures (Moorman, 1991). These procedures not only offer employees control over the outcomes they received but ensure those outcomes are fair. Roch and Shanock (2006) argued that procedural justice consisted of procedures associated with determining promotion, terminations, performance ratings, bonuses or any valued items that organizations make available. In turn, fair procedures can bring benefits to organizations in the form of effective job behaviours and positive work attitudes (Cohen-Charash and Spector, 2001). Past research evidence has revealed that procedural justice may have strong effects on employees' attitudes (Khatri, et al., 2001; Samad, 2006; Tremblay, Sire, \& Balkin, 2000; Yusof \& Shamsuri, 2006). Tremlay et al (2000) noted that procedural justice would result in stronger attachment to the organization, particularly for those who experience being respected by the organization. Loi et al (2006) proved that there is a strong positive relationship between procedural justice and effective commitment and this is significantly related to turnover intentions (Khatri et al., 2001; Dailey \& Kirk, 1992). Interactional justice, on the other hand, refers to the fairness the employees' perceive when they have been communicated with in a sensitive and respectful manner and are treated with courtesy and dignity in their organizational practices (Cohen-Charash \& Spector, 2001). Interactional justice has been commonly associated with personal-level outcomes such as supervisory relationships (Cropanzano, Prehar, \& Chen, 2002), organizational citizenship behaviour (Niehoof \& Moorman, 1993), job satisfaction (Masterson, Lewis, Goldman, \& Taylor, 2000), and job performance (Cropanzano et al., 2002).

The above explanation clearly indicated that the three dimensions of organizational justice have an influence on employees' work attitudes and behaviours (Colquitt, Conlon, Wesson, Porter, \& Ng, 2001; Kernan \& Hanges, 2002; Shaw, Wild, \& Colquitt, 2003). They act as a predictor of turnover intentions and have received significant attention among the researchers in various organizations including hotels (Aryee \& Chay, 2001; Khatri et al., 2001; Loi et al., 2006 Carbery et al., 2003; Hinkin \& Tracy, 2000; Lam et al., 2001; Pizam \& Thornburg, 2000). Despite this, studies of the predictors of turnover intentions within the hotel organization have mainly been conducted in the western world (Carbery et al., 2003; Hinkin \& Tracy, 2000; Lam et al., 2001; Pizam \& Thornburg, 2000) with very limited analyses carried out in Malaysian hotels. Previous studies merely focused on the operational hotel employees (Hemdi, 2006; Khalid, 2006) (Hemdi, 2006; Hemdi \& Nasurdin, 2003) with no attempt made to study operational departmental managers' behavioural intentions. Because of that gap, this study investigates the relationship between organizational justice and turnover intentions among the lower and middle-level hotel managers in the Malaysian hotel setting. In other words, the extent to which the operational departmental hotel managers' perceptions of organizational justice influence their behavioral intentions to leave the organization is investigated. The criterion variable of interest is "turnover intentions" and the predictor variable is the "organizational justice dimensions" (Distributive Justice (DJ), Procedural Justice (PJ) and Interactional Justice (IJ). The theoretical framework is illustrated in Figure 1and this is followed by the main and sub- hypotheses of the study.

\section{H1: There is a negative relationship between perceptions of organizational justice and turnover intentions.}

Hla: There is a negative relationship between perceptions of distributive justice and turnover intentions.

$H 1 b$ : There is a negative relationship between perceptions of procedural justice and turnover intentions.

H1c: There is a negative relationship between perceptions of interactional justice and turnover intentions.

\section{Methodology}

\subsection{Instrument}

For the instrument, the predictor variable of organizational justice (OJ) was measured using a 25 items scale developed by Niehoof and Moorman (1993). The justice scale consists of three dimensions measuring perceptions of distributive justice (DJ) with 5 items, procedural justice (PJ) 6 items and interactional justice (IJ) with 9 items respectively. The criterion variable, turnover intentions (TI) was measured via a 5-item scale adapted from Hom and Griffeth (1995). Responses to all items were made on a 7-point Likert scale ranging from (1) "Strongly Disagree" to (7) "Strongly Agree”. In addition, respondents' demographic profiles such as age, gender, marital status, ethnicity, educational level, job position, tenure and turnover experience using nominal scales were also asked.

\subsection{Samples and Data Collection Process}

Participants for this study consisted of lower (supervisor) and middle-level departmental hotel managers (line/outlet managers). Thirty medium-sized hotels ( $3 \& 4$-stars) located in the Klang Valley, Kuala Lumpur were identified from the Malaysian Accommodation Directory published by the Malaysian Tourism Promotional Board. The Klang Valley of Kuala Lumpur area was chosen due to its having the highest distribution of medium-sized hotels in the country. As the survey was not under the researcher's supervision, the cooperation of the human resource manager from each participating hotel was sought for distribution of the instrument. The human resource managers were briefed to randomly distribute the questionnaires to the managers in two major operating departments; the room department (front office and housekeeping) and the food and beverage department (production and service). A total of 600 questionnaires (in mini booklet form) were sent to the respective hotel human resource managers. Respondents were given two weeks 
to complete the questionnaire and return it to their human resource department. The completed questionnaires were returned directly to the researcher by the respective human resource managers via mail. In total, $281(47 \%)$ questionnaires were received. After reviewing the collected questionnaires, 27 were found unusable, 14 were answered by accounting, human resources, sales and marketing staff, while 13 came from operational employees. The 254 (42\%) usable questionnaires were then coded for analyses.

\section{Analyses and results}

\subsection{Respondents' Profiles}

The sample profiles have been analyzed and results are tabulated in Table 1. As can be seen from the table, the sample comprised $68.9 \%(\mathrm{n}=175)$ of male managers compared to $31.1 \%(\mathrm{n}=79)$ of female managers. The age range was between 20 to 51 years with a mean age of 32.3 years. $52.0 \%(\mathrm{n}=132)$ were married compared to $42.5 \%$ ( $\mathrm{n}=108$ who were single, divorced and $0.4 \%(\mathrm{n}=1)$ widowed. It was found that $50.8 \%(\mathrm{n}=129)$ of the managers had obtained a diploma qualification, 21.3\% $(\mathrm{n}=54)$ had the Malaysian Higher Certificate of Education or the Malaysian Certificate of Education, $16.5 \%(n=42)$ had a Bachelor's Degree and 11.4\% $(n=11)$ possessed their certificate qualification. As for organizational tenure, $1.6 \%(\mathrm{n}=4)$ of managers had less than 6 months working experience in their current hotel, $16.7 \%$ $(n=17)$ had worked between 6 months and 1 year, 33.1\% $(n=84)$ had worked between 2 and 3 years, while 23.2\% $(n=59)$ had worked between 4 and 5 years, and the remaining $35.4 \%(n=90)$ had worked more than 5 years in their current hotel.

\subsection{Confirmatory Factor Analysis of the Study Variables}

Prior to hypotheses testing, the assessment of confirmatory factor analysis (CFA), using a covariance matrix (LISREL 8.80) was undertaken. This test is to confirm a pre-specified relationship and to evaluate the distinctiveness of the measures used. As previously mentioned, 25 items were used to tap the respondents' feelings. Five items reflected organizational justice, six items measured procedural justice, nine items related to interactional justice and five items measured turnover intentions.

Table 2 depicts the iteration process that took place in achieving the perfect-fit model of the organizational justice and turnover intentions construct. As can be seen, the initial model of distributive justice had a perfect fit and no additional modification was required $(\mathrm{GFI}=1.00, \mathrm{RMSEA}=0.000)$ while the initial model of procedural justice indicated an acceptable GFI. Nevertheless, the RMSEA was high indicating a possibility of improvement to the measurement model $(\mathrm{GFI}=.86$, RMSEA $=0.225)$. Jöreskog and Sörbom (2006) suggested that only one item can be altered at a time to avoid excessive model modification and this iterative process continued until the model parameters and key fit indices met the recommended criteria. Iteration 1 was then carried out by dropping item PJ1 since the $\mathrm{R}^{2}$ value was the lowest $\left(\mathrm{R}^{2}=0.19\right)$, and the result showed that the RMSEA value did not improve. Item PJ2 was subsequently dropped in iteration 2 owing to the low $R^{2}$ value $\left(R^{2}=0.38\right)$, and the model showed a significant improvement with a perfect model fit $(\mathrm{GFI}=1.00, \mathrm{RMSEA}=0.000)$.

Similarly, the initial model of interactional justice had the acceptable GFI of 0.74 , but a relatively high RMSEA of 0.235 . The model however presented a perfect fit $(\mathrm{GFI}=0.98, \mathrm{RMSEA}=0.010)$ after iteration when item IJ4 was dropped owing to the lowest $R^{2}$ value $\left(R^{2}=0.30\right)$. On the turnover intentions construct, the initial model had a poor fit with an acceptable GFI of 0.94 and a considerably high RMSEA of 0.159 . Item TI1 was then dropped in iteration 1 owing to lowest $\mathrm{R}^{2}$ value $\left(\mathrm{R}^{2}=0.33\right)$ and the result finally showed a perfect model fit $(\mathrm{GFI}=1.00$, RMSEA $=0.000)$.

Consequently, 3 items (PJ1, PJ2, and IJ4) were eliminated from the organizational justice constructs and 1 item (TI1) from the turnover intentions construct, and the final constructs comprised 21 items, 17 items measuring the respondents' perceptions of organizational justice and 4 items measuring turnover intentions. This can clearly be seen in Table 3.

\subsection{Reliability and Validity Analysis}

After the evaluation of the model, the measurements of each construct were assessed for their reliability and validity. The reliability coefficient for each measure was examined by computing the Cronbach's alpha values. The items included in the test are based on the results of confirmatory factor analysis. As shown in Table 4, the reliability of the organizational justice dimensions of distributive justice, procedural justice and interactional justice were $.89, .83$, and .93 respectively. The dependent variable of turnover intentions had an excellent reliability coefficient of .91. With that, the internal consistency of all study variables was considered high and acceptable.

The validity of the instruments, particularly construct validity was assessed. Unidimensionality analysis was carried out by identifying the measurement model for each construct. A comparative fit index (CFI) value for the study variables exceeded .90 for the model which indicated strong evidence for unidimensionality. In addition, convergent validity using normed fit index (NFI) was also assessed. All scales had an NFI value ranging from .90 to 1.00 which implies a reasonably strong indication of convergent validity. The CFI and NFI values for all scales are summarized in Table 4. 


\subsection{Descriptive Statistics}

The descriptive statistics and the correlation among the study variables (predictor and criterion variable) are shown in Table 5 .

The respondents' perceptions of organizational justice were found to be relatively high; distributive justice $(M=5.23$, $S D=1.05)$, procedural justice $(M=5.39, S D=.89)$, and interactional justice $(M=5.54, S D=.79)$. The level of turnover intentions experienced by the respondents was relatively low $(M=2.85, S D=1.64)$. As depicted, all study variables were significantly intercorrelated. Correlations among organizational justice dimensions were significantly large, ranging from $r=.68(p<0.01)$ to $r=.83(p<0.01)$. Accordingly, the correlations between distributive justice and procedural justice were $(r=.68, p<0.01)$, interactional justice $(r=.72, p<0.01)$, and between procedural justice and interactional justice $(r=.83, p<0.01)$. The correlations between organizational justice dimensions and turnover intentions were negative and significant ranging from $r=-.43(p<0.01)$ to $r=-.58$, $(p<0.01)$. Distributive justice had a much stronger correlation with turnover intentions compared to procedural justice and interactional justice. From the results, it can be said that no serious multicollinearity exists among the study variables as the strength of the correlations was all below .90 .

\subsection{Hypothesis Testing}

A two-step hierarchical regression was conducted to assess the relationship between three dimensional measures of organizational justice and turnover intentions. The five demographic variables (age, gender, marital status, education level and organizational tenure) were statistically controlled and entered into the first step of the regression equation. In the second step, all three model variables of organizational justice were entered. Table 6 summarized the results.

As can be observed from Table 7, the control variables managed to explain $7.0 \%$ of the variance in turnover intentions $\left(R^{2}=.07, F\right.$-Change $\left.=3.49, p<0.01\right)$. Of the five control variables, only respondents' gender $(\beta=.19, p<0.01)$ and organizational tenure $(\beta=.21, p<0.01)$ were significantly related to turnover intentions. Adding the three model variables of organizational justice, the $R^{2}$ increased to .45 . This indicated that organizational justice was able to explain an additional 38\% $\left(R^{2}\right.$ Change $\left.=.38, p<0.01\right)$ of the observed variations in turnover intentions and the effects of demographic variables. Of the three organizational justice dimensions, only two dimensions namely distributive justice and procedural justice significantly and negatively predicted turnover intentions. Indeed, distributive justice had the most impact on the prediction of turnover intentions $(\beta=-.56, p<0.01)$, followed by procedural justice $(\beta=-.26, p$ $<0.01)$. In other words, distributive justice was found to be more influential in explaining the variation in turnover intentions. Conversely, the interactional justice dimension $(\mathrm{H} 1 \mathrm{c})$ had no significant relationship with turnover intentions. In sum, these findings only support $\mathrm{H} 1 \mathrm{a}$ and $\mathrm{H} 1 \mathrm{~b}$. Thus, the hypothesis is partially supported.

\section{Discussion}

As hypothesized, distributive justice has a significant negative influence on turnover intentions. This result is consistent with the findings of Aryee \& Chay (2001) and Lee (2000). What could be said from this result is that if the managers feel contented with what they receive compared to those of a referent other, they are more likely to be productive and remain with the organization. In fact, managers who perceived fair prospects of different work outcomes, particularly relating to pay satisfaction, work schedule, workload, rewards, and job responsibilities may view their current organization favourably and might not see outside alternatives as attractive. Therefore they are less likely to have the intention to leave their current organization. Similarly, as hypothesized procedural justice appeared to significantly and negatively predict turnover intentions. This finding is congruent with that of Khatri et al. (2001). This indicates that high perceptions of fairness of the formal decision-making procedures would influence the managers to stay in the organization. In other words, managers are less likely to experience turnover intention if they received, or were provided with fair and consistent organization policies and practices related to procedure, such as determining promotion, termination, performance ratings, bonuses or any values the organization makes available. In fact, many commentators argued that fair procedures can bring benefits to the organization in the form of effective job behaviours and positive work attitudes.

Besides the above findings, interactional justice was found to have an insignificant relationship with turnover intentions. This was contrary to the recent work of Hubbell and Chory-Assad (2005), who found that if managers' perceived fairness and quality of communication as being received in their organization, they were less likely to leave the organization. One possible explanation for this finding is that managers in this study sample may have perceived the interpersonal treatment that they received to be unfair (e.g. they were treated with dishonesty and disrespect) and, in turn, they progressively seek more options of better job positions through the external labour market. In other words, as the external labour market becomes more attractive, managers tend to engage more in job-search behaviours, thus increasing intentions to leave the organization. In other words, there may be a lack of interpersonal relationships between the lower and middle managers and the top management. Departmental hotel managers in this study may have less interaction with the top management, since according to their job descriptions they are performing more operational 
tasks rather than management decisions (Dittmer, 2002). In addition, the "culture" or the "nature" of human beings to continually seeking job promotion and job security could be one of the reasons to leave the organization as reported by Iverson and Deery (1997). Despite this, the overall findings of this study support most of the previous similar studies, although undertaken in different settings or industries.

\section{Conclusion}

Based on the aforementioned discussion, it clearly proven that the perception of fairness of reward allocations and procedures received in the organization prompts the lower and middle departmental hotel managers to reciprocate with their behavioural intentions. Thus, it is logical to predict that when managers perceive that they are treated fairly in terms of outcome and procedures; they tend to stay in their current organization and do not have the intention to seek a fairer alternative. Conversely, if they perceived the interpersonal treatment received to be unfair the intention of leaving or seeking an alternative is higher. The relevant hotel authorities concerned with reducing turnover intentions among their lower and middle departmental managers therefore should realize and be consistent, and focus their attention on providing to at least a decent amount of fairness in terms of reward allocation, formal procedures, and interpersonal treatment. By considering these, the likelihood of quitting or leaving among the lower and middle managers can slowly be reduced.

Some recommendations for future research could be made from this study. First, the use of a larger sample within the same industry, or from other industries would improve the generalizability of the findings. Second, given that there may be other organizational factors (e.g. psychological contract violation, organizational politics etc.) that influence managers' turnover intentions, these factors therefore could also be used to predict the hotel managers' turnover intentions. Finally, given the better ability to prove a cause- effect relationship between the predictor variables and the criterion variables, the experimental or longitudinal approach could be used instead of the cross sectional approach.

\section{References}

Aryee, S., \& Chay, Y.W. (2001). Workplace justice, citizenship behavior, and turnover intentions in a union context: examining the mediating role of perceived union support and union instrumentality. Journal of Applied Psychology, 86 (1), pp. 154-160.

Ajzen, I., \& Fishbein, M. (1980). Understanding Attitudes and Predicting Social Behavior. Englewood Cliffs, NJ: Prentice-Hall, Inc.

Birdir, K. (2002). General manager turnover and root causes. International Journal of Contemporary Hospitality Management, 14 (1), pp. 43-47.

Carbery, R., Garavan, T. N., O' Brien, F., \& McDonnell, J. (2003). Predicting hotel managers' turnover cognitions. Journal of Managerial Psychology, 18 (7), pp. 649-679.

Cohen-Charash, Y., \& Spector, P. E. (2001). The role of justice in organization: a meta-analysis. Organizational Behavior and Human Decision Processes, 86 (8), pp. 278-321.

Colquitt, J. A., Conlon, D. E., Wesson, M. J., Porter, C. O. L. H., \& Ng, K. Y. (2001). Justice at the millennium: a meta analysis review of 25 years of organizational research. Journal of Applied Psychology, 8 (6), pp. 425-455.

Cropanzano, R., \& Greenberg, J. (1997). Progress in organizational justice: tunneling through the maze. International Review of Industrial and Organizational Psychology, 12 (11), pp. 317-372.

Cropanzano, R., Prehar, C. A., \& Chen, P. Y. (2002). Using social exchange theory to distinguish procedural from interactional justice. Group and Organizational Management, 27 (3), pp. 324-351.

Dailey, R. C., \& Kirk, D. J. (1992). Distributive and procedural justice as antecedents of job satisfaction and intent to turnover. Human Relations, 45 (3), pp. 305-317.

Dittmer, P. R. (2002). Dimensions of the Hospitality Industry. $3^{\text {rd }}$. Ed., New York: John Wiley \& Sons.

Greenberg, J. (2001). Studying organizational justice cross-culturally: fundamental challenges. The International Journal of Conflict Management, 12 (4), pp. 365-375.

Griffeth, R. W., Hom, P. W., \& Geatner, S. (2000). A meta-analysis of antecedents and correlates of employee turnover: update, moderator tests, and research implications for the next millennium. Journal of Management, 26 (3), pp. 463-489.

Hellman, C. M. (1997). Job satisfaction and intent to leave. Journal of Social Psychology, 137 (6), pp. 667-689.

Hemdi, M. A. (2006). Turnover intentions of hotel employees: the role of human resource management practices, trust in organization, and affective commitment. (Unpublished PHD thesis, Penang: Universiti Sains Malaysia). 
Hemdi, M. A., Nasurdin, A. M, \& Ramayah, T. (2003). Motivational preferences of hotel employees: implications for managers. Proceeding of the National Human Resources Development Conference (HRDC2003), 217-226, Sarawak: Malaysia.

Hinkin, T., \& Tracey, B. (2000). The cost of turnover: putting the price learning curve. Cornell Hotel and Restaurant Administration Quarterly, 2 (1), pp. 14-21.

Hom, P. W., \& Griffeth, R. W. (1995). Employee Turnover. South Western College Publishing, Cincinnati, OH.

Hubbell, A. P., \& Chory-Assad, R. M. (2005). Motivating factors: perceptions of justice and their relationship with managerial and organizational trust. Communication Studies, 56 (1) pp. 47-70.

Iverson, R. D., \& Deery, M. (1997). Turnover culture in the hospitality industry. Human Resource Management Journal, 17 (4), pp. 71-82.

Khalid, S. A. (2006). Organizational citizenship behavior, turnover intention, and absenteeism among hotel employees. Malaysian Management Review, 41 (1), pp. 157-161.

Kernan, M. C., \& Hanges, P. J. (2002). Survivor reactions to reorganization: antecedents and consequences of procedural, interpersonal, and informational justice. Journal of Applied Psychology, 88 (7), pp. 764-773.

Khatri, N., Fern, C. T., \& Budhwar, P. (2001). Explaining employee turnover in an Asian context. Human Resource Management Journal, 11 (1), pp. 54-74.

Lam, T., Zhang, H., \& Baum, T. (2001). An investigation of employees' job satisfaction: the case of hotels in Hong Kong. Tourism Management, 22 (5), pp. 157-165.

Lambert, E. G., Hogan, N. L., \& Barton, S. M. (2001). The impact of job satisfaction on turnover intention: a test of a structural measurement model using a national sample of workers. The Social Science Journal, 38 (7), pp. 233-250.

Lee, H. R. (2000). An empirical study of organizational justice as mediator of the relationship among leader-member exchange and job satisfaction, organizational commitment and turnover intentions in the lodging industry. Published PHD Thesis, Virginia Polytechnic Institute and State University.

Linda, S. B., \& Ping, T. T. L. (1996). Distributive and procedural justice as related to satisfaction and commitment. Advanced Management Journal, 61 (3), pp. 25-37.

Loi, R., Ngo, H. Y., \& Foley, S. (2006). Linking employees' justice perceptions to organizational commitment and intention to leave: the mediating role of perceived organizational support. Journal of Occupational and Organizational Psychological, 79 (12), pp. 101-120.

Masterson, S. S., Lewis, K., Goldman, B. M., \& Taylor, M .S. (2000). Integrating justice and social exchange: the differing effects of fair procedures and treatment on work relationships. Academy of Management Journal, 45 (11), pp. 738-748.

Moorman, R. H. (1991). Relationship between organizational justice and organizational citizenship behaviors: do fairness perceptions influence employee citizenship? Journal of Applied Psychology, 76 (6), pp. 845-855.

Mor Barak, M. E., Nissly, J. A., \& Levin, A. (2001). Antecedents to retention and turnover among child welfare, social work, and other human service employees: what can we learn from past research? A review and meta analysis. The Social Service Review, 75 (4), pp. 625-661.

Nathan, C. (1998). Effect of the interaction of job involvement and organizational commitment of engineers' intention to leave their organization. Unpublished MBA thesis, Penang: Universiti Sains Malaysia.

Niehoff \& Moorman (1993). "Justice as a mediator of the relationship between methods of mentoring and organizational citizenship behavior". Academy of Management Journal, 36 (3), pp. 527-55.

Pizam, A., \& Thornburg, S. W. (2000). Absenteeism and voluntary turnover in Central Florida hotels: a pilot study. International Journal of Hospitality Management, 19 (2), pp. 211-217.

Price, J. L. (2001). Reflections on the determinants of voluntary turnover. International Journal of Manpower, 22 (7), pp. 600-624.

Samad, S. (2006). Predicting turnover intentions: the case of Malaysian government doctors. Journal of American Academy of Business, 8 (2), pp. 113-119.

Samad, S. (2006). Procedural and distributive justice: differential effects on employees' work outcomes. The Business Review, Cambridge, 5 (2), pp. 212-218.

Shaw, J. C., Wild, E., \& Colquitt, J. A. (2003). To justify or excuse? A meta-analytic review of the effects of explanations. Journal of Applied Psychology, 88 (3), pp. 444-458. 
Sweeney, P. D., \& McFarlin, D. B. (1993). Workers evaluations of the 'ends' and the 'means': an examination of four models of distributive and procedural justice. Organizational Behavior and Human Decision Processes, 55 (3), pp. 23-40.

Tremblay, M., Sire, B., \& Balkin, D. B. (2000). The role of organizational justice in pay and employee benefit satisfaction and its effect on work attitudes. Group and Organization Management, 25 (3), pp. 269-290.

Yusoff, A. A., \& Shamsuri, N. A. (2006). Organizational justice as a determinant of job satisfaction and organizational commitment. Malaysian Management Review, 41 (1), pp. 12-21

Zikmund, W. G. (2003). Business Research Methods ( $7^{\text {th }}$ Ed.). Ohio: South-West

Table 1. Respondents' Profiles

\begin{tabular}{|c|c|c|c|}
\hline Demographic Variables & Categories & Frequencies & Percentage (\%) \\
\hline \multirow[t]{2}{*}{ Gender } & Male & 175 & 68.9 \\
\hline & Female & 79 & 31.1 \\
\hline \multirow[t]{4}{*}{ Marital Status } & Single & 108 & 42.5 \\
\hline & Married & 132 & 52.0 \\
\hline & Widower/Widow & 1 & 0.4 \\
\hline & Divorced & 13 & 5.1 \\
\hline \multirow[t]{4}{*}{ Education Level } & SPM/STPM & 54 & 21.3 \\
\hline & Certificate & 29 & 11.4 \\
\hline & Diploma & 129 & 50.8 \\
\hline & Bachelor's Degree & 42 & 16.5 \\
\hline \multirow[t]{6}{*}{ Organizational Tenure } & Less than 6 months & 4 & 1.6 \\
\hline & 6 months -1 year & 17 & 6.7 \\
\hline & $2-3$ years & 84 & 33.1 \\
\hline & $4-5$ years & 59 & 23.2 \\
\hline & More than 5 years & 90 & 35.4 \\
\hline & Mean & Min. & Max. \\
\hline Age (Years) & 32.27 & 20 & 51 \\
\hline
\end{tabular}


Table 2. Description of the Modification Process of Unidimensionality and Convergent Validity of the Organizational Justice and Turnover Intentions Factors

\begin{tabular}{|cccc|}
\hline & Items & GFI & RMSEA \\
\hline $\begin{array}{c}\text { Initial Model of } \\
\text { Distributive Justice }\end{array}$ & DJ1, DJ2, DJ3, DJ4, DJ5 & 1.00 & 0.000 \\
\hline $\begin{array}{c}\text { Initial Model of } \\
\text { Procedural Justice }\end{array}$ & PJ1, PJ2, PJ3, PJ4, PJ5, PJ6 & 0.86 & 0.225 \\
\hline$\quad$ Iteration 1 & PJ2, PJ3, PJ4, PJ5, PJ6 & 0.90 & 0.227 \\
\hline Iteration 2 & PJ3, PJ4, PJ5, PJ6 & 1.00 & 0.000 \\
\hline $\begin{array}{c}\text { Initial Model of } \\
\text { Interactional Justice }\end{array}$ & $\begin{array}{c}\text { IJ1, IJ2, IJ3, IJ4, IJ5, IJ6, } \\
\text { IJ7, IJ8, IJ9 }\end{array}$ & 0.74 & 0.235 \\
\hline $0 \quad$ Iteration 1 & IJ1, IJ2, IJ3, IJ5, IJ6, IJ7, & 0.98 & 0.010 \\
\hline IJ8, IJ9 & 0.94 & 0.159 \\
\hline $\begin{array}{c}\text { Initial Model of } \\
\text { Turnover Intentions }\end{array}$ & TI1, TI2, TI3, TI4, TI5 & 0.000 \\
\hline $\begin{array}{l}\text { Itteration 1 } \\
\text { TI2, TI3, TI4, TI5 }\end{array}$ & 1.00 & \\
\hline
\end{tabular}


Table 3. Organizational Justice-Turnover Intentions
Abbreviated Label
Actual Scale Item

\section{Organizational Justice Items}

Distributive Justice
- DJ1
- DJ2
- DJ3
- DJ4
- DJ5

Procedural Justice
- PJ3
- PJ4
6 PJ5
- PJ6

Interactional Justice
- IJ1
- IJ2
- IJ3
- IJ5
- IJ6
- $\quad \mathrm{IJ} 7$
- IJ8
- IJ9
$\mathrm{J} 1$
3
J9

Fair work schedule

Fair pay level

Fair workload

Fair rewards

Fair job responsibilities
Clarifies decisions and provides additional information

Consistent job decisions

Can challenge or appeal job decisions
Treated with kindness and consideration Sensitive to personal needs
Concerned with employee rights

Discusses the implications of job decisions Adequate justification for job decisions Sensible explanations of job decisions Clear explanations of job decisions

Treated with respect and dignity

$\begin{array}{rr}\text { Turnover Intention } \\ \boldsymbol{\bullet} & \mathrm{TI} 2 \\ \boldsymbol{\bullet} & \mathrm{TI} 3 \\ \boldsymbol{\bullet} & \mathrm{TI} 4 \\ \boldsymbol{\bullet} & \mathrm{TI} 5\end{array}$

Plan to leave as soon as possible Actively look for a new job next year

Often think of quitting current job

Leave as soon as can find a better job 
Table 4. Unidimensionality and Reliability Indices for the Study Variables

\begin{tabular}{|c|c|c|c|c|c|c|}
\hline Variables & $\begin{array}{l}\text { Number } \\
\text { of Items }\end{array}$ & $\begin{array}{c}\text { Cronbach's } \\
\text { Alpha }(\alpha) \\
\text { (Before) }\end{array}$ & $\begin{array}{c}\text { Items } \\
\text { Deleted }\end{array}$ & $\begin{array}{c}\text { Cronbach's } \\
\text { Alpha ( } \alpha) \\
\text { (After) }\end{array}$ & $\begin{array}{c}\text { Comparative } \\
\text { Fit Index } \\
\text { (CFI) }\end{array}$ & $\begin{array}{c}\text { Normed } \\
\text { Fit Index } \\
\text { (NFI) }\end{array}$ \\
\hline \multicolumn{7}{|l|}{$\begin{array}{c}\text { Organizational } \\
\text { Justice }\end{array}$} \\
\hline $\begin{array}{l}\text { Distributive } \\
\text { Justice }\end{array}$ & 5 & .89 & - & .89 & 1.00 & 0.96 \\
\hline $\begin{array}{l}\text { Procedural } \\
\text { Justice }\end{array}$ & 6 & .88 & 2 & .83 & 1.00 & 1.00 \\
\hline $\begin{array}{l}\text { Interactional } \\
\text { Justice }\end{array}$ & 9 & .95 & 1 & .93 & 1.00 & 0.98 \\
\hline Turnover Intentions & 5 & .92 & 1 & .91 & 1.00 & 1.00 \\
\hline
\end{tabular}

Note. $\quad \mathrm{N}=254$

Table 5. Mean Scores, Standard Deviations, and Pearson Correlations Matrix for Study Variables

\begin{tabular}{|c|c|c|c|c|c|c|}
\hline Variables & $\begin{array}{c}\text { Mean } \\
(M)\end{array}$ & $\begin{array}{c}\text { Standard Deviation } \\
\text { (SD) }\end{array}$ & 1 & 2 & 3 & 4 \\
\hline 1. Distributive Justice & 5.23 & 1.05 & - & & & \\
\hline 2. Procedural Justice & 5.39 & .89 & $.68 * *$ & - & & \\
\hline 3. Interactional Justice & 5.54 & .79 & $.72 * *$ & $.83 * *$ & - & \\
\hline 4. Turnover Intentions & 2.85 & 1.64 & $-.58 * *$ & $-.46 * *$ & $-.43 * *$ & - \\
\hline
\end{tabular}

Note. $\mathrm{N}=254,{ }^{*} \mathrm{p}<0.05 ; * * \mathrm{p}<0.01$, All items used a 7-point Likert scale with $(1=$ strongly disagree to $7=$ strongly agree) 
Table 6. Results of Hierarchical Regression of Perceptions of Organizational Justice on Turnover Intentions

\begin{tabular}{|c|c|c|c|}
\hline Predictors & $\begin{array}{c}\text { Model } 1 \\
\text { Std. } \beta\end{array}$ & $\begin{array}{c}\text { Model } 2 \\
\text { Std. } \beta\end{array}$ & \\
\hline \multicolumn{4}{|l|}{ Step 1: Control Variables } \\
\hline Age & -.11 & -.12 & \\
\hline Gender $^{\mathrm{a}}$ & $.19^{* *}$ & .05 & \\
\hline Marital $^{\mathrm{b}}$ & -.02 & .03 & \\
\hline Education Level & -.10 & -.11 & \\
\hline Organizational Tenure & $.21 * *$ & .12 & \\
\hline \multicolumn{4}{|l|}{ Step 2: Model Variables } \\
\hline \multicolumn{4}{|l|}{ Organizational Justice: } \\
\hline Distributive Justice & & $-.56 * *$ & \\
\hline - Procedural Justice & & $-.26 * *$ & \\
\hline - Interactional Justice & & & .15 \\
\hline$R^{2}$ & .07 & .45 & \\
\hline Adj. $R^{2}$ & .05 & .43 & \\
\hline$R^{2}$ Change & .07 & .38 & \\
\hline F-Change & $3.49 * *$ & $55.01 * *$ & \\
\hline
\end{tabular}

Independent Variables

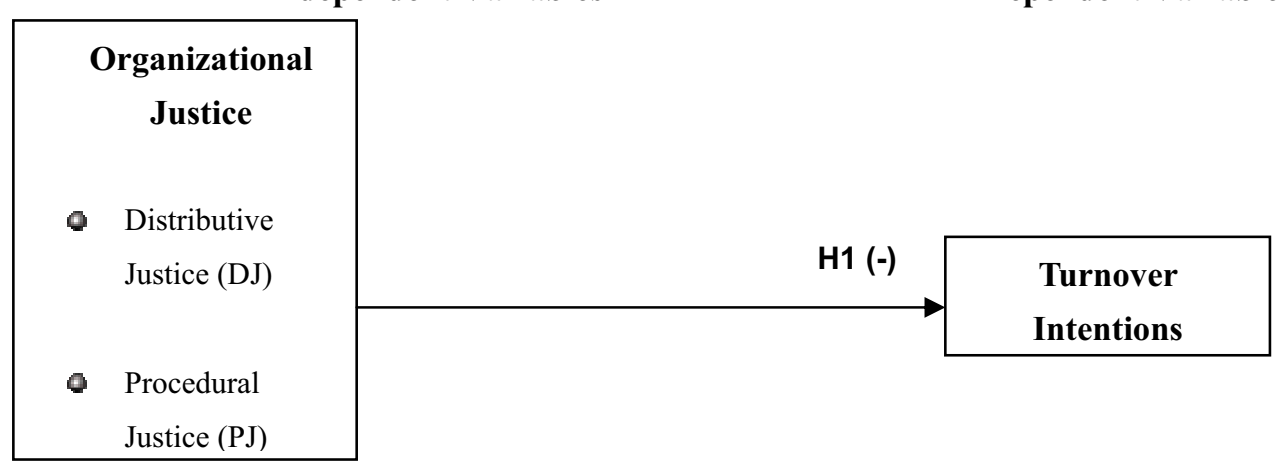

Figure 1. The Theoretical Framework of Hotel Managers' Turnover Intentions 


\title{
The Construction of Human Resource Management System
}

\section{in Small and Medium-sized Private Enterprises}

\author{
Jieyun Zhang \& Juhong Gong \\ Tianjin Polytechnic University, College of Industrial and Administrable Management \\ Tianjin 300387, China \\ E-mail: zhangjieyun0309@yahoo.com.cn
}

\begin{abstract}
The small and medium-sized private enterprises (SMEs) play an increasingly important role in creating output value and providing new employment opportunities, but there are a lot of problems with human resources in SMEs, such as poor quality of business owners, lack of strategic planning on human resources, etc. It's necessary, therefore, for SMEs to strengthen the setup of human resource management system. This paper puts forward some implementation details according to "human resource evaluation, assessment, \& examination methods" and "job evaluation table", and draws up the diagram on implementation of these steps, both vertically and horizontally evaluating human resource management system in SMEs.
\end{abstract}

Keywords: SME, Human resource management, Human resource management system

\section{Instruction}

With the progressive development of the market economy, SMEs play an increasingly important role in creating output value and providing new employment opportunities, but those factors, which do not adapt to the development of the market economy, have become more and more obvious. These adverse factors have restricted the reform and development in SMEs, followed by the polarization of SMEs: because of stronger market adaptability, some of them, with their congenital conditions poor, seized opportunities so as to achieve a swift development. In contrast, a few of them, though brilliant at one time, were made exhausted due to a variety of market economy shocks, and finally went bankrupt. There are lots of reasons accounting for the latter' failure, and one of the most important ones is because those firms lack in a good mechanism, viz a kind of human resource management mechanism by which staff abilities and enthusiasm can be explored and utilized, and by which employees attracted to be loyal to their owners. For private enterprises to have an edge in human resource management, they must adapt to the new era development trend of human resource management, avail themselves of their advantages, and take effective measures to strengthen human resource management, thus becoming a strategic business partner. Only through the improvement of human resource management, can private enterprises improve its effectiveness, so as to stand in an invincible position in a highly competitive market economy.

Therefore, how to strengthen and perfect human resources management of private enterprises is one issue that needs to be urgently addressed at present in this region and even our country.

\section{The definition of human resource management}

The function of human resource management (HRM) large organizations involves a wide range of activities, and crucial ones among them include deciding on what staffing needs a firm has and whether to use independent contractors or hire employees to meet these needs, recruiting and training the best employees, ensuring they are high performers, dealing with performance issues, and ensuring your personnel and management practices conform to various regulations. Activities also include management approaches, employee benefits and compensation, employee records and personnel policies. Usually small businesses (for-profit or nonprofit) have carried out these activities themselves because they can't yet afford part- or full-time help.

\section{Research on human resource management (HRM) at home and abroad}

The initial concept of HRM originates from the western resource of labor. Durkcer (1954) puted a emphasis on the labor force, followed by steady improvement by Sehultz(1963) and Beeker(1964). Among them, Beeker set forth the theory of human capital in 1964, which continues to be used until now. During the first half of twentieth century, the basic framework of modern personnel management theory has been formed under the guidance of scientific 
management and organization behavior represented by Taylor. HRM, which appeared in the early 1970s, took replace of personnel management. Later on, there are lots of researchers who contributed to HRM, such as Buraek and Smith, Foulkes and Livernash(1982), Klatt, Murdiek and Sehuster(1985), FISher, Sehoenfeldt and Shaw(1990), et al. In the 1980s, HMR was continuously adapted to the development of the market economy and corporate culture, and at the same time there had appeared issues such as whether business goals were suitable, in which way for firms to achieve the corrected aims, and the fact that senior personnel executives or human resource managers were more and more involved in the discussion of the direction of business development.

After the second world war, the speedy development of Japanese economy gave a imputes to the research on HRM. Countries all over the world amazingly discovered that the soar of Japanese economy didn't lie in the fact that rather than traditionally attaching single importance to material factors such as production, products, quality, etc., people put their emphasis on HRM. For the moment, the concept of HRM has been lifted to the strategic level. Jeffrey, Mello, Raymond. A. Neu, Wayne, Robert and others emphasized that a wide range of guidelines and polices related to HRM should be combined with business strategy, and become a important part of corporate strategies and a indispensable pillar of realizing other parts of firm's strategies, thereby proposing the concept of SHRM. The strong empirical characteristics of HRM pre-determine that its development and creation is greatly influenced by the degree of business development. Enterprises in developed countries have been practically groping for the rules of SHRM and the methods of how to be combined with business strategies in order to gain a bigger competitive advantage.

The HRM function and HRD profession have undergone tremendous change over the past 20-30 years. Many years ago, large organizations looked to the "Personnel Department," mostly to manage the paperwork around hiring and paying people. More recently, organizations consider the "HR Department" as playing a major role in staffing, training and helping to manage people so that people and the organization are performing at maximum capability in a highly fulfilling manner.

Humans are an organization's greatest assets; without them, everyday business functions such as managing cash flow, making business transactions, communicating through all forms of media, and dealing with customers could not be completed. Humans and the potential they possess drive an organization. Today's organizations are continuously changing. Organizational change impacts not only the business but also its employees. In order to maximize organizational effectiveness, human potential-individuals' capabilities, time, and talents—must be managed. Human resource management works to ensure that employees are able to meet the organization's goals.

The country has been using the concept of HR. The concept of human resource management has been spreading in a rapid way. Wang Tongxun, a expert on science personnel, speak volumes for the importance of HRM and the talent cultivation; Zhao Shuming et al, with Nanking University, made a comparative research on the system of HRM in various nations, introducing the indices of human resources invented by Schuster, and conducted a comparative study on the current condition in various kinds of enterprises. Wang Yulan et al. proposed the a counter-measure scheme of HRM associated with contemporary firms; Wang Qun et al studied sci-tech talents from the angel of the talent ability and comprehensive quality, and according a large amount of testing and assessment, established the multi-layer, dynamic and multi-dimensional checking on sci-tech talented people, and the expert system of optimizing groups.

But because of the later introduction of SHMR into this nation, it is still at the stage of waiting to be improved. The long-run history of planning economy has made reform in state-owned enterprises go through a comparatively protracted exploration, and the development of private enterprises has been made tardy; with the reform of "three terms of institution " and the transformation of business operation mechanic, a new opportunity has been brought into HRM, making lots of improvement in introduction, retaining, and training of talents. However, HRM in the country is yet in the phrase of learning from foreign advanced practices due to the inertia effect of macroeconomic environment and conventional system of personnel management, and the HRM differences ( for instance, differences in culture, policies and regulations, market environment, etc.) must hinge on digestion, improvement, innovation of overseas practices, and combined with property rights system in transition, inject it in the process of the actual management and lift it to a strategic level. As a result, the emphasis and implementation is imperative, and the key is to take concretive measures as soon as possible to put in place SHRM, such as in institution and status. In the meantime, close attention ought to be paid to the fluctuations in social environment.

\section{A overview of the current situation of HRM in SMEs}

There is a wide distribution of SMEs in almost all kinds of industries, which deal with processing and manufacturing, services, wholesale and retail, agriculture, forestry, animal husbandry and fishery, construction, logistics, catering industry, IT industry, etc. According to 2007 statistics released by Beijing Municipal Development and Reform Commission, high-tech industries accounted for less than 2 percent of aforementioned sectors. Most of SMEs concentrated on traditional industries with main characteristics of the labor-intensive sector, and had relatively weak strength of enterprise. 
A majority of SMEs have been developing between the system gap of market economy and planning economy at the beginning of reform and opening-up. Influenced by the institutional factors and atmosphere of establishing a firm at that time, the success of starting a business closely linked with entrepreneur's personal charisma, innovation spirit, and special endowment. But the huge chance given by the market in the phrase of institution transfer covers up the defaults existing in the management of SMEs. During this period, a great number of SMEs adopted the person-oriented and kin-dominated management mode, and the entrepreneur's personal charisma and appeal became the main source of cohesion, which played a decisive role in the early cohesion in order to ensure efficient decision-making.

With the deepening of institution reform, rivals faced by SMEs have been becoming increasingly stronge and diversified, with competition more fierce, and long gone are the days when market mechanic was depended on to obtain a large number of opportunities. In contrast, former chronic hindrances to SMEs management have been being laid bare, having becoming a shackle to their long-range growth. The main issues is embodied as follows: the conflict between scale expansion and management capacity of firms; serious phenomena of insider control induced by blurry property rights; etc. Those conflicts are prominently reflected in the HRM of interior enterprises.

In implementing the development strategies of SMEs, planning on human resources is often ignored, and there is a lack of consideration of the human resource condition and whether the system of firm's human resources is a effective support to its development strategy, with a result of a mismatch of human resources and business development. Meanwhile, there is utilitarianism in many SMEs, which thinks of staff as a kind of cost rather than resource, and there is a shortage of the concept of development of personnel, training personnel, the rational use of personnel, effective management of human resources. Lack of a strategic planning on HRM is a serious impediment to the realization of firm development strategy, and obsolete concept of talented people makes talent development stay at the stage of the current level. Failure to give full play into human potential and motivate the staff initiative and creativity is extremely detrimental to the business development, with a result of the fact that many firms can't develop in a a bigger and stronger way after they have developed to a certain degree.

With the growth in the number of organizations participating in some form of international business, the need for HRM research will only continue to grow. Therefore, it is important for human resource professionals to be up to date on the latest trends in staffing, performance appraisals, compensation and benefits, training and development, employee and labor relations, and safety and health issues - both in the United States and in the global market.

\section{Establishment of a Sound Human Resource Base and Corporate Human Resource Evaluation System}

A corporate human resource base is created based on its own mobility of human resource. It does not only can grasp the movement of human resource, but also provides human resource structure with systematically classified information, which is the basis for human resource management. Evaluation system of human resource is the key to human resource management, and whether or not the system is comprehensive, forward-looking, practical and able to objectively reflect enterprise management level and current human resource situation has a direct bearing on the effectiveness of human resource management.

5.1 Human resource evaluation system must comprehensively reflect the status quo of various types of human resources and balance of a reasonable structure. The design of human resource evaluation system complies with the development trend of production and needs to be continuously improved and added. It should be adjusted based on the status quo of human resources, vertically classified in accordance with position differentiation, and horizontally classified according to the individual quality of staff engaging in a given post. The staff's team collaboration ability and the overall quality of the team should be considered on the basis of practical production, and the mechanism of competition for posts ought to be gradually perfected. At this stage, uniformity can not be imposed in all cases so that it is conducive to stabilizing the staff thought and improving their own quality.

5.2 The human resource evaluation system must be very operational and forward-looking in order to adapt to the continuous development of production and operation. "Operational" refers to the fact that in designing evaluation system, test methods and assessment process should be made clear and simple as much as possible on the basis of comprehensive evaluation index and test contents, and a combination of the construction production process should be made as much as possible, reducing the psychological impact on staff. They must be favorable to the stabilization of staff, and help to promote the rise in staff's overall quality and ability. "Forward-looking" implies that in designing evaluation system, the advanced development should be thought of as a starting point, and in accordance with the planning objectives of enterprise, the potential that human resources should be equipped with should be formulated.

\subsection{The design and use of human resource evaluation system}

\subsubsection{Human resource evaluation system design.}

First of all, enterprises should create human resource assessment center out of human resource management department, whose main task is to provide an internal market for a reasonable and orderly flow of internal human resources, is responsible for all corporate human resource assessment, job evaluation and training and development of human 
resources, and comprehensively evaluate the technical inputs and output of professional and technical staff, as well as evaluation, assessment and determination of economic and technological indicators. Secondly, businesses should draw up "human resource evaluation, assessment, examination methods" and "job evaluation table" suitable for the actual situation. Job evaluation and technology assessment ought to be imposed on staff in a systematic and comprehensive way, and evaluation and assessment report formed accordingly. This report can be used to re-divide staff's posts and determine the nature of their work, which is the basic information of wage distribution.

"Human resource evaluation, assessment, examination methods" should focus on the design and evaluation of job system. Posts ought to be assigned on the basis of institutions, engagement by one employee in more than one post encouraged, and control and incentive conducted according to remuneration. As an integral part of "human resource evaluation, assessment, examination methods", "Job Evaluation Comparison table" horizontally evaluates the individual quality of human resources, which should be designed from the level of moral self-cultivation, personal comprehensive ability, and individual potential, as well as qualifications and other qualifications. There should be a longitudinal analysis of the importance of jobs, qualifications required, the degree of potential to be exerted, and so on.

\subsubsection{Utilization of human resource evaluation system}

According to the details on "human resource evaluation, assessment, examination methods" and "job evaluation table", planning charts can be implemented and prepared, and vertical and horizontal evaluation of the work carried out at the same time to prepare the accumulation of evaluation and analysis data. At the same time, there should be a recording of the amendment rate of evaluation index. In the first use of human resource evaluation system, middle-level and grass-roots management and service jobs should be ranked as key positions, placing extra emphasis on the efficiency evaluation. In accordance with the labor standards and related technical standards, physical and skill level must be evaluated for operation and implementation positions. Extra importance should be attached to the evaluation of skill level in the light of professional qualifications and staff structure.

\section{Conclusion}

With the implementation of human resource evaluation system, companies must set up corresponding price of wage standards, in accordance with the realized evaluation results, and otherwise, the evaluation of human resources will become a mere formality. In short, with the implementation of the scientific enterprise system evaluation system of human resources, human resources do not only promote the improvement of the overall skill level and stimulate the production of active employees, but also are able to promote the improvement in management of enterprises, and comprehensively improve the management level of enterprises, thereby enhancing market competition force.

\section{References}

Li, Wei. (2007).Training system for small and medium-sized construction abroad and learn from experience. Commercial time, (19).

National Development and Reform Commission, the State Council Informatization Office, Ministry of Information Industry. Informationization national survey of SMEs (2007), 2008.

National Development and Reform Commission, the State Council Informatization Office, Ministry of Information Industry. Informationization national survey of SMEs (2007), 2008. 


\title{
Study on the Issue of Staff Training in Business Hotel
}

\author{
Qiumei Fan \\ Tourism and Geography Science School, Shenyang University \\ Shenyang 110041, China \\ E-mail: fanqmsy@163.com
}

\begin{abstract}
According to the analysis of characteristics of hotel business and business traveler, a business hotel will have new requirements to employees. So this essay puts forward new ways of staff training in business hotels.

Keywords: Business hotel, Staff, Training, Ways

Along with the speeding of the social development and the information-based progress, the modern science and technology gradually gets into a hotel industry, so that, the degree of hotel intelligence is running higher, and the guest feels more comfortable and convenient. Reservation and promotion on the net gradually replace traditional ways with telephone and mails. Guests can choose the rooms he likes from the computer directly. The guest's identity data will also be recorded into a computer with scanners and avoid artificial register and confirm. The guest room provides with the VCD facilities, multi-media Internet and electronics to show and confirm his own personality service contents, such as: morning calls, dressing hours and schedule to ticket and dinner party, business consultant, the tour reservation, secretary service, etc..
\end{abstract}

\section{Characteristics of Business travelers}

Business travelers are not ordinary travelers. The major purpose of taking a tour is for the business or other public services, not only for leisure. Most of them are high-level white-collars with high education, high income level and rich travel experience. Their overall travel demand is convenient, fast and efficient.

Business travelers are strongly independent and not be dominative. They treat the hotel as an information and services provider. So hotels have to provide them with products in diversity, personalization and flexibility. Business guests pursuit an easy, comfortable relaxation after the business affairs.

Business travelers usually stay 2-3 days in hotel. Because they are generally highly educated entrepreneurial elites with international communication skills and rich experience in business management, the hotel staff's service attitude, language and communication skills have to show a high degree of courtesy and politeness.

\section{Business characteristics of Business Hotels and requirements of the employees' qualities}

A business hotel is the hotel that provides accommodation, meals, business activities and related facilities to business travelers who are engaged in business activities.

The most important feature of the hotel business is to have higher degree of returning customers. Therefore, the hotel's services items, qualities, and standards have to facilitate business travelers. Hotel facilities will be comfortable, convenient and safe. Hotels will consider and provide a number of facilities and communication systems for business travelers.

According to the analysis of characteristics of hotel business and business traveler, a business hotel will have new requirements to employees. Business hotels should train a group of skilled staffs with fluent foreign languages skills, good etiquette and courtesy to provide business travelers with quick meal and a small banquet service because business travelers often arrange a more in-depth business negotiation on the table.

Modern business travel is coming from the development of modern political, economic, scientific and technological, cultural, educational activities which requires the organizers of business travel should have good professional knowledge and skills, as well as a broad range of knowledge to master the latest information and to track changes in the market. It also requires business hotel reception service to be superb and accurate, or it will not only affect the business activities of business travelers, but also will damage the reputation of the hotel itself. Therefore, it is the top priorities for a business hotel to strengthen the trainings for their staffs and make them not only knows about tourism business, but also master the business activities. 


\section{Ways of hotel staff training}

The basic requirements for the staffs in the hotel industry can be summed up as ASKH: Attitude, Skills, Knowledge and Habit. Attitude means not only is "dedicated" to jobs but also is the love of lives and having positive, optimistic, and cheerful qualities. Skills refer to technical and service skills. Knowledge must be latest and comprehensive. Habit means that staffs will develop good habits in every aspect when getting along with others.

To build a high-quality workforce to meet the needs of modern business travel, hotel should be training staffs in the following aspects:

\subsection{Knowledge training}

Some people say that the tourism industry is labor-intensive industry, emotion-intensive industry, and intelligence-intensive industry because it needs people with extensive knowledge and wisdom smart.

\subsubsection{E-commerce training}

Hotel should hold a variety of computers, office automation knowledge lectures combining training and assessment.

\subsubsection{Foreign language training}

We need to hire for foreign language teachers to strengthen communicating with business guests. Types of Language have to be wide, but not too deep to understand, especially in the hotel common language and vocabulary.

\subsubsection{Business skills training}

To provide accurate and efficient service is our overall objective in hotels. Business customers, in particular the overseas Chinese and the Japanese, pay attention to efficiency and have a high degree of requirement of service quality because they believe time is money. Through business skills trainings, we can develop quality of care and flexible adaptability. In addition, business skills training include etiquette and manners training, etc.

\subsection{Training on attitude}

The reason why some people can not manage the business well is not because they do not have necessary knowledge, is because they do not have right attitude. And it is the same to some companies. Training, mainly make leaders in hotels change their attitudes to adapt to social development.

\subsection{Training on the ways of thinking}

Some people are not in shortage of knowledge, but lag of ways of thinking and lack of creative thinking skills. Some Chinese people gave lectures in U.S. before. During the lectures, some Americans said they did not want to listen anymore because they believe the lecturer's thing has been behind about 30 years than that of Americans'. Therefore, the way of thinking is an important content of the training.

\subsection{Finding the feelings}

That is the method of going out while coming back. Some Japanese business communities organize companies to study abroad, and do some researches on resource advantages of local destination, customs, local customers' buying preferences, and so on, so that entrepreneurs can find the feelings to sell goods internationally. In this way, it will help entrepreneurs to open up the market and win profits.

In the era of knowledge economy, there is an increasing demand on qualities of business hotels staffs. Hotels must pay close attention to staff training, and strive to create a large number of high-quality knowledge workers to adapt to the requirements of knowledge management.

\section{References}

Chen, Ying. (2004). New model of training in modern hotels. Human Resource Development, 8: 43-44.

Hong, Tao. (2005). On the hotel industry staff training. Coastal Business and Technology, 7:187-188.

Wang, Hua. (2005). Analysis on staff training in star hotels in Guilin city. Journal of Guilin College, 16(4):41-43.

$\mathrm{Xu}$, Wenyuan. (2004). Rethinking to hotel training. Enterprise economy, 4:139-140. 


\title{
A Preliminary Study of Strategic Competitiveness of MDF
}

\section{Industry in Peninsular Malaysia by Using SWOT Analysis}

\author{
Mohd Shahwahid Hj. Othman \\ Department of Hospitality \& Recreation, Faculty of Economics \& Management \\ Universiti Putra Malaysia, 43400 Serdang, Selangor, Malaysia \\ E-mail: msho@econ.upm.edu.my \\ Abdul Rahim Abdul Samad \\ Department of Economics, Faculty of Economics \& Management \\ Universiti Putra Malaysia, 43400 Serdang, Selangor, Malaysia \\ E-mail: abrahim@econ.upm.edu.my
}

The research is financed by the Yayasan Pak Rashid (YPR) research grant 2008, Universiti Putra Malaysia, Malaysia.

\begin{abstract}
Within three decades, the medium density fibreboard (MDF) industry has grown and contributed significantly to the external trade of the wood-based sector of Malaysia. However, at present, the industry is at a cross road. Although in Peninsular Malaysia MDF trade is expanding, but initial relative advantages over other competitors have marginally eroded. Over time new critical success factors played important roles as the industry responded to changes in global challenges. Through an industrial survey using the strength, weakness, opportunity and threat (SWOT) approach, this paper assesses only these four elements as a preliminary study for further analysis in analysing the strategic competitiveness and core competencies of MDF industry.
\end{abstract}

Keywords: Medium density fibreboard (MDF), SWOT analysis, Preliminary study

\section{Introduction}

The development of the MDF industry in Malaysia started in 1987 but has since rapidly developed to nine plants, eight of which is in the peninsula. The production, consumption, export and import status of MDF in Malaysia is provided in Table 1. Most plants used rubberwood as their major raw material. Projections show that in the near future the supply of rubberwood will not meet the demand by MDF plants (Ismariah \& Norini, 1994). One of the possibilities in overcoming this problem is to embark on intensive forest plantation programme. Effective utilisation of fast-growing non-wood lignocelluloses materials and agro-wastes has been of great interest due to a drastic fall in forest resource. MDF made from oil palm fibres and kenaf have been widely studied and developed.

The need for a forest plantation programme has long been recognised as an important move to supplement the supply of timber in Malaysia. To supplement the supply of raw material from natural forests for the expanding timber industry, the Government of Malaysia, through the Ministry of Plantation Industries and Commodities (MPIC), has initiated the establishment of commercial forest plantations. The target of MPIC is to plant 375,000 hectares of forest plantation within a 15 -year cycle to ensure the sustainable growth of the timber sector and to continue to contribute towards the growth and development of Malaysia's economy. The government has allocated RM200 million in the form of soft loans for financing the forest plantation establishment from 2006 to 2008. Eight fast growing timber species have been identified as being suitable for the forest plantation programme including Rubberwood (Hevea brasiliensis) Acacia Hybrid (Acacia spp.) Teak (Tectona grandis), Sentang (Azadirachta excelsa), African Mahogany (Khaya ivorensis), Binuang (Octomeles sumatrana), and Kelempayan (Neolamarckia cadamba). 


\subsection{Strategic Competitiveness Assessment}

From the above review, producers need to understand these changes to take advantage of the opportunities these present for production, investment and trade, and their impacts upon the competitiveness. They have to anticipate and response by planning effectively. Planning provides three primary benefits: (i) the identification of future opportunities, (ii) anticipation and avoidance of future problems, and (iii) the development of strategies and tactical actions (Anon, 2007). The development of feasible alternative strategies depends to a large extent on the ability of the producer to examine its internal and external environments and to identify its competitive strengths and weaknesses, potential opportunities and threats to its business. Figure 1, shows a simple process of strategic competitiveness assessment. The assessment involves conducting an internal and external analysis facing the industry concerned. A stock taking of the capabilities and unique competencies existing in the industry has to be undertaken. The gaps that exist in the internal and external environments together with information on the capabilities and core competencies would allow the industry to identify critical strategies and tactical actions to take advantage and to overcome impediments faced. The focus is on business-level planning rather than corporate-level or functional-level planning. The arrows indicate the primary sequence of planning tasks. In practice, the sequence is neither purely systematic nor one-way as the two-way arrows suggest.

Assessing strategic competitiveness is widely researched in the developed countries, but documentation of research on this topic for the wood-based sector in Malaysia is still wanting. Some of the related studies on strategic planning among Malaysian businesses include that on the food industry (Md. Zabid et al., 1988), agrobased industries (Zainal Abidin, 1988), insurance industry (Md. Zabid et al., 1991), furniture industry (Mohd Shahwahid et al., 1995), education industry (Ismail et al., 2007) and international information system of multi-national firms (Mohdzaher \& Ward, 2007). Owing to the regional transformation happening in the composite board industry, there is a need to conduct a strategic competitiveness analysis of the industry in Malaysia.

\subsection{Objective of Study}

Given the above issues and competitive situation facing the MDF industry, it is necessary for the industry to take stock of its strategic position and reassess its performance. In particular, the industry has to re-evaluate its comparative advantage, constraint and state of competitiveness. This paper seeks to conduct a preliminary study of MDF industry by using SWOT analysis as a foundation to conduct the strategic assessment of the competitiveness of MDF industry in Peninsular Malaysia. This will base on the objective of understanding and analysing its reactions toward issues and challenges being faced.

\section{Methodology}

The method applicable in strategic analysis are numerous, both quantitative and qualitative, either based on time series or expert panels. Apparently the most common practical analytical tool for strategic planning is the SWOT analysis (Thompson \& Strickland, 1999). The core of this procedure is to identify the content of all four elements of the matrix. It was originally meant for evaluation of business corporations or profit centers. According to Thompson \& Strickland (1999), a SWOT analysis enables an industry to understand its overall business environment. The information gained from a structured and well documented industry analysis can help support key decisions made in all areas across an organization, whether it is sales, marketing, business development, operations, technology or even human resources. In order to remain competitive in the marketplace, an organisation needs to understand the various components and drivers of the industry in which they compete. While the identification of capabilities and core competencies enable the industry to identify and understand the potential opportunities and constraints that exist in the organisation. It is then possible to make informed strategic choices and plan about the future of the organisation.

The SWOT analysis has been adopted in assessing the strategic performance of selected wood based industries including in overall forest industries by (Korpela et al., 2001) and in furniture by (Mohd Shahwahid et al., 1995).

To conduct the above research tasks, seven out of the eight firms from Peninsular Malaysia were surveyed and interviewed guided by a questionnaire in mid-2008. A questionnaire was frame and pre-tested with one of the firm in the industry after which further modification was made. Hence, the final questionnaire used in this study was developed based on the literature on strategic planning as well as after obtaining feedback from the industry. The questionnaire is composed of inquiries on;

a. The strengths or advantages endowed within the firms. These elements are within the control of the firm management.

b. The weaknesses or disadvantages faced within the firms. These elements are also within the control of the firm management.

c. The opportunities that exist in the business environment that the firm could take advantage. These openings are not under the control of the firm management. 
d. The threats that exist in the business environment that the firm would have to overcome. These challenges are not under the control of the firm management.

e. The identification of capabilities and unique competencies available within each firm that contribute to the survivality and competitiveness of the firm.

f. The strategies and actions undertaken by each firm to capitalise on its strengths and opportunities, and to overcome on its weaknesses and threats facing the firm. The relationships of these strategies and actions on the firm's capabilities and core-competencies are traced.

\section{Findings}

\section{Strengths}

Raw material supplies are procured by three means namely;

a. Long term forest plantation concession

b. Long term contract with raw material contractors involving $28.5 \%$ of the plants.

c. Monthly raw material agents

Long term agreement concessions are obtained by MDF plants at Acacia forest plantations in Rawang, Selangor. Only $28.5 \%$ of the plants in the industry have these concessions (Table 2). The concession involved 12,000 acres over 7 years lease. $14.2 \%$ of the plants adopted an alternative long term supply arrangement by entering into a long term contract with wood supply contractors who have an arrangement with the Ulu Sedili Acacia forest plantation concessionaire. This involved 56,000 acres for 5 years.

For the above plants concerned, these long term forest plantation concessions and contract are essential for wood material stability. These plants have the comparative advantage over other plants in steady raw material supplies, continuity of plant production capacity utilisation and long term business planning. Another $28.5 \%$ of the MDF plants assure themselves of raw materials by having regular monthly quantity supplies from dedicated and reliable independent wood supplying agents. The rest of the plants $(57.2 \%)$ have less regular and reliable wood material supplier.

The location of MDF plants vis-à-vis the raw material sites has an influence on production cost due to differences in the cost of transporting the raw material. Plants located in the north and the south of the peninsula faced less competition for wood raw material supplies unlike those located in the central region. Hence, plants in the northern and southern regions tend to have supplies from within $50 \mathrm{~km}$ radius. $71.5 \%$ of the total number of plants fall in this category while the rests have to source their wood material further than $50 \mathrm{~km}$ radius. For those log sources within $50 \mathrm{~km}$ radius, there is a transportation cost saving. For instance, transportation cost within $50 \mathrm{~km}$ radius of the plant at Kulim is only RM15-20/mt while for distances between $50 \mathrm{~km}$ to $150 \mathrm{~km}$ the transportation cost ranges from RM20-RM30/mt (Table 2).

A distinct strength of the MDF industry is the strong financial support received by the plants from their private owners (71.5\%) and the public listed company management board (14.3\%). These plants have received full support for further investment in production expansion and technology modifications. For instance, one plant is wholly owned by a financial company hence, its investment activities are fully financed by its own equity without external borrowing. Others make investments supported by finances from their foreign equity partners/owners.

Continuous production technology innovation, and research and development (R\&D) are very essential drivers sustaining competitiveness in high technology industries. The MDF plants in the country have been established since the eighties and many experiences have been gained in production technology innovation. These together with the ease of owners and partners financial support have enable investments in plant improvement activities for raising production efficiencies. $100 \%$ of the plants are producing at $126 \%-150 \%$ of their technical capacities. One of the plants accounted this performance to their efforts at press modification to overcome its normal production bottleneck involving an additional expenditure of RM4.4 million on press machinery and RM1.5 million on pre-heater as well as in investing on computer system and plant management.

Inadvertently, the above efforts provided other advantages;

i) Plants are able to keep low production rejection rate. $100 \%$ of plants are able to keep the rejection rate below than $2.5 \%$. It is interesting to note that this performance matches the international benchmark production rejection rate. One plant accounted this performance to the investment made on a drum debarker to get rid of latex as well as on shifters to rid off the remaining rubber in the fibres. This resulted in rejection rates due to rubber spot to below $1 \%$.

ii) Plants are able to lower their production down time to a minimum. The majority of the plants are able to keep production down time to less or equal to $10 \%$. Experience productions engineers are able to troubleshoot and diagnose the problematic production activities. However, another $14.3 \%$ are able to keep their down time in the range of 
$11 \%-20 \%$ but this is a temporary situation since the plant is involved in a rationalisation process involving its acquisition by a bigger cash strap concern.

iii) Plants are able to raise their line speed which is a measurement of the press factor that provides the speed of production that would directly affect the level of productivity. $85.7 \%$ of MDF plants are able to achieve a line speed of below $7 \mathrm{~second} / \mathrm{mm}$ for $12 \mathrm{~mm}$ board while the rest achieve a line speed by $8-10 \mathrm{~second} / \mathrm{mm}$.

Direct participation of management at major production operation activities could enhance an ambience of experience sharing while reducing bottlenecks in major improvement decisions. This would allow for direct knowledge and guidance of operational constraints and problems faced at the production level. However, this will only happen if management is not involved in petty and minor operational decision making. All MDF plants have the benefits of the active participation in production operations by management. Hence, the above productivity achievement reported earlier is also contributed by this influence.

All MDF plants in the country have the ability to retain their skill workers. There are many contributory reasons. One plant has attributed this to its human resource remunerative package of providing a clear career path and training opportunities, as part of its adoption of the concept of "gemba kaizen" (workplace continuous improvement concept). Several others relate their productivity incentive scheme as an important factor. For example, if the production exceeding the predetermined targets, workers would be rewarded. In some plants, a worker could obtain on average a productivity reward of RM150-RM600/month or RM2,000/year.

To ensure continuous running of the production line, plants would have to avoid long downtime periods. An important consideration is the availability of critical spare parts. $71.4 \%$ of the MDF plants have the foresight to maintain stocks of critical spare parts. For instance, two plants maintain a stock of RM18 to RM20 million spare parts, including of main motor, press steel belt, sanding belt, refiner feeding screw and casing. Such a stock assures the plant's readiness for potential breakdown with little downtime.

\subsection{Weaknesses}

Previously Malaysia was known for its relatively homogenous rubberwood MDF board. Malaysian MDF plants are no longer able to procure $100 \%$ rubber wood materials, hence affecting their ability to produce homogeneous pale boards. Ever since the shortages of rubberwood logs, Malaysian MDF plants have to utilise a combination of wood materials (Table 3). In 2008 on average MDF plants are utilising 40\% Acacia (25\% Acacia slabs-price at RM50/mt and another $15 \%$ Acacia log-at greater than RM100/mt), 20\% mixed hardwood log and slabs (price RM80/mt), and the rest are taken up by rubber $\log (\mathrm{RM} 120 / \mathrm{mt})$. Cost of mixed hardwood logs is high and more glue is needed in board production then when using rubberwood, yet a producer has to sell the hardwood MDF board at almost the same price as rubberwood MDF boards. As a result, this would reduce the profit.

Popular orders for MDF boards are in $4 \mathrm{ft}$ by $8 \mathrm{ft}$ board measurement. Despite rising demand for MDF, not all Malaysian plants could take advantage of this situation because of the design of their production lines. $85.7 \%$ of the MDF plants have their second production lines that are not $4 \mathrm{ft}$ by $8 \mathrm{ft}$ board size (Table 3). Instead these production lines are on $3 \mathrm{ft}$ by $7 \mathrm{ft}$ board size. Hence, these plants may not be able to fulfill rising demand for the high orders of the conventional $4 \mathrm{ft}$ by $8 \mathrm{ft}$ board size. However, since all plants are now operating in excess of their technical capacity, this constraint is not a major limitation.

An important tenet in marketing is the ability to meet customer needs such as board size and board thicknesses. A majority of the MDF plants could manoeuvre their production line to a range of board thicknesses from $3 \mathrm{~mm}$ to $25 \mathrm{~mm}$. Only $14.3 \%$ of the plants interviewed have difficulty in meeting the thickness requirements of customers at short notice. The difficulty occurs at the press machine involving pressure and temperature adjustments. Hence, these plants could not take advantage of varied board size and small quantity orders.

The production costs for MDF are rising in Peninsular Malaysia at a rate of $6 \%$ per annum. This occurs due to the plants facing stiff prices for all their major inputs that include rising prices of raw materials $(20 \%$ per annum during the period 1990-2006), and glue (33\% per annum). Raw material takes up a large proportion of production cost. The inability to manage these cost components would raise Malaysian MDF prices relative to competing international producers and may jeopardize Malaysian global market share. Plants would have to look at potential sources of cost reductions since wood material price increments are imminent.

\subsection{Opportunities}

International markets demand for MDF boards comprise of multiple dimensions. The largest market is for homogenous lighter boards and thick boards $(>6 \mathrm{~mm})$. There are also specific niche markets for more heterogenous darker boards, 'green' (E0) boards and thin boards $(<6 \mathrm{~mm}$ ). In general, the market mix for MDF boards are $8.3 \%$ for E0 boards, $62.5 \%$ for light and thick boards, $20.9 \%$ for darker boards and $8.3 \%$ for thin boards. 
Owing to difficulty of procuring only rubberwood or Acacia logs, there is a cost advantage of utilising mixed tropical sawmill wastes and off-cuts which are priced relatively lower. Hence, cost of production would be lowered with a little trade off on quality. There are markets that prefer lower quality (heterogeneous and darker) boards and prices. There is an opportunity for such niche market. 14.3\% of MDF plants are capitalising on this niche market by developing new geographical destinations successfully. Mixed hardwood MDF boards are now being exported to India and Sri Lanka by Robin Group (Robin, 2007).

There is an international demand for thin boards. Table 4 shows that, $14.3 \%$ of MDF plants have a production capacity for thin boards (less than $6 \mathrm{~mm}$.) Thin board fetches higher prices than thicker board by as much as $50 \%$, creating more value for the producer. Over several decades of trial and error experimenting with its production line, this plant was able to fine-tune its press profile in its production line to cater for thin board manufacturing. Although the market is relatively small, there is an opportunity to specialise in this market segment. This plant is producing thin boards in response to consumer needs and high competition for thick boards. The majority of MDF plants produced thick boards and there is less competition by producing thin boards. This plant started manufacturing $100 \%$ thin boards using their two production lines since 2006. Prior to this, the production base between thick and thin boards was 50:50. There is another plant that is manufacturing both thick and thin boards in equal proportions. The popular market destination for thin boards is Japan where there is a preference for lighter boards in their kitchen and bedroom cabinets and interior decorations. Additionally, the endurance of thin board was design as strong as thick board.

With the greater global consciousness on lower emission of formaldehyde from boards, there is a growing market for environmental friendly E0 MDF boards, particularly in Japanese market. Although the market is relatively small, but there is a high price premium $(10 \%)$ attached to such boards. Hume Fibreboard is actively involved in the manufacturing of E0 boards taking up $15 \%$ of their production base (Hume, 2007).

With the decline in supply and rising prices of rubber and Acacia logs, plants are now experimenting with alternative materials like forest residues, new crops (kenaf) and agricultural waste such as oil palm trunk, fronds and empty fruit bunches in the move to find complementary wood materials and as replacements. $42.8 \%$ of the MDF plants are now investing in R\&D efforts and collaborating with universities and research institutes with materials like kenaf (with Universiti Putra Malaysia) and oil palm fronds and empty fruit bunches (with Malaysia Palm Oil Board) with a focus to determine optimum combinations between these alternative materials and rubber logs. Preliminary findings from this R\&D effort have been promising (Harmaen et al., 2007).

The Malaysian government has allocated soft loans for financing of forest plantations. This is an opportunity for MDF plant to integrate vertically into investing in upstream investment for supplying wood material. This could facilitate long term log material security. However, based on feedbacks, none of MDF plant has been awarded this allocation. Apart from the above special loan scheme, the Malaysian government also provides fiscal and financial incentive such as Pioneer status (5 years), double tax exemption on spare part from Malaysia Industrial Development Authority (MIDA) and R\&D expenditure as well as export promotion activities. Majority of the MDF plants are taking advantage of this incentive package.

Recent development in forest plantation in Peninsular Malaysia has seen the privatisation of major forest plantation areas in Ulu Sedili, Johore, Kemasul, Pahang and Rawang, Selangor into smaller long term concessions. Although, many of the successful concessionaires are non-wood-based manufacturing concerns, $28.6 \%$ of the MDF plants were able to acquire strategic interests in 12,000 acres of the Rawang forest plantation. This is an opportunity for these plants to stabilise their long term wood material supplies.

Ever since 2004 with the reintroduction of the floating exchange rate, the Ringgit Malaysia (RM) has steadily been appreciating against the U.S. Dollar (USD). An appreciation in RM against USD has made repayment of imported plants and machinery cheaper. This involves $28.5 \%$ of the plants who have invested in refurbishment of their production lines and are now benefiting from the RM appreciation (Table 4).

\subsection{Threats}

Logistic affects procurement cost for raw materials. Ideally, plants would prefer to source their wood materials from contiguous tree holdings, which would cut down on delivery costs. However, $89 \%$ of rubber trees are planted in smallholdings with the rest in larger scale estates (Table 5). This situation is made worst by the irregular ages of the tree stands in smallholdings, hence replanting programs during which moribund trees are felled, are being scheduled at different time periods. Further, supplies from a smallholding do not have the economies of scale over estates. The average land area of smallholdings is about two ha (RISDA, 2007).

Owing to wood material shortage, MDF plants are facing intense competitions and a price war on rubberwood material among themselves. This is affecting particularly $71.4 \%$ of the plants especially when they do not own forest plantation concession (Table 5). There is no long term contract in the supply of raw wood material by independent suppliers and 
agents. These suppliers sell to the highest bidder among the MDF plants. Hence, in order to secure monthly wood supplies, plants tend to outbid each other. This leads to a rising trend in wood material prices.

In 2007, 35\% of rubber areas have been converted to alternative crops and for development purposes (Table 5). Of these rubber areas, $25 \%$ are being converted to oil palm which yielded higher monetary returns, $5 \%$ to other crops including fruit trees, and another $5 \%$ have been developed into building and infrastructural projects. When these tree crops mature, there would be a decline in the long term supplies of rubber logs from estates and smallholdings.

Latex prices have been buoyant in the last couple of years since 2002. Latex prices have gone up from RM3.50/kg in 2002 harbouring at around RM5.50/kg to RM7.50/kg in 2007 (RISDA, 2007). Rising latex prices can influence rubber log supplies by delaying the motivations of rubber smallholders and estate owners to replant their moribund trees. An interview of thirty Rubber Industry Smallholders Development Authority (RISDA) district officers, suggested that $30 \%-40 \%$ of rubber smallholdings have delayed felling matured rubber trees for replanting activities in order to continue extracting latex, even though the trees have reached the moribund stage of the latex production cycle. This delay in replanting has created a shortage of rubberwood supply, leading to an upward pressure on domestic rubber log prices in the last few years.

For long term security of wood materials, it is advantages for plants to establish forest plantations. 57.1\% of MDF plants are facing difficulties to establish plantation due to unavailability of land in substantial area to obtain economies of scale (Table 5). Only $28.6 \%$ of MDF plants were able to obtain concession rights over 4,860 ha of Acacia forest plantation at Rawang, Selangor. Further, all of the MDF plants in Peninsular Malaysia were not given priority in soft loan scheme under the government forest plantation program.

Malaysian workers have a preference for cleaner and conducive work environment like in electrical appliances factories in comparison to wood based mills. Hence, all MDF plants are facing competition for local workers from none wood based mills. MDF plants suffer this predicament and have to rely on imported labor. Relying on foreign labor is not without its problems. Foreign workers have work permits of up to two years, and renewable four times up to ten years. After which they would not be renewed. The majority of these foreign workers who are fully skill by that time would be an asset to their potentially new employers in competing countries. This action in itself is tantamount to exporting skill labor and in inviting competitions to Malaysian manufacturers.

The growing domestic demand for MDF in the downstream wood based industries is another market expansion opportunities for the MDF plants. But with the growth of the Chinese MDF industry, exports into Malaysian from China are creating stiff competition to domestic MDF plants (Table 5). Nevertheless, MDF plants in China are facing excess capacities owing to insufficient raw materials.

In the international market, China is now a growing giant. Statistics show that there were nearly 40 MDF plants in China manufacturing $589,000 \mathrm{~m}^{3}$ in 1995 . Of which, there was only one plant with an annual productive capacity of $100,000 \mathrm{~m}^{3}$, two plants $50,000 \mathrm{~m}^{3}, 11$ plants $30,000 \mathrm{~m}^{3}$, and most of the remaining plants around $15,000-20,000 \mathrm{~m}^{3}$. But by 2005 , Chinese MDF production capacities have increase to $2,900,000 \mathrm{~m}^{3}$. Similarly, exports have change drastically from $7,000 \mathrm{~m}^{3}$ to $200,000 \mathrm{~m}^{3}$ respectively (FAO, 2005). One of the reasons for this rapid growth is the opening of China to international investors that has led to a proliferation of MDF plants in China. The Chinese economy is characteristically efficient in labor and capital utilisation minimising production cost. Hence, MDF manufactured in China is very competitive in the market.

The appreciation of Ringgit exchange rates against the USD also acts negatively against Malaysian manufacturers by reducing profit margin on committed orders negotiated when the USD was stronger. This is disadvantages to Malaysia suppliers. Unless firms practice hedging or renegotiate contracted prices.

\section{Conclusion}

This paper has conducted a preliminary study of MDF industry in Peninsular Malaysia by using SWOT analysis. Hence, we found clear results of strengths, weaknesses, opportunities and threats of this MDF industry. From these results, it will then be used as a foundation to identify the strategic actions plan and core competencies for the extension of this study. Central to competitiveness of the industry is the looming decline in rubberwood supplies and rising input prices. The MDF plants have responded in several four elements of the SWOT analysis. From 2007 till present this industry are having a merger of a number of plants and investing in production line improvements, manufacturing of glue, power generation and forest plantations. Plants have taken advantage of niche market opportunities by turning raw material constraints to advantages, in raising production of thinner boards and environmentally friendly boards. R\&D on alternative wood materials and product development has also been given emphasis. As regards of the extension of this study, we intend to come out with several core competencies and strategic action plans that can be used to sustain this industry. 


\section{References}

Anon. (2007). Timber Market Brief. Volume 149/May 2007.

FAO. (2005). FAOSTAT database. FAO, Rome.

Harmaen, A.S., Jalaluddin, H., Paridah, MD.T. \& Nor Yuziah, M.Y. (2007). Properties of medium density fibreboard (MDF) admixture rubber tree RRIM 2020 clone fibres and oil palm empty fruit bunch (EFB) fibres blends. Paper presented at the $7^{\text {th }}$ National Conference on Oil Palm Tree Utilisation. 13-15 November 2007, Sunway Resort Hotel and SPA, Bandar Sunway, Petaling Jaya, Selangor.

Hume. (2007). News and Information. [Online] Available: http://www.humewood.com.my/eng/news.htm

Ismail, N.A., Ali, R.H.R.M. \& Hisbollah, H.M. (2007). Strategic information systems planning in Malaysian public universities. Campus-Wide Information Systems, 24 (5), 331-341.

Ismariah, A. \& Norini, H. (1994). Rubberwood: Processing and Utilization-Availability of rubberwood Resource in Peninsular Malaysia-Compiled using from Dept. of Statistics, FELDA, RISDA and FELCRA. FRIM Malaya Forest Record No. 39, pp. 247.

Korpela, J., Sierila, P. \& Tuominen, M. (2001). A GDSS-based approach to the strategy analysis of forest industries. Proceeding of the $34^{\text {th }}$ Hawaii International Conference on System Sciences. 10-13 December 2001, Finland.

MD Zabid, A.R., Samsinar, M.S., Badriyah, M. \& Mohd. Mansor, I. (1988). Planning Characteristics of Small Firms in Malaysia. Department of Management Studies, FEP, UPM, DEC., Staff Paper NO. 17:24.

Md. Zabid, A.R., Kamaruddin, S., Maisom, O. \& Roslan, A.G. (1991). Strategic planning in the Malaysian insurance industry. The Geneva Paper on Risks ans Insurance, 16, 448-461.

Mohd NOR, M.Y., Mohd. Zin, J. \& Wan Roshdan. (1993). Characteristic of MDF made from admixture of oil palm frond and rubberwood fibres. Paper presented at The National Seminar: Utilization of Oil Palm Tree and Other Palms. $\left(3^{\text {rd }}: 1994:\right.$ K.L).

Mohd Shahwahid, H.O., Saroni, J. \& Salleh, Y. (1995). Element of strategic planning among Malaysian furniture manufacturer. Journal of Tropical Forest Product, 1(2), 162-179.

Mohdzaher, Mohdzain \& Ward, J. M. (2007). A study of subsidiaries' views of information systems strategic planning in multinational organizations. Journal of Strategic Information Systems, 16, 324-352.

RISDA. (2007). Rubber information and statistic. [Online] Available: http://www.risda.gov.my

ROBIN. (2007). News and information. [Online] Available: http:// www.robinmdf.com/Production.htm

Thompson \& Strickland. (1999). Strategic management, $11^{\text {th }}$ edition. McGraw-Hill Book Company, New York.

Table 1. Production, consumption, export and import status of MDF in Malaysia (' $000 \mathrm{~m}^{3}$ )

\begin{tabular}{|c|c|c|c|c|}
\hline Year/Item & 1995 & 2000 & 2005 & $2010^{*}$ \\
\hline Production & 350 & 1000 & 1500 & 2000 \\
\hline Consumption & 100 & 180 & 290 & 417 \\
\hline Export & 250 & 820 & 1210 & 1583 \\
\hline Import & 0 & 0 & 0 & 0 \\
\hline
\end{tabular}

* Projected

Source: FAO 2005 
Table 2. Strengths existing in the MDF plants of Peninsular Malaysia

\begin{tabular}{|c|c|c|}
\hline & Factors & $\begin{array}{l}\text { Average } \\
\text { Percentage* }\end{array}$ \\
\hline 1 & $\begin{array}{l}\text { Stable raw material supplies: } \\
\text { - } \quad \text { Long term agreement forest } \\
\text { plantation concession } \\
\text { - Long term contract supplies with forest plantation concession } \\
\text { - Reliable and loyal independent raw material supplies/agent }\end{array}$ & $\begin{array}{l}42.8 \% \\
28.5 \% \\
28.5 \%\end{array}$ \\
\hline 2 & $\begin{array}{l}\text { Strategic location to raw material supplies: } \\
\text { - Raw material located with in } 50 \mathrm{~km} \text { radius of plant } \\
\text { - Raw material located between } 51-150 \mathrm{~km}\end{array}$ & $\begin{array}{l}71.5 \% \\
28.5 \%\end{array}$ \\
\hline 3 & $\begin{array}{l}\text { Strong financial support: } \\
\text { Financial backing from private owner } \\
\text { Financial resources provided by public listed company }\end{array}$ & $\begin{array}{l}85.8 \% \\
71.5 \% \\
28.5 \%\end{array}$ \\
\hline 4 & High production technology innovation & $85 \%$ \\
\hline 4.1 & $\begin{array}{l}\text { Production at; } \\
100-125 \% \text { technical capacities } \\
126-150 \% \text { technical capacities }\end{array}$ & $\begin{array}{l}0 \% \\
100 \%\end{array}$ \\
\hline 4.2 & $\begin{array}{l}\text { Production rejection rate; } \\
\text { less than } 2.5 \% \\
2.6 \%-5 \%\end{array}$ & $\begin{array}{l}100 \% \\
0 \%\end{array}$ \\
\hline 4.3 & $\begin{array}{l}\text { Production down time; } \\
\leq 10 \% \\
11-20 \%\end{array}$ & $\begin{array}{l}85.7 \% \\
14.3 \%\end{array}$ \\
\hline 4.4 & $\begin{array}{l}\text { Line speed/press factor }(12 \mathrm{~mm}) \\
5-7 \mathrm{sec} / \mathrm{mm} \\
8-10 \mathrm{sec} / \mathrm{mm}\end{array}$ & $\begin{array}{l}85.7 \% \\
14.3 \%\end{array}$ \\
\hline 5 & High participation of Management in major production operations & $100 \%$ \\
\hline 6 & $\begin{array}{l}\text { Plant improvement investments together with intensive guidance by corporate } \\
\text { procedures }\end{array}$ & $100 \%$ \\
\hline 7 & $\begin{array}{l}\text { Ability to retain skill manpower due to: } \\
\text { - Continuous work place improvement } \\
\text { - Human resource remunerative package }\end{array}$ & $\begin{array}{l}100 \% \\
100 \% \\
100 \%\end{array}$ \\
\hline 8 & Availability of stocks of critical spare parts & $71.4 \%$ \\
\hline
\end{tabular}

* Frequencies computed from field survey data most plants have several alternative sources of raw materials at any time.

Note: The $42.8 \%$ of the plants having forest plantations also rely upon the other sources to obtain their plants full raw material requirements. But $57.2 \%$ of these plants do not have regular and reliable wood supply agents 
Table 3. Weaknesses existing in the MDF plants of Peninsular Malaysia

\begin{tabular}{|l|l|l|}
\hline & Factors & Average Percentage* \\
\hline 1 & $\begin{array}{l}\text { Inability to procure rubber wood materials is jeopardising single species } \\
\text { pale board production }\end{array}$ & $100 \%$ \\
\hline 2 & Second production lines that are not $4 \mathrm{ft}$ by $8 \mathrm{ft}$ board size & $87.5 \%$ \\
\hline 3 & Marketing directed by size and thickness availability & $14.3 \%$ \\
\hline 4 & Rising production cost affecting profitability & $100 \%$ \\
\hline
\end{tabular}

Frequencies computed from field survey data

Table 4. Opportunities existing in the MDF plants of Peninsular Malaysia

\begin{tabular}{|l|l|l|}
\hline & Factors & Average Percentage* \\
\hline 1 & $\begin{array}{l}\text { Niche markets according to each plant production advantages - plants using } \\
\text { mixed hardwood slabs and off cuts focusing into India and Sri Lanka. }\end{array}$ & $14.3 \%$ \\
\hline 2 & $\begin{array}{l}\text { Niche market prospects } \\
- \text { for specific markets demanding heterogenous boards } \\
- \text { for specific thickness: thin boards }(<6 \mathrm{~mm}) \\
- \text { for green boards (E0) }\end{array}$ & $\begin{array}{l}14.3 \% \\
28.6 \%\end{array}$ \\
\hline 3 & $\begin{array}{l}\text { Availability of alternative raw material enable R\&D innovation } \\
\text { forest plantation establishment soft loans }\end{array}$ & $42.8 \%$ \\
\hline 5 & $\begin{array}{l}\text { Government incentive in: } \\
\text { fiscal and financial incentive }\end{array}$ & $0 \%$ \\
\hline 6 & $\begin{array}{l}\text { Appreciation in RM against USD has made repayment of imported plant } \\
\text { and machinery cheaper. }\end{array}$ & $28.5 \%$ \\
\hline
\end{tabular}

Frequencies computed from field survey data 
Table 5. Threats facing in the MDF plants of Peninsular Malaysia

\begin{tabular}{|c|c|c|}
\hline & Factors & $\begin{array}{l}\text { Average } \\
\text { Percentage* }\end{array}$ \\
\hline 1 & $\begin{array}{l}\text { Rubber log material supplies base is not contiguous because comprise of: } \\
\text { Smallholdings ( } \% \text { of rubber areas }) \\
\text { Estate( } \% \text { of rubber areas) }\end{array}$ & $\begin{array}{l}89 \% \\
11 \%\end{array}$ \\
\hline 2 & $\begin{array}{l}\text { Intense competition for wood material among MDF plants within the same regions } \\
\text { (\% of MDF plants) }\end{array}$ & $71.4 \%$ \\
\hline 3 & $\begin{array}{l}\text { Conversion of rubber areas to alternative use ( } \% \text { of converted area): } \\
\text { - Oil palm plantations } \\
\text { - Other crops included fruits } \\
\text { - Building and infrastructural projects. }\end{array}$ & $\begin{array}{l}35 \% \\
25 \% \\
5 \% \\
5 \%\end{array}$ \\
\hline 4 & Rising latex prices causing replanting delays ( $\%$ of all rubber districts) & $100 \%$ \\
\hline 5 & $\begin{array}{l}\text { Difficulties in establishment of forest plantation due to: } \\
\text { - lack of land availability ( } \% \text { of MDF plants) } \\
\text { - MDF firms not given priorities in long term forest plantation concession } \\
\text { - MDF plants not given priorities in soft loan scheme under the forest plantation } \\
\text { program. }\end{array}$ & $\begin{array}{l}57.1 \% \\
71.4 \% \\
100 \%\end{array}$ \\
\hline 6 & $\begin{array}{l}\text { MDF plants are facing competition for local workers from none wood based plants } \\
\text { (\% of plants) }\end{array}$ & $100 \%$ \\
\hline 7 & $\begin{array}{l}\text { MDF firms are facing intense competition in: } \\
\text { - domestic market from both local and international MDF } \\
\text { Companies } \\
\text { - international market from China }\end{array}$ & $\begin{array}{l}85.7 \% \\
100 \%\end{array}$ \\
\hline 8 & Appreciation in RM against USD is reducing profit margin on committed orders & $100 \%$ \\
\hline
\end{tabular}

Frequencies computed from field survey data

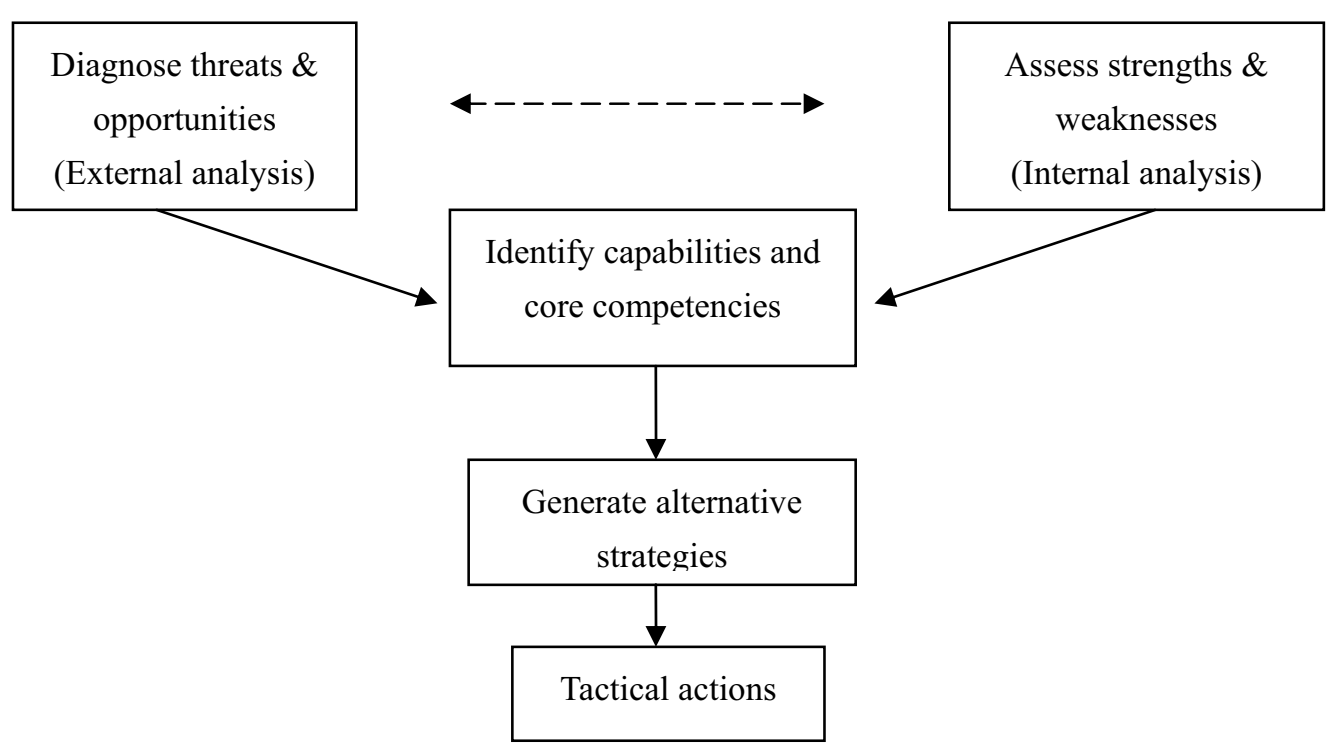

Figure 1. A Strategic Competitiveness Assessment 


\title{
Investigation and Evaluation of Product-Supplier's Company
}

\author{
Huaping Chen \\ Xi'an Polytechnic University, Xi'an 710048, China \\ Tel: 86-29-8233-0059Ｅ-mail:chenhuaping7024@163.com
}

\begin{abstract}
In the process of selecting the satisfactory product-suppliers the buyer should investigate and evaluate the candidates by recognizing the situation of the supplier's companies. The buyer should pay attention to the factors such as the suppliers' certificates and documents, the situation of manufacturing facilities and other hardware, technical performance and quality assurance, company's financial situation, organization and the management of human resources, ability to storage, transport and supply of products, management ability and team cooperation, company's environment, social responsibility and ability in sustainable development and historical records.
\end{abstract}

Keywords: Buyer, Product-supplier

In order to select the satisfactory product suppliers one of the prerequisites is to investigate and evaluate the candidates thoroughly and the in situ survey of the suppliers' companies is especially vital. According to the scale and the capital situation of the suppliers' companies the buyer needs to select 2-3 candidates as the survey targets.

A complete plan for the survey is essential for recognizing the supplier's situation in operation, capability and their status. The survey results for the suppliers' products quality, manufacturing capability, product delivery, product price and operation goal will affect the buyers' final decision. In addition to these there are other more important factors which include companies' historical operation record, production facility, technical level, financial situation, management, market reputation, program flexibility, communication situation, labor-management relationship, companies' location and their behaviors in social responsibility.

The buyer usually organizes a cross-functional team to perform the survey and the team consists of the staffs in supplying management, material management, engineering devise, manufacturing management, quality management and financial management. The survey can be in the forms such as discussion, documents reading, evaluation of the manufacturing facilities, functional branches visiting and the random discussion with the companies' staffs.

The following are the main factors considered during the survey:

\section{Checking the Suppliers' Certificates and Documents}

These certificates and documents mainly include the manufacturing license, operation qualification, enterprise legal certificate, product quality confirmation, award certificates and the brief introduction of the enterprise, which includes the operation category, brief history and the sales. The company documents related to finance, human resource management, manufacturing process management and the details of the current customers should also be investigated in order to meet the requirements in the following cooperation. The suppliers should be responsible for the actuality of these documents.

\section{The Situation of Manufacturing Facilities and Other Hardware}

These include the information such as workshop area and the arrangement, manufacturing facilities and the functional properties, the productivity for meeting the requirement of the customers' orders and the installation of the manufacturing facilities for production expanding or further modification.

\section{Assessment of Technical Performance and Quality Assurance}

The most important subject in the survey is to assess the company's technical performance. Through this assessment the buyer can recognize the supplier's ability for meeting the buyer's long-and-short requirement, whether the supplier can meet the buyer's lowest needs and the requirement in product function. In this process the supplier's superiority in product quality, the post-service situation, technical innovation, ability in product supplying and quality assurance system should also be considered. Normally the technicians, designers and the operators are in charge for these.

In the assessment process the following are normally considered factors. 
1) Whether the supplier's products can meet the lowest technical requirement and the lowest standards.

2) Whether the quality of the supplier's products surpasses the customer's requirement and it is beneficial to the customer.

\section{Technical skill of the manufacture}

1) Whether the suppliers meet the national rules or commercial standards and the market classification.

2) R\&D and innovation ability in products

5. The efficiency in manufacturing process, quality measurement, checking process and cost control system

1) Whether there is the manufacturing and quality measurement for product samples.

2) Whether the suppliers stipulated the post-service policy.

3) Whether the suppliers supply the permanent technical support which includes the maintenance.

4) Whether the supplier possesses the certificate in quality assurance.

5) How the supplier supply the post-service in case there is no service-net locally.

6) Whether there are the complete product indications.

7) Whether the raw materials can be freely moved from storage to the workshop.

8) Whether there is the bottle-neck to the production.

9) Whether there are the branches for manufacturing plan and control. How do they operate?

10) Whether the company possesses the ability in multi-times manufacturing.

11) Does the feasibility depend on normal duty time or extra duty time?

6. Since the product quality depends on the manufacturing facilities and the process the buyers should also recognize the supplier standpoint to product quality through asking the following questions:

1) How do you think about the zero-fault ratio and the management throughout the manufacturing process?

2) Does your company possess the ISO9000:2000 certificate?

3) Do you have the statistics process control?

4) Do you make the sample trial and measurement before develop the new products?

5) Do you have the complete plan to assure the product quality?

6) How do you assess customer's satisfaction to your products?

7) Please describe company's principle for quality control.

8) Do you have the quality control handbook?

\section{Analysis of Company's Financial Situation}

Through the investigation of the company's financial situation the buyer can recognize the company's financial stability, financial capacity and the situation of earnings. Recognizing the company's capital-credit situation through the bank and other routes is necessary. The debt ratio should not be over $70 \%$ since too high debt ratio can be dangerous for bankruptcy.

\section{Organization and the Management of Human Resources}

It is also important in the survey that the buyer recognize the company's interior organizations, their operation, inter-support ability and the operation rules. The human resource office should supply the documents related to staff's number, structure of the staffs, staff's education background, staff's salary, normal working time, the training and the sex ratio. The buyer should also ask for the staff's rule handbook and the copy should be used for the check.

\section{Ability to Storage, Transport and Supply of Products}

In the survey the buyer should also recognize the supplier's ability in raw material storage, product storage and transportation and whether the ability can assure the long-time development of the company. There are also other questions such as whether the supplier can assure to supply the products in time and whether this largely depends on the JIT (Just in Time) system.

\section{Management Ability and Team Cooperation}

The following factors should be paid attention in the survey:

1) The high-rank staff's management level and their cooperation 
2) The high-middle-rank staff's attitude and stability

3) The competitive ability of the technicians and administrative staffs

4) Do the staffs possess cooperative and competitive ability and work in a harmonious environment?

5) Do the staffs pay attention on company's product quality and the improvement?

Are the staffs proud of their company?

\section{Company's Environment, Social Responsibility and Ability in Sustainable Development}

The factors related to workshop environment and sanitary facilities such as workshop temperature, air pollution, noise and workshop sanitary situation should be recognized in the survey. Satisfactory sanitary environment usually implies the high efficiency. Are there stipulated rules on human right such as restriction of non-adult employee, salary paying in time and assurance of holidays. Satisfactory environment can assure the staff's satisfaction and high quality products. The situation of the staffs and the company can reflect the supplier's management level.

12. The treatment of the wasted products and unused materials should be recognized. In the treatment the company should consider the environment pollution and abide by the relative rules.

\section{Historical Records (Company's Credit and Honesty)}

These mainly include the supplier's past operation such as tax paying, business operation, public reputation and customer's opinions.

\section{Company's Ability in IT Technology}

It's important to recognize the supplier's ability in operating the EDI and ERP system and efficiently employing the information communication such as linking the customers in manufacturing plans, product design, engineering data and product supplying date.

In addition to these the buyer should also consider the following factors such as whether the supplier agrees to accept the customer's suggestions in reforming the whole management system, the supplier's supplying and buying system and whether the company's high-rank staffs can communicate efficiently. The buyer can give the efficient evaluation to the supplier through tabular analysis for the above situation in order to select the satisfactory supplier finally.

\section{References}

Leenders, M.R., \& Fearon, H.E. Translated by Zhang, Jie \& Zhang, Qun. (2001). Purchasing and Supply Management. Mechanical Industry Publishing Company, Beijing.

Xiong, Shengxu. (2007). Enterprise Plan Management. Nanjing University Publishing Company, Nanjing. Yu, Miao. (2006). Supplier's Management. TsingHua University Publishing Company, Beijing. 
A journal archived in Library and Archives Canada

A journal indexed in Canadiana (The National Bibliography)

A journal indexed in AMICUS

A journal archived in National Library of Australia

Ajournal indexed in APAIS (the Australian Public Affairs Information Service)

A journal included in DOAJ (Directory of Open-Access Journal)

A journal included in Google Scholar

A journal included in LOCKSS

A journal included in PKPOpen Archives Harvester

A journal listed in Journalseek

A journal listed in Ulrich's

A peer-reviewed journal in business and management

\section{International Journal of Business and Management} Monthly

Publisher Canadian Center of Science and Education

Address 4915 Bathurst St. Unit \#209-309, Toronto, ON. M2R 1 X9

Telephone 1-416-208-4027

Fax 1-416-208-4028

E-mail ijbm@ccsenet.org

Website www.ccsenet.org

Printer William Printing Inc.

Price CAD. $\$ 20.00$ 